\title{
A Risky Business?
}

Ukrainian Migrant Women in Warsaw's Domestic Work Sector

\author{
MARTA KINDLER
}


A 'Risky’ Business? 


\section{IMISCOE \\ International Migration, Integration and Social Cohesion in Europe}

The IMISCOE Research Network unites researchers from, at present, 28 institutes specialising in studies of international migration, integration and social cohesion in Europe. What began in 2004 as a Network of Excellence sponsored by the Sixth Framework Programme of the European Commission has become, as of April 2009, an independent self-funding endeavour. From the start, IMISCOE has promoted integrated, multidisciplinary and globally comparative research led by scholars from various branches of the economic and social sciences, the humanities and law. The Network furthers existing studies and pioneers new scholarship on migration and migrant integration. Encouraging innovative lines of inquiry key to European policymaking and governance is also a priority.

The IMISCOE-Amsterdam University Press Series makes the Network's findings and results available to researchers, policymakers and practitioners, the media and other interested stakeholders. High-quality manuscripts authored by Network members and cooperating partners are evaluated by external peer reviews and the IMISCOE Editorial Committee. The Committee comprises the following members:

Tiziana Caponio, Department of Political Studies, University of Turin / Forum for International and European Research on Immigration (FIERI), Turin, Italy

Michael Collyer, Sussex Centre for Migration Research (SCMR), University of Sussex, United Kingdom

Rosita Fibbi, Swiss Forum for Migration and Population Studies (SFM), University of Neuchâtel / Institute of Social Sciences, University of Lausanne, Switzerland

Agata Górny, Centre of Migration Research (CMR) / Faculty of Economic Sciences, University of Warsaw, Poland

Albert Kraler, International Centre for Migration Policy Development (ICMPD), Vienna, Austria

Leo Lucassen, Institute of History, Leiden University, The Netherlands

Jorge Malheiros, Centre of Geographical Studies (CEG), University of Lisbon, Portugal

Marco Martiniello, National Fund for Scientific Research (FNRS), Brussels / Center for Ethnic and Migration Studies (CEDEM), University of Liège, Belgium

Patrick Simon, National Demographic Institute (INED), Paris, France

Miri Song, School of Social Policy and Sociology, University of Kent, United Kingdom

More information and how to join the Network can be found at www.imiscoe.org. 


\title{
A 'Risky' Business?
}

\author{
Ukrainian Migrant Women in \\ Warsaw's Domestic Work Sector
}

Marta Kindler

IMISCOE Dissertations

AMsterdam University Press 
Cover design: Studio Jan de Boer BNO, Amsterdam Automated lay-out: Philos $\circledR$

$$
\begin{array}{ll}
\text { ISBN } & 9789089643278 \\
\text { e-ISBN } & 97890485 \text { I } 4472 \text { (pdf) } \\
\text { e-ISBN } & 9789048515523 \text { (ePub) } \\
\text { NUR } & 74 \mathrm{I} / 763
\end{array}
$$

(C) Marta Kindler / Amsterdam University Press, 20II

All rights reserved. Without limiting the rights under copyright reserved above, no part of this book may be reproduced, stored in or introduced into a retrieval system, or transmitted, in any form or by any means (electronic, mechanical, photocopying, recording or otherwise) without the written permission of both the copyright owner and the author of the book. 


\section{Table of contents}

$\begin{array}{ll}\text { Acknowledgements } & 7\end{array}$

I Ukrainian migrant women, migrant domestic work and risk 9

2 Risk, migration and migrant domestic work: Selected theory and research review

3 Theoretical approach and research methodology applied in this study

4 Ukrainian migrant women's images of risk 63

5 Legal risks of migration and legal risk-balancing strategies $\quad$ IO5

6 Risks and risk strategies in migrant domestic work $\quad$ I37

7 Familiar risk: Ukrainian women in the Polish domestic work $\begin{array}{ll}\text { sector } & \text { I75 }\end{array}$

$\begin{array}{ll}\text { Notes } & \text { I88 }\end{array}$

$\begin{array}{ll}\text { References } & 200\end{array}$ 



\section{Acknowledgements}

I would like to express my gratitude to all those who supported me while I was writing this dissertation, for its completion would never have been possible without their kind assistance and understanding. This was done under the supervision of two prominent academics, Professor Dariusz Stola and Professor Werner Schiffauer. I thank Professor Stola, who assisted me since I put forward the idea for the thesis in 2003 and supported my efforts throughout the whole process. My thanks goes to Professor Schiffauer for not only helping me obtain the doctoral stipend, but also offering very valuable feedback in terms of theory and praxis of migration studies.

My research was made possible by a three-year stipend (2004-2006) funded by the European Union Interreg III programme, which I received through the Graduate College Migration and Transnational Networks at Viadrina European University. I am additionally grateful for the subsequent half-year stipend funded by the Province of Brandenburg and the four-month SPIRIT stipend I received from Aalborg University in Denmark, where my academic work was supervised by Professor Anette Borchorst.

I would like to thank my colleagues at the Centre of Migration Research at the University of Warsaw and at Viadrina European University for their support and advice throughout my writing of this dissertation. I am also indebted to a number of friends who commented on draft chapters. My special thanks go to Izabela Koryś for editing the content of this work, Marlena Ryl-Zaleska for acting as a language and writing consultant and Karina Hof for her editorial work.

I would like to thank my parents, especially my father who was the first proofreader and supporter of my work. I am grateful to my husband Marek for a critical reading of the text and all our eye-opening discussions.

Last but not least, I must thank all the women who agreed to meet with me for interviews and who later hosted me in Ukraine and met with me in Warsaw. Without their kind cooperation this work would not have been possible.

Warsaw, 20II 



\section{Ukrainian migrant women, migrant domestic work and risk}

'[I]t's normal work, this is what you do, everyone does it,' said Maria, a 43year-old woman from Ukraine, when asked about working in Poland's domestic work sector. Maria first came to Poland eight years ago. At the time of our interview, her visa had expired. As an undeclared care worker, she initially lived in Warsaw's suburbs in a room shared with over twenty other people. And yet she referred to what she was going through as 'normal'. Maria's migration experience is similar to that of many other women interviewed. The risks of irregular migration, such as undeclared work, overstaying or poor living conditions, were a part and parcel of their experience. When asked how they understood the notion of risk, several of the women I interviewed mentioned a Ukrainian proverb: Who does not risk, does not drink champagne. They claimed that risks are an integral part of their migration. Well, where then was the champagne?

\subsection{The rationale and aims of this study}

The main purpose of this study is to examine how far the notion of risk may be useful as an analytical tool in explaining the process of irregular labour migration using the example of the domestic work sector. The study focuses on risk involved in labour migration of Ukrainian women who work as cleaners and care workers in Warsaw, Poland. The basic question to be answered in this study is to what extent the Ukrainian women's evaluation of and response to risk shape their experience of migration. Thus, the present study addresses risk both as an analytical and normative concept. The central issue is how the perception of risks contributes to women's choice of their destination country, modes of entry and stay, type of work abroad and how it affects their gendered roles as mothers and wives. I will use the notion of risk to analyse the complex decisions migrant women have to make when they undertake irregular labour migration. I will attempt to understand what it means for migrant women to 'take risks' and to 'be at risk' during migration, as well how far responses to risk are a factor shaping their migratory paths.

Although the literature on migrant domestic work abounds, studies on Ukrainian women migrating abroad to work in the domestic work sector 
are still rare. This may be due to the fact that contemporary labour migration from Ukraine is a relatively recent phenomenon. Research on Ukrainian migrant domestic workers was carried out in Italy (Scrinzi 2008; Vianello 2009, 2008; Solari 2006; Näre 2003) and in Austria (Haidinger 2008). However, their presence in Poland remains an uncharted territory (Kindler 2008a, 2008b, 2009a, 2009b).

Another area of research that has received little attention is the role of risk in migrant domestic work. The literature on migrant women working as cleaners and care workers addresses the negative experiences of migrant women, from physical violence, including sexual assault, to labour exploitation, to generally poor living conditions (Anderson I999; Ismail I999). Nevertheless, this literature seldom treats risk as the key explanatory variable. Risk is indirectly taken into consideration in research concerning immigration and labour policies, which determine the living and working conditions of migrants in this sector. This research addresses migrants' limited labour rights or their complete lack thereof (Hune I99I; Chin 1997; Hondagneu-Sotello 2003; Ehrenreich \& Hochschild 2003; Schwenken 2005; Anderson 2006) and the precarious working conditions of migrant domestic workers (Aronson \& Neysmith 1996; Anderson 2000; Hess 2002; Lan 2003; Anderson 2006). Other research themes revolve around a migrant's uncertain family status and the strategies he or she employs to cope with this insecurity (Young 2004; Parreñas 2005), the way migration influences the migrant's power position in the work place and in the household (Pessar I984; Williams 2005), as well as the development of transnational networks by migrants (Morokvasic 1984; Gamburd 2000; Lutz 2004). Many of these studies do imply that migrant women working in the domestic work sector are recognised as a group exposed to danger. The question of risk in labour migration has been addressed comprehensively mainly in economic studies (Elkan I959; Stark I99I). These studies, however, focus on economic risks, such as those related to the migrant household's income in the country of origin, rather than the financial risks that are also part of the actual migration experience. Studies that adopt a broader risk perspective to analyse labour migration, such as Wallman's (200I), who analysed the experience of migrants involved in prostitution, are rare and apparently non-existent in the case of domestic work sector research.

In this study, risk is understood as a series of potentially undesirable events, which are mediated by social interpretation (Lupton 1999). This definition is in keeping with the perception of risk presented by women interviewed in this study: when asked about their understanding of the word 'risk', they mentioned danger, uncertainty and instability. One of them told me that when she hears the word 'risk' she thinks of 'a flying bird, something...uncertain [...] Better to have earth underneath your feet..., as if you would fly, this... uncertainty, because when you stand on 
earth you know what's going on, and otherwise...'. The migrant's perception of risk is filtered through sociocultural contexts and his or her response to risk is based on particular value judgements.

In the light of what Giddens (I999) wrote about risk, Central and Eastern European societies are a perfect research field to analyse everyday risk perception and strategies. The region is undergoing rapid changes and the people living there have been and continue to be confronted with new risks caused by the restructuring of their political, economic and social environments. The change of the political system and the introduction of the capitalist economy deeply affected not only the official institutions, but also social relations. After all, capitalism forces individuals to rely on the calculation of future losses and gains, involving risk, seen as an ongoing process. Risk in that sense can be a mobilising force for the society to change, but it can also lead to potentially negative outcomes. If institutions responsible for ensuring security are weak, the responsibility for coping with risk will become increasingly individualised.

\subsection{Ukrainian labour migration: Background information}

Currently, Ukrainian labour migrants in Poland - among them women working in the domestic service sector - come mainly from the so-called western borderland. Labour migration from these territories is not a new phenomenon. In the nineteenth century, emigration from that area developed on a large scale: many people moved to live in the United States and South America, others engaged in temporary or seasonal migration to some regions of Germany, Denmark and France (Kacharaba 2003). There is little data available on migration from this region to work in domestic service in that period. The Soviet era brought internal and international mobility to a halt. However, with the Soviet Union's falling apart in the I990s, restrictions on cross-border movement were relaxed, allowing people not only to look for work abroad, but also to return home. This has had important consequences for seasonal and temporary migrants, who generally do not move with their families, but invest only in the migration of some household members.

Currently, Ukrainian nationals constitute probably the fastest growing migrant group in the European Union and certainly the fastest growing migrant group in Poland, with a number of researches being carried out. ${ }^{\mathrm{I}}$ What are some of the causes of the contemporary labour migration from Ukraine? Labour migration, as implied in the world systems theory, is triggered by economic inequalities (Wallerstein 2000). In I99I, with the disintegration of the Soviet Union, Ukraine became an independent state, attempting to establish a functioning democracy and to shift from command to market economy. However, the reforms failed and the economic 
situation began to deteriorate with Ukraine's GDP decreasing by between 40 and almost 60 per cent (depending on different sources) in the I990s. Inflation in the first half of the I990s caused real wages to drop by 63 per cent (World Bank I996: I). The decrease in the real value of public sector wages had a relatively greater impact on women, who made up the majority of the public sector employees. Additionally, payment of wages, pensions and stipends was delayed for several months. With the closure of many public enterprises as well as massive lay-offs in health care and education sectors, women were the first to lose jobs. They also faced higher unemployment and limited access to the labour market due to age discrimination. All of these factors, frequently combined with their husbands' loss of employment, made women look for work in the informal economy, for example, subsidiary agriculture on private land plots or cross-border trade, buying and selling imported goods at bazaars (Dudwick, Srinivasan \& Braithwaite 2002: 25). The economic decline in Ukraine in the I 990 os was accompanied by a relaxation of border regimes facilitating international mobility. Thus, the next step some women took was labour migration. Estimates from the early 2000 s ranged from below two to above five million Ukrainians working abroad (Malynovska 2004: I4). Exactly how many Ukrainian women are working abroad in domestic service can only be guessed at, due to the fact that the work they carry out remains largely undeclared.

As implied in the migration systems theory, migration between countries emerges from pre-existing cultural and economic ties (Castles \& Miller 1999). Poland has had a long history of ties to what is now Ukraine, starting as early as the fourteenth century (Snyder 2003; Szporluk 2004; Motyka 2000; Motyka \& Wierzbicki I997; Kersten I993; Hałagida 2002). The ties continue to exist today, with Poland supporting (so far with little success) the cause of Ukraine's accession to the EU (Barburska 2006). According to the estimates, after Russia, Poland was and continues to be the second most popular destination for Ukrainian labour migrants (Malynovska 2004; Prybytkowa 2004). Migration to Poland is characterised by a feminisation of the flow of immigrants from the former Soviet Union, primarily from Ukraine (Kępińska 2007). At the time this study was carried out, no official recruitment policy had been implemented to regulate labour migration between Ukraine and Poland. In view of their mobility, many of the Ukrainian women who work in Poland in the domestic sector fit into the definition of so-called incomplete migration. In contrast to what can be understood as 'complete' migration (that which leads to long-term settlement), incomplete migration refers to intense circulation between the country of origin and the country of migration. A person engaged in incomplete migration spends the majority of the year in the country of migration and the income earned abroad constitutes an important part of the overall household's income in the country of origin (Okólski I998: 7). This, together with trans-border 
mobility of persons engaged in petty trade, was the main emerging migration pattern of Ukrainian nationals to Poland in the I990s (Okólski I997, I998, 200I; Wallace \& Stola 200I; Wallace, Bedezir \& Chmouliar I997). The movement of Ukrainian women to work in Poland in the domestic sector is based on informal networks. These women can also be said to engage in temporary or short-term migration. As early as at the end of the nineteenth century, Ravenstein (I885) claimed in his migration laws that women constitute the majority of those engaged in short-term migration. Stola (200I: 95) defines short-term migration as 'international income-oriented population movements lasting no longer than one year'. According to the definition developed by the United Nations (I998), a short-term migrant is:

a person who moves to a country other than that of his or her usual residence for a period of at least three months but less than one year (12 months) except in cases where the movement to that country is for purposes of recreation, holiday, visits to friends or relatives, business, medical treatment or religious pilgrimage.

All of the above concepts define the temporary character of Ukrainian women's migration to the domestic work sector in Poland.

\subsection{Demand for domestic service: The term and the phenomenon}

In order to adequately analyse Ukrainian women working in the domestic sector in Poland it is necessary to understand not only the context of labour migration from Ukraine, but also the reasons behind the demand for workers providing domestic services in Poland. Domestic work can be defined as services concerned with housework, i.e. cleaning, cooking, washing clothes and care for dependent persons, such as the elderly, children, the sick or persons with disabilities. The term was introduced by the feminist movement in the I970s. Until then, domestic services were not generally seen as productive labour (Humm I995). The scope of paid domestic services has also changed as the concepts of household and family have transformed and the new technologies and equipment have mechanised housework. However, remunerated domestic work should not be associated solely with services sustaining the physical existence of the employer's household. Employing domestic help allows the employers to lead a particular lifestyle; in that sense, domestic work upholds the employer's social status. Thus, domestic work is also 'a role which constructs and situates the worker within a certain set of social and economic relationships' (Anderson I999: I20). 
Towards the end of the nineteenth century, many people in Europe believed that, with the coming of modernity, services of domestics would soon be a thing of the past (Momsen I999; Sarti 2006). However, the demand for care workers and cleaners not only continues into the present, but seems to be increasing. What are the reasons for this? There are at least three main causes: ageing population, women's entrance into the labour market and the state's inadequate provision of welfare services.

The first and most crucial of these causes is the ageing population. In 2003, the EU had 450 million inhabitants, 80 million (approximately I6 per cent) of whom were over 65 years old. Of these, 50 million were unable to care for themselves, thus needing to be cared for. These demographic trends are a result of the declining fertility rate (which is below replacement level in most developed countries), combined with the growing life expectancy. According to estimates, people over 65 years of age will constitute 28 per cent of the population of Europe in 2050 (Eurostat 2005). Poland is experiencing a similar trend: between I950 and I999, the number of people aged 60 and over tripled, to reach 17 per cent of the country's population (Frątczak 2002: 7).

The second reason behind the growing demand for remunerated domestic work is the entrance of women into the labour market. In Western Europe and in the United States, women began to enter the labour market on a regular basis in the late ig6os. Although many women were employed during World War II, there was a strong post-war trend among women to leave what was regarded as 'unnatural' industrial work for 'domesticity' and 'natural' family duties as the men returned from war (Fidelis 2004: 304). Introduction of institutionalised child and elderly care had a huge impact on women's presence in the labour market. This is especially the case in Northern European countries, where the number of women in the labour market has doubled in the second half of the twentieth century. In Central and Eastern Europe - mainly due to high war casualty figures among men - women started to join the labour force right after I945 (Fidelis 2004). In the Communist bloc, women were expected to handle both domestic chores and paid employment outside the home. Employing domestics was rare, primarily because of the low purchasing power of individual households. However, the state also pressured people to regard work as a social duty contributing to the development of socialism, which effectively discouraged informal labour arrangements that characterise domestic work. The demand for domestic services came after i989, when the introduction of capitalism intensified work relations and created new possibilities for women to have professional careers (European Foundation for the Improvement of Living and Working Conditions 2007). These new work relations made it difficult to balance the time spent engaged in paid employment with the time spent outside of work, including the time spent on domestic chores. 
The third explanation for the demand for remunerated domestic services is the inability of the state to provide adequate public social services to satisfy this growing need. Several countries, such as France, Spain and the United Kingdom, attempt to facilitate the provision of care by granting allowances, instead of providing the care itself (Anderson 2006). Some states create special programmes, like the au pair programme, where young, usually foreign, women care for children in return for the opportunity to live abroad. Their work is compensated by getting to practice a foreign language, lodging and 'pocket money' (Anderson 200I: 5). In Poland, privatisation of many of the social care services, such as residential homes for the elderly, meant that many people could nolonger afford them. In addition, the Polish recipients of domestic care services had little trust in institutional solutions; they preferred to use the services of someone recommended by a trusted informal source (Frąckiewicz 2002: I8).

The construction of a demand for cleaning services is different from that of care services. Here, the motivating force is the changing lifestyle of people in developed countries. With regard to cleaning, one can argue that supply creates demand: if a person has the capacity to pay someone a relatively small amount of money to carry out domestic chores on their behalf and the individual can spend that time involved in more enjoyable (or lucrative) activities, it is highly probable he or she will do so. The cleaners help keep up what is seen as proper living standards and their employers' particular social status.

Apart from the direct causes of the demand for domestic services, there are also financial, legal and sociocultural reasons for wanting to buy the services of foreigners. In financial terms, the work of foreigners is generally cheaper. According to some of the studies, migrant women in care work are generally paid the least of all care workers (Hondagneu-Sotelo 200I; Misra, Merz \& Woodring 2004; Romero I992). When it comes to legal reasons, foreigners are more willing to agree to work without a proper contract than native workers. The irregular status of the foreigner gives the informal employer additional power over the migrant. The sociocultural reasons are twofold. On the one hand, domestic work is not a prestigious job, so there simply may not be enough native workers willing to do that job at a given price. In the dual labour market theory, Piore (I979) claims that migrants separate their work status from their social status, because the status remains, together with their group of reference in the country of origin. That is why, Piore argues, it is easier for a migrant to accept work of a low social status. On the other hand, according to some studies, it is psychologically easier for employers to demand such low-status, 'dirty' service from someone who belongs to an 'out-group' (in contrast to 'in-group'), thus differing from the employer in terms of, for example, nationality or ethnic background (Arendt 2000). In that sense, domestic work of foreign women reproduces social, ethnic and gender inequalities. 


\subsection{Ukrainian domestic workers in Poland from a risk perspective}

The migration of Ukrainian women to the domestic sector in Warsaw is part and parcel of the global trend whereby women from poorer countries migrate in order to undertake domestic work in Europe's developed countries, as well as in other parts of the world. Together with Filipina women working in Hong Kong, Polish women working in Rome, Zimbabwean women working in London or Dominican women working in New York, Ukrainian women have joined the ranks of the global domestic workforce.

Analysing the migration of Ukrainian women to Poland's domestic work sector from a risk perspective, focus falls on the women's evaluation of potentially undesirable events and their response to these risks. The risk evaluation and response is influenced by the character of migration to the domestic work sector in Poland, which is determined by four processes. The first factor corresponds to developments in the Ukrainian labour market throughout the I99os. As women's employment declined and the living conditions deteriorated, some Ukrainians decided to look for alternative employment opportunities abroad. The second aspect is Poland's changing migration policy regarding the entry, stay and work of foreigners as it influenced the legal conditions under which the Ukrainian women migrated. The third factor is the perception of domestic work as a gendered occupation. Finally, the fourth aspect shaping the character of this migrant job is the demand for domestic workers due to Poland's institutional care solutions in the context of the ageing population.

This thesis is divided into seven chapters, moving from theoretical and methodological concerns to the analysis of the research material. Of interest to this study is the role of the notion of risk in understanding the process of migration. This analysis approaches the case of migrant women working in the domestic sector from a risk perspective, which has not yet been applied to this research subject. In all of this study's chapters, I analyse the social, political and economic processes that shape migrant domestic work.

Chapter 2 reviews migrant domestic work literature, analysing the demand and character of the domestic work sector as well as the extent to which risk can be used as an explanatory tool. I discuss the definition of risk, the role of risk in migration theories and different risk theories, focusing on theoretical approaches to sociocultural risk. I follow this up with selected migration concepts and theories that address the notion of risk.

Chapter 3 presents the approach to the analysis of risk adopted in this study. It draws on the preceding section and concerns the research methodology applied. Here I discuss the theory of structuration by Giddens. In my research I use qualitative methods, such as in-depth interviews 
and participant observation, which are reliable tools to analyse the strategies of irregular migrants, who are generally a rather hard group to access. Risk in this study is not treated as quantifiable, as in the positivist tradition of technical research into risk; rather, the qualitative methods I employ allow me to show particular sociocultural constructions of risks and the mechanisms involved in these processes. I also introduce the following notions that can serve as a useful framework for the analysis of risk: the imagined opportunity structure, the migrant institution, patronclient relations and the hidden transcript.

In chapter 4, I present the notion of the imagined opportunity space and use it to analyse the migrant women's evaluation of risk in Ukraine before leaving for Poland, their experience of having to part from their families, as well as how they envisioned risk during migration. I analyse the migrant women's attitude to migrant work (specifically to domestic work) within the context of the increasing material risks these women faced before leaving for work abroad, as well as their social status in Ukraine. Of interest are the stories that the migrant women had heard about successes and failures during migration, as well as information they had received before becoming migrants themselves. I also analyse how the women reconcile images of risk during migration with their own experiences.

Chapter 5 focuses on the issue of legal risks stemming from the migrants' irregular entry, stay and work in Poland. In the first part I shall address changes in the legal conditions under which women from Ukraine migrate. With changes in migration policy - primarily the introduction of a visa requirement for Ukrainian citizens in 2003 - it has been made more difficult for them to enter Poland as tourists. More ingenuity and resources were needed to enter Poland and stay there. The barriers to mobility have created risks to which the migrants respond by developing particular migrant institutions. However, these institutions have also introduced new risks to the migration experience. With regard to work, the main risks result from its undeclared character, the possibility of receiving no payment or too little, as well as getting ill while lacking health and/or social insurance.

In chapter 6, I analyse the risks related to the character of migrant domestic work. The first part of the chapter outlines the development of a niche for migrant domestic work in the context of Polish institutional care. I continue with an analysis of how work relations between the migrant domestic worker and the employer affect the migrant's exposure and responses to risk.

Chapter 7 draws final conclusions of the thesis and develops ideal types of risk responses in the migrant domestic work sector.

The background analysis for investigating the migration of Ukrainian women to the domestic sector in Poland from a risk perspective is based 
on a huge body of the existing migrant domestic work research, as well as risk and migration theories. The analytical section of this study is based on the following empirical research, conducted in 2005 and 2006 , concerning women who work in the domestic sector in Poland. My research comprised two major components: $\mathrm{I}$ ) in-depth interviews with the women and 2) participiant observation carried out in their households in Ukraine and en route to Poland, as I accompanied them while crossing the border. 


\section{Risk, migration and migrant domestic work: Selected theory and research review}

In the vast body of research on risk, it is rare to encounter a study on migration risks. The notion of risk has not been used extensively in migration studies, either, and even less so in research concerning migrant domestic work. This is surprising given the fact that migration very often is a gamble on a vector of unknowns. Migrants have to cross an international border, face the set of employment opportunities and work conditions in the destination country, and prove that they are capable of withstanding separation from home. Migrant domestic work seems to be especially risk-loaded due to its largely undeclared character, low wages, low social status and no upward occupational mobility.

\subsection{Analysing migration through the risk lens}

Why analyse migration from a risk perspective? The notion of risk has already been used in migration theories and research, but the work done so far has almost solely focused on economic aspects of migration. It is therefore of interest to use the notion of risk as an analytical tool, on the one hand, to understand the aspects of migration experience that go beyond financial considerations and, on the other hand, to find out what risk means for migrants. Is there potential 'space' for risk analysis in the current research on migrant domestic work? To find an answer to this question I provide an insight into the notion of risk, sociocultural risk theories as well as the role of the concept of risk in migration theory.

\subsubsection{The notion of risk}

When the notion of risk was first used in the late Middle Ages it was a spatial concept, related to voyage and maritime insurance. At that time, risk was understood as a phenomenon beyond human control: a natural disaster or a divine act. The meaning of risk changed with industrialisation in Europe in the seventeenth and eighteenth centuries, when it came to be seen as a result of human action, an event that is calculable and therefore manageable. The twentieth century saw a redefinition of risk and attempts to control it, largely due to new scientific and technological 
developments. There appeared risk analysis institutes and agencies dealing with occupation and consumer safety, as well as traffic and environment safety (Giddens I999). However, in the second half of the twentieth century, risk began to be seen again as less manageable: its causes were perceived as less identifiable and its effects as more serious than in the past (Lupton I999: 9). Currently, risk is a popular notion not only among experts, but also among the lay public. According to Lupton (I999: IO-II):

[...] it may be argued that the contemporary obsession with the concept of risk has its roots in the changes inherent in the transformation of societies from premodern to modern and then to late modern [...]. These changes include the end of the Cold War, the breakdown of the socialist and communist states, the spread of communication technology and changes in familiar relationships and the workplace brought by the feminist movement, economic decline and growing secularism.

At present, risk is seen as a temporal notion: it is linked to an uncertain future. At the core of risk is not what is happening, but what might be happening. A quick glance at the dictionary definition of risk may leave us with more questions than answers. Risk is defined as 'a situation involving exposure to danger', as well as 'the possibility that something unpleasant will happen' (Compact Oxford English Dictionary of Current English 2008). A person or thing can 'cause a risk' to someone and a person can incur risk on himself or herself by engaging in an action. Acting 'at one's (own) risk' means taking responsibility for one's own safety or possessions. And 'running (or taking) a risk (or risks)', means acting in such a way so as to expose oneself to danger. So what is risk? Is it something external to a person (a source of danger that we are exposed to) or the result of an activity that one engages in (a risky venture)? Is it something that will happen in the future or something that might happen, but might also be avoided? Does taking a risk involve thinking about the possible negative consequences or ignoring them and concentrating on the possible positive outcomes?

\subsubsection{Defining risk}

The definition of risk can be seen as comprising three elements: I) undesirable outcomes, 2) possibility of an occurrence of undesirable outcomes and 3) how these outcomes are acknowledged (Renn I992: 6I). I would add a fourth element defining risk: desirable outcomes, which are often the motivation behind engaging in so-called 'risky' activities. For example, when thinking about how to define irregular labour migration risks, we 
can assume that the desirable outcome of such migration is to improve or keep one's financial standing. ${ }^{\mathrm{I}}$ Conversely, an undesirable outcome would be a failure to do that. The negative outcome can be caused by, for example, getting caught by state authorities for working without a permit. To assess that risk, one would have to consider the likelihood of getting caught working without a permit in a given country's informal labour market sector. The individual would then need to decide whether it is possible to estimate the probability of this occurrence and how accurate the possible estimate would be. It is possible, then, to discuss expectations of potential migrants - that is, how they evaluate the chances of reaching or failing to reach the wanted and valued outcome of migration. These expectations are structured by the communal context (shaped by social and cultural norms), the demographic characteristics of the individual and the household, their individual traits, as well as the different regional opportunities. The different scientific perspectives disagree on how these elements of risk are to be understood and, consequently, how to define risk. The different branches of science also disagree on how far human knowledge reflects reality. Do our calculations reveal what is 'out there' or are they merely a reflection of 'what we think is out there' (Renn I992: 62)?

The approach to risk in social sciences ranges from the realist approach, which claims that risk is real and observable, to the social constructionist approach, which introduces social and cultural factors when defining risk. ${ }^{2}$ The constructionist approach, in turn, ranges from 'weak' to 'strong' At the 'weak' end of the constructionist spectrum is the risk society theory, ${ }^{3}$ regarding risk as socially interpreted actual dangers (Beck I992, 2000; Giddens I999). Cultural theory falls somewhere between the 'weak' and the 'strong' constructionism (Douglas \& Wildavsky I982; Douglas I985, I992; Adams I995), arguing that risk is culturally constructed and there is no guarantee that the dangers people seek to avoid are those that will actually harm them most. At the 'strong' end of the constructionist spectrum is the 'governmentality' approach, based on the writings of Foucault (I99I). Its proponents assume that nothing is a risk in itself; rather, risk is seen as a product of historically, socially and politically biased views. ${ }^{4}$ According to this perspective, the identification of behavioural norms in populations, a process that Foucault refers to as 'normalisation', leads to voluntary self-regulation in relation to risk. Proponents of this view focus on the change of social structures and meanings as well as the relations between power and knowledge in the construction of risk.

\subsubsection{Risk in migration theories}

Few migration theories feature risk as the key notion. ${ }^{5}$ In general, these theories derive from economic studies and are based on the assumption that the migrant is a rational actor. According to this perspective, the 
migrant acts to minimise or avoid risk. ${ }^{6}$ Risk aversion means preferring safer returns, even if they are, on average, smaller. Thus, a rational actor prefers less risky projects to more risky ones (Kuper \& Kuper I996). This approach to risk in migration was criticised by, among others, authors who introduced the notion of bounded rationality (Simon I957; Wolpert I964; Wolpert I966). The rationality of the actor, for example, during the migration decision-making process, is limited not only by the lack of information, but also by insufficient experience, emotions and inability to evaluate risks lying ahead. Therefore, migrants or potential migrants differ in their aversion to risk. The principles of rational choice are only applicable to situations in which choice is institutionalised (Jaeger, Renn, Rosa \& Webler 200I: 29). A rational actor approach to risk assumes a 'linear relationship between knowledge of a risk, developing the attitude that one is at risk and adopting a practice to prevent the risk happening to oneself (Lupton I999: 2I). In reality, the ability of the migrant to calculate the outcomes of his or her actions is limited by their social framework.

One of the currently best-known theories using risk as the key explanatory factor is the new economics of labour migration (NELM). It defines the migrant and his or her household members as rational and thus riskaverse actors. The authors of NELM present the additional source of income gained through temporary labour migration of household members as a strategy to diversify the household's income risks related to agricultural production in the place of origin (Stark \& Bloom I985; Katz \& Stark I986: 137). ${ }^{7}$ According to NELM, people engage in migration even if there is no guarantee that the level of earnings will be higher than in the place of origin or even if they have no guarantee of employment in the place of destination. This is explained by the assumption that the risks associated with agricultural production will be higher than risks associated with urban employment, which will diminish with time (Katz \& Stark I986: I35-136). NELM also points to institutional underdevelopment (market failures, inefficiency of welfare institutions) as a necessary condition for the shifting of responsibility of coping with risk from the level of the state to that of the household (Stark \& Bloom I985). Thus, in such conditions, a migrant's household acts at its own risk.

The notion of risk is also addressed in other research dealing with temporary labour migration or circulatory labour migration (Chapman \& Prothero I983-I984; Chapman I978). However, in contrast to NELM, the other approaches take into account not only income-related risks, but also broader opportunities and risks of political, religious and matrimonial character. Researchers point to the importance of security associated with the place of origin, such as access to resources and a continuation of social affiliations. Chapman and Prothero argue that the critical factors are not the time, distance and effort of migration, but 'the nature of opportunities 
and the risk involved in grasping them' (Chapman \& Prothero I983-I984: 564). The nature of opportunities and risks is related to the different degree to which individuals who circulate commit themselves to specific places and communities. The degree of commitment, in turn, depends on their location in the household hierarchy, type of land owned, proportion of savings sent back and social capital available, where social capital consists of ties to people who have access to resources useful during migration (Chapman \& Prothero I983-I984: 598).

Risk is future-oriented, but so is migration. Thus, contrary to Chapman and Prothero, I would argue that time plays an important role in risk and migration. In neo-classical theories, time was considered important. The theories inquired into the issue of when one has to pay the cost for migrating and when one will receive benefits. However, those theories portrayed migration as a static phenomenon. When it comes to analysing the dynamics of migration, the following features need to be taken into account (they also have an impact on risk exposure and response):

- The decisions made by an individual at different moments in time (the influence of past decisions)

- The moment in the life cycle and within particular external conditions when one engages in migration

- The person's experiences of mobility thus far (is it the first time or has the individual migrated before)

- The long-term influence of migration on socio-economic relations in the place of origin.

The success of pioneer migrants changes not only the income situation of migratory households in relation to other households in the community, but also the perception of migration (from one of stigmatisation to an ethos of migration culture) and the amount of motivation encouraging additional mobility. Massey and others (Massey, Arango, Hugo, Kouaoci, Pellgrino \& Taylor I993) defined such influence of mobility on other persons' decision about migrating as cumulative causation. Thus, the migration decision of individuals and households changes the balance of costs and opportunities as well as the balance of risks in the place of origin. With time and development of migration processes, the conditions under which migration occurs change (Kritz, Lim \& Zlotnik I992). The pioneer migrants experience a different risk from those who follow and can use the already extensive social networks to gain information about how to enter and find work abroad, thus reducing the costs and risks of migration. With time migrants create ethnic enclaves or immigrant niches in the labour market (Aldrich \& Waldinger I990; Waldinger I994), which may increase the security of migration, but may also lead to undercasting (Hoffman-Novotny I98I). During migration, motivations change with new aspirations for mobility and thus, new risk. 
Risk or risk-related notions, such as uncertainty, also appear in migration network theories. Massey and others define networks as 'sets of interpersonal ties that connect migrants, former migrants, and non - migrants in origin and destination areas through ties of kinship, friendship, and shared community origin' (Massey, Arango, Hugo, Kouaoci, Pellgrino \& Taylor I993). Several authors analysing the theoretical aspects of migration claim that networks are structures that lower the costs and risks of mobility and increase the expected gains (Gurak \& Cases I992; Massey et al. I993; Guilmoto \& Sandron 200I). Thus, networks are institutionalised uncertainty reducers. This is similar to what some risk theories argue: for example, Giddens (1984, I994) points out that social networks allow the maintenance of a sense of ontological security, which is a necessary precondition for agency (see section 3.I. in this book). They provide a certain routine and, combined with cultural rules, allow an individual to cope with uncertainty. Also, Douglas (I985) points to the network as an important source of information on what risk is and what it is not.

Based on the theories and research analysed above, in this study I will adopt a sociocultural perspective on risk. I will not search for an answer to the question of how much risk is present in temporary labour migration, because this would entail assuming a realist approach to risk. Instead, I will ask how migrants perceive, evaluate and respond to risks, and how this shapes a particular migration pattern. I define risk broadly, as a potentially undesirable outcome that is mediated by social interpretation. This 'weak' constructionist approach implies that risk in this study involves a social definition and sometimes a social construction of reality.

\subsection{Migrant domestic work research: A ground for risk analysis?}

Having briefly described the complexity inherent in the definition of risk and reviewed the role of risk in migration theories, let me now turn to research on migrant domestic work in an attempt to find a space for the notion of risk. Migrant domestic work is shaped by three main factors: gender, legal status and character of work. Firstly, domestic work is socially construed as 'women's work'; secondly, it is not treated as proper labour; thirdly, it is carried out in an intimate social sphere - the employer's home. This intimate character of domestic work leads to the development of a peculiar relationship between the employer and the employee, which is very personalised, often emotional and characterised by mutual dependency (Lutz 2008). The majority of migrants working in the domestic sector are women. Although there are men present in this sector, they are an exception rather than a rule. Gender also influences the mode of legal entry, stay and work. Migration policies create fewer opportunities 
for women than men to enter a state via legal migration channels. For example, one of the criteria for who is allowed to enter a country as a migrant worker is the number of years of his or her past employment. This creates a barrier for women, who have left the labour market to care for their families (Boyd 2004: 2). The state is also slow to regularise domestic work as proper labour because domestic work is carried out in private households.

So, where does risk enter the picture? I would argue that the intersection of gender, legal status and character of work influence the evaluation of risk by migrant women, as well as their exposure and response to risk. It is along these three dimensions that the interaction between family, state and labour market occurs. Women's migration experience differs from men's in terms of how their families, state policies and access to the labour market affect them. I believe the risks migrants have to evaluate are gendered. Moreover, greater pressure not to migrate is placed on women than on men due to the perception of women's migration by communities as a threat to the integrity of the family or a risk of sexual exploitation. It can also be assumed that women are exposed to different risks than men owing to particular legal and economic conditions: in general, women have less access to the labour market in their place of origin and fewer chances than men to enter the migration destination as migrant workers. Let me continue by reviewing the main conclusions from selected research on women's migration and domestic work and suggest where risk could potentially be used as an explanatory tool.

\subsubsection{Family and household: An obstacle to or a trigger of women's mobility?}

The I980s saw the beginning of research on women's migration together with the recognition that their mobility differs from men's and that migrants end up in sex-segregated sectors of the labour market, such as domestic work (Morokvasic i984). These studies confirmed that women's migratory opportunities are more restricted than men's due to social norms and particular gender roles, which demand that women, among other things, be part of the family structure.

The family can be defined as a gendered unit of reproduction and cultural transmission or a space for gendered social relations (Anthias 2000). The family plays a contradictory role in women's mobility. Due to the particular legal and economic context, 'migrating as a family entails the greatest risks and monetary costs, especially for those families travelling with young children' (Pessar I994: 75). Thus, in many instances it is not the whole family, but a family member who migrates to work abroad.

In migration research, the decision-making process related to migration is frequently analysed in terms of a family or household strategy ${ }^{8}$ 
(Hugo I998; Stark I99I; Sik 1993; Wallace 2002). However, this approach to the migration decision-making process often fails to acknowledge that the household is a contested area (Hondagneu-Sotelo 1994: 53; Boyd I989). Those most in power in the household decide who will migrate, but their decision can be questioned and even resisted by other household members. Some can decide to migrate against their family's will. Overall, when having already engaged in migration, women whose social status in the place of origin has been low to begin with are less pressed to return home than are their male counterparts whose social status declines upon migration (Parreñas 200I; Hondagneu-Sotelo I994).

Although for many women supporting the family is a main motivation for engaging in labour migration, families can become a barrier to women's mobility. The migration of mothers to the domestic work sector is particular to modern migration. According to Sarti (2008), single women and men for centuries have migrated to the domestic work sector, serving either before they got married or simply not marrying. Since women are regarded as the primary caregivers, migrant domestic work is sometimes analysed as a form of 'care-drain', with the migrants' children potentially experiencing a care deficit (Ehrenreich \& Hochschild 2003). The resistance to women's migration is based on a conviction that migration leads to the disintegration of families. Divorce, children's poor school performance and their moral delinquency are also attributed to the migration of women (Hochschild 2003). Such beliefs result in the stigmatisation of migrant mothers (Parreñas 2003:44). Not only do such convictions prevail in migrant communities of origin, but they are also present in the media and advanced by some migration scholars (Tolstokorova 2007). These public and academic discourses usually fail to take into account either the perspective of the migrating parents or the socio-economic context. In addition, they also ignore the overall divorce rate and family problems of non-migrating families in the given community, failing to see migration as a potential result and not the cause of marriage breakdown. For example, such factors as violence in the family or in marriage and an inability to get divorced may trigger women's migration (Sørensen 2005).

In contrast to understanding the family as a group (who has to interact in close geographical proximity, sharing common living space), transnational migration studies regard families as a form of 'imagined communities' (Anderson 1983). Transnational families or households can be defined as those whose core members are located in at least two nationstates. Migrants create transnational households to maximise resources and opportunities. They balance the unequal levels of economic development between sending and receiving nations, the legal barriers that restrict their participation and settlement in the receiving society and the rise of anti-immigration sentiments (Parreñas 200I: 84). Transnational households are considered 'broken' because they diverge from social expecta- 
tions of cohabitation among spouses and children. Neither do they meet the expectations of the division of labour in the family nor those of socialisation. Nevertheless, members of transnational families continue to interact, communicate and develop intimacy; they also have to deal with inequalities among its members across a spatial distance (Parreñas 200I, 2005; Mahler 2003). Family members are linked by emotional and financial ties and stay in contact by circulating between the countries of origin and destination or even a third country. They also use new technological means of communication.

There is an ongoing debate among researchers regarding the provision of long-distance care and the role of transnational care strategies (Escrivá \& Skinner 2008; Baldassar 2007; Parreñas 2005; Hondagneu-Sotelo \& Avila I997). Migrant women often come from a culture that lacks a social safety net (Ehrenreich \& Hochschild 2003: 25-26). They develop different forms of child-care substitutions, leaving children under the care of grandparents, female kin, fathers and paid caregivers (Parreñas 2005; Gamburd 2000; Hondagneu-Sotelo \& Avila I997; Hondagneu-Sotelo I994). Transnational mothering involves, on the one hand, pride these women take in performing paid work and, on the other hand, having to deal with stigma, guilt and criticism for leaving behind their children. The migrant women's identities as wives and mothers are often deeply rooted personal attitudes and a primary focus on work can lead to their feeling increasingly insecure and make them question their identity. At the same time, the economic independence in relation to their husbands may result in migrant women's increased dependency on exploitative working conditions (Morokvasic i984: 895). For example, migrant women from the Dominican Republic working in the US recommit themselves to patriarchal family systems because it gives them power as mothers over their children (Pessar 2003: 28). The process of women's migration is therefore full of contradictions and inconsistencies.

On the other hand, staying in the country of origin may mean that women have to face new financial and social challenges. According to Hondagneu-Sotelo (I994: 53), Mexican women who remain in the place of origin when their husbands migrate to the US, receive scarce remittances and little information from their husbands, while finding themselves forced to take over men's responsibilities at home. These women want to join their husbands to make them economically and socially responsible to their families. However, according to other research, Ecuadorian women whose husbands have migrated are empowered due to their role in remittances management (Pribilsky 2004).

The reluctance of families to send women abroad also results from linking migration to sexual promiscuity, exploitation and prostitution (Kempadoo 2005; Pessar 2003: 24). This is why families are often against the migration of single women. Evidence from research carried out in the 
US shows that none of the Mexican women who migrated while single was sponsored or sent as part of a family or household strategy (Hondagneu-Sotelo I994: 83). In general, the families disapproved of their migration and these women did not receive support from the family members. However, these migrant women did send remittances. Paradoxically, it is this sense of family obligation of migrant women, which seems to encourage families in other researched cases to send their daughters abroad. Daughters were less likely to spend money on their own needs and more likely to remit money to the family than were sons (Boyd i989). In societies where women's mobility is restricted, women who have lost an acceptable social status may actually be pressured by the family to migrate. This transgressing of socially accepted gender roles includes, for example, having a child when unmarried. These non-economic factors are closely linked to limited access to the labour market (Morokvasic i984: 898).

One of the possible responses to mobility barriers is to become part of a transnational network. Transnational networks involve social, symbolic and material ties between places of origin and different migrant destinations (Anthias 2000). Networks used by women are generally womencentred. Hondagneu-Sotelo (I994: 72) analyses the role of women's networks and claims that 'by the I970 and I980 women who wanted to migrate to the US after their husbands were more likely to rely on the direct assistance of other women to subvert or challenge their husbands' resistance'.

Migration studies addressed issues such as the establishment of transnational ties of migrant domestic workers from the Philippines to, among other places, the US and Italy (Gamburd 2000; Parreñas 200I). As already mentioned earlier in this chapter, social networks reduce uncertainty and play an important role in decreasing risks related to mobility. Still, many women do enter the destination countries on the basis of family reunion. Those women's residence status depends on their husbands, and those who arrive as fiancés or whose marriage breaks down within a specific time period face deportation (Boyd 2004: 8).

Another factor that might trigger women's migration are changes in the way the family functions in the migration country. Currently, many women in migrant destination countries are entering the labour market. In a research project carried out in Spain, Sweden and the UK, women employing domestic workers, although engaged in paid work, continued to have strong identities as mothers. This was particularly well shown in research done in Madrid and London, where women expressed a strong belief that hiring another woman for in-home care is the best solution as it allows them to work outside the home while still fulfilling their duties as a mother (Williams \& Gavanas 2008: 20). This opens an important employment niche for migrants.

Overall, the family or, better, the household can be both a risk to 
women's migration and a source of support in coping with risks. The family may seem to reduce risk, with the household members 'sharing' risks in the place of origin and during migration by supporting each other. However, the risks faced by the household are not shared equally by its members, with women migrants having to cope more often than men with negative stereotypes and the resulting lack of support on the side of their families. Absence of the family support network may mean engaging into migration at one's own risk. On the other hand, remaining in the place of origin may mean (though does not have to) increased risks for women. Women can respond to risks in the place of origin (such as violence in the family or unemployment) by migrating. They can overcome the challenge of having to migrate at one's own risk by developing or joining women-centred networks. They also reduce the risks resulting from their absence in their households by developing alternative forms of care.

\subsubsection{State entry, residence and labour market policies towards migrant domestic workers}

Currently, the opportunities of legally entering a country and accessing the domestic work sector are limited. ${ }^{9}$ It is rare that countries have recruitment policies and regulations making it possible to work in the domestic work sector on the basis of a work permit. In the year 2006 , only nineteen out of 64 countries analysed in a research had regulations dealing specifically with domestic work (UNF PA 2006: 52). Also, regulations of the domestic work sector differ from country to country. Southern European countries recognise the domestic sector as an area of employment, with Spain establishing annual quotas and Italy allowing the regularisation of domestic workers (Fasano \& Zuchini 2002; King \& Zontini 2000). The UK has also carried out a regularisation programme for domestic workers (Anderson \& Davidson 2004). In 2002, Germany introduced a special recruitment programme for care workers for the elderly; however, recruitment covered only Eastern Europe and was just for up to three years (Lutz 2008: 46). Belgium, Italy, Germany and France have produced collective bargaining agreements, a result of negotiations between trade unions and employers (ETUC 2005: I7). However, efforts to professionalise domestic work carried out in private households via state regulations do not bring expected results, either because they are too expensive for employers or they do not respond to the demand (Lutz 2008: 43). ${ }^{\circ 0}$ Special programmes, like that for au pairs, for 'work and travel' or for volunteer service as created by some states (including Germany and Austria), make it possible for migrant women to enter a country for a short period of time and work in a declared fashion. However, entering a country with one of such programmes means that the migrant is not recognised as a worker and 
thus has no labour rights. In this way, states attempt to bypass the labour laws (Anderson 200I). ${ }^{\text {II }}$ State's policies do not encourage settlement of migrants working in the domestic work sector. Domestic work programmes, such as the Live-in Caregiver Program in Canada, which are a bridge to the permanent residence status, are a rarity. Due to lack of official channels of access to the domestic work sector, migrant women often engage in so-called temporary migration.

In context of this policy, migrant women in the domestic work sector often experience so-called 'lasting temporariness'. Their migration lasts for several years, but their 'tourist' stay or fixed-term residence status in the migration country does not change. Meanwhile, their households in the place of origin become increasingly dependent on their earnings. Thus, domestic work that can initially be an opportunity, in the long-term may become a 'trap' for the migrant. In risk terms, 'the chance' is to earn a satisfactory sum of money compared to wages in the migrant's country of origin. The 'danger' is getting 'stuck' with a precarious status of residence and with a job that is often undeclared and below the migrant women's qualifications. This is especially true of modern migration, where the education level of migrant domestic workers is higher than in the past (Lutz 2008).

Through its policies and official discourse, the state shapes the meaning attached to the notion of 'migrant domestic worker' and thus the migrant women's social status. The official discourse of the key state actors may result in denying migrant domestic workers the right to be treated as workers. For example, Filipina and Indonesian domestic workers are presented in the state discourse as 'economic soldiers, criminals-prostitutes, pariahs, girls-slaves and/ or commodities' (Chin I997: 353). Filipina migrant women are also referred to as 'modern-day heroes' of the Philippine economy; however, they are neither rewarded nor protected for playing that role (Parreñas 200I). Labour attaches (officials in the diplomatic mission who monitor the situation of labour migrants) also often use hierarchies, claiming that the quality of migrant women's work depends on their nationality, with subordination and obedience presented as national characteristics (Chin I997: 366). For the benefit of potential employers, employment agencies also portray domestic workers according to national or ethnic stereotypes, with Filipina women at the top and African women at the bottom. Eastern European women are seen as more hard-working, while Latin Americans as more loving, but slow (Williams \& Gavanas 2008: 22). In the United States, a shift is visible from white foreign-born women being identified as the main representatives of the servant population by the end of the nineteenth century, to black Americans in the first half of the twentieth century and Latino women today (Sarti 2008: 80-8I). Kofman, Phizacklea, Raghuram and Sales (2000: 38) underline the fact that immigration policy leads to the institutionalisation 
of racism, by stating which nationalities are or are not allowed to enter the country and what type of work they are allowed to engage in. For example, Germany allows only citizens of specific countries from Central and Eastern Europe, among them Poles, to work in the domestic work sector (Ayres \& Barber 2006: 27). Parreñas (200I) refers to this experience of women shaped by state law and discourse as a 'dislocation'. Migrant women either subordinate themselves or resist the external force in society (in this case, governmental policies or employment agencies' strategies), attempting to displace their identities; they find the resources necessary to resist or negotiate dislocation in the dominant social structure. In attempting to do that, migrant women may actually recreate or reinforce the existing hierarchies, for example, when migrant women take over domestic work they may reiterate the gendered pattern of domestic work as being 'women's work'.

Few sending and receiving countries have bilateral labour agreements protecting workers' rights. In general, migrant domestic workers in the EU fall under the European Convention for the Protection of Human Rights and Fundamental Freedoms, which prohibits slavery and servitude (article 4.I) and discrimination (article I4), as well as the European Convention on the Legal Status of Migrant Workers of I977. ${ }^{\text {I2 }}$ In 2004, the Council of Europe issued Recommendation I663 concerning domestic servitude, demanding a charter of rights for domestic workers. ${ }^{\mathrm{I}}{ }^{\text {In }} 2002$, the European Parliament passed a resolution on 'regulating domestic help', acknowledging migrant domestic workers as an especially vulnerable group in need of protection and providing recommendation on how to improve their working conditions. However, neither the European Parliament nor the European Commission has acted on this resolution. In addition, the European directives explicitly exclude domestic workers from being recognised as workers. ${ }^{\text {I4 }}$ Exclusion from legal protection places the migrant at a risk of exploitation (Cyrus 2008). A breakthrough came with the development of a convention on decent work for migrant domestic workers by the International Labour Organization, which was adopted in 20II. ${ }^{15}$ Migrant domestic workers are organised in some countries, such as the UK, in non-governmental organisations that defend their rights. They are also a concern for trade unions in such countries as Italy, Ireland, Netherlands, Spain, Switzerland and Belgium (Anderson 200I; Lutz 2008: 6).

Very few countries have enforced standard contracts for domestic workers that specify working conditions and protect basic rights. A legal contract provides for specific work time and job responsibilities, which should limit the employer's power to command. However, according to research carried out in the UK, the arrangements are loose and constantly renegotiated, with the position of the worker being often too weak to enforce the contract (Anderson 2000: I73). There is strong evidence of 
dependency on employers of migrants working in a declared fashion. In the UK, the context of declared migrant domestic work is characterised by coercion, which ranges from migrants being in debt (financial dependence), being dependent on the employer for their immigration status, being emotionally pressured by the employer and even experiencing death threats (Anderson 2000). The most common abuses suffered by domestic workers in the UK included: denial of time off, psychological abuse, not being paid regularly and/or less than agreed in the contract, having their passport withheld, not being provided regular meals or a bedroom (ETUC 2005: I4, I6). ${ }^{16}$ In the UK, domestic workers are excluded from the Race Relations Act and, as a result, are not protected from racial discrimination. The negotiation of workload in migrant domestic work and potential exploitation has also been addressed in the research on live-in migrant care workers from the former Soviet Union working in Turkey (Akalin 2007). Another researcher, Degiuli (2007), refers to this phenomenon in her article on elderly care in Italy. In Southern Europe, the migration status of migrant domestic workers is similarly not separated from their work permit (Anthias 200I: 156). If those migrant women decide to leave an employer, due to poor working conditions or the preference to work in a different job, they could be deported. In Italy, the residence status of so-called guest workers is not tied to the employer; however, the workers are limited to the domestic work sector (Parreñas 200I: 49). According to Parreñas, contracts bind migrant domestic workers from the Philippines to stay with their employer regardless of working conditions. They are not protected by labour laws and thus vulnerable to sexual harassment and abuse, excessive work hours for no additional payment and poor living conditions. In Hong Kong, those migrant workers who flee abusive employers face deportation. In Singapore, migrants are prohibited from marrying or cohabiting with native citizens. In the Middle East and Asia, they are prohibited in the contract from becoming pregnant. In Taiwan, they cannot enter with their spouse and children (Parreñas 200I). For migrant domestic workers, the economic gains achieved through migration often result in the loss of civil and political rights: they are not present in the state of origin and their rights are limited to none in the country of migration (Parreñas 200I: 48). It seems that migration and labour policies, along with the political discourse of some states, fail to provide migrant women with any protection. Thus, migrant women are encouraged to migrate at their own risk.

The area of research into the way legal status affects working conditions and access to labour rights in migrant domestic work seems to be prominent (Chin 1997; Hondagneu-Sotelo 2003; Schwenken 2005; Anderson 2006). Status dependency resulting from entering via family reunification or having their residence status tied to the work permit may lead to women falling into so-called irregularity. Irregular migration de- 
velops when a state sets limitations on legal migration and it 'occurs when a person does not fully satisfy the conditions and requirements set by a state other than his or her own to enter, stay or exercise an economic activity in that state's territory' (Bilsborrow \& Zlotnik I997: 4I).

The majority of migrant women working in the domestic work sector are irregular migrants. In their case, irregularity occurs primarily through undeclared work and overstaying the official length of stay in the receiving country (Donato, Gabaccia, Holdaway, Manalansan IV \& Pessar 2006: 7). According to a survey carried out in 200 I by the European Foundation for the Improvement of Living and Working Conditions, it was estimated that from 70 to 80 per cent of jobs in the domestic sector are undeclared. ${ }^{\mathrm{I}}$ Undeclared work in the EU is understood as 'any paid activities that are lawful as regards their nature but not declared to the public authorities [...]'. ${ }^{\text {I8 }}$ Work can be undeclared due to: 'undeclared hours' as part of a declared job, a worker having one or several additional jobs that are not declared and the main job held by the worker being undeclared (Jølstad 2005). In France, the ratio of declared to undeclared workers in the domestic work sector was 5: I, in Italy 3: I (ETUC 2005: II). Undeclared work increases the migrant's dependency on the employer and his or her vulnerability to exploitation. Undeclared work means lack of social and health insurance, unstable conditions of work and, usually, low-paid jobs (according to standards of the receiving society) (Boyd 2004: 9). Migrant domestic work is also frequently coupled with the irregular residence status. This is the case for the majority of domestic workers in the US. In Canada, women represented half of the total applicants who sought admission after residing for five years with an irregular status (Boyd 2004: 6). Migrant domestic workers in Israel also work in an undeclared fashion and overstay their tourist visas, thus making their stay irregular (Rajiman, Schammah-Gesser \& Kemp 2003).

One could assume that the risk in migrant domestic work increases as the migrant's status irregularity grows. For example, a migrant who has a residence permit, but works without proper documents, would seem less 'at risk' than one who does not have a valid residence permit and still less 'at risk' than a migrant who is trying to enter the country without proper travel documents. However, the degree of risk exposure depends, to a large extent, on the level of tolerance for irregularity, the degree of stateness, as Zolberg (I98I) would have phrased it. Also, the risk of 'falling into' irregularity changes as the state introduces new regulations. Migrants attempt to respond to the newly implemented laws, based on information and experience they possess. In that sense, I believe, irregularity can become a reflexive strategy aimed at avoiding risks related to migration. However, the longer the irregular stay lasts, the greater the migrants' interest in attaining a regular legal status, due to health risks and the prospective inability to continue to work. Concerns about lack of health 
insurance and old age pension increase (Cyrus 2008: 188). Another reason why migrant domestic workers may want to work in a declared fashion is that this would facilitate receiving a visa and thus improve their mobility across international borders, allowing them to maintain ties with their family remaining in the country of origin (Näre 2003).

\subsubsection{The character of the domestic work sector and service}

The development of the domestic work sector depends to a large extent on institutional social support systems provided by the state and the market. The support systems in question cover areas such as child-care and elderly care, policies towards maternity, paternity and parental leave, cash provision to pay for care, as well as a particular 'care culture' discourse on what constitutes appropriate care (Williams \& Gavanas 2008: I5). Four types of welfare regimes can be distinguished: conservative, liberal, sociodemocratic and fundamental. Particular countries tend to lean towards one of those regimes, but in reality apply a mixture of welfare solutions. So, for example, France, which is generally regarded as a conservative regime providing service-based care, has recently introduced some forms of cash provisions to buy care, which is characteristic of the liberal regime. The liberal regime leaves its care solutions to the market, with the state providing very few services and relying on cash-based solutions as well as tax incentives to pay care providers. One of the countries opting for the liberal approach to welfare provision is the UK (Kofman, Phizacklea, Raghuram \& Sales 2000: I4I). The state policy whereby individuals receive cash payments to buy home-based care is regarded by some authors as leading to an increased commodification and marketisation of care (Anderson 200I; Lutz 2008; Williams \& Gavanas 2008: I4). The sociodemocratic regime prevails in Scandinavian countries and is characterised by a high degree of decommodification and access to well-developed childcare facilities. The fundamental regime (Spain, Portugal, Greece and, to a lesser extent, Italy) features little state welfare provision but calls for the support from extended family (Kofman et al. 2000: I4I). At the supranational level, the EU developed a directive on parental leave. ${ }^{19}$ Also within the EU, there is an increased participation of mothers in paid work and the development of child-care policies by states. State policies that provide extensive services and cash support to working mothers, attempting to equalise the opportunities among men and women, may be accompanied by a gendered division of household chores in the families (Kofman et. al 2000: I43).

The domestic work sector can be divided into employees living with their employer (living-in) and those living separately (living-out). Living conditions affect working conditions. Living-in can be understood as a form of low-risk entrance in migration at first glance. According to 
Anderson (2000: 40), living-in minimises expenses, secures work, accommodation and often food. It also gives shelter from the police and facilitates adaptation to the new language and culture. This is important for women who initially do not know the receiving society's language, have few migrant ties, are sometimes in debt and have an irregular residence status (Momsen r999: 6). However, living-in has many drawbacks. Combined with the nature of care work, it means spending most of the time inside the household, which can lead to isolation. Permanent availability - being constantly 'at work' - is highly psychologically strenuous. Migrant women have little control over their working hours. As Anderson puts it: 'to have to work twenty-four hours at an ill-defined job risks serious exploitation' (2000: 43). The migrant is caught between the public and the private domain where, on the one hand, working and living in the employer's private sphere she is treated as 'part of the family', and on the other, she remains a worker. In addition, migrant women have few opportunities to meet other migrants, exchange information and create their own networks. Living-in is also characterised by a lack of privacy. A migrant is dependent on the employer for her work, accommodation and her free time. She is an easy target for labour exploitation, including physical and psychological abuse. Moukarbel (2009: 159) wrote about the employer engaging in 'symbolic violence', to use Bourdieu's concept. They manipulate the migrants into accepting as 'natural' the employer's dominance and treating migrants as their 'possessions'.

Living-out is characterised by having several jobs or additional parttime work on top of the main job (Anderson 2000: 44). Migrants who live-out initially have to respond to higher risks than workers who live-in. They must learn about housing and work possibilities, often without knowing the language of the receiving society. They have to cut expenses by accepting poor living conditions. Another drawback is the time and cost related to travelling to various employers (Anderson 2000: 46). In addition, those migrants often have their own domestic and family responsibilities when they return from work. However, they have more independence and better-defined work duties than those who live-in. According to research, migrant women in this sector often start as live-in domestic workers and, having gained experience, move to live-out (Anderson 2000: 47). In Southern Europe (Greece, Spain and Italy), the majority of migrant domestic workers live-in while in Northern Europe (Germany and France), migrant domestic workers seem primarily to live-out, with many agencies in France dealing with migrant domestic workers (Anderson 2000: 66-79).

Domestic work means engaging in a work relationship in a household. Working in someone's household requires from workers an ability to integrate into the employer's home, respecting the different personal spaces and habits of employers (Lutz 2008: 2). A tension exists between the need 
to employ someone to carry out domestic tasks, on the one hand, and the need to preserve the intimate character of home, on the other. This tension results from the belief in the home as 'private' remaining in opposition to the market-productive as 'public'. The market, although associated with rationality and modernity, is also imagined as having self-interested actors who compete for resources. Relations between actors on the market are amoral, governed by contract. In contrast, home is based on moral norms and characterised by relations guided by emotions (Anderson 2006: 9). The woman is stereotypically regarded as more affective than the man. Thus, employing a woman to carry out domestic services, to some extent exacerbates the tension of having an employee in one's home.

Currently, domestic work is constructed as 'women's work'. The perception of domestic work as women's work results mainly from the gendered division of housework, with unwaged domestic chores continuing to be primarily women's responsibility (Anderson 200I; Andall 2000). It is more common for men and women to share child-care, but these changes are slow. Men also work in the domestic work sector in Europe; however, this is an exception rather than a rule. ${ }^{20}$ Remunerated house and care work partially replaces or complements work done without financial compensation. Paid domestic work is a response to an assumption built into the welfare state that women ought to combine waged work and unpaid domestic work. Employing someone to perform domestic work changes it into a remunerated activity, but the cultural understanding of it as 'women's work' remains. Domestic work is also primarily an exchange between women. A migrant woman takes over the chores of another woman. Women who are the employers of migrant domestic workers are part of the so-called post-feminist paradigm, with women outsourcing domestic chores to reconcile their waged work and family life (Andall 2000).

In general, women receive low wages for working in jobs labelled as women's work. Authors representing the so-called devaluation perspective claim that the low wages in women's occupations, including care work, result from a cultural bias, which depreciates women and thus the work they do (England 2005; Anthias 200I; Anderson 2000; Aronson and Neysmith 1997; Murray 1996). Murray (1996) claims that the assumed moral value received when caring for someone is often regarded as compensation for the low payment received for this type of work. Another false justification for accepting poorly paid jobs is presenting migration as the only chance for those women to engage in waged work, 'a blessing of modern societies to the Third World woman' (Morokvasic I984: 889). In fact, as Morokvasic (I984) argues, migrant women often had a higher participation rate in the labour market in their country of origin than women in the country of destination. According to her, there is no evidence that migration results in the improvement of migrant women's status - 
both in financial and social terms - and in a more egalitarian relationship between men and women migrants. However, other authors claim that migration for women may also mean the chance, if not to emancipate from a patriarchal system, then at least to weaken patriarchal relations. A redefinition of gender roles and division of labour in the household occurs: during migration, women acquire a degree of economic and social autonomy that they previously lacked (Hondagneu-Sotelo I994). This was the case, for example, of Dominican migrant women in the US (Pessar 2003). The low wages paid for domestic work increase migrant women's access to this type of employment. As Massey wrote (I993: 443-444):

...the negative qualities that people in industrialized countries attach to low-wage jobs, for example, may open up employment opportunities to foreign workers, thereby raising their expected earnings, increasing their ability to overcome risk and credit constraints, and enabling households to achieve relative income gains by sending family members abroad.

The devaluation of wages in domestic work can be explained by ethnicity and class. The migrant women who perform remunerated care work and who are generally of a different ethnic and class background from their employers are paid the lowest of all care workers (Misra, Merz \& Woodring 2004; Hondagneu-Sotelo 2003; Romero I992). ${ }^{2 \mathrm{I}}$ There are also differences among the migrants, with some ethnic groups having higher wages and better working conditions than others. In general, it seems that the fewer 'similarities' between the migrant and the native worker, the higher the risk of being at the low-end spectrum of the domestic sector in terms of income and social prestige.

With regard to services provided by migrants, we can talk about the interaction of three groups of women of different ethnicity and class in the two countries: firstly, women who are the employers and belong to the middle or upper class; secondly, migrant women who work as domestics; and thirdly, women who work as domestic workers in their own country because they cannot afford to migrate to work abroad and therefore care for the children and parents of those who migrate (Parreñas 200I: 73). The continuity of domestic work and the link between social inequality and care work is visible in the fact that some of the migrant women who work as domestic workers also themselves employ care workers or housekeepers in their countries of origin. For instance, this is the case with Filipino migrant domestic workers. Lan (2003) refers to this phenomenon as the 'maid/madame' boundary.

The work relationship between the employer and the migrant worker is characterised by reproduction and negotiation of structural inequality, based on such aspects as ethnicity, class, gender and citizenship (Parreñas 
200r: 73). The relationship between women of different legal, social and material status creates particular dependencies. These dependencies can result in migrants being excessively 'managed' by the women who employ them, thus opening grounds for labour exploitation with an increase of workload without a concomitant increase of wages. Anderson (2000: 6) points to the fact that since the worker is located in the employer's home, she is dependent on the employer for more than employment only. What is more, this work exchange between the two women requires a peculiar type of control of emotions. Women who employ migrants in their household do not want to be emotionally 'replaced' by the nanny and they do not want their position in the household to be questioned (Lutz 2008). In her work on Latina immigrant domestic workers in Los Angeles in the mid- to late I990s, Hondagneu-Sotelo (2003: 63-65) analyses the role of power relations between the migrant and the employer, their unequal social roles and the resulting conflict in this type of work. Migrant women themselves may also recreate ethnic and national hierarchies imposed on them by the employers. They claim to be better domestic workers than migrant women from other countries (Parreñas 200I: I52). While the employment of a domestic worker in some cases does allow women to enter or continue pursuing a professional career, there are also those women who, while employing a migrant worker, remain themselves in the domestic sphere. In some cases, it is because of their age and inability to run the household without help; in others, it is due to a need to reaffirm their social status and lifestyle by, as Anderson (2000: I7) refers to it, 'not doing the dirty work'. Working mothers wanting somehow to be the 'ideal housewife' without quitting their jobs on the labour market require a certain 'invisibility' of the migrant worker, who takes over some of the women's responsibilities in the household. This is similar to the findings of Rivas (2003: 73) in her research on care workers or so-called 'personal attendance' of persons with disabilities. She points to the social invisibility of those workers, who have to 'disappear' because those who are taken care of want to be regarded as 'independent'. This relationship leads to the construction of two identities: caregivers are seen as invisible and care receivers as independent. The 'invisibility' of migrant domestic workers was also analysed in a study on Sri Lankan maids in Lebanon. Racist treatment by employers, who were 'disgusted' by their employees, stemmed from power relations in the household. The dominance of the employer and the vulnerability of the migrant women was due to the fact that they were poor, had little opportunity to contact their families at home and depended on the employer for their legal status (Moukarbel 2009: I54).

Employers often resist treating housework as labour. This is related partly to the perception of cleaning and other domestic chores as unskilled work that anyone can manage. Housework is also regarded as an activity 
involving tasks that are difficult to define. This means that working hours are rarely precisely delineated and flexibility is required. According to some authors, not treating care work as proper labour stems from the belief that it is an emotional need, in other words, we care for those whom we love. Care work is structured as a woman's vocation, which requires not so much skills, but rather an input of emotions. This so-called 'care myth' is thus based on the conviction that care does not require physical and psychological work, only emotional engagement (England 2005: 389; Anderson 2000). Emotional involvement is one element of the process of 'familiarising' the domestic worker. The notion of the domestic worker being treated 'like a family member' was originally developed by Anderson (2000: I22). According to Anderson, this type of treatment is characterised by expectations for the worker to take interest in the employer's family, but there are few or no expectations that the employer will display interest in the migrant woman's family. The migrant worker's own family is symbolically 'erased' by the employer's not addressing the issue, as if the migrant women did not have their own lives (Anderson 2000: 125). The emotional engagement can, in turn, lead to increasing workloads, which are to be carried out not for payment, but out of emotional attachment, thus placing the migrant at the risk of labour exploitation. Although the household protects the undeclared migrant worker from the police and labour inspections, at the same time it excludes the worker from external aid, such as labour unions, in case of exploitation. However, migrant women also use intimacy to de-emphasise servitude (Parreñas 200I).

Domestic work is characterised by particular occupational hazards. According to a study conducted among professional elderly care workers in Northern Ireland, the home care workers experienced health hazards, injuries in moving and handling (related to hygiene and infection), verbal abuse and physical harassment from the cared for person, but also exposure to the cared for persons' pets and unsafe home equipment (Taylor \& Donnelly 2006: 245). In studies of home care workers in the US, 85 per cent experienced at least one work-related injury, from which 15 per cent reported verbal or physical abuse (Zechter \& Guidotti i987 in Taylor \& Donnelly 2006). In contrast to the domestic work of natives, however, migrant domestic work is characterised by the precarious immigration status. Combined with the isolation of domestic work and insecurity of employment, this fact apparently leads to many cases of mental illness among migrant women (Anderson 2000: 54).

To sum up, the migrant's exposure to risk is determined by the character of the domestic work sector and service. The gendered character of this job facilitates the migrant women's entrance into the labour market abroad. However, migrant women working in that sector have a low social status and are paid low wages in the receiving society. In general, this does not permit them to settle with their family, so this work does not allow 
them to reconcile paid work and family life. The migrant domestic worker is, in general, also excluded from legal protection. The domestic sector can be divided into two types of workers. On the one hand, there are workers who live-out; these are workers of a 'preferred' nationality who have more ability to respond to risks related to domestic work. On the other hand, there are those who live-in, are more isolated and often depend only on one employer.

\subsection{Applying selected sociocultural risk theories to migrant domestic work}

Having reviewed migration theories and migrant domestic work literature from a risk perspective, I will now address selected sociocultural risk theories. Through analysing their approach to risk, I will show how such understanding of risk is applicable to research exploring the experience of migrant domestic workers.

\subsubsection{Cultural theory: Risk perception and response}

The realist perspective on risk, with its claim that risk is an objective hazard and can be measured independently of social and cultural contexts, has come under heavy attack from the cultural theorists. Representatives of cultural theory argue that risk is a socially constructed interpretation of an actual hazard and cannot be analysed outside social and cultural processes. They claim that, first, risk perception is a selective process and, second, that in contrast to the realist approach, risk aversion is not the only rational response possible (Douglas 1992, I984).

Regarding the selective response to risk, cultural theorists argue that some dangers are identified by people as risk, while others are not. According to Douglas (1985), the reasons for choosing to acknowledge some risks and ignore others are found in the importance social groups and societies attach to the process of maintaining and redrawing boundaries between self and other. Specific dangers are selected for attention by society by being named 'risks' and may result in attributing the blame for the danger to a particular group. The perception of and response to risk also involves mutual obligations and expectations, with individuals helping each other avoid particular dangers. According to this perspective, individuals use culturally learned assumptions and weighing when it comes to estimating risks. Risk is therefore a politicised and morally loaded notion; as such, it plays a particular social function.

Douglas and Wildavsky (I982) reject the realist view that only experts can assess risks, while lay people have a distorted perception due to social and cultural influences. According to the cultural theory, both lay people 
and experts are influenced by culture. However, they base their understanding and response to risk on different cultural contexts; in other words, they have different 'cultural biases'. This approach assumes that competing rationalities exist within society, accounting for the existence of diverse perceptions of risk. Risk perception differs from society to society, it changes together with different social norms that influence behaviour and affect the evaluation of 'what dangers should be most feared, what risks are worth taking, and who should be allowed to take them' (Douglas \& Wildavsky ig82: 7). ${ }^{22}$

Another feature of the realist approach to risk - the risk aversion of individuals - has also been criticised by cultural theorists. According to Douglas, risk aversion is only one possible type of response to risk, even if it is at present the dominant one. Another potential behaviour towards risk is risk-seeking or risk-taking. ${ }^{23}$ For example, a risk-taking attitude in young men is often perceived as necessary to prove their courage - they are seen as 'courageous'. In contrast, women are usually associated with safe everyday life. A risk-taking attitude in women can be associated with a sense of guilt connected with crossing societal norms.. Responses to risk influence the process of self-identification: a person is classified as 'careful' or 'daring' based on whether he or she engages in or avoids risk, often attempting to conform to group norms.

In an attempt to explain the phenomenon of risk-seeking, the cultural theory introduces a distinction between acceptable and unacceptable risks. Acceptable risks do not pose a cultural threat to a social group, while the unacceptable ones undermine important cultural assumptions and, consequently, a sense of security. Risk acceptability is related to whether certain rewards are offered to the risk bearer. Some researchers refer to it as 'risk compensation'; other researchers claim that it is important whether a person's behaviour is socially approved or whether he or she fulfils social demands (Douglas I985: 50). Cultural theorists distinguish between voluntary risks, where there is choice, and involuntary risks, placed upon a person by an external force. People are willing to tolerate much higher risks when these are voluntary risks. According to Douglas and Wildavsky (I982: I6), 'people will either refuse a known risk or seek additional compensation for assuming it. Thus an involuntary risk due to ignorance is by knowledge converted into one that is averted or into a voluntary risk'. In other words, people may not be aware they are taking or facing risks. The moment they become aware they are taking a risk or are exposing themselves to a risk, they can employ two strategies. They can either try to avoid the risk or find out how they can balance the gains and costs related to it, thus turning it into a voluntary risk.

According to the realist approach, a rationally acting person is consciously averse to risk. In contrast, cultural theorists argue that acceptance of certain risks is part of a specific cultural pattern and does not have to 
be conscious; the responses to risk can be habitual and only after realising the results of an action may a person realise what risks were at stake. Risk aversion or risk-taking can be adopted in everyday routines and incorporated into our bodily actions without any special reflection. What is more, without additional information and conscious reflection, a person is able to categorise certain behaviours as risky. It means that certain assumptions and intuitions are present before the development of cognitive and moral judgements. These are based, among others, on acculturated stereotypes. Very early in their life, children are taught that through rational and responsible behaviour they can and should avoid certain dangers. We are acculturated to be responsible for controlling risk. As Douglas (I985:33) writes: 'the culturally learned intuitions which guide our judgment for any of our fields of competence teach us enough probabilistic principles but they are heavily culture-bound'. Acculturated nature of risk-related actions results in a routine-like, habitual behaviour.

People often think that they can cope with risks related to familiar situations: they underestimate these risks, feel immune to them, believe to be more in control even though the reality proves to be different. According to Douglas (1985: 59), people who estimate risk focus on middle-range probabilities, overlooking high-probability dangers, such as road accidents and low-probability dangers, such as earthquakes. Risks that are seen as low-probability ones and those of everyday character are usually downplayed. This process enables us to select risks; otherwise, we would not be able to act (Douglas I985: 30 ). In a familiar context people can easily engage in probabilistic thinking.

The advice a person receives on how to respond to risk depends on the characteristics of their social network. The more isolated a person is, the weaker his or her network and the less he or she can consult about decisions; thus, he or she has to set the norms of what is and is not a reasonable risk (Douglas 1985: 69). The context of how socially embedded a person is influences the risk strategies adopted: either group-based strategies or more individualised ones. Douglas introduced a model that categorises responses to risk and is known as the grid/group model. The model is based on two ideal types of social organisation in terms of the group's approach to risk. In the first type, members of a community have strong commitment to strengthening and maintaining internal bonds. They are unwilling to work out the risk-related situation via internal conflict; instead, they will tend to exclude from the group those who have challenged the group's norms through risky behaviour. For that reason, they place the responsibility for disasters on victims of the disaster and their families. Blame and punishment play a leading role in this form of social organisation. In the second type, the members of a community have strong dedication to individual activity and fair competition; the interaction in the group is based more on internal conflict than on solidarity. 
When faced with disaster, the response of the community members is neutral; they perceive it as chance or fate (Douglas I985: 6I-62). Douglas expanded these two ideal types into a four-cell model of risk rationalities. She equipped the model with the notion of group ethos, which can be high or low, pointing to the strength of the group's external boundary. Another new concept added to the model was the grid index comprising all other distinctions and social constraints related to gender, ethnicity, social class and other characteristics (Douglas \& Wildavsky i982: 138). The grid/group model's four ideal types of risk response are: I) hierarchists (high group and high grid) who respect authority, conform closely to group norms and expectations relating to risk and believe in establishing organisations; 2) egalitarians (high group and low grid) who identify strongly with their group and blame outsiders for risk; they tend to be distrustful of externally imposed norms and supportive of social equality issues and a participatory approach to risk; 3 ) individualists (low group and low grid) who are individualistic and entrepreneurial, support self-regulation of risk, trust individuals rather than organisations, believe in market forces, see risk-taking as bringing benefits as well as dangers with it and resent external constraints; and 4) fatalists (low group and high grid) who lack strong cohesion to a group but are otherwise highly constrained in their behaviours and tend to trust luck and fate in relation to risk, seeing themselves as having little personal control over it.

However, it is to be remembered that the grid/group model with its ideal types of risk presents a static picture or risk, while risk responses are in reality very dynamic. Risk perception is more complex than these categories would suggest, with people belonging to a number of cultural groups and playing different social roles (as determined by their life experience and the risks associated with different activities).

Applying the above to migrant domestic work, I make the following assumptions. A specific cultural bias influences the migrant women's risk perception and selection, as it was shown by examples given in the chapter reviewing migrant domestic work research. Communities saw female as more at risk than males during migration, which led to restricting women's mobility. On the other hand, women were regarded by their families as more reliable when it came to sending remittances. In addition, it is clear that migrants pay attention to risks 'advertised' by the public. For example, they feel concerned that their migration might have a negative impact on the upbringing of their children. Still, where a mother is not able to provide for the material well-being of her children, there is more acceptance for her migration and thus for seemingly taking higher risks than usual.

Regarding responses to risk, a crucial role is played by the awareness of being exposed to risk. A migrant worker's awareness that she is exposed to poor working conditions will lower her risk acceptability. On the other 
hand, a migrant who lacks awareness that his or her payment is substantially below that of others providing similar services will continue working for such wages. Lack of or inadequate information increases the migrant's risk of being exploited. The choices one has can also be analysed from the perspective of the location of a person within his or her social circle and access to networks providing information. This can be referred to as different 'risk positions'. For example, care work is constructed in such a way that it isolates the female migrant, giving her little chance to develop a social network and thus have access to information; a man working with a group of both migrants and native workers in the construction sector will have a different 'risk position' in that sense.

When a person has access to information, he or she not only perceives risk differently, but the degree of their risk acceptability also changes. Access to information in managing risk during migration is crucial. A person who has more reliable information faces less uncertainty when making choices. On the basis of available information, they will be able to estimate or evaluate the probabilities of gains and losses. However, being more aware of risk does not automatically lead to more cautious behaviour. It is also linked to the location within the social network, which gives a person resources to act on. These 'risk positions' also serve in some cases as a means of self-identification and help develop a group membership. For example, it can be assumed that migrant women in the domestic sector who are concerned about similar risks will tend to create temporary alliances and networks to stay well-informed about potential threats.

Certain social groups are, due to their positioning, categorised as being 'at risk' in terms of a number of dangers; they are seen as vulnerable and powerless or harmful to themselves or others. Irregular migrants are regarded as more 'at risk' than migrants with a regularised status, but also as more 'of a risk' to the host society than the latter. In general, women are regarded as more 'at risk' than men and thus tend to be socialised into high-risk awareness (Douglas I985: 70). Those who are 'at risk' are regarded as likely victims and are at times blamed for their own misfortune (Douglas i985: 56). For example, a female work migrant who leaves her family due to the lack of local labour market opportunities is blamed for 'abandoning' her children.

\subsubsection{Risk society and risk culture}

Risk society is another theoretical approach, which emerged as a critique of the belief that risk can be measured and managed. Its main proponents, Beck (I992, 2000) and Giddens (I999, I994, I99I, I990), understand risk as 'incalculable insecurities'. According to them, it is only possible to talk about 'risk scenarios' because, in the modern world, risks are charac- 
terised by non-localised nature and long-term consequences. The globalisation of risks makes it difficult to attribute risks to particular events, activities or even localities (Adam \& Von Loon 2000: I). Risks are no longer local in impact; they are not bound to a specific space, group or time (their results may be felt by future generations). It is increasingly impossible to hold someone accountable and responsible for what Beck (I992) refers to as the 'manufacturing of risks'. Human beings develop technology, the potential consequences of which they are not able to fully predict. The past risk experience or 'risk knowledge' is thus useless - it actually encourages the anticipation of the wrong risks, while the disaster strikes from factors that are incalculable and unknown. This is similar to Douglas's and Wildavsky's (I982: 7) writings, where they claim that although risk should be seen as a joint product of knowledge about the future and consent about the most desired prospects, the knowledge is uncertain and the consent is contested. The irony of risk is that one has to expect the unexpected (Beck I992: 3) and, if the outcomes are irreversible, there is no possibility for compensation. According to the risk society theory, the primary risk is 'social dependency upon institutions and actors, who may be alien, obscure, inaccessible to most people affected by risks in questions' (Beck I992: 4). The scale of risk is a direct function of the quality of social relations and processes. Instead of 'progress', it is the production of risks that dominates.

The main axis of Beck's (I992: 88) analysis is the opposition between scarcity, characteristic of class society, and insecurity, characteristic of risk society. Social class becomes dissolved in contemporary capitalism. According to Beck (I992: 36), with the production and division of labour spread across the globe, we share a common set of risks and thus we are all members of a risk society. In this way, risk is qualitatively different from scarcity. Beck has been criticised for claiming that risk is shared in a 'democratic' way by, among others, Scott (I992: 35) and Adams (I995). These cultural theorists argue that insecurity is a function of scarcity, i.e. uncertainty results from shortage, whether material or emotional. Scott claims that Beck's motto for the risk society - 'I am afraid' - is also appropriate for the class society. He undermines Beck's notion of risks being 'democratic': according to Scott, wealth continues to provide, at least to some extent, protection from risks.

Beck himself offers a counter-argument to his own claim about the 'democratic' character of risks, giving examples of the higher vulnerability of certain groups or individuals. He discusses how the 'freeing' of work relations is related to gender status: women have freed themselves from the traditional family network, through individualisation, but they have also lost a form of support network. At the same time, their position in the labour market is uncertain, with unemployment among women being much higher than among men (Beck I992: 89; 93). Beck argues that since 
women have currently more equal education opportunities and an increased awareness of their position, they have built up expectations of more equality and partnership in work and family relations. However, the developments in the labour market and men's behaviour run counter to these expectations (Beck I992: 103).

According to Beck (1992: 94), in modern-day society, the sense of community is 'dissolved in the acid bath of competition'. He gives examples of such individualisation when analysing the situation of the 'free wage labourer' who has been 'liberated' from the constraints of the labour market in modern capitalism, which results in the loss of the sense of security and the necessity to face new risks. According to Beck, individual mobility contradicts the preservation of social bonds in the forms of ties to family, neighbourhood and friends. The traditional support network of the individual is lost. Beck does not critically reflect on the relation between mobility and the development of ties across time and space, which Giddens (I990) refers to extensively as a new form of reflexivity, the point I will discuss below. Beck goes on to claim that the flexibilisation or 'freeing' of work relations results in the expansion of fuzzy zones between declared and undeclared employment (including the work of housewives, youth and early retirees), as well as between employment and underemployment (Beck I992: 87).

For Giddens (I999), the key features of modernity that increase the awareness of risk are institutional and individual reflexivity. Reflexivity describes an active response to conditions that arouse fear and involves a continuous monitoring of action and its contexts. Reflexivity is accompanied by the reorganisation of time and space and the expansion of so-called disembedding mechanisms, such as systems of expert knowledge or money. The concept involves an awareness of the conditional nature of expert knowledge and social activity as well as an understanding that they are likely to change as new information becomes available. While Beck underlines the lack of trust in institutions as the reason why risks now have to be dealt with in an individualised manner, Giddens points to the trust in abstract expert systems as a new way of coping with risks.

In general, individuals operate within clearly established routines that create and recreate a sense of ontological security, meaning 'the confidence that most human beings have in the continuity of their self-identity and the constancy of the surrounding social and material environments of action' (Giddens I990: 92). The stability of social routines is central to the continuity of personality and institutions. The routines are bound to a particular, familiar setting and thus an important element of safety routines is the creation and/or recreation of trust. With increasing trust, risk becomes 'acceptable' because the perceived danger becomes less serious. Trust is necessary to undertake action in response to risk. However, routines can also lead to a situation of closure or exclusion from informa- 
tion, which is necessary in order to respond to risk. When things go wrong, the routines are called into question and reflected on so that new solutions can be sought. When everyday routines are no longer available - as is often the case during migration - individuals have to make conscious decisions about their preferences. Giddens (I999) argues that 'a risk culture' is created, requiring a continuous negotiation of trust, with individuals and institutions interacting in a reflexive relationship.

In an attempt to relate risk society theory to migrant domestic work, I would analyse first of all the place of origin of migrant domestic workers. Migration can be understood as a response to the experience of new risks resulting from systemic and political transformations, such as unemployment and failure of institutions that used to provide trust in society. Also, particular new labour relations develop, which leads to workers becoming mobile. In addition, going against Beck's argument about democratic risks, migrant workers are able to influence positively or negatively their residence status, depending on their material standing. Those who can prove they have a regular income stand a better chance of obtaining a temporary residence permit in the country of migration. Those who do not, face overstaying and all the possible consequences of an irregular stay, such as lack of payment due to no work contract, health risks due to no insurance and/or deportation. 



\section{Theoretical approach and research methodology applied in this study}

\subsection{Structure, agency and social capital in migrant domestic work}

The migrant domestic worker can be analysed as an agent who creates and/or recreates a particular structure. According to Giddens (I979: 55), agency refers to a continuous flow of conduct. The agent is an active subject who has access to a common cultural stock of knowledge that allows him or her to act in a given temporal and spatial context. Being an agent means having an internal structure, which acts as both a constraining and a facilitating factor. Structure refers to particular structuring properties, such as rules and resources. Structures exist "paradigmatically as an absent set of differences, temporally "present" only in their instantiation, in the constituting moments of social systems' (Giddens I993: 36, I979: 64). Giddens refers to structure as particular 'sets or matrices of rule - resource properties governing transformations'. The rule-resource properties are constituted of three components. Firstly, it is knowledge, as memory traces of 'how things are to be done' by social actors; secondly, these are social practices organised through recursive mobilisation of knowledge; thirdly, these are capabilities that the production of those practices presupposes (Giddens I979: 64). The agent brings structure into being and, conversely, structure produces the possibility of agency. The central concept of structuration is the duality of structure, which refers to the recursive character of social life and expresses the mutual dependence of structure and agency. Duality of structure means that social structure is both enabling and constraining: people reflexively produce and reproduce their social life (Giddens i993: 37).

I will use the concept of agency to analyse the experience of migrant domestic workers. This involves discussing the meaning that migrant workers assign to their work abroad, their motivations behind migration and knowledge of their own situation as well as the ability to reflexively monitor their situation and change it. I believe the concept of agency allows a change in perception of the migrant as a passive individual who is entirely determined by circumstances to see him or her as an active subject in a specific spatial and temporal context. Agency also involves unintended consequences of intentional actions. This is what Giddens understands 
as risks of modernity; in the case of migrant domestic workers they revolve around their gender, legal status as well as the character of their work and migration.

In this study, I analyse migrant domestic work as recreation of a social practice, that is, recreation of domestic work, as paid employment-during migration. A social practice requires the exercise of meaningful communication as well as access to power and morality through the evaluation of conduct by means of moral rules and norms. According to Giddens (I979), the agent recreates and changes the structure through social practices. In the case of migrant domestic work, rules originating from one context are applied to another in order to enact a social practice. Migration in the domestic work sector creates a special setting and time for the creation of rules, which do not necessarily have a formal character. Rather, they are rules practised and recreated by migrants so as to order their lives.

In this research, I address evaluation of and response to risk through Giddens' notion of agency. Motivation, rationalisation and reflexive monitoring are the diverse elements of agency (Giddens I979: 57). The motivation of action involves the desires and needs that bring it about. Impulses can be both conscious and unconscious. Giddens claims that rationalisation of action occurs when social actors are aware about the conditions of social recreation in which their everyday activities are intertwined. According to Giddens (2002: 227), 'rationalisation of action is closely bound up with the moral evaluation of "responsibility" which actors' make of each other's conduct, and hence with moral norms and the sanctions to which those who contravene them are subject'. Reflexive monitoring of action involves learning, the capacity to act otherwise and the monitoring of the setting of interaction. Reflexivity means that the human being is a purposive agent, who has reasons for acting and is able to give details about these reasons in a discursive manner. ${ }^{\mathrm{I}}$ Migrant domestic workers can also be analysed as reflexive agents, seeing migration as a learning process during which the migrant gains awareness of how to respond to risks. A migrant domestic worker learns, for example, what working conditions she can accept. Even though the resources and thus the division of power between the migrant and the employer are asymmetrical, the migrant engages in what Giddens (I979) referred to as 'dialectic of control'. By introducing this notion, Giddens insists that even the least powerful agents - as migrant domestic workers are believed to be in the present research - have the ability to mobilise resources and have some control in a particular setting, because 'all relations of autonomy and dependence of resources involved, all power relations express autonomy and dependence "in both directions"' (Giddens 1979: 39).

We can say that the distribution of risk is related to the distribution of power and status. It seems that there is an inverse relationship between risk consciousness and social position. The more secure the position, the 
higher the risk awareness. In general, it is also true that the more power and the higher status one has, the greater their ability to decrease risks. An irregular migrant domestic worker seems to have a low status and little power, meaning the capacity to transform or mobilise social capital and other resources to act and respond to risk. Resources, an element of the dominant structure, are treated by Giddens as vehicles of power. They are used during interaction and recreated by the duality of structure. According to Giddens (I979: 69), this duality of structure means that 'structural properties of social systems are both the medium and the outcome of practices that constitute those systems'. ${ }^{2}$ In that sense, migrants' behaviour can recreate a social pattern, or it might change the pattern already established.

Access to and the quality of social capital may influence the migrants' ability to respond to risk. Social capital may be understood as the sum of the resources accumulated by an individual or by groups through possessing a durable network of institutionalised relationships of acquaintance and identification (Bourdieu I983, I986). The first contemporary author to systematically develop this concept, together with the notions of economic and cultural capital, was Bourdieu. To explain the operation of capital, he introduced the concept of social space (forces limiting the freedom of human action) and the notion of habitus (the habits that allow humans to cope with and in life). Bourdieu focuses on the convertibility of capitals creating a basis for tactics to reproduce capital. The different types of capital differ in terms of how easily they are converted.

Coleman's (I990) distinction of physical, human and social capital is also often used in migration analysis. According to Coleman (I990: 305), social capital constitutes 'resources that can be used by the actors to realise their interests'. The author defines social capital by its function. It is 'a variety of entities with two elements in common: They all consist of some aspect of social structures, and they facilitate certain action of actors whether persons or corporate actors - within the structure'. Thus, for social capital to exist, relations among persons have to be changed in order to facilitate action. Coleman analyses the mechanisms that generate social capital (reciprocity expectations and group enforcement of norms), the consequences of possessing social capital (privileged access to information) and the social organisation that provides the context for both resources and effects to materialise (Portes I998). According to Coleman (I990: 306), there are two main sources of social capital: consummatory motivation (internalised norms, bounded solidarity) and instrumental motivation (reciprocity exchange, enforceable trust). The expectation of reciprocity by those who agreed to provide someone with access to information depends on how far the possessor of social capital (the person making the claims) feels obliged to repay, when and in what form. This is influenced by the level of trustworthiness of the social environment. 
Thus, there are the possessors of social capital (those making claims), the sources of social capital (those agreeing to these demands) and the resources themselves.

According to Coleman, a dense network and strong ties are necessary for the emergence of social capital. This contrast with Granovetter's writing on weak and strong ties. According to Granovetter (I978: 136I), 'the strength of a tie is a probably linear combination of the amount of time, the emotional intensity, the intimacy (mutual confiding), and the reciprocal services which characterise the tie'. Strong ties are characterised by time commitment and psychological strain of consistency. Whatever is to be diffused through weak ties can reach a larger number of people, and traverse greater social distance than through strong ties. According to Granovetter (1978: 1367):

since the resistance to a risky or deviant activity is greater than to a safe or normal one, a large number of people will have to be exposed to it and adopt it, in the early stages, before it will spread in a chain reaction. Individuals with many weak ties are, by my arguments, best placed to diffuse such a difficult innovation...

Social capital functions among others as a source of control (Coleman I990) and a source of resources mediated by non-family networks (Bourdieu I983, I986), facilitating access to jobs, market and loans. Not every type of social capital is useful during migration and not every type of social capital allows a person to respond to risk. According to Górny and Stola (200I:165), migrants use individual social capital, which involves a person's connection, possessing particular resources that facilitate migration and gaining access to these resources through this connection. These resources mean the knowledge, experience and material belongings of other people (Górny \& Stola 200I: I66). Górny and Stola refer to this capital as migration social capital. ${ }^{3}$

The migrant uses different forms of migration social capital. One of them is relying on social networks. According to Górny and Stola (200I:I8I), the need to use networks depends on how much knowledge one has about the destination country. The wider the knowledge, the less need there is to use the network. In that sense, social capital is, at the beginning of migration, a substitute for knowledge, money and skills. Górny and Stola (2001:I77-I78) claim that circular migrants use mainly the social capital located in their country of origin. The initial possession of social capital (in the form of access to migration networks) is related to greater eagerness to migrate. Having a family member with migration experience is also a high-quality social migration capital. With growing experience, the migrant uses fewer family and friend contacts because he or she is already rich in different resources. 


\subsection{Research questions}

Little quantitative data is available on irregular labour migration. Migrants entering Poland as tourists escape the official statistics. However, qualitative data may give an insight into this hidden world, which sometimes exists even in our own households, without our realising the web of alliances, battles fought and strategies involved. This research is based on qualitative methods: I primarily use in-depth interviews and ethnographic observation. I also refer to some secondary statistical sources to give an overall context for the data analysed.

The research focuses on the migrant women's reflections on the images of risk before and after engaging in migration and their risk strategies during migration. These areas of research firstly analyse the notion of risk as a particular thought exercise and, secondly, as a certain practice. The thought exercise takes place both before and during migration, with new types of risks being taken into account. Thus, this research, apart from attempting to answer to what extent the notion of risk is useful in analysing migration, addresses two basic questions.

I) What do the Ukrainian women perceive as risk and how do they evaluate risks related to labour migration to Poland?

2) How do the women studied respond to risks during migration and what are the consequences of their actions for the migration experience?

These research questions are based on the assumption that a person undertaking international labour migration is initially exposed to risks because they must cross one or more state borders and function in an unknown social, economic and legal environment. The exposure to risk seems even more relevant when analysing irregular labour migration. However, it is also believed that by examining the strategies, one can find responses to risks that are unconscious yet have become habituated. At the basis of these questions is also the assumption that the social characteristics of a migrant influence the ability to perceive and respond to risk. Following Giddens (I999), we can say that risk requires agency.

The first question allows me to analyse what the women regard as risks that is the potential undesirable outcome of labour migration, and how they evaluate the possibility of the occurrence of these unwanted results. Drawing on the works of Douglas (I992), I assume the selectiveness of risk. Migrants become aware of some risks and, depending on their evaluation of them, select which to respond to. I would argue that migrants possess a risk knowledge, meaning the ability to decide what is and what is not risk on the basis of social and cultural norms through which information and images are evaluated. These norms also enable them to assess which risk is acceptable and which is not.

I attempt to find the answer to the question of how the women's risk 
images in relation to migration are formed, from whom they receive information about the potential negative outcomes and whether they are able to identify with those who have had bad experiences of migration. Thus, they can gain some reference point of the risk to which they themselves may be exposed. The aim is to explain why certain potential negative outcomes are perceived as risks and regarded as important, while others are not. The main underlying theoretical notion regarding the answer to this question, apart from Giddens' reflexivity, is the concept of the imagined opportunity space (Schiffauer 2006). This notion allows us to treat the process of engaging in migration as a complex relationship between the category to which one belongs, the conditions in which the decision is made and moral judgements and premises.

The second question concerns migrant strategies. A migrant recreates and modifies certain strategies to strike a balance between potential costs and opportunities, between the sense of security and the desire to achieve a new goal. The answer to the second question also involves observing the different patterns of women's risk response during a specific type of migration. Demographic and social factors, such as age, sex, stage in life, level of education and work experience all shape risk exposure in the country of migration and the response of migrants. Other important factors are the legal status and nature of work. Three main notions will be used here: the migrant institution, based on Giddens' concept of institution, the patron-client relationship and everyday forms of resistance.

The first notion of the migrant institution is 'a complex articulation of individuals, associations, and organisations which extends the social action of and interaction between these agents and agencies across time and space' (Goss \& Lindquist I995: 319). Here focus is on the manner in which knowledgeable agents (potential migrants) employ their understanding of rules of interaction and exploit their access to resources within the migrant institution in order to find work (Goss \& Lindquist I995: 335). I would argue that risks related to labour migration are constructed and responded to through different migrant institutions. A routinisation of the social practices of migration occurs as does the articulation of strategic goals of individual and institutional agents. So, in that sense, international labour migration becomes structured by specific modalities of interaction, and access to international migration is conditioned by the operation of specific rules and mobilisation of resources (Goss \& Lindquist I995: 336). Migrants interact and use their access to resources not only to find work, as Goss and Lindquist argue, but also to balance the risks related to labour migration.

The second notion of the patron-client relation is a personal relationship that exists between unequal individuals; the inequality results from the existence of a hierarchy, understood here as a structure linking unequal persons in relations of dominance and subordination (Tarkowski I994: 
45). The patron-client relationship is based on a long-term, continuous existence of structural unevenness. The need for patron-client relations increases when individuals or groups lack a sense of stability and security. A sensation of vulnerability and constant threat due to weak legal, economic or political guarantees of security is related to the unpredictability and instability of living conditions (Tarkowski I994: 88). This is the case with irregular migrants, who often enter with the employer into a patron-client relationship, treating it as a mechanism that allows them to respond to risk.

The third concept, everyday forms of resistance, is based on writings of Scott (1985), analysing peasant resistance towards those who wanted to exploit them, such as by forcing them to work. This class struggle is characterised by the use of commonplace defence strategies of the relatively powerless groups, such as dissimulation, false compliance, feigning ignorance and others. Scott saw these acts as a form of individual selfhelp. Due to the power discrepancy, it was important for those resisting to avoid any direct confrontation with authority or with norms (I985: 29). One of the acts of resistance Scott refers to is the hidden transcript: a form of speech produced for a special audience and under different constraints of power than what the person experiences when facing supervisors. The public transcript is the performance of deference and consent by the subordinate, who attempts to foresee the intentions of the power-holder (Scott 1990: 3). This notion can be useful to explain the way migrants present themselves to actors in migration, such as border guards and employers.

\subsection{Study participants and research setting}

In this study I focus on a set of risk strategies exercised during migration to Poland. These strategies result from the agency of specific actors Ukrainian migrant women - and are embedded in a particular setting the domestic sector in Warsaw and its suburbs, chosen as my main research setting.

The ideal participant of this study can be identified as a Ukrainian woman entering Poland on the basis of a visa issued for up to three months and working without a permit in the domestic work sector. However, women who entered the country on a year-long multiple-entry visa or entered without proper travel documents were also included in the study. To find respondents I used the snowball sampling technique; I met the first migrant domestic workers through Poles for whom the migrants worked and they referred me to their friends and acquaintances. I also met two migrant women through a non-governmental organisation that offered migrants a volunteer status in Poland. Overall, I interviewed 
nineteen women, most of whom originated from western Ukraine, often from the borderlands. The age of my interviewees ranged from eighteen to 57; however, the majority were between 40 and 60 years old. Most of the women had secondary education. At the time of the research, ten women were divorced or separated from their husbands. One was a widow. Seven of my interviewees were married (three of the five Ukrainian husbands were also labour migrants and two of the husbands were Polish citizens). Sixteen of the nineteen interviewees had children. Only one of the women had her child with her in Poland at the time I conducted my research. One of the interviewees was single.

In Ukraine, the majority of the women interviewed were unemployed or experienced so-called hidden unemployment - remaining employed but not being paid wages. Some were retired or had just finished their studies and were unable to find work. Many of those unemployed used to work in state-owned factories, which closed down with the falling apart of the Soviet Union. Almost all of them have participated in the informal economy, trading at the local bazaar and growing their own vegetables and fruits on small land plots. The women's experience of circulating between Poland and Ukraine ranged from several months to ten years. For the majority of my interviewees, Poland was the first foreign country they had visited. In general, they spoke communicative Polish.

The domestic work sector can be subdivided according to the types of tasks performed, such as cleaning, home maintenance (involving cleaning, washing, cooking, garden work), elderly care (depending on the degree of dependence - from being a companion to also feeding, washing and carrying the person), child-care, disabled care and pet care. Different domestic chores are generated by diverse demands. The women interviewed performed one or more of the following types of work: elderly care (six interviewees), child-care (eight interviewees), disabled person care (one interviewee), cleaning (ten interviewees). When it comes to combining the different work types, the following pattern emerges: child-care as the main occupation and part-time cleaning (four interviewees), cleaning as the main occupation and part-time care work (one interviewee) and care work (children and elderly) combined with home maintenance for the same employers (seven interviewees).

The type of work performed is often related to live-in or live-out status, with care workers often living-in and cleaners living-out. Of those interviewed, almost half were live-in domestic workers, living in the apartment of the person they were caring for. Living arrangements and the type of work the women engaged in influenced the organisation of services, with some types of work more suited for part-time working arrangements than others. Different types of domestic services each have a different status attached to them, with child-care being probably the highest in the hierarchy of importance in the receiving society and cleaning the lowest. At 
the same time, cleaning is highly valued from migrants' point of view: the form of payment (per cleaning session or per hour) and living arrangement (living-out) allows for a high degree of independence compared to care work, especially elderly care (usually paid monthly and done in a livingin arrangement).

In general, the women I interviewed worked in Poland without a work permit. Three cases diverged from what was otherwise considered a 'pure' undeclared employment pattern. One woman was officially a volunteer while working in care and two women had falsely declared employment, meaning that they had a work permit but performed additional undeclared work.

The study participants (women migrants) and the research methodology (in-depth interviews) influence the level of analysis, which in this study is carried out using micro and meso approaches. At the micro-level, I focus on the individual migrant, searching for their values, expectations and resources available in relation to risk. The micro-level allows me to focus on the perception and evaluation of risks related to migration. In contrast, the meso-level of analysis allows me to analyse the local context, which structures the options available to migrants and provides a framework in which decisions about risk are actually made. The meso-level includes social networks and ties of solidarity and exchange, which give access to resources of other people. It points to existing power relations, to trust and solidarity or lack thereof (Faist I997: I88).

As for the research setting, Poland was and continues to be primarily an emigration country. ${ }_{4}^{4}$ According to official statistics, migration to Poland remains low. ${ }^{5}$ But the estimates of irregular labour migrants oscillate between 50,000 and 300,000 , depending on the research consulted (Golinowska 2004). Others give even higher estimates of 300,000 to 600,000 (Koryś \& Weinar 2005). Ukrainian economic migration to Poland started in the beginning of the I990s, when the border regime was liberalised and free market reforms were introduced in both countries. The discrepancy in the economic development of Ukraine and Poland and significant differences in salaries (\$20-30 per month in Ukraine and over $\$ 200$ per month in Poland) stimulated cross-border petty trade and labour migration, especially to seasonal work in agriculture and service work in large cities, such as Warsaw.

Warsaw lies in Mazowieckie Province, currently the region with the most long-term migrants and short-term migrants, both. The long-term migrants are those with a permanent residence permit or those who have a fixed-term residence permit (allowing a stay of up to two years). Shortterm migrants are those who enter as tourists and remain in Poland for less than one year. There seems to be a tendency among the Ukrainian women who come to work in the domestic sector in Poland to register their temporary residence with the local administration office. ${ }^{6}$ In 2005 , 
from the total of $\mathrm{I} 4,374$ Ukrainian nationals who registered a temporary residence under a specific address in Poland for more than two months, 4,389 were registered in Mazowieckie Province (Central Statistical Office following Kępińska 2006).7 In 2004, 23 per cent of all Ukrainians living in Poland lived in Mazowieckie Province. Warsaw had the biggest population of Ukrainians from the five major Polish cities (I7.7 per cent of all Ukrainians living in Poland) and, among those, there were more Ukrainian women than men (Fihel 2007: 24). ${ }^{8}$

Demand for migrant domestic work seems to be the highest in large cities, of which Warsaw, as capital, is a prime example. People here have better earnings and less support from extended family due to internal migration. After 1989, with the political and economic changes, Warsaw started to develop at a fast pace. It became the main site for the headquarters of international companies and the local workforce was paid sufficiently well to afford domestic services. At the same time, internal migration from other towns and cities to Warsaw consists of many young women (GUS 2002). They leave their care support, such as mothers and grandmothers, in their hometowns. Thus, if they decide to have children, they have to rely on paid child-care. Having found employment in Warsaw, they are committed to their work, which means they have little time for any sort of household chores. However, they earn sufficiently good salaries to afford to pay someone to do the cleaning for them. The demand for care workers and cleaners concerns not only those who are newcomers to Warsaw, but also older inhabitants whose working patterns changed with the introduction of the market economy. Another reason for Warsaw's demand for domestic workers, especially care workers, is that the city has one of the fastest growing elderly populations in Poland and, compared to others, a very high number of single parents (GUS 2003). In addition, Warsaw's attractiveness for irregular migrants, a category many domestic workers fall into, lies in the fact that, as a city of approximately two million inhabitants, it gives them some degree of anonymity. Until recently, migrants were also drawn to Warsaw because of its large open bazaar,9 informal hiring fairs and agricultural enterprises in its suburbs, which provided a good starting point to look for work in the informal economy.

\subsection{Methods}

Over the course of several months in 2005 and 2006, nineteen Ukrainian migrant women allowed me to gather data by using in-depth recorded interviews and participant-observation methods (see Appendix). ${ }^{\mathrm{IO}}$ By asking questions focusing on their migration experiences during the interview, I indicated to them that they should highlight some parts of their lives and not others. This allowed me to go deeply into the subject of risk 
strategies of migrants. ${ }^{\text {II }}$ During the interviews I paid special attention to the anxieties linked to migration that these women expressed, because, in its everyday understanding, the risk is associated with danger, and the most common response to danger is fear. When evaluating the women's response to risk, I also tried to take gender into account. For the majority of the interviewees, it was the first time they had talked extensively about the overall effects of their migration. Some of them responded very emotionally, crying or expressing anger. Three Ukrainian women refused to give an interview. Their migrant friends who helped me contact them said that they were afraid to be interviewed.

I conducted the first thirteen interviews in Polish, but having learned Ukrainian later at a communicative level I offered my respondents the choice to conduct the interview in Ukrainian during the six last interviews. All of the remaining interviewees decided to speak in Ukrainian. ${ }^{\text {I2 }}$ It is important to underline that the in-depth interviews I carried out in Ukrainian with migrants working in the domestic sector are one of the first instances of such methods applied to this group in Poland. Earlier research studies addressing Ukrainian domestic workers in Poland were carried out primarily in Polish. The setting of the interview with women who worked as cleaners (and who therefore were more mobile) was my apartment. However, I had to interview most of the women working as care workers at their workplace because they had little chance to leave it. ${ }^{\mathrm{I3}}$

My research includes several participant-observation studies. I used participant observation to complement the information gathered during the interviews. Participant observation involves 'participating in the social world in whatever role and reflecting on the products of that participation' (Hammersley \& Atkinson I983: II). This was necessary because it allowed me to develop closer relations with the interviewees, which made it possible to obtain more the confidential information. To give an example, one of the women told me only general fragments of her migration experience during the interview, omitting important parts of the story, especially regarding the number of people for whom she had found work in Poland. I only fully realised this after meeting up with her in Ukraine. She showed me around her hometown and only then did we discuss her migration story in great detail over a beer.

I accompanied one of the migrant domestic workers on her way home in January and August 2005 and in February 2006. I stayed during that time in villages and a small town near Lviv from which four of the interviewed migrants originated. This involved getting acquainted with migrants, attending gatherings of their friends and observing exchanges of information about the prospects of working abroad. It also allowed me to judge the overall material situation of their households and further needs that would stimulate migration. I participated in trips to the Polish consulate and used services migrants use to enter Poland, such as the 
'drivers' circulating between Ukraine and Poland. I also became a member of an association in Warsaw that gave migrant domestic workers a volunteer status in Poland. I participated several times in the social gatherings of my respondents on weekends in Warsaw, accompanying them to the bazaar or meeting in the evening at their homes for small social events, as well as accompanying them on their way to work. I tried to approach both the city of Warsaw and Polish households, which are familiar settings for me, as anthropologically strange - to make explicit the assumptions that are usually taken for granted by culture members (Hammersley \& Atkinson I983).

In general, the women were rather keen on having me as a guest in their homes in Ukraine. One person refused, only to admit later that her living standards were so poor she believed she could not be a proper host to me. However, I was not able to conduct participant observation at her work. My suggestion that I could go to work with her and participate in the cleaning was met with surprise and flat-out rejection. First, the woman claimed it was heavy physical work and I would not manage and, second, it was a matter of trust towards her employer (she could not just come with a stranger to the house, nor did she want to pretend I was a friend or cousin from Ukraine).

\subsection{Risk typology}

Having reviewed selected migration literature (see chapter two), I will now develop a risk typology for the analysis of the data presented in this study. Although risk appears as the key notion in some migration theories, research concerning migrant domestic work is concerned not so much with risks, as much as with the cost of engaging in this type of labour migration. To make use of the reviewed literature, I assume that the unexpected and undesirable costs of migration constitute a risk to the person deciding to engage in migrant domestic work. On the basis of the literature review, risks of migrant domestic work can be divided into three basic types: I) risk of remaining in the country of origin, 2) risk of migration and 3) risk of migrant domestic work.

I) Risk related to remaining at home means the continuation and conservation or even worsening of a current undesirable status quo (primarily loss of work), which eventually may lead to a decline in social status. The quality of family relations also affects risk exposure in the place of origin, ranging from verbal quarrels to physical violence.

2) Risk of migration relates not only to undesirable outcomes of entry and stay in the country of destination, but also to the potential losses due to one's absence from the country of origin. First of all, the basic risk in this category is to be refused entry, which translates into a loss of costs 
already incurred (preparation of travel documents, travel to the border) and lost opportunities (migration wage). Second, the form of entry into the country of migration matters when taking into consideration the migrant's risk exposure. When entering a different channel than that of regular work (via au pair or work and study visas), migrants lack access to labour rights and thus are placed at risk of labour exploitation. Their basic migration purpose is at stake here: earning enough money to be able to remit some of it home. Third, the form of entry also influences exposure to the risk related to stay. Migrant women, entering as dependants of their husbands (via family reunification) are at risk of having to remain in an abusive marriage so as not to lose their residence status; otherwise they fall into irregularity. When residence is tied to a work permit, a migrant who enters as a worker and loses his or her job, and consequently has an irregular status of residence, is at risk of being deported. When entering as a tourist, the migrant worker had to circulate between the country of migration and origin to keep up this façade of legal stay. On the other hand, overstaying the allowed time of residence increases the migrant's vulnerability to abuse by employers. Risk related to stay may be due to the women's low social status in the receiving society, cemented by having to accept very poor living conditions to decrease the living costs. Fourth, gender also influences migration risk. Female migrants' sexuality is an element of public discourse prevalent in the country of origin, equalising migration to prostitution and thus stigmatising migrant women. Fifth, there are undesired aspects of being absent from the country of origin: women's absence from their families may mean lack or insufficient care of their children (increasing the risk of child delinquency) and even family disintegration.

3) Risk of migrant domestic work results from the character of the domestic work sector and of the job's status. First, risk may be caused by the fact that migrant domestic work generally belongs to the informal sector of the labour market. Migrants usually work in an undeclared fashion (they are not protected by labour laws), which places them at risk of labour exploitation. Second, risk stems from a particular work environment - someone's home - which shields the migrants from external aid. Combined with a precarious legal status, these factors make the migrant women vulnerable to physical, emotional and sexual abuse or even death. Third, domestic work as 'women's work' it not treated as a proper labour, resulting in low payment (risk to income) and low social prestige (risk to social status). Fourth, currently migrant women are often well-educated skilled workers and, by undertaking a job in the domestic work sector, they risk losing their professional skills. Sixth, the domestic work sector has an informal hierarchy based on ethnicity, which ranks the different migrant groups, limiting or giving access to jobs and influencing the level of wages (risk of ethnic discrimination). Seventh, the living conditions 
impact migrants' working conditions, with those living with the employer being at a higher risk of exploitation than those living independently. Living-in means fewer chances to develop social networks, which are an important risk reducer because they provide migrants with necessary information. 


\section{Ukrainian migrant women's images of risk}

The Ukrainian women had to go through a particular thought process before they took their migration decision to go work in Poland's domestic work sector. What role did risk play as their decisions were being made whether to migrate, where to and what type of work to engage in? The women had to create a particular image of migration as a worthwhile undertaking. To analyse this process, I introduce the notion of the imagined opportunity space (Schiffauer 2006). An imagined opportunity space is tied to reality as a representation of something that can happen in the future. It can be expressed by using unreal conditional sentences, which have four interrelated characteristics: premise, category, evaluation and condition. Since risk involves a similar thought exercise on possible future outcomes, it can also be said to belong to the sphere of the imagined.

The first characteristic of the imagined opportunity space, premise, displays the causal relationship between $\mathrm{X}$ and $\mathrm{Y}$, for example: 'If I go abroad [X], then I will earn a lot of money [Y].' A premise is created and reproduced through social interactions during which biased information about specific countries is interpreted. Risk is also reflected upon through the use of unreal conditional sentences of the type 'If X..., then possibly Y may occur.' What type of premises do the Ukrainian migrant women refer to when evaluating migration risks?

The second assertion of the imagined opportunity space has to do with the category to which a person belongs: does he or she have the qualities required to be able to identify with migrants? If we know someone abroad who is somehow similar to us (and thus belongs to the same category), we can identify with their lot. Such identification makes it possible to consider migration: 'If she can work abroad, why can't I?' The probability of identifying with the fate of compatriots abroad rises with migration becoming a mass phenomenon, instead of an escapade of a few brave eccentrics. Another factor that determines the type of risk imagined is a person's multiple categories or, better, identities. With whom did the women identify when considering migration? How did this influence their evaluation of migration risks?

The third feature relates to evaluation of the imagined space - in other words, is it good or bad to migrate to a particular country? I address the link between moral evaluation of an activity and the category in which the 
person engaging in the activity belongs. How does the category, such as being a woman, young or old, with a specific marital status, influence their own and their social circles' judgement of migration?

The fourth characteristic involves particular conditions that make the future realisation of the imagined plausible (Schiffauer 2006: 3). What conditions made the Ukrainian women in this study start thinking about searching for opportunities abroad? What was the situation of the women's households? How did their extended networks function? How do the conditions in Ukraine influence their perception of risk at home and during migration?

Having introduced the notion of the imagined opportunity space, I will now give a brief overview of economic changes in Ukraine in the I990s and early 2000.

\subsection{Economic conditions in independent Ukraine}

With the collapse of the Soviet Union and the emergence of Ukraine as an independent state, the country became open to global economic forces. For Ukrainians, for years accustomed to guaranteed full employment under Communism, the institutional order began to fall apart. In a study monitoring social changes in Ukrainian society between I994 and 2005, where respondents were asked every year how satisfied they were with their current job, over 40 per cent were unable to answer the question because they were unemployed at that given moment (Panina 2005: 105, table 8). While in I99I, according to official statistics, only I.2 per cent of the adult population in Ukraine experienced long-term unemployment (one year or longer), by 2002, the figure was 6.I per cent of the population (Oksamytna \& Khmelko 2004: 9).

The systemic changes affected male and female workers differently. In the second half of the I990s, women constituted up to 67 per cent of discharged workers (Pavlychko I997; Human Rights Watch Report 2003: Iо) and women's unemployment was increasing. During the period I998-2002, the real rate of women's unemployment in the $15-69$ age group grew by Io.8 per cent (UNDP 2003: 34). According to local labour offices, the majority of those registered as unemployed in 2002 were women: in the oblast of Lviv, it was 59 per cent and in the city of Lviv it was 73 per cent (Human Rights Watch Report 2003: I0). Overall, more women than men were registered as unemployed between 1999 and the first half of 2007. Unemployment levels among women in rural areas were affected by the reduction of sectors dominated by women, such as vegetable growing, cattle breeding and beet production (Dudwick, Srinivasan \& Braithwaite 2002: 33).

It should be taken into account that women and men respond in dif- 
ferent ways to job loss (Ashwin 2000). Overall, men who become unemployed lose their professional identity and self-esteem. In the case of the former Soviet Union, men often found refuge in alcohol abuse. Women, in contrast, have other strong identities in addition to their identity as workers - namely, their identities as mothers and wives. For that reason, they are said to cope better with new economic conditions (Ashwin 2000).

In addition, in the second half of the I990s, many Ukrainians worked shortened hours, were on unpaid leave or were only partially employed. Ukrainians experienced 'hidden' unemployment, a situation of an employee without work. ${ }^{\mathrm{I}}$ In I996, 3.4 million workers (24 per cent of the total working population) were on unpaid administrative leave. In Ukrainian industry, women were proportionally more numerous than men among those dismissed and were more frequently on administrative leave, without receiving any pay (Caceres 200I: 24). One of the reasons for taking leave without pay is that there was little motivation to declare unemployment because the benefits for the unemployed were low. In 200I, monthly unemployment benefits were equal to 85.23 Ukrainian hryvnia (herein abbreviated as UAH) (less than € I2) and did not cover even the most basic living expenses (Jakubiak 2002) ${ }^{2}$. Meanwhile, unpaid leave allowed one to keep the social benefits related to being employed, such as health insurance.

In the aforementioned period, almost 50 per cent of Ukrainians experienced shortage of money for daily food and over 80 per cent did not have enough money to buy clothes or shoes (Oksamytna \& Khmelko 2004: 7). To survive the economic crisis, people relied on barter, petty trade and private subsistence agriculture (Raiser 1997). By 2002, almost two thirds of the whole urban population was engaged in cultivating small land plots (Oksamytna \& Khmelko 2004: I). Participation in the informal labour market was visible in the expenditures of Ukrainian household budgets, which in 2002 exceeded the households' income from the formal economy by $15-25$ per cent. By 2003 , the estimated number of persons employed in the economy's informal sector was between 2.6 and 4.4 million (I2-20 per cent of all the employed) (UNDP 2003: 45).

One should also note that corruption is widespread in Ukraine. According to a Razumkov Center poll in February 2003, only 3I per cent of the general public did not offer bribes or gifts in the medical and educational sphere in 2002; 24.5 per cent of respondents confessed that some part of their income was 'unofficial' (Freedom House Report 2004).

Failure of the known social order coupled with the unemployment made people place their trust in themselves and their closest relatives. There was little faith in Ukrainian society in the ability of state institutions to solve economic problems and people searched for methods of coping with the new risks individually or via household strategies. One such 
method was engaging in cross-border petty trade and, later on, migrating to work abroad. ${ }^{3}$

\subsection{Ukrainian women's evaluation of and responses to risks in Ukraine}

All of the Ukrainian women interviewed faced shrinking employment opportunities in their place of origin. They were also aware of the political changes and the resultant increase in freedom of movement across the border in the early I990s. These conditions allowed them to develop a particular imagined opportunity space. However, this involved not only the comparison of the imagined abroad to the period of economic and political transition they were experiencing, but also to the past. In the stories of these women, a shift is visible from a sense of security experienced within the known, predictable institutional and societal setting to the increasing unpredictability, with the women perceiving and evaluating new risks to be coped with.

\subsubsection{Images of the Soviet past and of systemic transition}

Anxiety triggered by the disorder that followed the creation of newly independent Ukraine, with the systemic transition from Communism to democracy and from planned to market economy, is visible in Svietlana's story. I met Svietlana in 2006 in Warsaw through a non-governmental organisation, for which she was a volunteer media spokeswoman. She was an energetic person, with thought-through opinions about the situation of labour migrants in Poland and in-depth reflections on her own life. At the time of the interview, she had been working for four years as a care worker and cleaner in Warsaw. For one and a half years, she had held a work permit for her care work employment, while also doing undeclared cleaning jobs. The 40-year-old is a divorced mother of two boys who, until migrating, lived with her parents in T., a town in western Ukraine. She recalled the following:

And in '9I there was such... well... the beginning of ... great chaos, let's say, great chaos. There was no work, there was no occupation somehow agreed on, the country's [independent] status was given but not agreed on [what it means], the people's status was not clear and people did not know in what country or in what system they were living, how to live. ... wages of people, who [...] worked were very low [...] in the organisations where they worked: in schools, at work, in production [...], simply earnings were so much lower than the needs, that this somehow became a terrible, huge [problem]. 
In I99I, when the Soviet Union disintegrated, Svietlana finished her studies in Russian philology and faced a great unknown.

In the opinion of the women I interviewed, political and economic transition brought a great sense of insecurity, making the former Soviet Republic of Ukraine look like a safe, predictable heaven. Among the interviewees who voiced this uncertainty was Ulyana, a 35-year-old divorced mother of an eight-year-old boy living in the town of B., south of Lviv. I met Ulyana through another migrant woman. She worked in Warsaw as a child-care worker. She appeared very young, smiled a lot and frequently referred to her faith in God throughout the interview. Formerly a radio electronics engineer, she had worked in her profession for several years in a factory in Ukraine. Ulyana very emotionally recalled the period of political and economic transition in her country of origin.

\begin{abstract}
After Ukrainians began this...when Ukraine went out of the Soviet Union, terrible problems began. Until then everything was good, but later on we didn't have any money, because my mom put everything in...., because my father was in Bulgaria and [he] was working [there], we lived in Bulgaria for a while, [so] until then we had money, but mom put everything in the bank, but when this happened with the Soviet Union, we lost everything [...]. And until today no one returned to us this money. We don't have this money.
\end{abstract}

At first, Ulyana experienced a high degree of safety and wealth, which disappeared literally overnight. Local institutions, often ill-functioning during Communism, totally fell apart when faced with global competition. People lost their life savings. Many lost their jobs. Unemployment was a new phenomenon, causing great anxiety of falling into poverty. This context of insecurity is similar to that described in the writings of Beck (I992) and Stark (I99I), where institutions responsible for the provision of order and security no longer work and the responsibility for coping with risk falls on households, families and individuals. With the loss of prosperity, the sense of security was gone and awareness of new risks increased.

As was already visible in Ulyana's story, the women's image of Ukraine in the early I990s often stands in sharp contrast to their comments concerning their lives during the Soviet era. Lilyana, a 30-year-old migrant woman, who originated from a village near the town of $\mathrm{K}$. in eastern Ukraine and who used to come to Poland in the ig8os for pioneer camp in the summer, recalled her childhood as follows:

Life...life was very nice, when we were all countries of the Soviet Union. I, for example, I always had a very poor family, but we lived better than today, much better. Life was better before. 
Although Lilyana stated that her family was poor, in the narratives of other migrant women, past security was often associated with prosperity. One of the women studied, Maria, described to me in great detail the story of her village. In her view, it was the richest village in the region during Soviet times. She claimed that the village inhabitants had so much money that they did not know how to spend it, so 'people were buying adult shoes for children'. The majority of people from the village worked in the local factory producing sugar from beetroot. There were two kindergartens. Maria used to work in a shop and later on as a hairdresser next to the factory. In addition, she earned money by giving haircuts privately. She liked her job and led a peaceful life. With the breakdown of the Soviet Union it suddenly became cheaper to import sugar than to keep the factory working. The factory was closed down and its machinery was sold for scrap metal. One of the two kindergartens was also closed. At that time, as many as five or six persons from her village had migrated to work in Warsaw and she started to consider migrating. During the interview, she claimed that 400 people from her village already lived in the outskirts of Warsaw and worked in the capital. ${ }^{4}$ Maria's story shows a clear-cut transition - from almost unimaginable wealth and plenty, to the death of the village, with the closure of the kindergarten and the factory (it had a literal 'meltdown'), as well as the ensuing exodus of a large number of village inhabitants. According to her story, she was among the pioneers from her village who created an extensive migrant network. In the context of the former social order having fallen apart, migration became a norm for her village.

For some of the women, the Soviet past became a past imagined space of lost chances, against which they evaluated their situation during the transition period; some of them continued to use this reference point to judge their migration.

\subsubsection{Risks and strategies before migrating to Poland}

The imagined opportunity space of the interviewed women's was formed against the background of good living conditions during the Soviet era, the subsequent dramatic decrease in living standards and the shrinking employment opportunities, all consequences of the systemic changes. Unemployment, particularly long-term unemployment, was one of the major consequences of the economic transition in Ukraine experienced at some point by all of the interviewed women. The women lost their work either due to group layoffs or closure of their workplaces, most of them state-owned. Unemployment soon became a 'familiar risk', as Douglas and Wildavsky (1982) would name it, when the women recalled that declared employment on the Ukrainian labour market was not a guarantee of sufficient earnings nor did it even bring any earnings whatsoever. The 
local labour market had little to offer. However, in the opinion of some interviewees, declared employment at least provided one with health insurance. This can be regarded as a rather weak argument, taking into account the quality of public health care in Ukraine, where one has to pay a bribe for treatment. Still, the women did mention this issue. They also stressed the fact that if they had continued to be employed in Ukraine, they would have a guarantee of receiving a pension (however small) in the future.

An analysis of the women's responses to unemployment allows us to point to different risk assessments and strategies. A spectrum of risk strategies can be seen: at one end there are women with dependents, who remained economically inactive and sometimes reached the point of social exclusion; at the other end of the spectrum are women displaying agency and responding immediately to what they foresee as a potential danger resulting from unemployment.

Let us start the analysis at the end of the spectrum where women were at the greatest risk: these were the women who were the only breadwinners in their families and after becoming unemployed did not search for alternatives sources of income for some time. Long-term unemployment placed them at risk of social exclusion, meaning the inability to participate in society by being unable to satisfy their basic needs, such as buying daily food. For example, Chrystyna, a widowed mother of two children, who used to work as a bookkeeper in Lviv, earning 300 UAH (approximately $\$ 80$ ) per month and whose company went bankrupt, experienced a steep deterioration of living standards after losing her job. As she recounted: 'Either you ate something and did not pay for the apartment and did not wear any clothes, or you did wear clothes and didn't eat...'. Unable to find work and not searching for other income alternatives in the informal labour market, these women borrowed money at first. As they were unable to pay their debts, borrowing opportunities shrank. This led to their falling into poverty and placed them at risk of social exclusion. Only then did they turn to labour migration as a last alternative. Another example is visible in the story of Olga, a divorced mother of two school-age children who worked as a dentist's assistant.

When A. [her son] went to first grade I was dismissed from work with a whole group...24 persons were dismissed from work and I was one of them. I was for ten months without any work then, I was starving, I simply had no money, no money for bread, for the apartment, I was in terrible debt.

Another risk addressed by the women was how they would respond to a situation in which they would have little, if any, income, thus leading to borrowing money and falling into debt. Finally, the women became aware 
that they were unable to meet basic living needs, such as buying food or making their apartment rent. Poverty slowly came to the fore in the women's stories. Another divorced mother with two sons, Zenya, after having worked for 22 years in her job was earning UAH I5O (approximately $\$ 40)$ per month. She said:

It's difficult even to talk about it, because these earnings were not sufficient to pay for the apartment. [...] So, even today I am still heavily indebted. [...] I don't know what will happen next, with all those debts [laughing], but somehow my whole life is in debt [smiles]. When my son was ten, he already did not understand how I live, [he asked]: 'Mom, how can you live like that? Our whole life is on credit. You borrow, you return.'

Later on during the interview, Zenya mentioned that she mainly borrowed money from her female friends. She spoke about her difficult circumstances, being divorced and having to support two sons, the youngest of whom was only three years old at that time. However, she had social capital, in the form of ties to people with enough financial resources to lend her money. Olga similarly said:

I constantly borrowed; my eldest daughter from Russia sent me money four times, I think. And so I lived, constant debts, for the apartment, for light, for gas and...for bread, because I took bread on credit from a woman who had her own private bakery, a small one, and that's how I lived.

Olga was initially supported by her daughter, a migrant herself. However, the daughter had a family to support in Russia and for that reason could only sporadically send money to her mother. In general, family members did not make a profit on lending money. However, Olga mentioned that informal services as such existed in Ukraine, lending money at a monthly interest of as much as 20 per cent. Borrowing money (having somebody to borrow from) was an important coping strategy; however, it changed the risk position of the interviewed women. Once they were abroad, they had to work irrespective of the working conditions at least to raise the sum they had borrowed. This placed them in a very precarious situation.

In the middle of the risk spectrum were those women who displayed agency by searching locally for alternative sources of income when unemployed or not earning sufficiently. For example, Svietlana recalled that as a Russian language teacher she was only able to buy four kilograms of tomatoes with her monthly income. The interviewed women were often the primary salary earners in their families. This means that they fall into a special category, which has to be taken into account when analysing the 
development of the imagined opportunity space. Svietlana was the only breadwinner in the household, where she lived with her parents and two children. She was in conflict with her three older brothers, who assumed she would take sole responsibility of caring for their parents. For some of the women, abusive relationships in the family or with their spouses were the driving force to search for financial independence. Unable to earn a sufficient salary in the official labour market, Svietlana began to search for profit in the informal economy- she traded at the local bazaar. As she said:

...my parents already did not work and that is because they were already pensioners in the year '9I. So this was such a different situation, I was the only person capable of working, but also without work [...] I couldn't go to work [as a teacher] to school, because I had two children and I had already divorced my husband at that time. And I began to work in petty trade, because then a lot of people began to trade. I traded and that's how I made a living.

Another woman who turned to trade was Larysa, a 40-year-old divorced mother of a sixteen year old, who originated from the town of B. in western Ukraine, and supported three members of her family. Her earnings did not suffice, so she learned how to make hair bands and sold them at the local market before going to work. Then at the bazaar, she tried to sell what she called 'Western sweets', imported candies that usually came from Poland. She bought them at one market and sold them at another. In the beginning, no one wanted to buy the sweets, but slowly she gained experience and managed to make a profit. She became acquainted with a man at the bazaar who was trading in used clothes brought from Germany. One day she approached him and asked whether she also could try to trade in used clothes. He gave her Ioo $\mathrm{kg}$ of clothes to have a go, and later on she got $500 \mathrm{~kg}$. She managed very well. She asked a female friend for cooperation (the friend had financial problems because her husband was in prison) and they both traded. For the first time in her life she began to earn large sums of money. She mentioned that she was so rich that people even borrowed money from her. She decided to quit her regular job because she still was not getting paid. When her friend's husband got out of prison, he joined them in the trading business. However, they began to quarrel over earnings. The couple decided to trade alone. At this point Larysa made a risky investment. She invested \$ I,800 that she had saved while trading into a pyramid scheme and by the time she realised the firm was a scam, she had already lost everything. She recalled: 
I was left at home without work, because I had worked for two years but I didn't have any money, there was no...for half a year there was no [money] for which I could normally buy food. I lived off my grandmother's pension.

Larysa was fortunate enough to have a grandmother who was willing to share pension with her. Support from family members was another riskcoping strategy. However, the Ukrainian pension at that time was insufficient to support even one person, so for two it meant living in poverty. At this point, Larysa began to think about migrating to Italy, but had neither the money for the visa nor anyone from whom she could borrow. Now that she was poor, she felt that everyone had abandoned her. The absence of support from friends and acquaintances or, in some other interviewees' cases, from family, led to a lack of essential ties for survival. This is precisely what placed Larysa at risk of social exclusion. Having no one to turn to for help, Larysa became a Jehovah's Witness. In the end, one of the Jehovah's Witnesses who worked in Poland decided to help her. ${ }^{5}$ Larysa's religious network also played an important role for her in Poland, both in terms of emotional and work-related support.

In her story, Larysa points to a particular risk knowledge, which she gained and later on used during migration. First of all, she had worked in Ukraine in an undeclared fashion before: she successfully traded in different products. Larysa, like many of the other interviewed women, had shown that she could manage to earn substantial amounts of money. She displayed agency, not remaining passive when faced with hidden unemployment. She also drew conclusions on how not to lose her source of income again: she claimed she has to fully trust the person she shares her work with. Because she did not come across any such partner, she worked individually as a cleaner in Warsaw, investing trust into the employers, who 'waited for her' to return from Ukraine. She diversified her social network by becoming a Jehovah's Witness. The agency of several of the interviewed women was visible primarily in their flexibility to adapt to the changing circumstances, entrepreneurship and their ability to access different support networks.

Only one woman studied - Gala - engaged in paid domestic chores in Ukraine to cope with financial difficulties: she cleaned the local parish building. This woman had primary education, in contrast to the majority of my interviewees, who had secondary education. Educational status can play a role in being willing to accept work unrelated to previous employment in the country of origin. It seems that the lower the educational level, the easier it was for the migrant women to accept domestic work as an opportunity to earn money and not have a negative influence on their social status. However, Gala was very emotional when telling me about her situation at that time, ending up in tears during the interview. 
I wanted to cry! You know! When I was going to Poland, you know, I had worked at home for eighteen years in a bakery. And it so happened that there was not enough to pay for electricity, for gas, everything was shut down. And so it was that my daughter was supposed to give birth in one month. And me, you know, I live next to a church, not far, and from time to time [...] I was washing all of this, those table-cloths and you know, and so I took the job and it was very heavy, and I didn't have [the money] with which to get the passport [...] And so I borrowed [...].

The migrant woman underscored her dramatic position by repeating that her daughter was about to give birth. Events such as birth, marriage and death, linked to a particular stage in the life course, were often the ultimate trigger of migration. Only at that point did Gala engage in a migration. She lost her long-term job and working in the informal economy did not give her enough money to acquire travel documents necessary to migrate. Earning insufficient income meant she had to borrow.

One of the strategies to respond to not being paid or being underpaid at their jobs used by the women was to take unpaid leave. Ulyana, the engineer now working in care, experienced so-called hidden unemployment and took unpaid leave from her factory.

I took those holidays, they gave them to us for half a year per year. This is on one's own account, because they did not pay. I went to eastern Ukraine, I worked...I herded cows...I never herded cows in my life...[...] But, what I got there, it was some sort of....we got, there were six people, we got some grain, very poor quality, [...] instead of payment we got it...we were supposed to get wheat, but it didn't grow. I brought it home and we sold it as animal food, for horses and so on. And so you lived everyday on potatoes [...]. The times were such that we only ate potatoes and those...squash. There wasn't even any bread. Well, such difficult times. Because I had a job, but I didn't get money. My mother had a job, but she didn't get money.

The work Ulyana engaged in during her leave in Ukraine was not only of low social status, but also did not win her any real profits. Ulyana, like a number of people in Ukraine, remained officially employed, although her wages were not paid, because it gave her social security and health care benefits. For that reason, Ulyana mentions later on in our interview that leaving this work, which provided her with at least this basic form of security, was a form of risk-taking for her.

Women also used unpaid leave from their jobs to work abroad. However, in the mid-I99os, the Ukrainian labour law changed and long unpaid leaves were no longer available. One had to either leave the job or contin- 
ue working for very low wages. Zenya, who worked for over twenty years for a children's theatre, mentioned this during the interview.

At that time, when I went for the first time [to Poland] for those two, one and half months for [to pick] apples I was on...[...] unpaid leave, because that was still possible then. Then, maybe half a year later, the law changed and it was no longer possible to take this sort of leave for a longer time. [...] So either you worked or you quit. So, I had to quit. [...] Then I had to look for one job after another to have work. Because it didn't make sense to return [to the theatre], because,.. for such small income that I got after 22 years of working in one institution, I made UAH I50, that means 25 to 30 dollars per month. ${ }^{6}$

After the legal changes in Ukraine, most of the women who worked abroad while taking unpaid leave from their jobs back home decided to quit them. The risk of being forced to work only at home was seen as too high, so they decided to rely entirely on income from undeclared work abroad. This shows the role that external legal and policy-related conditions (such as new policy or legal regulations) plays in the changing perception of the quality of risk involved in a specific activity (in this case, declared employment in Ukraine). It also points to the agency and dynamics of the decisionmaking process among the women. Zenya mentioned changes to the law, which was what pushed her to leave her job. She said, 'So I had to quit.' In a situation of no choice, risks are perceived as higher. An involuntary risk, such as having to quit work, is forced upon a person from outside. Voluntary risk relates to situations where there is choice. People are willing to tolerate much higher risks when they are voluntary. However, they are also more willing to take risks when they have little to lose (Douglas I992). The interviews show a pattern of decreasing opportunities at home. Having a regular job in Ukraine (even an unpaid one) and working abroad in an undeclared fashion diversified both financial and social risks. On the one hand, one was able to increase one's financial standing at home via remittances, at the same time increasing the social status in the place of origin. On the other hand, having employment in Ukraine, in accordance with one's qualifications and skills, meant that the women could perceive their migrant work as a temporary remedy and could disassociate from its low social status. The imagined opportunities abroad triggered decisions, such as leaving employment in Ukraine (which provided a marginal sense of security) for undeclared work abroad.

Practically all of the interviewed women engaged some way or another in subsistence agriculture. Even when living in towns, they had small plots of land next to apartment buildings, hen coops and sometimes even a goat. However, with the ongoing recession in Ukraine, neither subsistence 
agriculture nor the informal sector allowed the interviewees to cope with the economic insecurities long term. Svietlana commented that she saw no work opportunities for herself in Ukraine.

I didn't have any idea how I will survive, I didn't have any idea how to find work, how, how to feed my family, how to sustain them, there were no prospects...

Although Svietlana, like many other women, presents her migration as a 'no alternatives' situation in Ukraine, the reality is more complex. In general, it is not the poorest ones who migrate. Potential migrants still must have certain means that will allow them to initiate the trip. The women had social networks, which allowed them to reach out for work alternatives abroad. The women 'could have acted otherwise', for example, by continuing to trade at the local bazaar, as Svietlana's brothers did.

The least risk exposure was visible among interviewees who had family support and job opportunities in Ukraine, but wanted more than basic survival for themselves and their children. Two interviewees, who were in their twenties when they first came to Poland, separated from their partners and decided to remain in the country. They claimed that they had a chance to work in Ukraine, but the salary would be barely enough to survive, which they saw as a risk. One of them, Irina, an engineer who was the mother of a three-year-old boy, recalled the following:

My situation was that I divorced my husband, and I can't go back home because I don't have a chance to find work there to support myself and the child. And then I had... I did not have the need to have food and clothes. I had the need to...to buy some books, and to buy toys for the child and to go for a holiday somewhere and I knew that with work in Ukraine I will not, not...not get such a wage in Ukraine to let my child and me live a normal life....not for food, to survive, I didn't want to live to exist, I simply wanted to live normally. And I decided that I have to make some savings...

Irina wanted to avoid merely existing in Ukraine, engaging in continual coping strategies so as not to live in poverty. It was a decent life that was at stake for her. She longed for financial independence, which would allow her to start a new life in a new place, leading to personal development and increased social status. Another migrant woman, Marta, lived in Ukraine sharing one room with her parents and her brother. She did not see any chances in Ukraine to earn enough in order to have her own living space. At the time of our interview, she hoped to earn a sufficient amount of money during migration so as to have her own apartment. As she put it: 
...if I save something and when I have saved something [in the past], even when I worked at home, I always dreamed about my own apartment. Always. Because at home, we have such a small apartment. It is in a house, but still [...] So I always dreamed about my apartment. It can be a studio.

Longing for financial independence was mainly visible among the younger migrants, who are divorced, have fewer dependents and/or are in conflict with their families. These women seem to have higher expectations of migration than just a strategy helping to cope with financial difficulties. Higher expectations may place them at higher risk, because there is much more at stake for them. However, they seem to face fewer material risks in the country of origin. Their stories are more future-oriented than those of other interviewed women. Older women I interviewed, who had more dependents, stressed how they are sacrificing themselves for the sake of their families.

For the interviewed women, the conditions in Ukraine have changed from a secure routine to what can be summed as two main features: limited work opportunities in the official labour market (resulting in the loss of sense of security) and an increasing 'normalisation' of irregular economic behaviour, including cross-border trade and labour migration. These conditions meant that the interviewed women's images of an opportunity space extended beyond their national boundaries.

\subsection{Migration images}

One element that allows development of an imagined opportunity space is the category we belong to. The studied women's gendered identity influenced their evaluation of the degree of risk present during migration. Women's gender identities meant that they related to the experiences of other women, usually their close family members or friends. The information and images related to migration travelled along female-based networks - both before and after having engaged in migration. The women learned about migration experiences from stories told directly by returning female migrants or repeated by non-migrants. It was vital for the women to gain information about migration from persons with whom they could identify: it was important who the storyteller and the heroine of the story were. In their stories, the migrants referred to people in whose 'footsteps' they followed. For the majority of the interviewed women, it was other Ukrainian women (their mothers, sisters, aunts, cousins or female friends) who worked abroad in care, cleaning or other types of jobs. Under these circumstances, migration did not appear as something frightful, but as a familiar activity carried out by close relatives and friends. 
One such example was found in Roma, a petite, platinum blonde 28 year old whose role model was her mother. Roma was, at the time of the interview, working for the first time as a care worker in Warsaw. In the past four years she worked seasonally picking fruit and vegetables in Poland. She reminisced during the interview.
Maybe that is why I want everything for my daughter, because I had everything. My mom worked as a bookkeeper, I had everything at home, I had prosperity. Dad also worked, he went [as a driver] on buses for long trips. And then mom began to go for excursions. I went with my mom for the first time when I was fourteen years old. This was a trip to Poland, the Czech Republic and Hungary, by bus. We traded in everything, such as material, underwear and the like, because it was cheap [in Ukraine]. And then TV sets sold well in Poland. We bought gold, sold it in Cracow at the bazaar. Once we went by bus, all the tourists were trading. And hotels and food were there. But there was no trip, only the bazaar. So I went for the first time. [My mother] went all the time, she was in Romania and in Germany.

The economic situation in Ukraine pushed Roma's mother to engage in cross-border petty trade. Roma went trading for the first time at a rather young age. She went together with her mother on a 'tourist trip', though the main aim was trade, not tourism. Many Ukrainians did so at that time, facilitated by services provided by semi-formal tourist agencies. As Roma remembers, her mother 'went a lot'. The image of migration as a non- or low-risk strategy was shaped by the mother and repeated by the daughter. As an adult, Roma went to work first in the Czech Republic and later on traded and worked in agriculture in Poland before entering the domestic work sector in Warsaw. Zenya, the divorced mother of two, comments on how her entrepreneurial sister, who found work in Spain (but also used to work in Poland) was an example that encouraged her to start migrating and a connection to enter migrant domestic work.

[The first time]...it was this sister, who is now in Spain, who helped me to go together with some sort of distant family of ours, to Poland. That was the month of August and the contract was for [picking] apples. [...] [The next time] Someone from our [distant] family was [working] in Warsaw, on the street M. [caring] for some granny [...]. And she [the woman from distant family] had to return home for longer and she asked my sister to replace her [at work]. [...] [the sister] only could stay there two months, because she was leaving for Spain and so she asked me whether I could not stay there for one and half months. 
It is these women's experience of migration, either in trade or work abroad, which primarily influenced their images of migration as something positive. It made them develop particular premises, such as: 'If I migrate, then I will be able to live peacefully.' The positive evaluation of migration as a step leading to material security and a sense of stability is visible in the narratives. Simultaneously, there is a negative evaluation coming from those who have not migrated. According to the interviewed women, those who did not migrate are jealous of migrants' rising living standards and ignore the sacrifices that migration also involves, such as family separation and related risks. Some of the interviewed women mention that they are seen by people in their places of origin as making 'easy money'. They claimed that those who do not migrate doubt the honest character of work done abroad and downplay the efforts of the migrants. This evaluation of migration is partly related to the image of domestic work as women's obligation, for which they do not receive payment at home. The migrant women claimed that this type of judgement affected more strongly the migrants who went further abroad than Poland because they earned substantially more money and were able to display this change of financial standing at home. However, the studied migrant women's financial 'success' was also visible in their improved living standards in Ukraine, which exposed them to the judgement of those who remained. I observed how migrants' living conditions changed during one of my trips to Ukraine in August 2005, when staying with Ulyana in a town south of Lviv. As this excerpt from my field notes records:

In the morning we were supposed to go to T., but we have to stay in and wait for the gas men to connect gas pipes to Ulyana's apartment. The new apartment is on the outskirts of B. in an old 'Polish' building, on the second floor. She is renovating it.The kitchen opens to the living room - Ulyana saw this in Poland and liked it, a small bathroom in the back, one bedroom, which will be for her son. There will also be stairs to the attic, if she manages to earn enough money to renovate it. The apartment is almost 50 square meters, she paid $€ 3,000$ for it. The renovation will cost her more than the apartment.7

Ulyana claimed that when she went to the local administration office to try to get things sorted out for her new apartment, she was always forced to pay bribes because the officials knew that she was working abroad and felt justified to expect 'additional fees' from her.

According to Schiffauer (2006), the financial 'success' during migration evokes various emotions: from jealousy on the part of those who have made the wrong decision to not migrate to the bad consciences of those who have migrated and succumbed to shame or guilt (linked to feelings of responsibility). A tension is visible between images of migration as 
something positive for the interviewed women and its negative judgement by their communities at home. This can be understood as a risk threatening the work status of the migrant women, where the work abroad is not regarded as proper work, but as 'easy money'. According to the interviewed women, people who see migration as 'easy money', do not take into consideration the risks the migrating women must take by being away from their families. However, many of the women also stressed that migration was treated as an accepted strategy to cope with the material difficulties at home. They rationalised their decision by saying that 'everyone who wants to, can go and earn abroad', and those who do not do it are personally responsible for their own fate. However, this attitude of migrants is generally combined with a feeling of guilt for having to separate from one's children.

Migrant stories, retold several times, created a reference framework a mind map of risks for the interviewed women. These stories produced what Schiffauer (2006: 2) refers to as spaces of lost chances and avoided dangers. In this way, the imagined opportunity space underwent a continuous change, with every new story expanding or shrinking the imagined alternatives. The spectrum of migrant stories ranged broadly: from migration being seen as a familiar activity, associated with acceptable risk and moderate expectations of gains (this was often the case when other close family members were migrants), to the local community's negative judgement of migration (risk of stigma), to stories of great danger, but also great success.

A potential migrant, being convinced that he or she is highly likely to earn more money abroad than at home will be motivated to take risks related to migration. All of the interviewed migrants shared the expectations to earn more during migration than in Ukraine. These expectations were usually realistic, based on experiences of their close friends or family members. However, there were also stories of high financial risk and gain, which placed the image of migration at the high-risk end of the spectrum. One such story was told by Nadya. I met Nadya through another migrant I knew. She is a 55-year-old divorced mother of two adult sons. As a cashier in a circus, she travelled all over the former Soviet Union and has great memories of those days. At the time of our interview, Nadya circulated between her house in a small village south of Lviv and her work in the care sector in Warsaw. She was aware that Ukrainian women farther abroad than Poland can earn even up to four times more for the same type of work. The story she told me recalls the experiences of a Ukrainian migrant woman who went to Italy and worked taking care of pigs at a desolate farm. The employers came to see the woman every two weeks.

... when they [the employers] came, they were very pleased, but they didn't pay her. Well, she was working and they gave her no money. 
So one month had passed - no money, second month, third month, and so almost the whole year passed. She said: 'The situation is so difficult for me, I will not manage to be with these pigs any longer.' Well, so she wrote somehow, I don't know how, what she wrote, but she asked [her family] to send a telegram [to her] that she needs to go home, that she has to go home quickly, because of something. Then she told her signori that 'I received a telegram and I have to go home'. 'Alright,' [they said], 'No problem, if you have to go, you have to go.' So, they bought her a plane ticket and gave her an envelope of money. And she - I don't know if out of happiness or fear - she did not check how much money they put into the envelope, but when she came home and realised what a sum it was, she was upset that she had left Italy, because they had treated her very well, they paid her for everything.

The leading theme in the first part of the story is the risk of not being paid adequately, or not being paid at all. The migrant in the story was at the mercy of the employers due to her irregular status. She was isolated at a desolate farm - left with the pigs - with no access to information about any possibilities of changing jobs. After one year of work, the risk of not being paid and not being able to change jobs passed the threshold of acceptability. It is unclear whether she had agreed to the terms of payment with her informal employers at the start of her work or whether she tried to ask them later on for payment. It seems that she felt she was in such a weak position in relation to the employers that she did not dare ask. That is also why she asked her family to send her a telegram about a false emergency at home instead of quitting the job openly. The culmination of the story is the discovery that the woman's expectations about the opportunities of work abroad were met - she was paid for her work very well.

Two premises can be derived from the story told by Nadya. The first one is that migration means having to take the risk of investing in going abroad and then not being paid for the work done. There is fear and distrust related to work abroad. This story leads to the imaginary creation of a dangerous terrain. The second one is that migration means earning a substantial amount of money. This money may allow the migrant to rebuild her sense of safety at home. Nadya kept repeating throughout our interview and during other meetings that she would like to go to Italy one day. Positive premises trigger migration, while negative ones can prevent it. Premises are a result of the migrants' reflections and evaluations. The moral seems to be that the heroine of the story should have stayed longer, that she lost a chance to earn even more money because of her mistrust towards the Italian employers. Stories of earning great sums of money are only played out in Western European countries. I did not come across such stories about Poland in my interviews. Overall, the migration stories 
told by the interviewed women were clearly retold several times. They all had their culmination point; on the one hand, they encouraged migration's dream of 'great money' while, on the other hand, they warned of migration's risks.

\subsection{Migrant domestic work risks: Images and experiences}

The women's shared images of migrant domestic work ranged from a familiar activity to a risky business. This is partly due to the fact that, following Giddens (I979), domestic work can be seen as a social practice. Its rules are applied to a new space and transformed through mobility abroad as well as payment. Thus, domestic work, a familiar practice, acquires a new meaning. At home in Ukraine, domestic work was these women's sphere of influence. Domestic work in Ukraine continues to be women's work. It is time-consuming due to the limited infrastructure. During my participant observation conducted in 2005 at the homes in Ukraine of women who migrated to work in Poland, a lack of public utilities in the villages continued to affect the number of hours needed for domestic work. During field research in one of the women's houses, I observed the following:

Recently, they connected the water to the house, meaning that you no longer have to walk to the well on the street, but there is a well and a tap right next to the house. The kitchen is outside the house in a small shack next to the chicken coop. Apart from an old gas stove there is a used fridge that Marta got from one of her employers in Poland. There is no bathroom, so every type of washing requires getting water from the tap and heating it on the stove. ${ }^{8}$

However, working as a waged domestic worker abroad means having to fulfil the demands of the employers, often other women. Parreñas (200I: 73) rightly notes that the 'international transfer of caretaking refers to a social, political and economic relationship between women in the global labour markets'. According to Anderson (2000: 20), the female employer 'has some control over the management of the process, retains an emotional stake in the household [...]. The well-kept house, children and husband are a tribute to her managerial skills'. In the case of the interviewed women, their employers were Polish women who also did not want to lose their sphere of influence in the household. As Anderson (2000: I6) notes, domestic workers not only do the work of their female employers for them, but they often have to perform chores that the employer would never consider doing. As noted also by the interviewed women, once cleaning becomes paid work, the standards of 'cleanliness' rise to service a higher 
life style. This change in the character of domestic work placed the women at risk. On one hand, they reinforced the gender division of labour, regarding the quality of domestic services performed as their 'natural' skills, something familiar and usually giving them a sense of power and control in their own households. On the other hand, under 'domestic work', they experienced a different, more demanding type of labour with tasks difficult to define. They often found it impossible to negotiate their work conditions; what is more, due to their status in the household, it was not they, but the female employer who gained social respect for the cleanliness of her home. Thus, their initial expectations of domestic work often differed from what they actually experienced during migration.

Even with the hardships of domestic work in the village, many of the women found migrant domestic work very demanding. Ulyana was wellinformed before migration about the difficulties of migrant domestic work. As she said:

No, I was prepared, cleaning is hard work. She said that it will not be easy, that it will be hard, that from morning till night a person is on her feet, and different people, different demands and so on. No, so....no, I was not surprised. I was prepared for everything, for difficulties. However, I have never worked as [hard as] I do here.

A vision of migrant domestic work as a familiar, manageable activity results from preconceptions about domestic work and insufficient information about migration experiences, leading to the creation of myths about this type of work. In this context, Larysa offered a telling comment on the expectations and the actual difficulties of migrant domestic work.

Before I didn't understand this, you see? I didn't understand this work, I didn't understand how it is done abroad, I didn't understand how this is, you know. I would even say, now, when I go back to Ukraine, they all think that they give money for nothing abroad, and they don't understand this work. When I say that I work in someone's home, no one can imagine what work it is at home, how heavy it is. They all imagine that at home, well, here you dust a bit and clean a shelf and they think it's nothing. But no one knows what this work is really like.

Nadya commented on her misperception of elderly care work abroad.

I even did not imagine how difficult it is, how difficult, that you cannot go on, every day you wait, wait this hour in the evening so that the day comes to an end, so another one comes, so that there will be less and less of these three months. 
The excerpt above illustrates how very different this woman's expectations of the work must have been. It is mostly the standards of 'cleanliness' set by the employer, isolation related to living-in domestic work and being on 24 -hour duty that comes as surprise. The ability of the women to cope with the risks related to the new character of domestic work depends on the information they received before migrating.

Visions of migrant domestic work depend on the potential migrant's access to information. Olena, an eighteen-year-old student working as a cleaner in Warsaw at the time of our interview was the daughter of a migrant woman. Her mother came to Poland for the first time in I999, when a friend asked her to rotate with her, caring for an elderly person. Olena stayed in Ukraine with her father and her sister, two years younger than her. When her mother was away, Olena was responsible for the housework, the livestock and cooking for her father and younger sister. Olena's mother did not share the negative experiences of her migrant work, not wanting to worry her family. According to Olena, her mother never planned for her to work as a cleaner or care worker and maybe that is the reason she also did not find it necessary to warn her about the downsides of such work. Olena's mother met a Ukrainian woman married to a Pole on the bus to Ukraine; the woman studied at university in Warsaw and explained to her all the necessary procedures. In 2004, Olena came to Poland for the first time with the intention to work and learn Polish and possibly apply to university. Olena found out about her mother's difficulties during migrant domestic work only after having migrated herself. As she recalls:

You know, my mom never told me a thing. When I came to Poland, they told me how she suffered [when caring for] an old woman, but she never told us, because she knew we would worry about her...And no one would... say that it is no good there. On the contrary, I wanted to go to Poland. Oh, so much money. I will earn, clean. And here I clean and no one pays so much, you know...

Olena's image of domestic work also fits well in overall expectations that migration means 'big money'. It was the financial success and not the messages of hardship that came to the fore. Olena lived together with her mother in the employer's house in a small village two hours away from Warsaw. She stayed for one week alone in the house taking care of the dogs and says that she almost went mad from the isolation. That August, her father died in an accident and she had to return to Ukraine together with her mother for the funeral. In September, she returned to Warsaw for the university entrance exam. She passed it, but got accepted for extramural studies, which meant she studied during the weekends and had to pay 3,000 Polish zloty (herein abbreviated as PLN) (approximately € 660) 
per semester. Being a student in Poland allowed her to apply for the oneyear multiple-entrance visa. At that time, her mother's employers left for Italy and asked Olena's mother, who was taking care of their child, to join them.

Olena's studies were partly financed by her mother, now working in Italy. However, she had to pay for her own stay in Poland. At the time of the interview, she was cleaning two days per week in four houses and also worked as a 'salesperson' for Amway cosmetics, which had not brought her any profits as yet.9 She did not think that finding cleaning jobs was difficult in Warsaw. However, she found the work itself physically demanding. Only through her own experience and having access to migrants other than her mother did Olena find out about the problems of domestic work abroad.

There are several potential reasons that problems related to domestic work were not addressed by the migrants who returned home. This subject was regarded as taboo, because the work abroad was below the migrant's social status at home, but also because they felt that they would not be understood by those who did not have any migration experience. Access to information about poor working conditions was also limited because the migrant women wanted to be perceived as successful and, for that reason, rarely shared the downsides of domestic work abroad.

The imagined opportunity space involves the creation of specific images allowing comparison. Risk also must be contextualised in those images. Visions of domestic work abroad are linked to the creation of an imagined dangerous terrain. Almost all the stories concerning negative outcomes of migrant domestic work took place in Italy. For the migrant women, Italy was, on the one hand, a land of wages approximately four times higher than in Poland but, on the other hand, it was less familiar and distant, both spatially and culturally. In order to go to Italy, it is necessary to rely on informal travel agencies who were treated with suspicion by my interviewees. The women also feared the potential consequences of informal recruitment to work abroad and their irregular status in the country of migration. The legal status made the migrants excessively dependent on their future employers. The distance to Ukraine, the money invested and the limited support networks meant having to agree to what frequently were exploitative working conditions. According to the women, the risks ranged from being unable to find the type of work expected to not getting paid for work and being psychologically or physically abused. Some of the interviewed migrants knew about such working conditions from stories shared by their female relatives. Ulyana, who is physically rather small, was warned by her cousin about potential abuse during domestic work. She recalled her cousin's story as follows: 
[S]he was caring for an old man in Italy, I even saw a photo, so tall, almost two metres, and he is handicapped, legs...he doesn't walk and is in a wheelchair. [...] And she had to [carry] ...this wheelchair... She took, on purpose, a photo of these stairs - they were very high stairs. Because, below, there was the sea and, above, his apartment his house. She was simply carrying this wheelchair on her back. And him! [...] First the wheelchair, then him. Well, I would simply...and so, she had to...she said she was heading for a nervous breakdown. He also had a bad temper... [...] And this old man...that means, she had her own room and there was a bell right over her head and he always, a couple of times at night with this bell [he would buzz] $z z z z z$ because he wants to go to the toilet, he wants her to...he was in pampers, to clean him and so on. She suffered terribly. And for that reason she didn't want me to go somewhere to undertake care work. She said that I would not manage, that it would be difficult for me. And she simply said it was terrible to work so hard...

This hard work described in the story exceeds what Ulyana's cousin is willing to regard as acceptable working conditions. For her, being in Italy probably meant having to 'stick it out' so as to make this trip worthwhile. The limited possibility of quitting this sort of hard work is a risk, both in physical and mental terms. If we compare this story to those of other migrants, we can see a particular spectrum of imagined scenarios in the transnational space, in which exposure to and response to risk play an important role. Ulyana can identify with the person in the story, a close cousin. This information allowed her to think about the risks of migrant domestic work. As a result, Ulyana refused to work in Poland in elderly care and is working now as a caregiver for a small boy and as a cleaner. She also insists on living independently from the cared-for person.

To some extent, these stories show that they were unwilling to take the risks related to migrating to Italy and justified their choice of migrating to Poland. Some of the imaginary risks, such as sexual exploitation, were related to the interviewees being women, based on the assumption of women's greater vulnerability then men's to such form of abuse abroad. Some of the studied women told me stories about migrants who went to work in the domestic service sector and were sexually exploited. Nadya, the 55-year-old divorcee who wanted to go to Italy one day, shared the following story:

Another one told me about a man and a woman in a [Italian] family, well so it was and ...well, this man began to behave in such a way to her [the Ukrainian woman], well, you know, and she said right away: 'No, no.' But, when they took her passport away and she had nothing and didn't have a place to go, she had to sleep with him. [...] and the 
woman said that his wife knew and didn't say anything. Do you understand? And later on it so happened that when she was leaving for home, he gave her an envelope - 'this is the money you earned, and that is for the treatment' [said the man]. [I asked: 'And what was he ill with?'] AIDS... [...] Well, I don't know how she returned, how it went with her husband, well, briefly, she has two grown-up daughters, but they are still in school, tenth and eleventh grade. And she hanged herself.

The storyteller identified with the heroine of the story: the woman, like Nadya, came from a small town near Lviv and was the mother of two children (she had daughters while Nadya had two sons). Nadya is also like the woman in her story because she works on a living-in basis. Nadya pointed to the fact that the informal employer took the woman's passport away and thus turned her into their slave, who was unable to refuse giving sexual services. The culmination of the damage done in the story occurs when the employer pays the migrant for her work and additionally gives her money for health treatment; only at this point is the migrant woman informed that she almost certainly has been infected with HIV. In that story Nadya pointed to the high vulnerability of migrants with an irregular status: working in someone's private household, isolated from other migrants and unable to ask for external help. In contrast to this story, Nadya can regard herself as working in a safe environment. Although she earns less money than Ukrainian women working in Italy, she does not feel trapped in her job should her working conditions change because Poland is close and she can easily return home. The story gave her a warning sign about the power of the employers over a migrant.

After hesitating for some time, the aforementioned Roma told me about her neighbour, who went to Italy to work in the domestic service sector. Her story went like this:

This was a neighbour, a close one, I knew her because she was a teacher in our school, not in my class, but in the parallel one. And she went to Italy. She was a very pretty girl, so nice. In school [in Ukraine] they didn't pay, so she went. A woman whom she knew arranged the trip [...] she called this teacher [and said]: 'Do you want to take care of someone?' Good, they sold a car, to pay for the cost of the visa - I,500 dollars. She [the teacher] was away for two years, she didn't give any indication of where she was. And then she came back...she was there in a bordello, the woman put her there. This neighbour [who arranged the trip] put her in a bordello and she [placed] many people this way... but when she [who arranged the trip] returned, she claimed that she never put anyone anywhere. This husband of the teacher went to the militia [police], but there was no 
evidence, and the wife went crazy and she threw herself from a bridge and committed suicide and left two children. And she [the teacher] was my neighbour...

Roma can clearly identify with the migrant woman, who was her neighbour, a teacher at the local school and a mother, like herself. It is a story of betrayal, where a woman, whom the heroine of the story knew, deceived her and instead of providing her with a job in the domestic service sector, made her work as a prostitute. Roma stresses the graveness of the phenomenon: 'she [placed] many people this way'. The Ukrainian authorities and the closest family are shown as helpless. Again, the outcome of migrating for the sake of domestic work is dramatic: the woman takes her life.

The migrant stories are well structured, with a spectacular culmination point. They have probably been retold several times. Such stories are essential to create a mind map of potential risks and responses. They create what Schiffauer (2006) refers to as spaces of lost chances and avoided dangers, thus providing background for self-identification.

The association of migration with prostitution is still very much present in today's public discourse. One aspect of the public discourse is antitrafficking campaigns. The side effect of these campaigns is that they turn every female migrant into a potential victim of forced prostitution. ${ }^{\mathrm{IO}} \mathrm{A}$ tension exists between being empowered via migration and simultaneously being perceived by the surroundings as a person at risk due to migration, without any power to exercise control, but rather being controlled by particular institutions. The migrant's risk position shifts with new migration experiences. One of the migrant women I interviewed commented angrily on an anti-trafficking pamphlet by Caritas she came across, claiming that 'someone' wants to stop women from improving their lives by going abroad. She perceived the information about the dangers of falling into prostitution contained in the pamphlet as propaganda similar to that from Communist times, when a negative picture of the West aimed to prevent people from going abroad. The woman's reaction to the pamphlet is in line with Kempadoo's (2005: xxiv) statement that the concept of 'victim' robs the individual 'from any notion of agency and subjectivity'. Migration gave the woman a sense of agency and the pamphlet seemed to negate her experience. Describing such a pamphlet as propaganda means ignoring it as a reliable source of information and thus ignoring the risks mentioned in it.

\subsection{Migrating to Poland: Images of familiarity}

In the interviews, the migrant women portrayed Poland as generally 'safe'. They mostly commented on how easy it is to find a part-time job quickly 
and the low cost of the trip to Poland. ${ }^{\text {II }}$ Four main risk-related themes appear in the images of Poland: spatial distance, entry, cultural distance and working conditions. When it comes to the first three characteristics of migration to Poland (spatial and cultural distance, as well as entry), the migrant women perceived them as acceptable risks or as non-risky. However, working conditions (including payment and treatment by employers), made migrating to Poland a risky undertaking in the opinion of the interviewees.

Let me first turn to the non-risky images of migrating to Poland. For the migrant women interviewed, Poland's proximity to Ukraine was a safety measure. The journey by bus from Warsaw to the Ukrainian border takes approximately six hours, a fact that made Poland familiar in the eyes of the interviewees. As Roma remarked:

No, to Poland it is somehow normal. I feel safe. Even when I went for the first time, it is close to home. I feel safe.

Svietlana also commented on the easy entry to Poland during the I990s and its spatial proximity.

[pauses] Well, I, it's difficult to say now [...] how I went to Poland because it was close, no visa was needed, that's it first of all. It didn't cost much, the ticket for the journey wasn't expensive and the fact that, that it was so close, so it didn't involve such great expenses. I [...] simply decided that when I realise that there is no work waiting for me there, or there are some sort of unacceptable [work] conditions [...] Some [word incomprehensible], some doubts, I will immediately leave. I was worried if there would be no, well, some sort of indecency...

In contrast, trips farther abroad - for example, to Italy or Portugal - were not characterised by the ease of returning home, which Svietlana mentions when referring to Poland; financial investment was much greater and the migrant, even when faced with poor working conditions, had to 'stick it out' at least for several months to repay the costs of travel and the visa. The interviewed women placed the images of Poland on a spectrum of risk along with other countries. In general, migrating to Poland was regarded as safer compared to migrating farther - to Italy or Spain. The closeness of Poland and Ukraine allowed migrants to return quickly home if there was a need to do so. For some of the women who continued to be employed or insured in Ukraine, this offered a possibility to return for treatment to their country of origin if ill.

Still, for almost all of the interviewed migrant women, migration to Poland was their first trip abroad. During Communism, the Soviet gov- 
ernment restricted contact between inhabitants of the different countries in the bloc (Burant I993: 4IO). No wonder that for some of the women Poland, although spatially close, seemed unreachable. As Marta recalled:

Poland was once for me the end of the world. I remember when I was standing at the border in Hrebenne [border-crossing point between Poland and Ukraine] for the first time and I thought that... I don't know... 'Where am I going?!' That there is nothing there, that this is the end of the world!

Proximity is visible in the symbolic ties that have appeared in stories of migrant women whose Polish employers had been born or raised in what is today Ukraine and could relate to places known to the migrants. As Ulyana said:

I say, this world is big, but it connects people, I never thought it could be that way. So it is that here I cleaned and Miss L. gave me work - to earn some extra money - at Mr. K.'s and it turned out that his father was studying in C. and my mom is from $\mathrm{C}$.

Although Poles have been, and to some extent continue to be, viewed as former colonisers by Ukrainians, ${ }^{\mathrm{I} 2}$ this theme did not arise in my interviews. It seems that the ties to Poles were too important a source of social capital. For that reason, the interviewed women used their knowledge of the past selectively and tried to find common ground with their Polish employers. ${ }^{\mathrm{I}}$ The migrants drew on the common Communist past and the fact that Poles also suffered poverty and had to migrate. As Ulyana mentioned during the interview, Poles had 'empty shelves' in shops and even had to migrate to trade in Ukraine; even today there are Polish women who continue working abroad, for example, in Italy.

According to the interviewed women, language skills were one of the basic advantages that decreased the risk of not finding work when migrating. They saw the ease of learning Polish as an advantage that increased their chances of finding work and negotiating working conditions. With a good command of Polish, the migrant had a broader choice of jobs, especially in care work. Cleaning did not require a good command of Polish. Still, the ability to communicate in Polish usually made it easier to meet Poles and to build a social niche outside the migrant community, at least for those who felt the need to do so. It is to be remembered that Polish and Ukrainian are both Slavic languages, which facilitates learning. As Chrystyna, a 50-year-old widow from the oblast of Lviv with two children, who had worked for many years as a bookkeeper and was a care worker in Warsaw at the time of our interview commented: 
Well, it is a different country, different customs [...], language [...] firstly, however, with Polish one can manage somehow in terms of speaking, even in those first few days and one can understand, because this is a lot...well, you know Ukrainian a bit, so you know yourself, how many similar words there are [...] Here you have doshch and deszcz [meaning 'rain' in Ukrainian and Polish, respectively] [...] I would certainly need some more money, but no matter how much you have, it is always not enough [...] Well, but it is firstly the language that scares one, because I am already used to the Polish language and somehow, it is easier than with Spanish or Italian or some other language, learning some other language...

The majority of the interviewed Ukrainian women came from the Ukrainian western borderland, where they came in contact with the Polish language. Chrystyna had Polish roots and her home in Ukraine was close to the Polish border.

First of all, my great-grandfathers were Polish. Secondly, as I already said in the beginning, we lived very close to the Polish border and during the time of the Soviet government, there were no foreign TV channels, and we had everything in Polish. [...] Yes, Polish television [...] and so I knew the basic words and in addition, [...], the Ukrainian language and Polish language have a lot in common. The accent is different, different pronunciation and there are words that I do not know, for example, but I have a Polish-Ukrainian dictionary, so I can find them.

Symbolic ties to Poland of the interviewed migrant women played an important role in creating imagined closeness through linguistic familiarities. Ulyana commented on how she knew Polish already, living close to the Polish border and how this made her mother decide that it was safe enough for her to go to Poland. She evaluates Poland in opposition to the imagined dangerous terrain: Germany. As Ulyana put it:

When I got divorced, so then I wanted simply...[it was] hard, so I wanted to go to Germany. I started the procedure to get a visa, but my mom says that [...] they can destroy women there, take away your passport and mom said: 'No, you will not go. And here is Poland, close, here you can go.’ I know Polish.

However, having to learn a new language was more difficult for some of the interviewed women. Larysa recounted a different experience from that of Chrystyna and Ulyana when first confronted with the Polish language during migration. 
I was just starting to say something. This was for me, you know [...] I was so speechless, I thought that I had lost the ability to speak, I saw that I would not be able to speak in any language, neither in Ukrainian nor in Polish, so this was hard. I was like this sheep, you know [...], like a stupid human being, I felt like...[...] the worst thing was that I couldn't speak, because, when it comes to understanding, I understood when they spoke to me. I understood everything when someone spoke slowly. Because when [they spoke] fast I couldn't [understand] too well.

In addition, the migrant women claimed that because they spoke Polish with an 'eastern' accent they had difficulties finding accommodation: landlords, due to negative stereotypes of Ukrainians, were unwilling to rent them apartments.

The image of Poland as a safe country was accompanied by the prospect of working for substantially less money than in Western European countries. Thus, less risk meant less gain. This fact, however, could place the migrant's social status back home at risk. Chrystyna mentioned the reaction of her Ukrainian acquaintances when they learned that she was working in Poland. As she recalled:

To come here to Poland, well, to work, well, some feel pity and some seem to have an impression that you go and 'do [work] for someone [for free]', because they know that the earnings are small [...] that it is not the right money for such hard work. Well - and some react with laughter - that you 'work for someone [for free]' for so little money. Well, but in general my friends and neighbours are not so sarcastic, they understand.

Work in Poland was often compared by the women to the images they have of work farther abroad, for example, in Italy. When asked what Ukrainians fear mostly when coming to Poland, Chrystyna claimed that migrants worry about poor treatment; she offered an interesting comparison between Poland and Italy.

...treatment. Human treatment, they treat us here as a second-category nation [...] eh, I have not been to Italy, I haven't been anywhere else for zarobitky ['labour migration'], apart from Poland, but I have a lot of...my friend, a close friend of mine, my cousins, were everywhere. I told them about my life, how I was treated and how my friends were and what they did. Well, no one would have agreed to do something like this in Italy, for example, to come here, earn pennies and work like I work [...]. In there, you have the Sunday off, obligatory, you work from hour to hour, obligatory. [...] In there, they 
do not degrade us.... Well, I myself, thanks to God, did not have any bad experiences with Mrs. M. and I hope that I won't. Because I say, she is a very nice person, very wise and I like her....

Chrystyna claimed to have good working conditions at the time of the interview, but overall, she was very critical of the situation of labour migrants in Poland. Partly, this could have been an expression of her need to voice in front of me the necessity of changes in this area (I was speaking to her as a Pole coming from an institution dealing with migration). At this point, the comparison has two different aspects. According to Chrystyna, not only was the treatment of Ukrainian women worse in Poland than in other countries, but the payment for the work they do was much lower, too. Sufficient remuneration is part of the expected treatment of the migrant worker, a prerequisite of decent working conditions. Throughout the interview, Chrystyna claimed that she was very poorly treated during her first work as a care worker in Poland. The person who told her about this job opportunity said 'prepare for hell'. Chrystyna's explanation for the poor working conditions was discrimination ('secondcategory nation'). She claimed that Ukrainians would never have been treated by Italians the way they are treated by Poles. However, for all her complaints about Poland and praise of the positive aspects of migrating to Italy, Chrystyna continued to work in Poland. At the end of the day, she preferred the stability and familiarity of her social environment and working conditions in Poland to the opportunities of unknown Italy. The other migrant women I interviewed made a similar choice. The low earnings and the degrading treatment received in Poland made some of the women place Poland at the high-risk end of the risk spectrum. Nonetheless, this is not a dominant pattern: overall, when comparing their wages in Poland to the situation in Ukraine, the interviewees regarded the opportunities to be much higher than the risks.

Despite the working conditions, migrating to work in Poland was still regarded as an opportunity and Poles as a reference point by some of the migrant women in Poland. The community inhabiting the new opportunity space may become one's new imagined community. For Svietlana, Poles embodied a longed-for way of living.

Well, I did not have any idea how to earn normally, calmly and in a decent manner [in Ukraine]. And I saw [in Poland] that you can live in peace, earn in peace, spend that money in peace. I really liked the fact that I am living among people who also cope somehow, that there are many people who are successful...

At the same time, maintaining a sense of identity with those who remained at home was increasingly difficult. It was an element of the culture of 
migration to stigmatise local alternatives as second rate. The distance to Ukraine was also present in the migrants' utterances: they expressed disappointment with reforms at home, complained that they cannot earn a decent wage in their own country. The lack of opportunities at home proved that they had made the right decision by migrating to work abroad; this was especially the case with those of the women who decided to take their children with them to Poland.

According to the women, undeclared work was not criminalised in Poland: although laws to curb this type of work exist, they are not usually well enforced. This is crucial, because it is the undeclared character of their work that made migration worthwhile for these women; it gave them a competitive advantage in the Polish labour market. Working in an irregular fashion guaranteed higher earnings, though obviously at the expense of social and working rights.

\section{6 'Bad' migrating mothers: Gendered risk}

Although engaged in paid employment, women in the Ukrainian Republic of the Soviet Union were also seen as primarily responsible for domestic work and care (Brown I968). Ukrainian women's identity was summed up in the term 'working mother'. According to some researchers, the 'working mother' gender contract was abandoned in the I990s, with the state no longer providing support and guarantee of employment (Zhurzhenko 200I: 30). However, woman's obligations continue to be linked to the family, while men are still seen as less bound by family responsibilities.

The migration of parents, especially mothers, was regarded as controversial by the Ukrainian public. Ukrainian newspapers address the situation of the children of migrant parents, in particular migrant women. ${ }^{\text {I4 }}$ The main idea presented in the articles is that the absence of parents, especially mothers, leads to the moral deprivation of children. In addition, young girls are burdened with domestic chores in their mothers' absence. Since many of the Ukrainian women have been migrating since the mid-I990s to Italy, the term 'Italian orphans' is used by the media in Ukraine to describe labour migrants' children, seen as deprived of proper family socialisation. Similarly, the writings of some Ukrainian scholars reinforce the view that migration leads to the disintegration of family. ${ }^{15}$ In general, such analysis fails to take into account the overall state of family as an institution in Ukraine: in 2003 , for every I, 000 people, the average number of marriages was 7.6 and the average number of divorces 3.7 (Derzhkomstat 2003). ${ }^{16}$ In a study conducted in 2006 on children of Ukrainian labour migrants, the interviewed experts claimed the ultimate consequences of migration for the children are more negative than positive 
or entirely negative, due to the fact that the children are left without proper parental care (Halustyan, Doroshok, Kovalchuk, Levchenko, Trubavina \& Shvab 2006: I2). ${ }^{17}$ All in all, as one of the scholars claims, migration leads to:

emotional distancing and even aloofness between family members [...] This, in turn, ruins family connections and often results in divorces and the collapse of marriage. Furthermore, it increases the risk of children becoming social orphans and may lead to juvenile delinquency and criminalization of children. (Tolstokorova 2007: 39)

This excerpt sums up all the themes related to the effect of labour migration on families that are present in the public discourse in Ukraine.

Most of the interviewed Ukrainian women left behind their families, particularly children, when engaging in labour migration. It seems to be a rational decision in view of costs and risks involved in migrating to another country and working mostly in an undeclared fashion. However, this line of argument becomes debatable when we assume that the family is an important emotional and material support network, which is largely absent during migration. Also, the migrant women were well aware of 'blame' put on migrating mothers by the society, as I discussed in previous paragraphs. This discourse of blame has been addressed by Keough (2006) in her analysis of the trope of 'mothers as the key to social order' in postsocialist transnational labour practices. As Douglas would say, these risks of migrating mothers were 'advertised' by the public and for that reason cannot be ignored. Ludmila, the married 45-year-old nurse who had a daughter at university and a son in the army, spoke during our interview about the 'moral burden' of being away from her family. Even Svietlana, who stressed that migration was her path to independence, at first did not want to migrate because of family obligations. Svietlana recalls:

This [family] situation of mine did not allow me to leave because, when leaving, I had to leave two children, two parents - this was unacceptable.

The responsibility of women for social reproduction was a space for negotiation between two conflicting needs: the need to socialise their children by staying in Ukraine and the need to improve future chances for their standard of living and pay for their studies with money earned away from home. When presenting their migration decision, the woman placed it between the need for material care, their families being at risk of falling into poverty and the need for moral care, of which their children were to some extent deprived while they migrated. Gendered identity played a 
crucial role here: on the one hand, the women felt responsible as breadwinners for their family's well-being; on the other hand, they believed their main responsibility as women was family care. The migrant women claimed that they sacrificed themselves for their children and, because of that, were better mothers than those who stayed. At the same time, by engaging in migration, they were insisting on a new social order. Their decision was not rationalised in financial terms; rather, it was the good of their children that came to the fore. Migrating 'for the family' was an important rationalisation. As Ludmila said:

No one goes for oneself, to earn for oneself, no one goes. It is always for someone else.

The more the studied women were involved in their life in Ukraine (in terms of reproduction, work or other aspects of life), the higher they evaluated the risks related to migration because there was more to lose. Due to their family roles, the interviewed women can also be placed in a risk spectrum of least to highest exposure. Elderly women with adult children usually felt the least risk of failing in terms of family care. Those most at risk seemed to be women with teenage children. Women who no longer had any care responsibilities themselves felt free to migrate. One of the interviewed women, a pensioner, said the following about her children and her migration decision:

They [the children] have their families, they should stick to their wives and husbands. I am old, so I have to go [...] Some [people] say that it is unnecessary [to migrate], others say: 'She is schooling her son - she has to go.'

Older women, who were already retired and had grown-up children, claimed to be sacrificing themselves for their families; they felt that they 'saved' their children's marriages from falling apart because their financial support prevented the next generation from having to migrate. Another woman, who was already retired, commented on supporting her adult son's studies with the money she made while migrating to Poland.

[The studies] cost UAH 2,000 - that is, 2,000 per year - that is, 500 dollars, and that is a lot. The money I make here in three months, I have to give it to him, because he has a small child. If there were no children, maybe my daughter-in-law would work [...] he doesn't work much, only from time to time, there is no work.

The woman's justifications include not only education, but also the good of her son's family: he has a small child and for that reason neither her 
son nor his wife should, in her eyes, migrate in order to work. In this way she reinforces the negative moral judgement of those parents who migrate leaving their children behind.

Ludmila began to think about migration when her daughter was about to enter university. At the time of the interview, Ludmila had been circulating for two years between Ukraine and Poland, taking two to three months of unpaid leave from work each time. She worked as a caregiver for an elderly person, while her family remained in Ukraine. Neither her husband's earnings nor hers were sufficient to pay university fees and financially support their daughter's stay in Lviv. They decided together that she should try to earn in Poland as a care worker, although her husband had to be convinced by her. Ludmila rationalised her migration decision using the welfare of her children as an argument.

Paying for the studies of children was one of the dominant pro-migration arguments among the interviewed migrant women with older or even adult children who did not have a stable income. The migrant women, who mostly had secondary education, wanted to invest in their children's higher education to improve their social status and future chances of finding work in Ukraine.

Zenya justified her labour migration to Poland by saying that 'I am spending all my earnings on my own children' while she herself leads a 'beggar-like living' in Poland. She continued by presenting herself in a context where it is a norm for families with children to go and earn abroad.

As you see, almost one in three families that have children, right, goes where they can, because I am sure you know that our situation is much worse than that of Poland at this moment [...] And for me it is sad because, for example, I have two sons, one has finished university, Pricarpathian, he is a physicist and he has studied economics as well, he has a post-graduate diploma in economic studies. And he has two qualifications and it is sad, because he is without work [...] Well, and so, I have to stay here now, because there is so much money [needed], I am investing so hugely in my sons, and even now, when he is 24 years old, I still have to work by myself [to support him].

Her sons were her 'investment', but they had little prospects of finding work in Ukraine, so she hoped to raise her social and economic capital by working in Poland to finance the emigration of her sons. Leaving her sons in Ukraine, with the present economic situation, was too much of a risk in her view. At the same time, if you read between the lines, the message is that her sons - who cannot find work or exit Ukraine - are presently a burden, placing their mother at risk of very low living standards.

The greatest fears about children going astray were voiced by women 
with teenage children, such as Larysa. After we had finished the interview, she continued to complain about problems with her teenage daughter, who 'changed' while she went away to behave as though she is 'no longer hers'. Among other things, her daughter borrowed money from friends and Larysa also had a huge phone bill to pay upon her return to Ukraine. As she recounted:

She [her daughter] simply,...[...] when I leave money at home, when there is more money she no longer values it, you understand. So, on the one hand, I would like her to work a bit. But [on the other], I don't want my child to work as I do. Maybe she would [...] learn and understand [...] that one has to study, because she does not want to study. [...] At [her] school, they laugh at those who learn well, they think that they are stupid. But this is not stupid. When I was studying, this was different. Everyone wanted to study and go to university. Now children don't understand this. They laugh at those who study. So she should come and try to earn with her own hands.

Larysa attempted to teach her daughter to respect her work by making her experience the difficulties of migrant work. This was a new form of socialisation, a 'life lesson', which was to make the child realise that one should study.

Larysa's daughter was not aware of the conditions in which her mother earned. Larysa hoped the migration experience would push her daughter to study so as to avoid being among the hard lot of migrants.

The perception of care, particularly child-care as women's 'obligation' towards their families, meant that a household without a mother was regarded as incomplete. It diverged from societal expectations, which demand that mothers and children should live under the same roof. This placed the interviewed migrant women with small children at the greatest risk of blame for being 'bad mothers'.

The absence of a mother means, among other things, a changed division of labour in the family. Although Ludmila felt guilty for leaving her husband alone 'in charge' of the household, as it became clear later on, it was actually her daughter who took care of the household chores.

My daughter...it is hard, because [...] when she comes [home] on Friday in the afternoon, it is necessary [for her] to wash and clean everything, to cook something for herself, for her father and it is hard for her. When she comes [home] ...she wants to relax and not to be responsible for everything...

Particular gender roles are reinforced when women migrate: it is women daughters, grandmothers or female neighbours - who take over the 
household work of the 'missing' woman. As mentioned earlier, a similar case is Svietlana's. She had three brothers, who lived in Ukraine, but none of them regarded it as his responsibility to care for their parents. She had to pay a female neighbour to care for them, especially for her ill mother.

In general, the migrant women did not mention receiving any support through domestic work carried out by their husbands, brothers or sons. However, the fact that husbands were not mentioned is also due to the fact that the majority of the interviewed were divorced. For that reason, it was mainly the women's daughters and mothers who took over household chores. When her mother migrated, sixteen-year-old Olena, who was left at home in Ukraine with her younger sister and uncle, was also responsible for the housework and the livestock. As Olena recalls:

We had a cow I had to milk before I went to school. So the mornings were terrible, because I went to the barn, milked the cow and then took a shower, because [if I didn't shower] I would come to school and they would say 'what a pig'. I took a shower and then went to school. Then I came back and again went to [milk] this cow, then cooked something because, you know, that mom wasn't there, so I didn't waste a lot of time studying, because I wanted my sister to study and later in the evening, when everything was already done, then I could read something and in the morning again; so I was so fed up with this cow that I couldn't look at it any more. I was so fed up that when I was on my way to Poland I was jumping for joy that I was leaving this cow behind.

It was rare for the interviewed women to admit being relieved by having a 'holiday' from their own domestic obligations when migrating. However, some women commented on how domestic chores would prepare their daughters to better cope with life.

The women with young children mainly expressed a sense of loss. As one named Marijka said, remembering her first trip to Poland:

...I was very homesick [...] Very homesick, because I left my child, who was then thirteen years old, a girl. [...] she lived with her grandma in the village [...] so that was very hard - the longing mentally, it was difficult.

Migrant women with young children usually left them in the care of their own mothers. Some of the migrant women were not pleased with the way their mothers raised their children. One of them, whose daughter was five years old at the time of our interview and was left with her grandmother at age one, claimed that her daughter no longer recognises her and instead calls her grandmother 'mom'. This woman saw her absence as a risk of 
losing an emotional bond with her child. However, when imagining what would have happened if she had not migrated, she decided she had made the right decision.

In general, the migrant women felt that they partly compensated their absence in the life of their children with material goods, for example, fashionable clothes. According to Marijka:

...I could not make ends meet so I had to go on zarobitky ['labour migration'] But, the child was also longing and cried and said: 'Mom, come back.' And when mom came back, she said: 'Mom don't leave', but with time, she grew up. So she knew that mom would come, bring something and bring money and bring clothing and she was pleased with this [...]. Because earlier, it was all from humanitarian [help], we bought [things] second-hand. And later when she grew up to become a girl, there were already boys coming and she went to discos. So she coped with it all [laughing].

In saying 'I could not make ends meet', the woman signals that the economic conditions in Ukraine did not provide her with sufficient opportunities to support herself and her daughter financially. She presented her migration decision as a 'no choice' situation. The expressions 'Mom, don't leave' and 'Mom, come back' show the emotional difficulty of separation between mother and child. Throughout the interview, she repeated, as if to reassure herself, that the daughter 'grew used to it'. Similarly, Marijka mentioned how migrants and their families, in general, 'get used' to the risks of separation related to migration.

Well, people are afraid of something, I know, the same it was [the] first time [for me], the same, it was horrible and all this longing, it was difficult: morally and mentally, but then people get somehow used to it.

With time, certain risks become familiar and possible consequences are feared less. As Bourdieu (1983) claimed, the acculturated nature of riskrelated actions results in a routine-like, habitual behaviour. 'Getting used' to migrating means that fears are decreased and the judgement and response to risks become habitual at some point. The avoidance of risk or risk-taking is present in everyday routines, unreflexively incorporated into our bodily actions. In the women's evaluation of migration, risk characterised by successively short negative outcomes (such as the potential effects of a poor financial situation) outweighed risk characterised by consequences that were distant in time, such as the possible effects of alternative forms of children's socialisation. Those of the interviewed women who were single or divorced mothers and received little parental 
support decided to bring their children to Poland. In this case, emotional risks related to family separation were traded for financial costs (having to support the children in the county of migration) and an increased risk of a failed migration.

A reason Poland was chosen by the women to begin with was that, in their opinion, it allowed them to combine waged work with childrearing and domestic duties, circulating between Poland and Ukraine every three months. However, the short-term trips nonetheless amounted to the migrant women spending most of the year abroad. As Victoria, who started circulating between Poland and Ukraine in 200I, said:

First year, I was here longer than 200 days, next year even longer. My daughters told me: 'Mom, you are rarely home.' The following year it somehow happened, that I was longer in Poland, because, they counted: 'Mom, you have been some three months home!'

Long absences from Ukraine were notable for the majority of the interviewed women whose earnings from abroad were the main source of income. In those cases, family separation as a risk thus receded to the background, while financial support of the family took primary importance. These women also felt to some extent empowered by the fact that they could influence their own and their families' future. They were aware of the conditions in Ukraine: one of the women was sure she would be worse off if she had not migrated.

The studied women engaged in new forms of socialisation and cultivated emotional ties with their families at a distance. As one of them explained: 'With my children I send text messages everyday, sometimes several times and I call every second, third day [...] devotedly - every week devotedly.'

Apart from overall fear of failing as a mother, only one woman expressed concern about her marriage. This may be influenced by the fact that the majority of the women were divorced before leaving Ukraine. Ludmila, whose husband was a journalist and remained in Ukraine, was convinced that a marriage can fall apart if the wife is separated from her husband for too long. She not only evaluated migration as potentially leading to a couple's breakdown, but also said: 'You can earn more money and lose a lot in marriage.' In Ludmila's eyes, greater financial benefits stemming from a longer stay abroad put the well-being of married life at stake. She regarded migration as 'safe' until a certain point in time. According to Ludmila, cohabitation was needed for a marriage to function. Circulating between Poland and Ukraine allowed Ludmila both to provide material care for her family and be present at home. Proximity of the countries played a role in the length of separation. Migrating any farther from Ukraine than Poland did not belong in Ludmila's imagined opportunity 
space. For Ukrainian labour migrants, migration to Italy or Portugal meant a separation from their families and spouses for at least one year due to the travel expenses. ${ }^{\mathrm{I}}{ }$ Meanwhile, commuting between Poland and Ukraine was financially feasible and, following Ludmila's reasoning, did not place the migrant's marriage at risk.

However, Ludmila's belief in the clear-cut link between migration and the breakdown of marriage was not shared by all of the women. According to the interviewees, when the husband was a migrant, it was more acceptable for the wife to migrate, too. Victoria noted the following about her relationship with her husband, who worked in construction in Russia:

He also goes...to Moscow to work, it often happens that we do not see each other nine months, half a year [...]. You see, it's like that: I go there for a month or something and now he is in Moscow, then he comes and I am here, so we don't see each other. [...] So we don't even quarrel; I always joke: 'Oh, like a honeymoon!' And that's how it goes.

According to the women, men also migrated to large cities within Ukraine, such as Kiev, to work in construction. Among my interviewees, there were women who joined their migrant husbands and yet still ended up divorcing them. For other interviewed women, extramarital affairs of their husbands during their migration were a good justification for divorce and offered escape from an unhappy marriage. Others actually met their future husbands - both Ukrainian and Polish nationals - during their migration. However, the majority of the interviewed women were divorced and did not count on their ex-husbands' support when it came to raising children. Not only did they not count on receiving any child support from them, but some women also went to court to strip their husbands of parental rights. This way they did not need the father's consent for the child to move abroad.

How Ukrainian men's situation has influenced the migration of their wives might be worth mentioning here. According to Vianello (2009) Ukrainian migrant women who returned home from working in the domestic work sector in Italy claimed that having the primary responsibility for family care made them more reliable and stronger than their husbands. The women decide to migrate due to their unemployed husbands' apathy and reluctance to engage in labour migration for fear of losing social status. According to Vianello's study, it is sometimes on the request of husbands or children that the migrant women return to Ukraine and give up migration. Once home, the women have to face husbands who are suspicious of their fidelity and angry that the woman took over their role of 'head of the family'. The returned migrant women attempt to challenge this negative stereotype and social disapproval of female migration. In one 
case, women who returned from Italy to Ivano-Frankivsk created a nongovernmental organisation to provide support for returnees and provide the local community with an alternative picture of migrant women in Italy: as martyrs who self-sacrifice for their children (Vianello 2009).

A gradual evaluation of the imagined opportunity spaces is visible among the interviewed women: the more experience they had, the easier it was to decide what exactly is beneficial and what is potentially dangerous. The process of self-identification either reinforces the known pattern of mothers or expands to more self-centred forms of identification.

\subsection{Conclusions}

The studied Ukrainian migrant women developed a particular imagined opportunity space - Poland's domestic work sector - with risk images playing an important role. It developed against conditions of systemic risk in Ukraine, resulting in the women's long-term unemployment and the opening of borders between Ukraine and Poland.

The studied women also belonged to several categories, which influenced their perception of migration risks: they were women of different age, marital and parental status, having rather limited financial resources and social ties. Their social networks were either rather small or they shrank due to the decrease in their social status related to unemployment. This meant that they did not have sufficient social support to learn about the opportunities of migrating farther than Poland and to borrow the money to do so. The younger migrant women had other women with migration experience among their family members, some of whom migrated to Portugal, Spain or Italy. However, rather than encourage further migration, these family members claimed that it was safer to stay closer that is, to go to Poland.

In general, the women acted on the following assumption: 'If I migrate to Poland, I can easily return should there be trouble.' Migration to Poland is seen as safe and posing little risk. Only in one case were Poland and Poles heavily criticised for degrading treatment and low earnings: in this testimony, the interviewed woman said she was exploited in her first migration job.

The risks the women faced in Ukraine due to unemployment, among other factors, were, following Douglas (1985), so-called involuntary risks placed on them by an external force. They balanced these risks - declining living standards, leading potentially to poverty - by various means, such as engaging in trade or borrowing money. In the end, they diversified the risk in Ukraine by taking a voluntary risk: engaging in irregular labour migration. Overall, the women responded to the systemic risks by migrating to a place with low travel costs that seemed familiar, as well to a 
specific type of work - domestic work - which brought with it an association of the safety of home (even if not their own). Again, these expectations of familiarity and safety, when unmet, increased the sense of insecurity.

The women's different risk exposure at home led to the creation of specific migration images. The women who were working-age, divorced and had children and parents to support regarded migration as a way to gain financial independence. The potential costs of not migrating were very high for them because they were either unemployed or experienced hidden unemployment, which indeed made staying at home almost impossible. They saw the possibility of earning decent money abroad as rather attractive, pointing to the wide range of examples of people migrating and making their way. For women who had children and were married and/ or supported partly by their parents, the main justification for migration was their responsibility towards their families; it was the 'good of the family' that held highest value for them (and which could, paradoxically, also be threatened due to migration). Beliefs about the gendered order at home meant that when a woman became a migrant she risked her reputation as 'good mother' and/or 'good wife'. Those women who had retired and had since fewer family obligations (their children were adults) did not believe that migration placed their family lives at risk. Furthermore, due to their age, they did not regard themselves as a main target for sexual exploitation, as was the case with younger women. 



\section{Legal risks of migration and legal risk-balancing strategies}

Individual decisions and actions are conditioned by a set of factors operating at each stage of migration (Fawcett \& Arnold I987). One factor that influenced migration decisions of the interviewed Ukrainian women was Poland's changing administrative procedures for entry. As part of Poland's EU accession process, new legislation was introduced to comply with the acquis communaitaire. In I997, a new act on aliens restricted entrance to Poland for citizens of the former Soviet Union, among them Ukrainian nationals. By I998, the new laws were implemented and their effects were felt by Ukrainian migrants when crossing the Polish-Ukrainian border. The Aliens Act of 2003 brought new legal barriers to mobility, the most important being the introduction of a visa requirement. In the I99os, access to the Polish labour market by foreigners was also limited by labour market regulations. The regulations in force (dating from I994) required, among other things, that the employer pay a fee (equal to the current minimum monthly wage in Poland) for submitting an application for a work permit and justify the need to employ a foreigner.

Increasingly restrictive regulations regarding entrance and stay in Poland introduced between I997 and 2003 have changed migrants' exposure to risk. To balance the risks of the new legal context, migrants had to gain access to more resources as well as become involved in a complex interaction of different actors, such as migrant families and aquaintances, who could lend money for travel, other migrants, who are a source of information, Polish employers and representatives of Polish state authorities. To analyse this phenomenon, I use the notion of the migrant institution, by which I mean a complex communication of individuals and organisations that allows boundaries of social practice to stretch and interact in time and across international borders (Goss \& Lindquist I995: 3I9). ${ }^{\mathrm{I}}$ In migrant institutions, communication and interaction takes place between the migrant and various actors.

Using the notion of the migrant institution, I analyse strategies the Ukrainian women employed to balance the risk related to irregular entrance, stay and undeclared work in Poland. I am interested in two complementary aspects of the problem. First, I would like to look at the ways in which migration and the implementation of labour market policies affected the migrant women's risk exposure. Second, I would like to 
analyse how they influence their context of action using strategies, such as developing migrant institutions and thus what their perceived exposure to risk is. Giddens (I979: 69) referred to this phenomenon as the duality of structure, with migrants on the one hand being impacted upon by the existing conditions, while their behaviour recreated or changed an established social pattern.

\subsection{Poland's migration policy and labour laws: Changes of legal risks}

In the early I990s, Poland liberalised its passport regulations, relaxing the entry and exit restrictions. ${ }^{2}$ Apart from the outdated I963 Aliens Act, Poland lacked a legal and institutional framework to deal with arriving foreigners (Kępińska \& Stola 2004: I60; Okólski 2004: 28). ${ }^{3}$ At that time, all of Central Europe was characterised by such legislative lag. However, Poland slowly began to integrate into the international legal framework. ${ }^{4}$ The Aliens Act of I963 was first amended in I991 and new changes were continuously introduced, creating a chaotic document and making the implementation of the laws rather difficult (Weinar 2005).

In the I990's, a new 'flow' of people developed in the region. Citizens of Central European countries, among them Poles, were allowed to enter the EU without a visa, while citizens of the former Soviet Union were able to travel without severe restrictions to Central Europe. Differences among the EU candidate countries began to appear in the second half of the iو9os regarding the implementation of migration policy measures. Poland did not restrict trading in open bazaars by foreigners and only loosely applied the law that forbade trading on the street, with the police only rarely intervening. Poland was also the last to introduce entry restrictions for its eastern neighbours (Wallace, Bedezir, Chmouliar \& Sidorenko I998; Wallace \& Stola 200I; Drbohlav 2003; Drbohlav \& Janska 2004). In the early I990s, it was easy for Ukrainian citizens to enter Poland, unlike Western European countries. 5 Since I995, Ukrainians were required to obtain a Schengen visa (earlier a national visa) in order to enter most Western European countries. Via the official route, the visa costs $€ 35$; to obtain it, a traveller must prove that he or she has the financial means to cover the costs of stay in the country. Due to the material situation of most applicants, hardly any can meet this requirement. According to information received from the interviewees, the Schengen visa could be obtained via semi-formal tourist agencies, which charged a substantial fee ${ }^{6}$ for their service, additionally offering transport and the promise of finding a job in the informal labour market. Meanwhile, Ukrainians were entering Poland as 'tourists' or guests on the basis of notarised invitation letters from Poles. Tourists needed a voucher proving that the costs of their stay 
in Poland would be covered. However, it was easy to buy forged vouchers and invitation letters, when crossing the Ukrainian-Polish border (Stola I997).

In the second half of the I990's Poland gradually began to introduce regulations and rules supported by European institutions, primarily the European Commission. This was related to Poland's EU accession negotiations and the necessity to adjust Polish regulations in the area of Justice and Home Affairs (JHA) to EU requirements (Weinar 2006: 9). ${ }^{7}$ The focus of policymakers was on fortifying the eastern Polish border, which by 2004 would become the external border of the EU. Funding was given for improving the equipment of the Polish border guards and implementing EU standards. ${ }^{8}$ Poland introduced new aliens acts, a first one in 1997 and the second in 2003.

The Aliens Act of 1997, apart from enabling the free movement of persons from and to Poland, was to prevent 'unwanted foreigners' from arriving and staying in Poland. 9 The act focused mainly on issues of admission, entrance, stay and deportation, extending the list of reasons the Polish state has the right to refuse entrance to the country and to expel a foreigner. ${ }^{\mathrm{IO}}$ It also introduced regulations on the basis of which the border guards were able to refuse people entrance into Poland: firstly, when a foreigner was suspected of entering with an aim different from the officially declared one and, secondly, when he or she lacked sufficient financial standing for the stay in Poland. The regulation on the required financial standing demanded a PLN Ioo (approximately $€ 25$ ) for each day of stay in Poland, but the sum was not to be smaller than PLN 500 (approximately € IIO). ${ }^{\text {II }}$ Confirmation of sufficient financial standing could be proven by, for one, a letter inviting the foreigner to enter the country. It could be issued by one of the following: a Polish citizen, a foreigner legally resident in Poland for at least five years, a person with a settlement permit or a legal entity based in Poland. In addition, the Aliens Act of I997 contained a regulation according to which overstaying could result in deportation. The border guards also had the right to check the foreigners' registration of residence upon exit, as every foreigner had the obligation to register their stay in Poland with the municipal office within three days of arrival. ${ }^{\mathrm{I} 2}$

In 200I, Poland's Aliens Act of 1997 was amended. ${ }^{13}$ Among other changes, the amendment extended to two years the period Poland could refuse an entry visa to foreigners who had been deported. According to the amendment, to receive a fixed-term residence permit, it was no longer sufficient simply to be running a business: one now had to prove that this economic activity was beneficial to the Polish economy per se. The fixedterm residence permit was also limited to university students, though earlier it included all types of students. Mixed marriages were to be scrutinised so as to reduce the violation of migration rules. The minimum 
residence time in Poland for eligibility to apply for a permanent residence permit was extended from three to five years (Weinar 2006: I7). All in all, rules of entrance and stay were tightened.

In 2003, Polish parliament passed a new aliens act. ${ }^{14}$ The most important innovation of this act was withdrawal from the agreements on visafree entry, which were signed in the I970s with countries in the Communist bloc (in particular, with the USSR) and the introduction of a visa requirement for citizens of Ukraine, Russia and Belarus. The introduction of a visa regime for non-EU countries was a condition for Poland's entrance to the EU. ${ }^{5}$ Questions were raised during public debates concerning social and economic consequences of this move: the introduction of visas was expected to affect cross-border trade, which was an important source of income for people inhabiting Poland's eastern border regions, as well as to constitute a travel barrier for people of Polish origin living in the former Soviet Union. To reduce the negative side effects of the new visa regime, the Polish government reached an agreement with the Ukrainian government to exempt Ukrainian citizens from visa payments in return for allowing visa-free entrance to Ukraine for Polish citizens. The visa requirement was implemented on I October 2003.

The Aliens Act of 2003 upheld the provisions of 1997 on expulsion (overstaying could result in receiving on official order to leave, i.e. expulsion, and, in some cases, it led to actual physical deportation from the country) and introduced new rules in that respect. The following categories of persons residing on the territory of Poland qualify to be expelled: those without a valid visa, a fixed-term residence permit or a permanent residence permit, those working or conducting economic activity without a permit, as well as those lacking financial means to reside in Poland. ${ }^{16}$ Expulsion results in the cancellation of a visa, a fixed-term residence permit and a work permit. ${ }^{17}$ An expelled person may be refused entrance to Poland for a fixed amount of time (one year, if they left Poland voluntarily within seven days of receiving notice; three years if deported) (Kępińska 2004). However, these regulations tended to be implemented at the border when the border guards checked the person's travel documents and not inside the country by means of checks in public or work spaces.

After the introduction of visas in 2003, Ukrainian migrants generally entered on the basis of a short-term visa, which allowed them to stay in Poland for up to 90 days within a period of six months. The so-called 'time corridor' forced the migrants to remain in Ukraine for at least three out of every six months. They rarely entered on the basis of a long-term visa (up to one year over a maximum period of five years). Some of the migrants decided to overstay.

Let us now turn to changes in Polish labour laws. In the I990s, there were few institutional solutions that would channel the inflow of labour 
migrants into regular economic activities. In I989, the Act on Employment introduced an obligation to apply to a voivodship ${ }^{\mathrm{I} 8}$ labour office in order to employ a foreigner. ${ }^{\text {I9 }}$ The situation in the local labour market had to be taken into account: migrant workers were perceived as a threat to the domestic labour force. When applying for a work permit both the employer and the migrant had to prove that they were eligible to conclude the contract. Poland made efforts to facilitate the work of Ukrainian nationals in Poland: in I994, a bilateral agreement was signed with Ukraine on labour migration. However, with the restrictive measures concerning the issuing of a work permit, this agreement had no significant impact on the character of labour migration between the two countries, which remained largely informal. ${ }^{20}$

In December 1994, a new Act on Employment and Counteracting Unemployment was introduced. To get a visa with a work permit it was necessary (as already stated in the I989 act) to get the permission of the voivodshiplabour office; however, the visa with work permit could be issued for a period of up to one year, for a specified position and specified employer. The cost of the work permit was the minimum monthly wage in Poland (Kicinger 2005: I9). ${ }^{2 \text { I }}$ The rules regarding work permits for foreigners were created when unemployment in Poland was high, reaching around I8 per cent in 2005. Efforts to protect the Polish labour market against foreigners are still visible in the form of amendments introduced to the Act of Employment and Counteracting Unemployment in $2002 .{ }^{22}$

Receiving the work permit was a rather complex endeavour. A foreigner could not seek work in Poland on his or her own initiative. An employer had to submit a request to the local administration to employ a foreigner, which cost the official minimum monthly salary for the first-time application and half of that amount each subsequent time. ${ }^{23}$ Before granting the work permit, the voivodship labour office had to check if there was any Pole suitable for the job, in order to secure opportunities on the labour market for native workers. The foreigner had a basis to apply for a visa and a fixed-term residence permit after the voivodship labour office granted the employer an official confirmation that a work permit for a specific job would be issued (Kępińska \& Stola 2004: I68). The process was timeconsuming (it took over two months) and, until 2007, rather costly. ${ }^{24}$ No wonder Polish employers and Ukrainian workers were simply not interested. The former were not willing to apply for an individual work permit for the Ukrainian workers and pay the fees, while the latter decided it was easier to enter as tourists and work in an undeclared fashion (IOM 2008: 35). The undeclared work of foreigners was triggered by the restrictive attitude of the Polish labour law towards the employment of foreigners as well as the existence of a rather large informal economy, in which both Poles and foreigners are active, thus proving a partial acceptance of irregular economic behaviour and low penalisation of undeclared work. 


\subsection{Legal risks of irregular entry and stay}

Due to the irregular character of their migration, one of the main legal risks faced by the interviewed migrant women was to be forbidden from entering Poland. Not being able to enter meant losing both the migration investments (costs of travel documents, social ties developed in Poland) and any chances of future financial gain. Almost all of the migrant women did attempt to enter Poland as 'tourists', although they clearly were labour migrants. During the interviews, the migrants voiced three main factors that exposed them to legal risks of being turned away or even deported when trying to cross the Polish border: a false declaration of the reason for travel, lack of financial standing and lack of proper travel documents. The migrant women attempted to balance this risk of 'entry refusal' by engaging in strategies both at the Polish-Ukrainian bordercrossing points and at Polish consulates in Ukraine.

\subsubsection{Falsely declared travel aims and insufficient financial standing}

The migrants declared a false purpose for their trip when applying for a visa and when passing the border-crossing point between Ukraine and Poland. The interviewed migrant women were well aware that they could be turned away from the border if they were suspected of having declared a false reason for their journey. This regulation was introduced by the Aliens Act of I997 and upheld by the Aliens Act of 2003. ${ }^{25}$ They usually declared 'tourism', 'shopping' or 'visiting friends' as their travelling plans. $^{26}$ Chrystyna, the former bookkeeper, mentioned this practice during the interview.

... They [the border guards] know very well that we work here [...] very well, but they ask: 'Why are you going?' Well, you won't say ‘to work', that's for sure. So you lie: 'I'm going for a visit', to do shopping or to see friends or something else.

The interviewed migrant women, like Chrystyna, were conscious of the need to lie before the border guards, at the same time knowing that the guards were aware of their real travel purpose. ${ }^{27}$ Another interviewee, Marijka, said the following about crossing the border with a falsely declared travel purpose:

Well, clearly, each time when you go to the border, you cross the border, you are nervous, because this is... this is a border [...] Well, you know that we work here illegally [...]. And for that reason every one of us is nervous, everyone is scared because of this, at the border it is really tough and very strict and they turn away many people [...] 
They look at the passports, see that you have been here [in Poland] three months [before], and [send you] back, because [they know that] you are going to work. They cancel the visa right away at the border and simply send you back and that's it.

Marijka was a 40-year-old single mother from D., a town in western Ukraine. She decided to migrate to Poland in 2003 after the textile factory she had worked in closed down and local alternative jobs, such as trading, no longer proved plentiful. In Warsaw, she first cared after a small girl for two years; at the time of the interview, she was the nanny of a small boy. The border-crossing point is portrayed by Marijka as a dangerous locale. The interaction with the border guards places at risk migrants' migration investments and plans.

Chrystyna, who was as a care worker in Warsaw at the time of the interview, commented that the migrants were refused entrance, although they had not broken any rules. According to her, the entrance regulations are implemented unfairly. At the same time, she was aware that migrants are breaking the law by entering Poland with the aim of working without a permit. As Chrystyna said:

...In the car there are, for example, 30 people and he [the border guard] points randomly: 'You, you and you - out.' And it's deportation and the end of the story. And our Ukrainians, they cry: 'Noooo!' and go immediately back, and go to the consulate and explain: 'Maybe you can give me another visa because....' And at the consulate they ask: 'And on what basis did they deport you? Did you have alcohol?' [...] And she says: 'I didn't', - 'Maybe you had a lot of cigarettes?', - 'No, I didn't have any, either', 'So on what basis did they send you back?' - 'Well, they said that I had been there many times already', - 'And what do they care, you did have a visa... [...] ...that means you can [enter], you have not violated anything, no laws. Well, at the border, [...] you had to go to the commander and demand an explanation why you are being sent back', and so on. Our people simply do not know this [...], they are not informed and that is why it is all so sad. They are uneducated people, who cannot cope with life and who end up here [in Poland].

Chrystyna pointed to the arbitrariness of the border guards' decisions: migrants get deported on a lottery-like basis. However, she was also critical of border-crossing Ukrainians who lack knowledge about their rights as well as assertiveness to see them enforced. She portrayed them as passive victims.

Another migrant strategy at the border I discovered during the interviews was to have some 'friends' among the border guards. During the 
interview, Larysa, the 40-year old Jehovah's Witness, was moved by the story of a friend of hers who recently tried to enter Poland.

...this girl, O., she had been travelling since Sunday [...] Every time they came to the border and [they were sent] back, no entrance. She didn't have cigarettes, she didn't have a thing and they sent her away every time and she was travelling three days to Poland. The problem is [...] things have changed at the border, there are no more acquaintances, nothing. There are Germans now...[...] this girl was travelling three days and couldn't enter Poland. This is horrible.

In the interview, Larysa pointed to the disappearance of known border authorities (and, consequently, the end of informal arrangements, which had made entrance to Poland easier) and the appearance of unknown ones, whom she even imagined to be German. For Larysa, relations at the border were becoming less familiar, thus increasing her sense of insecurity.

Appearance and age also played a role when crossing the border. Marta is a young childless divorcee who worked as a volunteer in Warsaw caring for a disabled person at the time of our interview. She was in her twenties when she began to circulate between Ukraine and Poland.

The first time I went, there was nothing, I crossed without a problem. Only the second time I had [problems]. Because [I am] a young woman...because this friend of mine was older than me a bit...well, a bit...actually a lot...and I later on understood that they [the border guards] thought that I am going to an agency [for prostitution]. Because they even said so, in that sense: 'Are you bringing this woman to work [...]?'. They didn't want to let me in, they sent me back to Ukraine, but ...later on I came with a different car.

The second potential reason for being sent back from the border was failing to meet the requirement of having sufficient financial standing for one's stay in Poland. This rule was introduced with the Aliens Act of I997. The required sum equalled PLN Ioo per day (approximately $€ 25$ ) and the minimum sum required was PLN 500 (€ I25) per person. If the person was unable to present such a sum when crossing the border checkpoint, the border guards had the right to refuse them entrance. The migrant women had to apply strategies in order to bypass this requirement, which they were generally unable to fulfil. One of the migrants, Ulyana, was supposed to be sent back when endeavouring to cross the border due to lack of money for her stay in Poland. 
There was once a real fear, a very unpleasant one, when I was going by car, the driver was going and one more man to work. And this driver was bringing me to Warsaw and that man somewhere to Lódz. And so it was that this driver and this man did not have the money to show. It was 200 dollars or something like that at that time [...] And I had it, but they didn't. So this Pole [border guard] screamed: 'Back to Ukraine!' This was so unpleasant, so impolite. This was until they paid him [a bribe].

In general, migrants had either to borrow the money and return it within a short time after arrival or they used the 'money-lending' service provided by the drivers, which will be discussed later on. The sum depended on how many days a person declared he or she was staying in Poland. This meant not revealing their planned length of stay in Poland, so the migrants had to take very few belongings for their three-month journey. Last, but not least, as can be seen from this and other migrant stories, bribes were used by migrants to facilitate the entry. However, these also increased the risk of receiving a deportation stamp when confronted with an honest border guard.

\subsubsection{Inadequate travel documents}

Another reason for not being allowed to enter or re-enter Poland were issues related to travel documents that expired, were tampered with or were simply lacking. The risks ranged from being refused entrance, through having to pay a fine, to being deported.

One of the concerns of the women was having the possibility to legally enter and stay in Poland. The duration of Ukrainians' legal stay in Poland was determined by the officially declared aim of migration. As 'tourists', the migrants were allowed to stay up to 90 days. ${ }^{28}$ According to the interviewed women, before the introduction of the visa requirement in 2003 , a Ukrainian who entered Poland as a tourist complied with the allotted time of stay by returning home for several days (sometimes two weeks) after three months. Upon the migrants' exit from Poland, the Polish border guards checked the date of entrance and the length of their stay. Initially, those who overstayed were obliged to pay a fine. Later on, the regulations changed and overstaying migrants were expelled and forbidden to enter Poland for up to one year.

Some of the women remained in Poland after their visa had expired. The reason they overstayed was fear they would not get a visa to enter Poland again and would lose their job. The risk position of those who overstayed was different from both the group of women who continue circulating, as well as those who settled in Poland. There were also differences in the risk position within the group of those who overstayed. Some 
of the 'overstayers' were very poorly connected in Poland and thus heavily dependent on their current job, while others had few obligations in Ukraine and could afford to be away for a longer period of time, thus saving on the money needed for the trip and visa arrangements.

'Losing' their passport was a strategy used by those who overstayed their legal time in Poland and did not want to be expelled when finally deciding to return to Ukraine. Getting the passport 'stolen' or 'accidentally' putting it in the washing machine so stamps of entry were no longer visible also occurred. In general, the migrants usually stayed for one year or longer and decided to re-enter Ukraine only if seriously ill or they had to attend an important family event (a funeral, for example).

A major risk of not being able to legally enter Poland emerged with the advent of the visa requirement. The Aliens Act of 2003 introduced a visa regime allowing Ukrainians who wanted to enter as tourists to obtain one 90-day visa every six months, unless they could prove having good reasons to apply for a year-long visa. ${ }^{29}$ The official visa refusal rate for Ukrainian citizens was low. According to expert studies, the introduction of visas was not supposed to affect seriously the inflow of labour migrants, who were to continue entering (on the basis of tourist visas) and work without a permit (Bradley Dunbar Associates Consortium 2002: 8). However, the interviewed women complained that information about the application procedure was unavailable, which made the migrants insecure about whether they would be able to enter. According to Svietlana, who already had a year-long visa and a fixed-term residence permit at the time of the interview:

...there was no information for Ukrainians: how to [...], what they should be prepared for. It was known that there would be severe restrictions, that there would be barriers. But how to prepare for that was not known [...]. And this is a rule, simply, simply it has always been a rule in our state bodies, in our consulates, simply no one informed anybody, and everyone coped with the situation by themselves. I already saw before the visa regime that there would be the change and that there would be restrictions, and I was looking for information by myself.

Visas also meant new costs and thus new risks of migrating to Poland. The migrant women in this research pointed to two new problems related to the introduction of the visa regime, which restricted their mobility: risk of receiving a visa for less than 90 days and being able to receive only two visas per year. Firstly, receiving a visa for less than three months decreased the financial attractiveness of the trip and reduced a migrant's chances of keeping a job in Poland. The same consequences resulted from the fact that Ukrainian citizen claiming a tourist purpose of travel could only apply 
for two visas per year. This so-called 'time corridor' meant that the migrant had to spend at least three months of every half-year in Ukraine. This lengthy absence from Poland could result in the migrant losing her job.

The migrants claimed that the rules of receiving visas for a particular period were not transparent and that the consulates issued visas arbitrarily. Chrystyna complained how people were randomly assigned the number of days they were allowed to stay in Poland.

It goes like this: Ukrainian citizens have the right to stay on the Polish territory no longer than i 80 days during one year, that makes it half a year [...] But, the Polish consulate gives out the visas any way it wants to, not exactly according to the rules, but as it wants to, because when my friend goes to apply for a visa and I go, we fill out the questionnaire - I and her identically, only our names are different [...] And the rest is identical - I go as a tourist and she goes as a tourist. They open the half-year corridor for her for 90 days and for me they open the half-year corridor for 45 days [...]. How can you call this order? And this [practice persists] until today. In the beginning it was not that bad, because they gave almost everyone 90 days in the half-year corridor [...] And then again 90 days. So, [...] a Ukrainian woman could work here for three months and then she had to go home for three months. Then the corridor ended and she had to start again. So, during a year she could only work for half a year.

The majority of the migrant women originated from villages and small towns in the Ukrainian western borderland and applied for visas at the consulates in Lviv and Lutsk. In the case of having already been refused a visa in those consulates, they used an intermediary company, which applied to the consulate in Kiev. ${ }^{30}$ According to the interviewed women, at the Lviv and Lutsk consulates, queues required up to several days of waiting, making the application process rather time-consuming. There were separate queues to get information, to receive the application form, to obtain a registration number, as well as to submit the application, and later on to collect the documents once ready. Informal ways of submitting visa applications also existed at the consulates. After the introduction of the visa regime, Larysa applied for her first visa at the consulate in Lutsk. Here is what she told me:

...some boys approached us, who...well, you know it is all about bribes, the boys came and said: 'How many of you are there?' And we said that we arrived here, that it is important to get the visa today, that we would be waiting until tomorrow, but there were people who had been waiting for two, three days for a visa, because there are a lot of people, and they gave a visa to 400 to 500 persons a day, not 
more, and there were more than a thousand people [in the queue]. So it was impossible to get a visa [that day], but we paid money that is, for five persons we paid 350 'ours' [UAH 350 or approximately € 28]. So much money for nothing... And these boys said, they were very young boys [...] because we had [the number] 500 something in the queue and he said, [...] 'I will place you [in the queue],' and said to go at the end [of the queue]. And I said that it is a bit suspicious [...] to go to the end... that the Pole [the official from the consulate] would come to the end [of the queue] that was something strange to me. But then at 8 o'clock he [the Polish official] came finally, and what do you think?! He goes to the end. The people standing in the front looked at him and said: 'What are you doing?' And he said: 'If you talk too much, you will not enter at all.' And he went to the end. And there was with him a boy who wrote something in Ukrainian and then we went in there where they gave us the applications and that was all [...], so that this day, around I2 o'clock, I already had a visa.

This account points to the new costs that appeared with the introduction of visas. With higher costs - more bribes required to enter Poland - the financial risks of migration were becoming higher. Larysa used informal services to 'facilitate' the visa application procedure. Bribes were a way to move closer to the head of the queue and, from her story, it seems that an informal cooperation existed between the consulate workers and those who, for a fee, 'facilitated' the migrants' application. In addition, people earned money by selling their 'place' in the queue. ${ }^{3 \mathrm{I}}$

This process of shortening the hours - if not days - spent queuing is related to the importance of time for labour migrants. The women who planned to migrate had to respond quickly to a demand voiced by a Polish informal employer and to enter Poland as fast as possible. Otherwise someone else would take the job: they had to be flexible. The requirement for the migrant to be flexible is at odds with the rigidity of entrance, stay and work barriers. Via informal means, the women 'softened' the barriers, decreasing the risk of losing a job opportunity.

As mentioned above, the interviewed migrant women claimed that a second barrier to mobility placing their migration at risk was being allowed only two visas per year. The women attempted to override this rule and obtain a third visa. This meant having to cancel one of the two old visas. Marijka, a 40 year old I interviewed, once entered Poland on a visa and another time without proper documents. When asked whether it is difficult to receive a visa, she replied: 
Well, it is not that difficult to get a visa, it's not a problem. The visa is free of charge [...] Well, the way it is one has to pay money to annul the old visa and to make a new one [...].

Migrants needed 'connections' to facilitate the cancellation of one of the visas. Olga, who by the time of our interview had worked for seven years and was fully dependent on the job in Poland, described her efforts. She had endeavoured to get a visa, then a third visa within one year and a new passport.

...And, in general, people sleep overnight there in the queues, give bribes, as I did in the past for the other visas. This last visa for A. [her son] was for a bribe - they took I9o dollars. [...] I paid money and they went to Kiev and did it through the Polish Embassy there without a problem. This way I got three visas and then I had to change my passport, because you do not get three visas in one year. The new passport, I also got it through bribes, in four days. Otherwise you would have to wait two months.

Larysa, whose visa was to expire within a few days from the time of our interview, also mentioned changing passports as a strategy to enter Poland. She had arranged for a new passport so she could apply for a third visa because two visas were already attached to her old passport. A new passport generally takes two months to be issued, though Larysa tried to shorten the wait by relying on her connections for help. She was unsure whether she would be able to enter Poland again. As she put it:

I called this woman and told her that I would have all the documents for the passport and [asked her whether] I would have a passport or I wouldn't have a passport. 'Will I get a visa?' [I asked]. She says: 'I cannot [make a] guarantee.' She tells me to call. I am going home and do not know. Will I be going with a new passport, or will I not leave [Ukraine] at all?

Following her case, I learned how she managed to get a new passport and a third visa, but was given a stamp in her passport at the border-crossing point, disallowing her entrance to Poland for one year. Thus, the strategies mentioned by the migrant women are not infallible. Time and money are needed to apply for new passports and visas. The stakes are high because if these strategies fail, the alternatives are few, such as crossing the border with false or no documents (which involves even higher financial costs and increases the risk of deportation).

Using two different passports was reported by an interviewed woman who entered on the passport issued under her maiden name and, on a 
second time, on the passport issued under her married name. Judging from stories, the 'two-passport' strategy seems widely used, yet the migrant women also underline times when these strategies failed. The introduction of a computerised registration system at the border complicated this strategy. As Chrystyna said:

...They [the migrants] change and they change their last names and first names and change everything. [...] What also happens is that when a person goes with a new passport, they are angrier with her than with you, 'Ah, you've changed your passport!' And [they ask about] everything, what their last name is, what family they are from or something else. And once...[someone] changed her passport, changed her family name, well, and he [the border guard] checked somewhere in the computer and saw [...] that there was the same photo of that person in the computer [...] So, he came and called her out by her old family name: 'Who is that?' Everyone was silent. And then 'And who is that?' [saying her new name] - 'It's me' [...] they deported her from Poland [...]. Somehow, they knew that she changed her passport. So now it is risky to go [on two different passports].

According to Chrystyna, crossing the border again was a kind of 'lottery' one could pass through several times and nothing would happen and then suddenly the migrant was caught. Her story also showed that the border was becoming less 'porous', thereby increasing the risks of irregular migration.

Another way to avoid the 'time corridor', which forced the Ukrainians to remain at home for at least three months, was to enter without a visa. During an informal conversation, Marijka told me how she entered on a visa for three months and, after returning home, soon re-entered Poland again. The driver of the bus that brought her to Poland had 'financial arrangements' with one of the border guard shifts. When the driver crossed the border, the guards did not check the passports of his passengers on entry and exit from Poland. During the interview - which was recorded, possibly making her thus hesitate to share this sensitive information she only mentioned this service indirectly.

Somehow I manage to go and go again [to Poland] [laughs] [...] Somehow God helps me [...] I come alone, without a 'replacement', because [...] ....the child gets used to one person and the child cannot go here and there and here and there, because it is a child [...] Well, that's how people go. I knew from people that this is possible [...] that you can enter again and again. 
She did not want to disclose what the fee for this service was. Marijka was aware of the risks during migration.

[W]ell, we all risk, we risk, I risk when I come here and work. Well, this is risk, because it is..., very serious with all this that we work here and illegally. We do risk [...] What do we risk with? Everything, we might not be let in, we can be deported. Everything is possible. Although we have our trust in God, different accidents still happen $[\ldots]$.

She justified her behaviour by identifying with other Ukrainian labour migrants who all engage in such irregular strategies. The fact that, according to her, everyone ignores the legal regulations is a display of practical consciousness. She knows that omitting legal procedures and regulations is culturally accepted in both Ukraine and Poland. She stressed the fact that they risk at every stage of migration-entrance, stay and work-because they can be refused.

\subsection{Development of migrant institutions as a response to legal risks}

Changes in legal regulations increased the costs and the irregularity of migration, thus magnifying migration risks. The main risk was being refused entery into Poland, meaning not being able to diversify the risks to income at home. Risks also entailed the rising costs of migration, with more time, money and stress involved in the process of acquiring travel documents and crossing the border. Several migrant institutions developed in response to the new requirements regarding the entrance and stay of Ukrainians in Poland. These institutions involved ties and networks in Ukraine and Poland, along which interactions across the border occurred, and the people who made money on this procedure.

\subsubsection{Drivers: Balancing the risks of irregular entry and stay}

The first type of migrant institutions, already partly discussed in section 5.2 and to be continued in this section, was linked to the country of origin. This involved interactions with non-migrants in Ukraine who had established semi-formal businesses (such as the 'queue waiters' or people with ties to consulates), thus making a profit by facilitating migration. These persons were aware of the migrants' need for their services when applying for a visa or entering Poland, and used it to their own benefit.

Among these non-migrants forming migrant institutions as a way to balance the risk of non-entry is the vodiy, which in Ukrainian means 
'driver'. This person owning a car, either alone or together with one or two partners, drives migrants for a fee from their hometowns to their workplace and back. ${ }^{32}$ The labour migrants who used this service knew about it through their migrant friends or family and friend networks at home. The driver often came from a town or village near their own place of origin. Some drivers used to be labour migrants themselves and, having invested in a car, started to provide the service. The drivers were an attractive alternative for irregular labour migrants who were afraid to return to Ukraine by bus in case they were robbed by people extorting money at bus stations in Warsaw and Lviv, or some other mishap.

The functioning of the vodiy involves the interaction of migrants, nonmigrants and border guards. It changes the context of crossing the border between Ukraine and Poland. This was not solely a transport service provided for the payment of a fee: it involved particular 'border knowledge' on the part of the driver, who was to guarantee a successful passage despite legal barriers. The drivers were professionals at crossing the border. Those I had a chance to speak with claimed that crossing the border by car gave people a better chance of successfully getting through than a bus journey would. According to them, travelling by bus more often resulted in refused entrance than travelling by car. During my participant observation, I saw several persons returning on foot from the border-crossing point after being refused entrance via bus. However, after seven hours of waiting in the queue at the border, people in a car in front of us were also refused entrance.

Entering Poland via the Ukrainian-Polish border-crossing point with the driver consisted of several steps. They included attempts to shorten the waiting time in the queue, control by the Ukrainian border guards and customs officers, waiting in the queue between the two border-crossing points and, finally, the time when the migrant prepared for the culmination of this process - that is, face-to-face interaction with the Polish border guards and customs control. 33 I had the opportunity to observe these different phases during my participant observation carried out when crossing the Ukrainian-Polish border. The driver tried to cut or skip the queue on the Ukrainian side. After checking whether any of his friends were in the queue to let him move closer to the front, he handed his passport (with a ten-dollar bill inside) to the guard overseeing the queue order. ${ }^{34}$ The guard looked into the car and asked whether everyone was Ukrainian. The driver replied, pointing to me, that I was Polish. The guard gave the driver his passport back, but he did not take the money and he let us skip the queue. The driver laughed saying that he should cross the border checkpoint with me more often, because the guard must have been too scared to take the bribe.

During similar participant observation in a car crossing the border in February 2006, all of my fellow passengers were going to take up work 
in Poland. The driver was instructing them on how to make their 'declared' purpose of travel seem more believable and how to behave so as not to attract the attention of the border guards. He suggested his passengers not leave the car or look around nervously when the guards approach. He also rehearsed with one of the passengers - a young Ukrainian man on his way to work for a Polish farmer - what he ought to answer when asked by the guard about the aim of his trip and where he would be staying. They both agreed that he should pretend to be going to a wedding. The driver also quickly invented an address in Poland and the Ukrainian man nervously repeated, trying to remember it, in case the guards would ask for more details about his destination. The driver also asked me whether one of his passengers - a young Ukrainian woman who was going to work as a cleaner in Warsaw and who had already been refused entry to Poland twice - could pretend to be a friend of mine who was going for a visit. The whole venture required mutual interest based on trust between the driver and the passengers, so that the latter, aware of the former's real travel aim, would not use it against him or her.

The driver also provided a money-lending service to facilitate the migrant's fulfilment of proving sufficient financial standing. A migrant could be charged an additional fee for this service or it could be included in the price of the drive. Here is how Olga recalled this service:

....and [I] asked the driver to show money at the border for me. I had to give him ten dollars, so that he would show the money. I didn't know, I thought that he would show it [to the border guard] for me and he would give it to me at the Polish border, because at the Ukrainian one they didn't really ask for money. But at the Polish border they did and checked it...

I witnessed the money-lending procedure when crossing the border in January 2005. I was in a car with three other passengers and, right before the border, the driver took out a thick pile of dollars and handed over $\$ 400$ to each of the passengers. The guards did not ask the passengers in the car to show the money. After crossing the border, the driver did not collect the money for another one or two hours in case there was another control by the border guards. In general, this service required the driver take trusted passengers who would not rob him at the next stop. For this reason, this service is no longer provided by drivers of official bus lines between Ukraine and Poland, among others. As one of the migrant women claimed, the 'money-lending' service offered on buses stopped due to the fact that passengers who got on the bus in Lviv and received the money for crossing the border disappeared with it at the border-crossing point.

The drivers knew the border guards. They were able to distinguish between those who were more willing to negotiate the grounds of entrance 
and those who were stricter. The drivers circulated between Poland and Ukraine, leaving one day and returning the next; thus, the border guards could not accuse them of working in Poland. They knew how to cut the queue and how to improve the chances of their passengers' successful crossing. They were experts at this due to their routine passage of the border two or three times per week.

Summing up, the risks to entrance, which jeopardised the women's access to work in Poland, were mainly related to the fuzzy execution of rules by the border guards. This, however, provided space for the development of responses to mobility barriers in the form of migrant institutions, such as the vodiy. The institutions, such as the vodiy, bound everyday life routines with the migrant's life cycle and migration laws. Crossing the border several times per year, a risky activity in itself, thus became a sort of routine. The vodiy established his or her presence among the migrant community as a trustworthy service, using social networks or interacting with migrants on a regular basis. Drivers shared information about work in Poland and controlled knowledge about the risks related to migration, but it was not necessarily in their interest to reveal it because they wanted labour migration to continue. Due to their presence, they changed the context of crossing the border, helped migrants 'act out' the credibility of their journey's aim and in one way or another supported their financial standing for stay in Poland.

\subsubsection{Employers: Balancing the risks of irregular entry and stay}

The second migrant institution was linked to ties established in Poland, primarily with Polish employers. As Goss and Lindquist (I995: 34I) claim, employers 'have no particular knowledge of the migrant institution but have the power of distanciation by virtue of their social status and their connections beyond the immediate locale where they can speak for the potential migrant'. The employer, according to Giddens' terminology, is 'established' due to his or her access to material and political resources. The interviewees claimed that employers played an important role in allowing the migrant domestic workers to enter and stay in Poland. The migrants and employers entered a patron-client relationship, meaning a personal relationship that exists between unequal individuals; the inequality results from the existence of a hierarchy understood here as a structure linking unequal persons in relations of dominance and subordination (Tarkowski I994: 45). The individuals involved in this relationship have access to varied and unequal types of resources, with migrant and employer having a different legal, social and economic status. The migrants were vulnerable due to their legal status and the patron-client relationship was a mechanism allowing them to adapt to conditions of irregularity and receive some form of protection. 
To avoid having to fulfil the requirement of proving financial standing for their stay in Poland, the interviewed migrants asked the Poles they knew, often their employers, to apply for a notarised invitation letter on their behalf. According to the invitation letter, a Pole who invited a foreigner was financially and legally responsible for his or her stay in Poland. Thus, Poles, especially employers, became part of the migrant institution. They acted as informal 'facilitators' who, motivated by migrants, assisted their entrance. The interaction between the Ukrainian migrant and the Polish employer stretched across time and space. In the case of experienced migrants, arrangements were made in Poland before leaving, then consulted about over the phone from Ukraine and involved an intermediary who would bring the invitation to the invitee.

Migrants themselves displayed agency by changing the meaning of 'invitation': they used it to circumvent the financial standing requirement. After arriving in Poland, they did not rely financially on the person inviting them. Notarised invitation letters also guaranteed receiving a three-month visa. The invitation strategy as a response to legal risks resulted from an agreement based on mutual trust and interest between the migrant and the employer. The latter wanted the former to work in Poland and thus were willing to facilitate their entrance. In reality, however, the employer was not legally or financially responsible for the foreigner while in Poland. Here is how Nadya described this procedure:

I was invited here by some respectable people, to live in Warsaw [...] through friends and this woman, who invited me [...] This gave us the right to an easier crossing and I did not need those 200 to 300 dollars for the border [...], because, well, they ...check money when you go $[\ldots]$ yes, money for the stay here. Now, after the New Year they are saying that it will be more... ah... it'll be difficult to cross because a larger sum will be required.

Developing a closer relationship with employers meant that migrants were able to use their social capital. A migrant who had access to resources in the form of the employer's social network could also become one of the 'facilitators' of the migrant institution. He or she provided other migrants with information about jobs and was an important link between the employer's friends (e.g. searching for a domestic worker) and other migrant women. Having access to several reliable employers increased the migrant's chances of finding ways to enter and stay legally in Poland.

According to Chrystyna, opportunities to use the employer's social capital differed among migrants. Chrystyna, who was a live-in care worker herself, claimed that migrants living with the cared-for person or the employer could count on receiving an invitation letter thanks to a closer relationship. She was convinced that for those living-out, such as cleaners, 
chances of benefiting from employer's access to resources were lower. However, Chrystyna's conviction to a certain extent stands at odds with research results, which show that cleaners who had a long-lasting relationship with their employers not only managed to get an official invitation from them, but sometimes even had a work permit arranged for them.

Several of my interviewees received visas through their employers' connections. Through their social networks, some employers had access to people working in ministries or consulates in Ukraine. This illustrates how informal networks permit getting around 'cumbersome' legal procedures in Poland. When asked who helped her obtain visas, Olga said the following:

Acquaintances, acquaintances [...]. In Warsaw and through the ministry, they called the consulate in Lviv and I went without queuing, without a problem and got my visa in half an hour in November and, in January, I waited for one and a half hours.

Olga obtained a visa by using her social capital in Ukraine (borrowing money from friends) and in Poland (ties of her employers).

Employers were also able to provide migrants with work permits. The aim of applying for a work permit was not to legalise the foreigners' work, but to allow the migrant domestic workers to apply for a year-long, multiple-entry visa and a fixed-term residence permit, thus facilitating circulation between Poland and Ukraine. The employment was falsely declared because these migrants, besides working for employers who registered their work, also worked for other employers in an undeclared fashion. In addition, migrants also received wages different from those officially declared. The theme of falsely declared employment will be analysed in greater depth later in this chapter.

Employers provided another measure to balance legal risk in regard to residence registration. The Act on Population Registration introduced a requirement for those foreigners who remained in Poland for longer than three days under a given address in Poland to register with the local administration. 35 The studied migrant women were asked to display a proof of this registration at the border-crossing point when leaving Poland. Among my interviewees, those who did not have the proof of registration claimed that they had to pay a fee equal to three days of earnings for a migrant domestic worker. ${ }^{36}$ Registration was regarded by the women as an important step towards fulfilling at least some of the stay requirements, thus decreasing the exposure to legal risks.

Larysa, who works as a cleaner and had commuted for four years between her town B. and Warsaw, mentioned this when asked about her residence status. 
But I am here legally anyway, because I have the registration [...] or this or that woman that will do it...so I always have, somehow through all those years I have always had registration, always. And it turns out that this stupid paper is needed when I go home. Everyone asks at the border to show it, it was rare not to be asked...[...] when you don't have registration, well, then you buy it, it costs - the [false] registration - it costs PLN 5 (€ I.2)...

Larysa's premise - that fact that she was staying legally since she had residence registration - shows that she considers her status to be safe. She claimed that migrants could also buy false registration documents at the open-air bazaar in Warsaw known as Stadion.

To receive residence registration, the migrants used social ties to Poles, mostly their employers. People renting apartments or rooms were rarely willing to register them because registering required a trip to the local administration. In addition, owners of flats were renting informally and were thus unwilling to inform local authorities that someone is living in their apartment. Some of the apartment owners asked for additional money for registration. Several of the studied migrants who worked as cleaners, among them Larysa, rotated among the employers, asking a different employer to register them each time. This meant that the migrants generally did not live where they were registered. At the time of the interview, Larysa had a stable group of employers in Warsaw. As she put it:

I am always registered. Now I have come only for 30 days so it's not worth it, but I have always been registered, for the past four years I have always been registered. I ask this one [employer] or that one, I do not always ask the same person, because I don't want to. You see, it is not good if you are always registered by the same person. For example, this time I ask someone, and some other time, someone else, because if it were always the same person, this could draw attention in the administration office...

Larysa pointed to the informal rules of balancing the risks of undeclared work. Since she stayed for one month only, the registration was too much trouble for her and she preferred to take the risk of not being registered. By rotating between employers she diversified what she perceived as the risk of exposing her undeclared jobs. Having proof of a registered stay in Poland (e.g. residence registration) was also necessary in case the migrant planned to apply for a fixed-term residence permit.

Employers' role in the migrant institution is visible in Halina's story. At the time of the interview, she had been working for two years for the same employers, taking care of three children and maintaining their 
house. Because her employers could not find anyone to do her job during the children's holidays, they asked her to overstay her allowed time in Poland. The migrant first checked with a border guard she knew, whether (for a bribe) he would 'turn a blind eye' to her overstaying, when she was returning to Ukraine. The answer was yes; for \$ 50 , he promised to let her cross the border without checking her passport. The employers gave her the bribe money and she overstayed. Consent from the employers to be involved in this practice shows the acceptability of irregular arrangements. However, when Halina was crossing the border, none of the 'known' border guards was present. She received a stamp in her passport, disallowing entrance to Poland for one year. In this case, overstaying showed the development of a complex migrant institution with a number of participants: the employer (who gave the bribe), the migrant (who overstayed) and the border guard (who was to accept the bribe). However, due to extraordinary circumstances, the migrant institution failed to avert the risk of being expelled from the country. Upon her return to Ukraine, the woman changed her surname from her married name to her maiden name, applied for a new passport and entered Poland a few weeks later. According to the interviewee, changing one's last name was a rather easy procedure in Ukraine when backed by an appropriate bribe.

Overall, the interaction in this migrant institution crossed the national border, with an employer using his power position as a Polish citizen and providing the migrant with a notarised invitation letter or an official promise of work (with which the migrants were able to support their visa application at the consulate and when crossing the border).

\subsubsection{Other strategies to balance the risks of irregular entry and stay}

The third type of migrant institution was based on access to Polish institutions: educational, non-governmental or matrimonial. This institutional setting provided a particular opportunity structure for irregular migrants to balance risks related to their status. An important role in all these institutions was played by other migrants, who shared information and recommended particular services.

A foreigner wanting to stay in Poland for longer than three months needed to find grounds for eligibility to apply for a year-long visa. Larysa, who needed to enter Poland for the third time, applied to a language school. She told me the following:

...someone told me there is a school here [...]. I paid PLN 400 [€ IO०] for this course, she gave me this document and I went to Ukraine. And this was arranged, because a friend of a friend of mine who works in Italy is friends with the consul and she called the consulate $[\ldots]$ and the consul came out and said [to me]: 'I think you are too 
old to be studying. I think you are working there.' But there was the phone call...

Larysa enrolled in a language course that, backed by connections, proved sufficient to get one visa annulled and receive a third one within a single year. According to the interviewed women, migrants applied for evening or weekend university courses to receive student visas. University students could apply for a fixed-term residence permit, which allowed stay in Poland for up to two years and could be renewed. However, when applying for a permit, foreigners had to have at least PLN IO,O०० (€ 2,500) in their bank account to prove they had the financial means to cover the cost of their annual stay in Poland. A way to overcome this financial barrier was to borrow the money from someone, ensuring the sum would be in their account at the time they applied for the residence permit. Two of my interviewees enrolled in university this way. In general, migrants did not have the time to attend all or any of the courses they were enrolled in. A different phenomenon was that of actual students from Ukraine. They attended university courses and often worked in an undeclared fashion in the domestic work sector as baby-sitters or cleaners, like their Polish colleagues.

Volunteering in a non-governmental organisation was another migrant strategy that guaranteed a three-month-long visa. In some cases it also offered the possibility to receive a year-long visa and thus a fixed-term residence permit. A migrant can become a volunteer on the basis of the Act on Public Good Activism and Volunteering. ${ }^{37}$ According to this, a volunteer is a person who voluntarily and without payment provides services that are listed in the act. A volunteer has the right to the reimbursement of expenses that he or she has incurred due to the volunteer work. In the case of the interviewed women, the reimbursement of these expenses equalled to more or less the average earnings of migrants working in care - that is, approximately PLN 800 (€ 200) per month. Thus, the migrants performed their services legally without having to apply for a work permit. The non-governmental organisation signed a contract with the person for whom the volunteer was providing services. The contract involved covering health insurance costs, which were often paid by the migrant because the person receiving the service refused to cover them. Engaging in volunteering was an example of how migrants and potential Polish employers creatively used institutional channels to minimise the irregularity of migrant work and the related risks.

Getting married to a Polish citizen also gave a foreigner the possibility to receive a fixed-term residence permit. In Poland, Ukrainian women predominated among foreign spouses of Polish men (Kępińska 2006: 72)..$^{8}$ Among my interviewees, two were married to Polish men. The first one was Zenya, a 48-year-old divorcee who worked as a cleaner in Warsaw. 
Her two sons were in Ukraine and she admitted that her unstable financial situation pushed her to marry.

[...] Somehow I lost work, got married...because I lived most of my life alone ... and I didn't really plan to get married. But somehow this moment of fear came, that I will have to pay for my second son for the next three years [of studies], this son is young, the older one is without work. This year, my son will finish [a degree in] physics and this year he is already doing paid economic studies so, for this reason, I panicked and this pushed me to get married, so that I could stay here. But I do not use that person [her husband] financially, not at all, and I try not to. One can say that all that I use I give back, for example, when I use water or something, so in these financial relations, more or less, we are clear, so that I don't use this person, so that he doesn't waste a kopieika ['penny'] on me.

Zenya's story shows how the future of her sons in Ukraine, her unstable legal status in Poland and lack of financial means led to marrying a Polish citizen. Zenya referred to her Polish husband as 'this person' in our interview and pointed to the separate financial arrangement, which meant that this marriage could be typified as a stay strategy.

The other interviewee who married a Pole was Irina, a divorced 30 year old who had an eight-year-old son from her first marriage. She wanted to study in Poland; however, her application was rejected. She recalled the reaction of a Polish acquaintance, whom she later on married.

I already knew W. at that point [...] and we went [she and W. together to the university] and they [the university administration] gave me back the PLN 400 registration fee and I got back my documents [...] and I came out so disappointed and W. said: 'Irina, maybe you would marry me, so that you don't have to study just to receive a visa.' And I said: 'I don't want to marry you, I don't want to study for a visa and I don't want to marry to get a stay.' But it seems that he wanted somehow this way to propose to me...

Throughout the interview, Irina recalled her former Ukrainian husband, whom she seemed to see as the love of her life. Meanwhile, marrying W. allowed her to bring her child to Poland from Ukraine and she began to study. Although Irina claimed that she did not want to marry for her 'stay', it was to some extent exposure to risk that made her finally consider getting married. Irina separated from her Ukrainian husband in Poland and, for a while, was the single mother of a small child, attempting to make a living in a foreign country. Her attitude towards risk changed-she claimed that once, before she had a child, she was willing to take risks, but at the 
time of our interview she was ready to compromise for the sake of safety. Her marriage to a Pole could be interpreted as such a compromise.

However, in general, my interviewees were sceptical about getting married to Poles as a tactic to receive a fixed-term residence permit. As Marta observed:

The only success, but I don't think it is a success...for me, it's stupidity, as they say, marry a Pole and then you will have a residence permit. That's the only thing that girls say, they think they will marry a Pole, and then she will be successful. But it is not like this, because a Pole is the same as a Ukrainian, a Frenchman, as any other, only to...It depends on what kind of person he is. It's no success to marry a Pole and stay in Poland.

I believe there are two reasons for this attitude towards marrying a Polish national. Firstly, many of my respondents were divorced or separated from their husbands and were wary of marriage. Secondly, the migrant domestic workers generally declared that they wanted to return to Ukraine and they were not planning their future in Poland.

Apart from decreasing the risk of irregular entry and stay, how did a fixed-term or permanent residence status in Poland change the migrants' risk exposure and agency? In general, the women who circulated on a three-month 'tourist' basis avoided having any contacts with Polish authorities, including with the police. However, when they received a residence status, at least on a temporary basis, their interaction with authorities changed. This can be seen from the behaviour of the women married to Polish nationals, but also in the case of Svietlana. During our interview, Svietlana had a work visa and a fixed-term one-year residence permit.

Not long ago, I was in touch [with the police], because... I turned to them myself, because there were, there were some sort of bandits at the Stadion, [...] because I... there at the Stadion there were such thieves, who robbed our people, extorted money from them and so it happened, and I [...]. When I arrived or was leaving [by bus to Ukraine], I always saw them, and twice they approached [me], this summer for the third time [...] I was sending my son to Ukraine and I was staying [in Poland] and immediately [...], I immediately wrote a letter to the newspaper and gave a signal and all the newspapers were writing about it and also after that the police [took care of it]. [...] [A]fter that I contacted the militia [police] to explain [...] I thought that the police aren't doing enough at the Stadion, because there were often such unpleasant moments, because they [policemen] ask our people there [at the police station] for passports and ask: 'Are you here legally or illegally?’ and this cynical approach starts. And 
what it is all about is that the bandits attack you and you have no security $[\ldots]$.

Svietlana's story gives an illustration of a criminal procedure and points to how vulnerable migrants are when leaving for Ukraine. This phenomenon was also analysed by other researchers, who pointed to the fact that migrants who traded and worked generally had too little profits to be of interest to organised mafia, but became an easy target for regular thieves (Wallace I999: 28). At the same time, due to their irregular status, migrants were unwilling to inform the police. Thanks to her fixed-term residence status in Poland, Svietlana did not fear Polish authorities and decided to act. Not only did she contact the police, but also wrote to newspapers, describing the extortions.

\subsection{Legal risks of undeclared work}

Since I994, more than 10,000 work permits were issued in Poland annually, amounting to approximately I7,000 in the late I990s. Although the numbers were very small, Ukrainians received the largest share of work permits and Mazowieckie Voivodship was their main destination area. The low number of work permits issued was not a result of applications being rejected, but of scarce applications being filed. That was because employers were unwilling to go through the costly, time-consuming process of applying for a permit for their future employees, nor were they happy to pay for their insurance. Application for a work permit made migrants' services no longer financially attractive for employers or for the migrants themselves.

The interviewed women differed in their perception of risks in declared and undeclared work. Two characteristics influenced their evaluation of those legal risks: past work experiences and their age.

Those women who had previously worked in Ukraine were no longer convinced that work in the official labour market provides one with financial security. Many of them experienced so-called hidden unemployment and were forced to go on unpaid holidays. Undeclared work abroad was perceived by them as more predictable and giving higher chances of profit. Some of my interviewees initially worked in an undeclared fashion, as seasonal agricultural workers in Poland. Obviously, their experiences differed. Some farmers paid well, providing assistance in the event of accidents and helped to find work on other farms in the event of a poor harvest. In other cases, migrant women found out that there was no work for them after arriving in Poland or they were paid less than the farmers initially promised. However, their experiences were generally positive. On the other hand, the few who experienced declared work (apart from the 
domestic sector) associated declared work only with obligations rather than with rights. That was the case of Lilyana.

I met Lilyana in March 2005. She was a 30-year-old schoolteacher who had worked for the past five years as a cleaner in Warsaw. In the early I990s, Lilyana lost her job in Ukraine. In I995, she came to Poland for the first time to work for a horticultural company. She arranged her job via an intermediary work agency. This was rather exceptional because migration to Poland was and continues to be based mainly on informal ties and networks due to the spatial proximity and overall distrust of official arrangements. However, these networks developed primarily in Ukraine's western border region. The various elements of the migrant institution, such as informal recruitment of labour migrants by Poles, only began to develop in the early I990s. According to the interviewed women, Polish farmers unable to find workers in Poland got on a bus to personally recruit seasonal workers in Ukrainian villages near the border with Poland. Such informal networks did not develop at that time in other parts of Ukraine. For this reason, Lilyana, who originated from central Ukraine, used recruitment companies to find work in Poland.

At the Polish horticultural company, Lilyana worked fourteen to sixteen hours per day, with one hour-long break, first collecting tomatoes and later on roses. According to Lilyana's story, the workers were at risk due to lack of knowledge about the working conditions they discovered after arrival and the work, which was physically demanding, thus exposing the migrants to serious health risks.

When a person first comes to Poland, the first day she doesn't know the Polish language and nothing, but fear and all. Some were clever, saw it all [the working conditions] and took the next bus back [home]. [...] And... those tomatoes. They sprayed them with some sort of poison. They said that you shouldn't be for two days in the block after this poison had been sprayed, and we worked there even so... for example, these were such long, big blocks and we worked the beginning and at the end they had already sprayed this poison. The stench was horrible. After all of that, after working in M. [name of town where horticultural company is located], women couldn't have babies. It's horrible.

The work of the migrants was constantly supervised and the workers were punished for the smallest offences by having money deducted from their earnings. The migrants had limited opportunities to negotiate their working conditions with the employers or supervisors. The contract was signed for half a year, with the possibility for extension. Lilyana received a weekly sum of PLN 40 ( $€$ IO) and was paid the rest of the money only at the end of the stay (PLN 560 per month $-€ \mathrm{I} 40$ ). As part of the contract, 
she had to pay a form of security fee to the employer at the beginning of her working period, ensuring that she would not abandon her work before the end of the contract. The fee was approximately $€ 90$. The case of this horticultural company has already been described in other research (Stola I997: I8-19; Łukowski I997: 13).

Lilyana decided to search for a different job after her contract with the horticultural company ended. She knew by then from other migrants that she could find work at an informal hiring fair in a nearby bazaar. Bazaars 39 were places where migrants often moved from trading to working or, as in Lilyana's case, from declared to undeclared work. Informal hiring fairs allowed migrants to find part-time, ad hoc work. Almost every day, Lilyana was able to get some job, sometimes picking fruit, another time renovating an apartment, at other times cleaning. That is where she met other Ukrainian migrants working in the informal economy, among them her future husband. Lilyana's legal status, entering Poland as a tourist and working in an undeclared fashion did not give her the stability to raise and support her child in Poland. As such, several months after giving birth in Ukraine she decided to return to work in Poland, leaving her child with her mother, to whom she sent remittances.

Working seasonally in agriculture or in various odd service jobs provided the women with a particular knowledge about working in Poland. This knowledge concerned both the opportunities (that is, the money one could earn in different types of job) and the negative outcomes of labour migration (such as not being paid or getting ill from the hazardous working conditions); this knowledge allowed them to avoid future risky situations. Past experiences in working abroad meant that the women had developed social ties to some Poles, who were either employers themselves or potential 'facilitators' for finding other types of work.

Lilyana's experience was unusual, with her shift from declared to undeclared work. The interviewed women questioned, as did Lilyana, the advantages of declared work, but there were also those who were worried about their undeclared work status. A tension between the risks and chances of declared and undeclared work was visible in the stories. Legalising one's work by receiving a work permit was regarded by many women as making their migration trip no longer financially attractive. As one of the women said:

To work legally it does not work out so well, because there are always a lot of problems, because you have to go to the labour office... and place an advertisement, [...] you have to pay a lot [for applying]. This means for us... this is not very comforting, when you earn I,००० $[P L N]$ and pay 800 [for the application], and ... 200 will remain, well, then why did I come here? [laughs] 
The women migrated due to financial risks in Ukraine. Although declared work in Poland gave them insurance and, after several years of work, a future pension, the women again faced financial insecurity due to the living expenses involved. On the other hand, although in undeclared work the lack of insurance and pension posed a risk, the money earned during migration gave the women a sense of safety; its purchasing power in Ukraine was much higher.

Another characteristic that divided the women working in an undeclared fashion in terms of their perception of risks was age. Migrants who were older than 45 used to work in the official labour market in Ukraine; some continued to be employed, while others had already retired. They had their own households, their own reference group and a sense of stability in Ukraine and they treated Poland as their 'workplace', focusing on the fast gains from migration. These migrant women had their lives back in Ukraine. Those younger than 45 had less or no work experience in Ukraine. Some did not have their own household in Ukraine, which meant they had no need to send remittances home, but they found it difficult to establish stable social relations either in Poland or Ukraine. Still, they seemed to have more ties to Poland and thus were more affected by their legal status. One of the migrant women who continued to work in Ukraine, while treating work in Poland only as an additional source of income, commented on the future consequences of treating work in Poland as the main occupation.

...my neighbour, who has been going, I don't know for how many years already, maybe ten years, to Lublin, to [care for] small children [...] so she has been going for ten years already. And she says - there will be no pension for me. That is because she doesn't work [in Ukraine]. She said - I have to find something in Ukraine now, she is more than 40 years old, some fifteen more years [of employment] and that's it...

Marta, the 30-year-old migrant who only had a few years of work experience in Ukraine and had been working in an undeclared fashion in Poland for the past three years at the time of the interview, wanted to declare her work. As she put it:

I would simply like to work normally somewhere, well I don't know... I say, so that it is written somewhere that I work, that there are, for example, some taxes [...] That's the only thing that I would like to change in this. Because then I think there would be more chances to get those [permanent residence] permits, for all of this.

Declared work is associated with 'normality' and Marta links it to the 
possibility of receiving a fixed-term residence permit. In her story it is clear how the undeclared work status introduced a large degree of insecurity in her life.

[...] I think the whole time: 'What will I be doing tomorrow?' Well, now I have a home, I have this visa, but what will happen when I go in March and no one will allow me [to enter] ever again? [...] And this worries me the most. I only think about this... what to do to have all of this? I don't know...to have some sort of permit to work, to go to work, for example, to...to open something of my own, although now I don't have the possibility? But if I did...clearly, if I could start working, maybe I would meet someone who would like to work with me. For example, I like to make pierogi and I would like to work for a restaurant or a pub, but only if it is all legal, that it is written somewhere, that I work, that they pay taxes for me and all. With pleasure, I would do it, then. And this is what worries me. Tomorrow, what will be tomorrow?

Marta is overwhelmed by concerns that she might not be allowed to enter Poland again. For her, undeclared work in Poland meant not only quick financial gain, but possible losses due to the job's undeclared nature, not having a pension in the future and, above all, not being able to find different employment outside the domestic work sector.

\subsection{Conclusions}

One of the basic factors influencing the character of migrant domestic work in Poland is the change in migration regime. There was a shift from a liberalising tendency with regard to entrance and stay in the I990 (accompanied by the restricted access to the official labour market), to increasingly restrictive admission policies with Poland becoming a member of the EU and a new liberalisation of admittance to the labour market as of 2007. The period of interest for this analysis was the 'restrictive' period for Ukrainian citizens: after the introduction of the visa regime in 2003 and the highly protected official labour market until 2006.

The arbitrariness in the implementation of many of the regulations, together with lack of controls (especially with regard to undeclared work) was an important element of an opportunity structure for irregular migrants. Social acceptance of the undeclared character of work in the domestic sphere in Poland increased the probability of engaging in informal work. The migrants based their actions on informal arrangements via social networks. This was first of all regarded as a form of compensation for the assumed inefficiency or 'injustice' of existing formal institutions, 
resulting from a cultural legacy - a 'patched' functioning of the command economy during Communism due to too many informal arrangements. Secondly, these networks were an enabling structure. They allowed migrant institutions to develop, giving migrants access to particular forms of social capital to help them cope with risks related to their irregular status.

Migrant institutions that developed as a response to legal risks of irregular entrance, stay and undeclared work in Poland exemplify how structure limits and facilitates agency and how agents influence changes within structure. The migrant institutions were based on the existence of particular opportunity structures and consisted of several actors as well as multiple strategies. The strategies around the entrance phase included an interaction between the migrant (who already had a particular migration experience), people providing direct migrant services (for example, the driver), people having access to important resources (such as the employer through a notarised invitation) and the border guards' willingness to negotiate the entrance. Some of the resources in the migrant institution were used to solve 'routine' problems, regarding entrance or stay, while others had to be mobilised quickly in an emergency.

The different migrant institutions created as a result of these actions minimise certain risks while generating new ones. These risks may be of different character. For example, by engaging in action to decrease risks related to irregularity, a migrant may expose himself or herself to financial risks. A trading of risks occurs; while at times it can be conscious, new risks can also result from unexpected outcomes of actions undertaken.

Interactions within the migrant institution took place at particular locales, such as the border-crossing point and the consulate. The first place where the migrant had to display agency was the Polish consulate: there the migrant used her ties and connections to secure a 90-day-long visa. A number of strategies was involved to enter: declaring a false aim of travel, tampering with travel documents, establishing ties to border guards. The employer, who provided a migrant with a notarised invitation letter, was of great relevance for decreasing the risk of irregular entrance and stay. The invitation was not only a guarantee for receiving a visa, but also meant that the foreigner would not be asked to prove sufficient financial standing at the border. The second locale of interaction with Polish authorities was the border-crossing point. The migrants based their information about changes at the border on loose ties to other migrants and on the driver. When it came to crossing the Polish-Ukrainian border, the migrant domestic workers displayed a Giddens-described (I979: 59) practical consciousness: 'the unarticulated beliefs and knowledges that people use to orient themselves to situations and interpret the actions of others'. 



\section{Risks and risk strategies in migrant domestic work}

Poland's demand for home-based care is due to a limited provision of institutionalised public and private care services. In large urban centres, such as Warsaw, cleaning services are also sought after. Ukrainian migrant women have learned that the Polish domestic work sector, with its need for care workers and cleaners, provides opportunities to earn sufficient wages to be able to support their families in Ukraine. However, work in the domestic work sector exposes the migrant women to particular risks. On the one hand, the risks result from the character of domestic work: it is undeclared, unstable, related to low social status and yields insecure income. On the other hand, the risks taken by domestic workers depend to a large extent on the attitude of the informal employer. To gain insight into the Ukrainian women's opportunities to respond to risk present in their relationships with informal Polish employers, I use the notions of patron-client relationship (Tarkowski I994) and everyday forms of resistance (Scott I985, I990).

The patron-client relationship is an asymmetrical relationship characterised by a domination-subordination division (Tarkowski I994: 45). In the case of migrants, this is especially visible when analysing those with an irregular legal status. Such a relationship is generally voluntary, with both engaged parties expecting gains from the exchange of goods and services. The individuals involved have access to different and unequal types of resources, a result of their positioning at different levels of the societal hierarchy (Tarkowski I994: 47). This exchange differs from an economic exchange because there is no equivalence. When one side does a favour for the other, that party has a right to expect reciprocity in the future, though the character of reciprocity may not be determined; there are no formal rules or legal guarantees. The reciprocity norm defines the rules of behaviour. Thus, it is not about the obligation to repay a debt, but about 'being grateful' (Tarkowski I994: 48). The exchange, based on the interest of both sides, ought to be hidden; instead, it takes the form of a favour. The actual underlying aim and function of offering a gift has to be concealed.

The paradox of patron-client relationships is that they are based on personal ties of solidarity and, at the same time, ties of subordination and inequality, thus creating ground for potential exploitation. This calls into 
question the voluntary character of this relationship: it is in fact the person with higher social standing - the patron - who decides whether and, if so, how the relationship will be created. Meanwhile, the client tries to find favour with the patron. Patrons can force clients to engage in a relationship. This is related to the norm that does not allow one to refuse a service - a tactic called 'aggressive charity'. The exchange between the patron and client is unequal, making the client more and more dependent (Tarkowski I994: 90-92). In that sense, the relationship becomes a risk for the dependent party.

Everyday forms of resistance involve the struggle of relatively powerless groups to reach their basic objectives (such as physical safety or income) vis-à-vis the various forms of exploitation by those in power. They can involve inventive practices such as dissimulation, false compliance, stealing, feigning ignorance, evasion or deception (Scott I985: 29). These small modes of resistance are persistent and require little coordination or planning; they constitute forms of individual self-help. The idea is to reach immediate gains and at the same time avoid any direct symbolic confrontation with authority or the elite norms. As Scott (1985: 33) writes: 'The success of de facto resistance is often directly proportional to the symbolic conformity with which it is masked.' The character of resistance is influenced by 'the existing form of labor control and by beliefs about the probability and severity of retaliation' (Scott I985: 34). The more individualised the resister, the greater the risks. The more collective the grievance, as shared through stories, the less it is only a fantasy and the more it can become a collective act. What matters is the meaning given to their acts by the resisters.

A demystification of the relationship with the power-holder by the resister occurs in the so-called hidden transcript. The hidden transcript is what is said offstage. It is produced for a special audience and under different constraints of power than the public transcript, which is a performance of deference and consent by the subordinate, who attempts to foresee the intentions of the power-holder (Scott I990: 3).

The work relationship between the Ukrainian migrant and the Polish employer in the domestic sector can be generally described as a patronclient relationship. It features personal ties, with the exchange guaranteed by norms of reciprocity and not by a formal contract. Moreover, it occurs between individuals with unequal access to political, economic and social resources, placing the employer in the dominant and the migrant in the subordinate position. Both parties enter this relationship aiming to achieve particular gains. At first glance, the employer simply wants a clean house and well-cared-for children or parents and the migrant seeks a decent wage. However, the relationship is more complex than that. Three main aspects of working in the employer's household influence the exposure and management of risk in this work relationship: I) irregular legal status 
of the migrant, 2) social status of the migrant and 3) trust as a structural feature of domestic work.

\subsection{Development of a niche for migrant domestic work in Poland}

The Polish domestic work sector provides Ukrainian migrant women with certain opportunities. What was the development of migration from Ukraine to the Polish labour market, including migration to the domestic work sector? What is the character of the domestic work sector and why is there a need in Poland for such workers?

Wage differences between countries are an important (although not the exclusive) pull factor for labour migration and, with time, lead to the development of a work niche. To provide some background about the economic disparity between Ukraine and Poland, let me quote some figures. In I993, the real buying power of the GDP per head in Ukraine was 5.2 times lower than that of the EU-I5 and I.8 times lower than Poland's. Between I993 and I996, the real GDP per head in Ukraine fell I.6 times and, by I996, amounted to I2 per cent of the EU average and 30-35 per cent of Poland's (Revenko I997). Ukrainian GDP per capita in 2000 was equal to \$ 639.90, while in Poland it was $\$ \mathrm{I}, 836.00$ (in 2005 , the figures were $\$ 4,456.50$ and $\$ 7,967.70$, respectively). ${ }^{\mathrm{I}}$

In the early I990s, Ukrainians started to engage in cross-border petty trade. Stuck between the socialist legislation and new (but rarely implemented) market regulations, Ukrainians and Poles each responded to discrepancies between supply and demand. These individual responses created a new set of social relations between ethnic groups, neighbouring countries and between producers and consumers (Stola I997). According to border guard statistics, between I990 and I993, 'suitcase importing' was at its peak: approximately 37 million foreigners crossed Poland's border with bags full of goods to sell on the street (Stola I997: 7).

At the time, Ukrainians involved in trade learned to respond to various risks, among them those related to the changing legal regulations. For example, the introduction of customs controls, import and export tariffs, taxation and licensing of traders were major risks to their trading activities. To avoid paying customs while also keeping under the capped value one could carry out of Poland ( $€ 400)$, Ukrainian migrants only brought a small amount of goods over the border. With the introduction of trading licenses in Poland, Ukrainians faced the risk of being blackmailed by those collecting the dues, which would mean having to pay more than the required fee due to their irregular status.

Traders also had to respond to risks resulting from structural economic changes that could influence profits from trade (Wallace I999). Up until 
I992, traders bought goods in Ukraine, brought them over the border and then sold them at Polish bazaars. By I993, prices of goods were higher in Ukraine than Poland due to inflation and economic crisis. The supply of goods decreased, in so doing diminishing opportunities of the known trading arrangements. Wallace (I999: 36) and Stola (I997: II) point to traders' incredibly fast adaptability to the changing circumstances. Ukrainians involved in trade introduced a new strategy: entering Poland to buy goods and reselling them at home or in Poland at a higher price. But selling goods in Poland meant a longer stay in Poland and the need for accommodation.

At the time, Ukrainian traders began to develop ties to Poles - something important for the development of labour migration, including to the domestic work sector. The development of a minimal social niche, some sort of social anchoring, gave the traders a sense of security. Later this would also be an important feature of the risk strategies employed by migrant workers. The economic terms of exchange were cemented by ties of friendship, using the existing business friendships or creating an asymmetrical patron-client relationship (Wallace, Bedezir \& Chmouliar I997: 35). Social capital in trade was characterised by enforceable trust, where moral pressures were upholding economic transactions. Wallace points to the 'trader's dilemma', where a trader risked the obligations towards others outweighing the profits. Still, traders from Eastern European countries did not have to rely on ties to their compatriots to the same extent as some other foreign traders, for example, those from Asia. Wallace claims that the traders' ethnic ties were rather weak, unless they overlapped with family or friend relations. She puts forward the hypothesis that the importance of the ethnic community is dependent on how far one had to travel and how conspicuously 'different' one was from the local population. This hypothesis seems to be valid when looking at the case of Ukrainian traders and migrants. Family networks facilitated particular stages of the trading process such as storage of goods, accommodation, drivers and potential sources of financial and social capital, but it was mainly the family - the household in Ukraine - that had to be supported by the traders and not vice versa (Wallace et al. I997: 33).

Apart from structural political and economic features, the traders also had to respond to risks related to the character of their economic activity. Stola (I997: 27) points to the 'legality layers' of trade as a feature exposing the foreign traders to different degrees of risk. In general, the goods sold by traders were legal, but the actual trading was not. Stola refers to this unregistered and untaxed trade in Poland by migrants from the Eastern European countries as a form of tolerated semi-legality, which also characterised labour migrants, who entered legally but engaged in undeclared work.

Since the introduction of visas for Ukrainians in 2003, the border 
traffic has changed, with fewer people being engaged in petty trade. The structure of the traffic has changed, too, and now more Poles, who do not need visas to enter Ukraine, are shuttle traders instead of Ukrainians. The shrinking role of cross-border traffic has been accompanied by more Ukrainians travelling farther from border agricultural regions in order to work in agriculture and to reach larger cities, mainly Warsaw (IOM 2008: I6).

But what about attitudes of Poles towards the presence of Ukrainians on the Polish labour market? According to an opinion poll from I999 by the Public Opinion Research Centre, more than half of Poles saw the presence of Ukrainian workers in the Polish labour market as negative (CBOS I999b). Interestingly, almost half of the respondents were against a foreigner being a nanny to their child. But, according to an opinion poll from 2002, Poles were either generally or relatively satisfied with the work of Ukrainians (Konieczna 2003: 8). For many Poles, the work relation was their first face-to-face contact with a Ukrainian. By 2006 , only I3 per cent of respondents were of the opinion that foreigners should not have any rights to work in Poland (3I per cent in I999), while 34 per cent claimed that they ought to have the right to undertake every type of work (CBOS 2006). ${ }^{2}$ Over half the respondents claimed that foreigners should earn the same wages as Poles performing the same type of work. It seems that, in the eyes of Poles, work partly legitimised the presence of Ukrainians in Poland.

Turning now to the domestic work sector and reasons for the demand of care work and cleaning, there are three main reasons behind the growing need for home-based elderly care in Poland. Firstly, the Polish population is ageing: since the I980s, Poland has been experiencing a decrease in fertility and a reduction in mortality, especially among elderly men (Perek-Białas, Ruzik \& Vidovicova 2008: 560). In 2004, the share of those aged $6_{5}$ and older in the total population in Poland was I3 per cent (Eurostat 2005). ${ }^{3}$ Population ageing occurs more rapidly in Poland than in old EU member states (but the shares of older age groups are smaller). ${ }^{4}$ In 2003, 60 year olds (living in cities in Mazowieckie Voivodship) were expected to live, on average, I7.89 more years in the case of men and 22.6I more years in the case of women (Stępień 2006: 216). From the point of view of this research, what matters is the fact that large cities, such as Warsaw, are demographically the eldest, with the population being even older here than in rural areas.

Secondly, there is limited state support for underdeveloped institutional elderly care solutions. Having the biggest foreign debt among all of the post-Communist countries, Poland was forced in the I990s to cut its social spending in health care expenditure, which includes financial support for elderly care institutions (Rutkowski I999). 5 The availability of care services is limited and their quality questionable. Although the 
number of medical personnel, especially of nurses, is increasing, it is linked to vocational migration abroad and does not improve the quality of services offered in Poland (Nunckowska \& Perek-Białas 2004: I7). ${ }^{6}$ State institutions and non-governmental organisations fail to provide adequate elderly care. State institutions have insufficient financial means, while non-governmental organisations operate on a rather small scale (PerekBiałas \& Ruzik 2004:36).7 In I999, there were 904 residential care institutions in Poland (providing places for 79,000 persons). Approximately I0,300 people were on waiting lists (Krzyszkowski 2002). Privatising some social care services, such as residential homes for the elderly, meant they became expensive and thus no longer affordable for the majority of those in need (Frątczak 2002: 7). By 200I, there were twenty public and eleven non-public elderly care institutions in Mazowieckie Voivodship (Halik 2002: 158). This amounts to 635 care treatment institutions and 89 nursery care and hospice institutions. All the underdeveloped care institutions in Mazowieckie Voivodship made the demand for private care solutions high.

Thirdly, the elderly prefer to be left to live in their own homes. In I997, 68 per cent of respondents claimed that even if they were unable to care for themselves independently, they would not want to leave their home. Only 6 per cent would prefer to move to a care institution (Frąckiewicz 2002: I8). This negative attitude stems mainly from the Communist legacy of poor-quality services that were provided by care institutions at that time as well as their persisting bad reputation. Polish receivers of domestic care services have little trust in institutional solutions; they prefer to have someone recommended by a trusted informal source. This gives them a sense of privacy and independence, with someone coming regularly to help out and bring meals or being willing to share the apartment with someone who can provide such help. Over half of the respondents (57 per cent) in the Public Opinion Research Centre's research said they preferred to stay in their own apartments and to be occasionally helped by relatives and friends (CBOS 2000).

Home-based child-care was practised in Poland before the political transition in 1989 and continues to the present day. There are various reasons for this state of affairs. First of all, institutional child-care support in Poland is characterised by a declining availability of nurseries and kindergartens. In 2006 , for every I,000 children aged three or younger, 28 were in nurseries in Mazowieckie Voivodship (GUS 2007: 648). As a result of local governments' unwillingness to subsidise nurseries and kindergartens, some institutions were closed down and others introduced user fees. It is important to note that there was little opposition to the closure of nurseries because, during Communism, they were of rather poor quality, tending to be over-crowded and inadequately staffed (Heinen \& Wator 2007: 194). In addition, admission to nurseries is also often 
conditioned by the requirement of both parents being employed. Freemarket solutions are not very common: in 2002, private nurseries 'comprised only 4.7 per cent of all nursery places and by 2005 they had dropped to 3.8 per cent' (Saxonberg \& Szelewa 2007: 359).

Second of all, with the decreasing number of nurseries, a shift from nursery care to parental leave occurred (UNICEF I997: 54). Parental leave, known in Poland as child-care leave, lasts up to 36 months, but has to be used before the child turns four. It can be extended if the child has a disability or chronic illness. ${ }^{8}$ However, by 1997 more than two thirds of women with higher education returned to work early, not using the full parental leave (UNICEF I997: 54). One of the reasons for women's unwillingness to use more time was their professional career. Although women were working on the labour market during Communism, they were rarely in executive positions. After I989, this began to change, with women constituting 32 per cent of all managers and chief executives in Poland in 2006 (European Foundation for the Improvement of Living and Working Conditions 2007: 5, table 3). Even though the number of women using parental leave is declining, parental leave continues to be almost exclusively used by women and care work remains their responsibility. 9

With the state providing little child-care support, Polish women, who did not manage to place their child in a nursery, have two choices: either quit their work or search for private care solutions so as to be able to return to the labour market. When looking for care for their children, they have to rely on their families, depending on non-working or retired relatives, or on the informal market by employing a domestic care worker ${ }^{10}$ According to some authors, Poland, with its declining public provision of care, is characterised by a 'private maternalism', where the market and the family are becoming the primary institutions responsible for welfare provision (Glass \& Fodor 2007: 325). Between I985 and I995, the percentage of women who relied on family help increased from io per cent to approximately 60 per cent. In terms of child-care, the policy changes have increased women's dependence on their husbands or, in general, female relatives. According to Siemienska (2002: I93), a new informal system of care appeared, based on 'an intergenerational resource flow', with nonworking mothers and grandmothers caring for children. However, the context of demand for care workers in Warsaw is peculiar: it is the destination of internal migrants, who leave behind their family support networks, such as grandparents, and it is also dominated by single-person households, far removed from the intergenerational household providing support for family members. The solution for these people is engaging care workers - among them migrants - to complement or replace their care work.

In general, remunerated domestic work in private households belongs 
to the informal sector of the Polish economy, both for Poles and foreigners. ${ }^{\text {II }}$ According to a study on undeclared work in Poland, I,OI9, , ०० households received service from undeclared workers (GUS 2005: table 4.I) in 2004. Of these, 377,000 used the service of cleaners and I95,000 of care workers (elderly care and child-care) (GUS 2005: table 4.3). What is important in this study is the fact that the majority of 485,000 women working in an undeclared fashion did so only one day per month; thus, for Polish women working in this sector it was only an additional source of income. In cities, I7I,000 pensioners used the services of undeclared workers. Households in cities used services of undeclared workers primarily for cleaning and household maintenance (on average four times per week), but also for renovations and care work (GUS 2005:26).

Since the mid-I990s, Ukrainian nationals have been working in the domestic work sector predominantly in an undeclared fashion. In Poland, as in many other countries, domestic work is part of the informal economy. According to the most recent representative household survey carried out in 2007, approximately 80,000 Polish households - that is 6 per cent of all in the country ${ }^{\mathrm{I} 2}$ - employed foreign workers on both regular and irregular bases in the previous two years (Grabowska-Lusińska \& Żylicz 2008). However, migrants generally work for more than one household, which leads to the estimated 40,000-60,000 foreign workers in the domestic work sector.

Taking into account the fact that Mazowieckie Voivodship has a high concentration of immigrants, the discrepancy between the number of work permits given to foreign women and the number of foreign women having registered their temporary stay goes some way to prove that these women undertake work without a permit. In 2006 , I9 per cent of all the permits issued to foreigners in Mazowieckie Voivodship went to women. ${ }^{\mathrm{I3}}$ Only 237 work permits were given to foreigners working in the domestic work sector. ${ }^{14}$ In the same year, 6,292 foreign women who arrived from abroad registered for a stay of more than three months in Mazowieckie Voivodship (Kępińska 2007: table 20). ${ }^{15}$ It seems that the majority of Ukrainian migrants remain in the informal sector of the Polish economy as work permits are not suited to the temporary character of their migration. The requirement of a separate work permit for every employer did not correspond to the flexible employment demands of domestic work, where the migrants had to provide service to a number of clients. Taxes and financial payments related to declared work make the contract financially unattractive for both the worker and the employer. 


\subsection{Risks of undeclared migrant domestic work and related strategies}

Overall, the interviewed migrants evaluated potential negative outcomes of undeclared work as low. Housework and care work were generally perceived as safe and there was little danger of injury. There were no cases of being caught by labour inspectors and being penalised for these types of work. However, the following three issues were mentioned by the interviewed women as risks in relation to the informal work contract in Poland: being without work, being paid below the agreed rate (or not being paid at all) and not being able to rely on health insurance when ill.

\subsubsection{Lack of work}

In general, the Ukrainian women interviewed tried to arrange a job in Poland before leaving Ukraine. They received information from their friends or acquaintances working in Poland, who searched for new workers on behalf of their employers. ${ }^{.6}$ The women's social networks in Ukraine played an important role in 'getting their foot in the door' of the migrant domestic work sector. The quality of the social networks differed. Not all were useful for migration purposes. As Chrystyna, the 50-year-old bookkeeper, said:

When a person comes here to work, she has to have work already. It does not happen that I go and I do not have work here, I do not have a place to live, I go and somehow I find something. No one will help you. [...] And no one will let you stay overnight. Someone goes to someone else, for example, I call a friend, give her an address, give her a contact. She calls there and they meet her there. Well, it's also important to know at least a bit of Polish [...] because this also helps.

Chrystyna points here to a basic element increasing the security of migration: a particular type of social capital. In order to enter the domestic work sector, the migrant needed to have ties to migrants who could provide recommendations or, if trying to find a new job, recommendations from former employers. A recommendation system developed into a migrant institution, which helped to reduce the risks related to an undeclared work environment. Interaction between the potential employer, the migrant and the intermediary occurred when arranging work from Ukraine, as well as when searching for a job after arriving in Poland.

Trust was a necessary element for this process to function. Firstly, the potential employer had to trust the person who recommended the new worker. For example, Chrystyna had worked in Poland as a care worker 
since 2000 and claimed to be a trusted source of information about future employees for her former employers and service receivers.

...yesterday I had a call from this Mr. M., I once took care of his mother. She died already. And he was so grateful to me, well, and he called, [saying] that his friend [...] wants to have the same [care] experience like with me taking care of [his] mother and that he wants me to give him advice. I know him, so I will send a friend of mine there, but what the mother [of his friend] is like I don't know. Is this mother nice or not nice, what will he treat her like? So I am worried about my friend. It was [through] me that they employed her, so then she will complain [to me].

Chrystyna is empowered by the trust of former employers, but also feels responsible for the migrant for whom she has found work. This brings us to the second point: the person searching for work had to trust the intermediary to recommend a job with decent working conditions. To some extent, this allowed migrants to avoid exploitative work relations. However, the person who acted as an informal job intermediary also had to trust the recommended migrant worker not to ruin her reputation as a trustworthy intermediary by meeting the expectations of the employers. Marta, who had already worked in the domestic work niche for three years at the time of the interview, explained it like this:

Someone calls, they say, 'Listen, find me a girl to take care of my mother.' [...] Then of course I do not look for a person who asks me about work, but [I search] for someone who I know is honest and will be working. She can do it slower, but it will be an honest person, so that I will not be ashamed for that person...

Marta knew that when she recommended people who were reliable, she strengthened her own position in the eyes of the employers. The potential migrant had to fit the requirements of the employer: the migrants who acted as intermediaries followed the employers' expectations, thus the employer exerted indirect control over the process. The intermediaries, as seen in Marta's aforementioned quote, had control over the information: they could share it with those whom they believed would fit the requirements, and they were not necessarily those who asked them about work. However, there were also jobs that were easily 'given away' to fellow migrants they did not personally know because of the poor-quality working conditions and lack of usefulness of the employer within the migrant institution.

In some cases, the migrants who were 'established' in the domestic work sector also entered into a type of patron-client relationship with the 
new migrants searching for work. The migrants providing information to a new migrant had a particular interest in keeping the employer satisfied: the employer usually had access to his or her current employer-based network. Another migrant institution used to find work in Poland was the self-organised rotation system. The rotation system consisted of a migrant replacing another migrant domestic worker in her job while the latter returned to Ukraine. It developed as a response to the risks of losing work in Poland versus overstaying. For the majority of the interviewed migrants, rotating every three months was their work routine. But it was also a strategy for new migrants: by replacing another migrant, they could develop ties to yet more migrants as well as Poles and find work and accommodation. The rotation system was used by those who were unwilling to take higher risks related to an illegal stay and those whose migrant capital was not great enough to arrange for a stay longer than the three-month alleged tourist visit.

The rotation system, similar to the recommendation system, required mutual trust between migrants. The character of ties between rotation partners introduces risk in the rotation system. Weak ties involve relationships between acquaintances, while strong ties reflect relationships between close friends and relatives. Weak ties maximise information flows and social mobility opportunities. They require less commitment than strong ties (Granovetter I978). With multiple weak ties to Ukrainian acquaintances, migrants increased their access to information. Information spread mainly via ties to distant friends, migrants met in public spaces (at the bus stop, at a bazaar or in a shopping mall) or while commuting between Poland and Ukraine. Apart from hearing the familiar language, there were non-verbal signs - bodily reference schemes - that allowed the interviewed Ukrainian migrants to recognise other migrants: gold teeth, certain types of clothes and pink gold earrings, a type of gold more commonly found in Ukraine. Weak ties to Poles were also sometimes 'gate openers' to the domestic work sector. For example, Larysa's landlady found her two cleaning jobs in private households through a friend. However, when it came to the rotation system, weak ties increased the risks. Conflicts arose around the self-organised rotation system when employers were more satisfied with the replacement worker than with their usual employee. Chrystyna found work in care while replacing a migrant she did not know personally.

This was through a friend who told me about it ... [a woman] from Ukraine worked there before me, she worked nine months and she was tired, because it is heavy [work] and she wanted a change, well, for a month or two. So this friend called me, and I had already had a rest [after a former job] and wanted a job [...]. So she called me: 'Don't you want to come for an exchange for two months? Here, the 
woman is leaving and you can come.' Well, I agreed, and when I came here, Mrs. M. liked me and she didn't want the other one and she allowed me to stay [laughing]. [...] It was not pleasant, because the other one also wanted to work [...] but it is not my fault.

Chrystyna's story of searching for work via the rotation system refers to the period before the introduction of the visa requirement, because the woman she replaced stayed in Poland nine months and decided to return to Ukraine for 'holidays'. Before the introduction of the visa, the rotation system was less important because migrants were willing to spend most of the time in Poland, returning only for several days to Ukraine to validate their stay. Chrystyna quit her job in Ukraine to be able to migrate to work and she was determined to succeed.

The rotation system showed the complexity of how a migrant institution develops. It was first a response to the risk of losing work that migrants faced if they did not overstay the allowed period and circulated between Poland and Ukraine. Trust was an element of the migrant institution that allowed it to function: the migrant acted within the institution at a distance, over time and space, exerting control over her relations with the employer while staying in Ukraine. However, the rotation partner was also a source of risk, a potential competitor for the job. The employer, who has the power to decide whom to employ, is often unaware of his or her role in the migrant institution. The rotation system thus introduced certain new elements of risk to the migration experience. As Chrystyna's story illustrates, when dealing with a less intimately known rotation partner, the migrant may find herself without work upon returning from Ukraine. Instead of being a work partner, the 'replacement' could turn into competition, taking over the job full time by overstaying or by introducing a different rotation partner. Migrants with limited useful ties and social networks had difficulties finding a trusted rotation replacement.

The quality of jobs received via so-called weak ties was rather poor. Irina, who came to Poland to join her husband and did not have a job arranged, had bad experience with information received via weak ties to migrants.

...I met this T. [...] she was to help me to find work. And she gave me a couple of phone numbers where I should call and search for work. In general, these phone numbers were hopeless [...] [These other jobs] were hopeless because $\mathrm{T}$. gave me phone numbers where they either had someone already, or there was something that I didn't want, because the work was once every two weeks or once a month. And this for me...it was so fragmented. It was unstable. She [T.] had a stable job and later on, when she left, she gave me her work and her sister's work. But this was only for one month, because 
then she came back and took it, although the people wanted me to stay very much. [...] And for a long time I did not have stable work... I didn't manage to save money...

In her story, Irina mentioned three issues: quality of information, the already mentioned conflict in the rotation system and work routine. Regarding the first issue, migrants who knew each other through weak ties often shared information or handed over contacts that were no longer useful to them. These contacts provided access to jobs of poor quality: lower paid or unstable ones, meaning that instead of working every week for the same employers, the migrant worked for them on an ad hoc basis, once a month or once in two weeks. Such jobs did not give the migrants a sense of stability of income. Jobs received through weak ties meant that migrants went through periods of an abundance of work (e.g. before holidays) and lack of work (e.g. during holidays). The development of a stable work routine was mainly dependent on complementing the weak ties to migrants in a patron-client relationship with the employer.

In general, the studied migrant women were able to create a reliable work schedule through ties to employers. Entering a patron-client relationship with Polish employers gave the migrant access to the employer's friends and family as potential new employers, where the former secured a tried and tested standard of employment. To access the employer's resources, migrants displayed helplessness or explicitly asked for help with finding work. This form of subjection was the price the employer provided for the patronage. Using the employers' network guaranteed a certain routine and stability of employment, which was essential for the sense of security felt by the migrant domestic worker in the climate of insecure, undeclared work. In addition, the employer was able to provide the migrant with assistance in the event of health-related, financial or even legal emergencies.

According to the interviewed migrants, the informal employer's trust in the honesty of the migrant, as well as the quality of services provided by the migrant, are two important resources allowing the migrant to keep a job. Larysa claimed that her employers depended on her because of the good-quality cleaning she provided and she thus did not lose her jobs when leaving for Ukraine. In her words: '[T] hey all wait for me, now I've changed jobs a bit, but I always leave for one month [to Ukraine] - and they always wait for me.'

The ties within this migrant institution that allowed the migrant to find work in the domestic work sector were not limited to the strong-weak ties division; the interaction was based on a patron-client relationship. A complex system of protection and recommendation developed in an irregular work environment in an attempt to decrease the risks of exploitative working conditions. 


\subsubsection{Non-payment or underpayment for work}

When analysing the risk of receiving a lower payment or no payment at all, one must keep in mind that the majority of interviewed women had experienced a lack of wages when working in a declared fashion in Ukraine. Compared to the risk of not being paid on the Ukrainian labour market, the migrant women regarded the informal economy in Poland as more predictable in that respect. Still, the women employed various strategies to guarantee being remunerated adequately for their work.

In the domestic sector in Poland an informal wage list existed and both employers and migrants knew how much a migrant domestic worker could earn. This list offered a sort of benchmark that allowed the migrants to evaluate whether they were being paid fairly or being exploited. It gave them grounds on which to negotiate with the employer and it was also a basis for the selection of jobs, eliminating those where the pay failed to reach the expected level. Larysa's story shows how information about the changes in wages in the domestic sector travelled via weak ties.

Later on I met one [woman] on the street, at the Stadion [...]. And they spoke in Ukrainian so I said: 'Hi, girls, what are you doing? How much money do you get?' What, and for how much, you know, this interests me a lot. And I asked about cleaning and at that time I didn't have the same rate - ten zloty [€ 2.5] and I was very upset. When I heard (...) that the girls get ten zloty [per hour], and I still got five (€ I.25), my heart ached and I thought: 'God, why is that so?' [...] Initially, I was very, very upset. Because I thought: 'Why is that so? I work like an ox, from dawn to dusk, this girl earns twice as much and me nothing. I save money, put it away, do something and see nothing. [...] Later on I started to change work. One woman was offended that I left her. But I told her: 'I can't work twelve hours for 50 zloty [€ I2.5] [...].

Exchange of information is of great importance for the reduction of risks related to undeclared work. In contrast to the low quality of information about jobs received via the weak ties mentioned in the previous section, information about the level of payment seemed reliable according to the interviewees. Awareness of being 'underpaid' motivated the women to take action and change jobs. To reduce the risk of not being paid, Ukrainian women also diversified their sources of income by having more than one job. Having more than one job allowed the migrant to leave work with unfavourable conditions as well as minimise the risk of being unemployed. In addition, more than one informal employer was equal to more than one trusted source of information on new jobs. According to the information provided by the interviewees, workplaces recommended 
by those employers who provided satisfactory payment could be expected to offer a decent standard of working conditions. Larysa said that only access to the 'right' employers allowed her to earn PLN Io (€ 2.5) per hour and, at the time of our interview, all her service receivers paid this rate. ${ }^{\mathrm{T}}$

Cleaners were also paid per cleaning session. The wages offered by employers 'per cleaning' were in the range of PLN 35-IO0 (€ 9-25). The earnings in undeclared migrant care work, both for children and elderly, were in the range of PLN 600-I200 (€ I50-300) and PLN 700-I,500 ( $€$ I75-375) per month, respectively. In 2006, the average level of earnings on the Polish labour market was equal to PLN 2,477 (approximately € 620) (GUS 2007: I72, table 3 (99)). ${ }^{18}$ In rare cases, the migrant women were paid at the end of their stay - that is, after three months. The form of payment involved less or more risk. Daily payment or payment for a specified workload involved less risk than being paid on a weekly or even monthly basis. Care workers were usually paid on a monthly basis. Their earnings depended on the difficulty of the case, the financial situation of the employer and his or her willingness to spend money on care.

Many of the women refused to depict their work solely as a 'financial contract'. During the interview, they presented themselves as offering a necessary service. They showed moral superiority over the employer, often a woman, whom they perceived as not being able to perform her household duties. In this way, the migrant women reinforced the pattern of domestic labour as 'women's work'.

The migrant women displayed agency by claiming to evaluate the financial situation of their employers, which gave them a basis to decide what payment they were willing to work for. Lilyana told me that she cleaned for a woman who was raising her son alone. She knew that the woman's financial situation was unstable and, for that reason, did not want to ask for more money. However, Larysa was rationalising her selection of employers in a different way.

Maybe two months ago I left this lady, a very good one, all my ladies are very good. But I will say this. I understand that a person is very good, that they treat you well, but everyone has to understand that I am here to earn something, and not because I want to. I don't want to. I would rather sit at home behind a desk and do nothing [...] this is such a lesson for me now, such hard lesson [...]

Larysa refuses to engage in moral economy, and calculates whether it is in her interest to continue working for a particular employer. Although the 'goodness' of an employer is important in an irregular work situation, Larysa points to the fact that 'all' her employers were 'very good' and so, with that sort of network, she can afford to select jobs that increase her financial security. 
Women who legalised their employment and stayed in Poland for longer than three months faced higher living expenses than those who continued to commute every three months. Being away from Ukraine for most of the year also meant additional expenses at home, such as paying someone for the care of children or parents. Some of the interviewed women with younger children and lack of family support in Ukraine decided to relocate them to Poland, thus increasing their living expenses. At the same time, however, they decreased expenses related to arranging travel documents and a trip to Poland at least twice a year and were able to stay longer, thus maximising their work opportunities.

\subsubsection{Illness and injuries at work}

Undeclared work meant that the interviewed migrants did not have social or health insurance. Nevertheless, cleaning and care work could cause serious health problems. As Zenya remarked:

And, in general, every person takes a risk that when they have an accident or die, then no one will pay one kopieika. There is no social insurance and this is a great risk because, for sure, each one of us goes after a piece of bread [...].

Chrystyna claimed that she nearly died due to health problems during her care work in Poland. She was lifting the cared-for person, who was ill, and she became ill herself as a result.

I carried her, lifted her, sat her down on her potty, carried her from her potty and so on a couple of times per day and something [a gland] broke. [...]. It's a long story, but I won't go into details of what I lived through. In one word, blood was flowing from my inside ...for seventeen hours without stopping...

Two hospitals refused to send an ambulance because Chrystyna was not insured, did not have Polish citizenship and was unable to pay PLN 2,000 ( $€ 500$ ) for the service. Finally, the personnel of one of the hospitals agreed to send an ambulance after hearing that her life was in danger. After having been admitted to the hospital, Chrystyna was not treated because she lacked insurance and had no money to pay for the treatment. She managed to call a migrant friend who was replacing her at the time of her hospitalisation and, through her, asked the elderly person whom she was looking after for help.

Then Mrs. M. [the care charge] called her cousin, and this cousin called the director of the hospital and asked him, she told him her 
last name, her first name and asked them to treat me, give me all that I need, she told them that she would pay [...]. For four days they said 5,000 zloty [approximately $€ \mathrm{I}, 250$ ]. Well, they checked me out [of the hospital], and then this cousin went to the director of the hospital for so-called negotiations, [...] and she explained that the person for whom this woman who was hospitalised works, that she doesn't have money and the Ukrainian woman came here to earn money, so she has even less money [...] because I earn kopieikas here. I would need half a year without food, without sleep to...And no one can pay. So give a sum that is normal, that one could pay - so that the hospital will be satisfied and that she can pay by herself. Not more than, for example, about I,००o [Polish] zloty, not more [...]. Well, so we paid I,200 zloty [€ 300]. That was later on for everything, for medication too, but for the treatment in the hospital it was I,০०० zloty.

As seen in Chrystyna's story, the informal employer or cared-for person can become a form of support in the event of emergency. The migrant woman managed to motivate the cared-for person to use social capital (her cousin) to enable her treatment at the hospital. The cared-for person was also dependent on the good health of her care worker. In addition, the story reveals specific information about the nature of the Polish health care system: informal ties between the cared-for person's cousin, the director of the hospital and further 'negotiations' about the price for the treatment point to a grey zone that allows agency to take shape where there is access to good-quality social capital. This example shows the existence of a particular opportunity structure for irregular migrants in a state that has - from a democratic point of view - weak institutions that tolerate informal arrangements.

In instances of serious health problems, the migrant women returned to Ukraine for treatment. However, receiving fast treatment in Ukraine necessitated bribing the doctors. The informal employers also played an important role in lending money to the migrant for treatment. Receiving such financial support from the employers, although initially positive, may ultimately pose a major risk to the migrant. This is what Olga, whose employer lent her money for an operation in Ukraine, said:

... but, unfortunately, I work there without money and [her employer] does not pay me at all and I asked one day, 'How much money do I owe you? Until when am I supposed to work for nothing?’ And she got so terribly mad and screamed at me: 'You will owe me money until the end of your life!' Well, I say, I understand that I am indebted with my life, because if I had not gone immediately when I got money from her I don't know how this would have ended [...], because I had bleeding inside my stomach. [...] I worked already two 
years [without payment] [...] and I reckoned that I already long ago managed to pay her back with my work, because this is a two-storey house and I worked there every Friday...

In this story, Olga presented herself in a position of subjection, not opposing the increasing demands of unpaid work by those to whom she was indebted. What was played out in her story was a form of emotional blackmail and the resulting labour exploitation. At that time, she was unable to get out of this patron-client relationship because her employer had also supported her on another occasion: she lent her money to fulfil the minimum bank account balance requirement in order to apply for a fixedterm residence permit. In the end, however, Olga left these employers.

Those women who had a fixed-term residence permit through marriage though no work permit were also uninsured and returned to Ukraine in instances of serious health problems.

I went privately [to a doctor] here in Warsaw a couple of times because I was ill a few times and couldn't get to a doctor [in the public health care system] because I did not have a work permit and did not pay taxes. Although I am married now, I still have problems with this because I do not work in a declared fashion [...]. Being insured through the husband is also a problem because you have to get some sort of an identity card or something like that. Well, and I don't have such...[...] such possibility to pressure someone to help me somehow [...] so I have to go home, because if it is something more serious I have to go home, because here it is very difficult and expensive.

In Ukraine, although unemployed, the migrant women still were able to use the public health care service. However, in general, they had to bribe for treatments. Still, the expenses were much lower than in Poland.

Some of the migrant women's employers were doctors, so if ill they asked them for informal advice and even got health check-ups. This was the case with Marta. At the time of our interview, she already had a work permit and was insured, but she recalled how she had relied on her employers in the past.

...I worked for some doctors and I asked them when I had problems, when I wasn't feeling too well and they helped me [...]. They helped to do some check-ups [...] They helped me to do this, to what extent it was legal or illegal, I didn't think about it, didn't think that it was something so extraordinary. I paid for some check-ups [...], for some, I didn't. They arranged it somehow, insurance and well, I don't know what the problem was, I felt terrible, was ill, I was weak, then it came out that I have a weak immunity system. They said it is possibly 
related to Chernobyl [the nuclear plant explosion], but I couldn't do such check-ups in my village...in the end, thanks to those check-ups I at least know what defects I have [...].

However, Marta, who was in her thirties, was rather an exception when it came to the health problems mentioned by the younger part of the interviewees. In general, the older the women were, the higher they perceived the risk of their health problems.

During the interviews, other migrants mentioned health risks they were exposed to while cleaning. As Zenya commented on her job:

This is very dangerous. You can [...] fall out the window when you clean windows [...]. No one will be responsible for you, you have no insurance here. This is the most dangerous thing there is, the 'weak spot' for us Ukrainians, because when something happens then you are the first to lose out and you not only get old illnesses, but new ones as well. Because you do the same work every day, for example, with those chemical detergents one has allergies, oh, on the skin and in the lungs, and for the whole [body] it is destructive [...].

This excerpt highlights the notion of self-responsibility in facing the consequences of risk during migrant domestic work that accompanies Ukrainians' lack of legal and social protection in Poland. Some of the women refused to return to work for employers who lived on higher floors and expected them to clean their windows.

Apart from extreme life-threatening situations, the women also had accidents that rendered them unfit for work; inability to work was prolonged due to lack of proper treatment. Larysa, who hurt her knee while cleaning, did not see a doctor in Poland. As she recalls:

...You know what the costs are. I went to the landlady, where I live and showed [it to her]. [...] So she gave me some ointment to put on it. I put it on, but it was still had one month before I could go home. When I got home, the knee hurt and hurt, for half a year it hurt and hurt. I went to a doctor [...] in Ukraine. It's also very expensive there... Here you work hard for your money and then give it away to a doctor...

\subsection{Risks of labour exploitation and social marginalisation and their related strategies}

One could argue that Ukrainian women working in an undeclared fashion in the domestic work sector in Poland face similar risks to Polish women 
also working in there, for example, the risk of non-payment. However, migrant domestic workers differ from Polish women in terms of possibilities to balance such risk, due to their particular legal and social status in Poland. As a result, they also face other types of risks than Polish women. There are five main reasons that migrant domestic workers are more at risk than native workers.

First of all, the migrant women often depend on the employer for their migration status, as was analysed in section 5.3.2. The employer facilitates the migrants' entry and stay. He or she can influence the degree of irregularity of the migrants' status. This gives them a particular power over the migrants, which they may abuse. As Marijka said:

...one person will understand you well, the fact that you came here to earn money, she sees that you are trying and she appreciates your work. And there are people who will [treat] you like 'Hey, you Ukrainian! You can work, but we can even refuse to pay you, because you are Ukrainian.'

The majority of the interviewed migrant women treated domestic work as a temporary remedy, even though for many it had been the main source of income for several years, thus making them very dependent on their migrant job.

Second, the migrant women have, at least initially, a very limited social network in Poland. Such social networks provide information about jobs, as was discussed section 6.2.I. To make their migration worthwhile, the migrant women had to find work quickly after their arrival. It often meant that they initially had to accept very poor (if not exploitative) working conditions.

Third, a sensation of temporariness due to both their unstable legal status and weak, if not lacking, social anchoring was present during their migratory experience. An example of this is found in 35-year-old Ulyana's story. She had been working in Warsaw for the past three years at the time of our interview, cleaning and caring for her employer's child. As she said:

[...] And I really had this feeling that I am not needed, that I was a 'thrown-out' person. But this passed; now I have some friends. But... there continues to be such a sensation of instability here. Everything is temporary. It is all temporary. It's just that I have to survive and my home is waiting for me. I already can 'smell' my home, seriously.

Fourth, the migrant women are usually qualified workers, with secondary education and some with even higher. Working in a job below their qualifications places them, in the long term, at risk of deskilling.

Fifth, as qualified workers in Ukraine they were used to having jobs 
with a higher status than that attached to domestic work. They were thus affected by the risk of decreased social status should they stay longer than what was foreseen in a job of temporary migration. Due to these factors, the migrant domestic workers were in a precarious status, which placed them at risk for labour exploitation and social marginalisation, among other things.

Insecurity stemming from the precarious legal and social status made the potential benefits stemming from the relationship with the employer especially important for the migrant. As Tarkowski wrote (I994: 88), the patron-client relationship is a mechanism to adapt and protect oneself from the sensation of vulnerability and constant threat due to weak legal, economic or political guarantees of security. The development of personal ties between the migrant and the employer helped partly neutralise arbitrary decisions and produced a higher degree of predictability as well as a sense of being more in control.

The degree of trust involved in domestic work placed the work relationship somewhere between familiarisation and depersonalisation. By familiarisation I refer to the development of a personal relationship and display of familial interest between the migrant and the employer or the caredfor person. Depersonalisation is understood as a lack of emotional involvement and keeping a social and spatial distance between the migrant and the employer or the cared-for person. The more mutual trust in the relationship, the closer the migrant and the employer are to the familiarisation end of spectrum; the less mutual trust, the closer they are to depersonalised work relations. These types of relationships are not mutually exclusive. They were often used interchangeably by migrants when working for different employers, depending on the context of the interaction.

\subsubsection{Living-in: Context of the risk of labour exploitation and social exclusion}

The migrant's status within the household (living-in or living-out) influenced the degree of exposure to risk of exploitation. Availability is one of the basic features of care work, thus the majority of the interviewed care workers were living with the cared-for person. A care worker had to be available to intervene as needed. However, the continuous presence of the migrant in the household increased the demands of the employers or cared-for persons, diverging from the working conditions and remuneration that were earlier agreed upon. When the migrant was living with an employer, boundaries between her and the employer's family blurred. The migrant became part of their life.

The demands and expectations of the employer severely limited time off work in the cases of several interviewed migrants. The interviewed livein migrant domestic workers were generally not allowed to leave and return to the household however they pleased. Having to ask for permission to 
leave the home, being asked how long she would be away and being checked up on when outside the home was constraining for an adult who was not a family member. As Irina said:

Officially, I had days off...I had those days off but, as I said, those days somehow got entangled into their life, that in the end...these were not my free days. I remember, at the beginning it was terrible, then I didn't know that it was terrible, only now I understand this. For example, on Saturday, I remember, I asked for permission to go shopping. I asked for their permission. Of course they told me: 'Yes, but when will you be back?' Only now do I realise this...Also, when I went shopping they ...I would forget about everything and...a phone call: 'Why aren't you back yet?'

This interview excerpt points to the psychologically strenuous part of being a living-in care worker whose personal space and time are very limited. The live-in care worker Ludmila had a similar experience. When she left the apartment on her day off, the cared-for person, as she put it 'was very displeased that I didn't tell her when I will come back'.

The importance of having time off from work was also stressed by migrants giving elderly care. Forty-eight-year-old Zenya, who worked as a cleaner at the time of our interview though had prior been a care worker, said the following about living-in:

Well, you have to watch out how they treat you financially [...] And, when - that is already from my own experience [...] - you have to defend your [rights], so that even when you are in a living-in job, you must have one or two hours per day to go out [...] because it is psychologically very hard, because a person toils there and has to have some rest somewhere with her thoughts, somewhere on the street or where one will find [a place], in the shop or somewhere one likes. So that's what I could recommend to someone, to warn those [people], that they [the employers] can say, 'Don't go anywhere', and you have to stay.

It is to be remembered that free time was essential for migrants to build up their social capital and find out about different jobs and working conditions from other migrants. The living-in migrants I interviewed were isolated from people other than their employer and his or her family. They had little chance to meet other migrants, to develop ties, to create their own network or to exchange information on their working conditions. This isolation limited the migrant's opportunities to find new employment, so as to leave an unfavourable working environment. They tended to rely on very few weak social ties. Apart from the employer, they had no or very few 
contacts with Poles. They retrieved news only during their occasional shopping excursions to the bazaar and during social gatherings for one or two hours on Sundays with other migrants who lived in close proximity. The circulation of migrants also meant that social connections with other migrants could be tenuous, as people frequently returned to Ukraine.

One of the options for women who did cleaning jobs was also to find accommodation in exchange for cleaning or providing companionship to an elderly person. However, this also included the risk of increasing dependency and additional, unpaid workload. According to Nina, the retired 57year-old trade specialist who worked as a cleaner in Warsaw and lived with an elderly lady whose apartment she also cleaned in exchange for a room:

...I do not [have any] rest, do not rest. If I manage to open the visa again or to prolong the visa and enter, I do not want a free [of charge] apartment anymore. I am very tired: this is a house [where she lives now], there are two floors to clean, you need to cut the grass in the yard [...] and the woman wants me to give her some of my attention, because she is old [...]

Since apartments in Poland tend to be small, live-in migrants often lacked their own living spaces. ${ }^{\text {I9 }}$ On the one hand, this could mean more egalitarian relations in the household. On the other hand, it could mean more pressure on the migrant to become 'invisible'. Svietlana lived in the common room of her employers for two years.

...I do not have my own room, because the apartment there is not big. It is simply not a big apartment, there is a big hall and there, for example, like here [in the apartment where the interview took place], there is the kitchen and right away the room [the kitchen combined with the living room], it is also like that. And there I have my bed. And the mom with her children, she has also two bedrooms on the second floor, also small ones. So it is all quite small and problematic and we suffer and we are all together.

Later on, Svietlana mentioned that because she did not have her own room she was forced to witness all of the family's conversations and quarrels. She commented that she sometimes felt reduced to an object, a piece of furniture, because the employers did not feel embarrassed to argue in front of her.

\subsubsection{How familiarisation can lead to labour exploitation}

All the women stressed that a good rapport with the employer was essential for the work relationship to function. To the migrants, an 
emotional tie meant that in an irregular work environment, without an official contract, the employer seemed more trustworthy and predictable in his or her behaviour. As Nadya said:

The most important thing [in the migration experience] is the person with whom I work [...], what the family is like where you are going to work. Well, so that they are... well... a bit nicer, docile [...] so that, you know, you can get on with them, just get on with them.

According to the migrants, both they themselves and their employers tended to familiarise the work relationship. The majority of the interviewed migrant women claimed to be treated 'like family members' by the employers. As Ulyana said about her work-relationship: 'So now I am also taking care of this boy. It is very good there, I cannot complain. Because they treat me like a family member.' A similar case was that of Marijka, who initially cared for a small girl for two years and, at the time of our interview, was the nanny of a small boy: 'I lived there with them, I worked. Well, I was "theirs", simply like a member of the family, I was part of it.' What Marijka described was a form of 'inclusion' through friendly relations (but also through subordination) with the children and the children's mother. Familiarising the domestic worker was, among other things, a strategy of the employer to mask their domination in the household. The employers attempted to - in what Scott (I990) refers to as the public transcript - adjust their power, treating the migrant as supposedly an 'equal', although aware of the migrant's subordinate position.

The employer and the migrant engage in familiarisation for particular interests. For the migrant, a familiar relation with the employer means higher predictability of working conditions (payment, workload, etc.). This proved to be an important source of migration social capital, resulting in access to privileged information (e.g. about new jobs), housing, opportunities to borrow money and protection when needed. All this leads to reducing risks of irregularity and labour exploitation. For the employer, an interest to familiarise the migrant falls on a spectrum: from simply having a reliable, trusted worker to friendliness and familiar interest in the employer's life (though this often results in additional, unpaid work). Through familiarisation, the two parties involved in the patron-client like relationship hide their particular interests and instead behave as though rendering each other favours. The purpose and function of giving someone a gift in this type of relationship has to be concealed (Tarkowski 1994: 48). In some cases, familiarisation made the employer more sensitive to the migrant's or her family's needs; in others, it meant pressure on the migrant to put the care needs of her own family aside in favour of that of the employer's. Friendliness towards the employer is generally the result of the employer's domination, as Hochschild (in Scott 
I990) wrote on power relations between people of different status:

[T] o have higher status is to have a stronger claim to rewards, including emotional rewards. It is also to have greater access to the means of enforcing claims. The deferential behaviour of servants and women - the encouraging smiles, the attentive listening, the appreciative laughter, the comments of affirmation, admiration, or concern - comes to seem normal, even built into personality rather than inherent in the kinds of exchange that low-status people commonly enter into.

The motivation behind offering access to social capital can be instrumental when reciprocity is expected. By helping the migrant, the employer holds a form of power over her or him. But the migrant is unable to return the favour due to a lower social and economic status. The migrant is initially in an unfamiliar environment, lacking migration experience, and the employer is an influential position vis-à -vis the migrant. One could assume that in the early stages of the work relationship, the employer set out particular rules, most of which were accepted by the inexperienced migrant. The employer accepted the migrant domestic worker's submissiveness as a norm and tried to 'gain' the most from his or her work. This places the migrant at risk of labour exploitation. This phenomenon is visible in the story of Irina, the 30-year-old migrant from Lviv who worked as a live-in nanny for a small boy in the suburbs of Warsaw. Her employers were owners of a family business and they tried to 'include' Irina into the family. However, as she noted:

A foreigner, who comes for the first time to a country, goes for the first time to work, is not familiar with this and, as a rule, agrees to everything: 'Yes, I will do', 'Yes, of course', 'Yes, I have time', and later, when at some moment he realises that he wants to do something for himself, he wants to have some private time, somehow and sometimes refuses to come during the weekend to [work for] someone, then there is great offence, great unhappiness [on the side of the employers]. And sometimes there is such exploitation for small payment and it is not worth it. And then it [the additional chore] turns into a duty.

Interestingly, Irina pointed to the subtleties of power relations and justified her employers' behaviour: 'No one dictated anything. It was, you know, they were as they were, but the problem was they would ask whether I could [do some additional work] and I was stupid for I always agreed to everything.' Irina's submissiveness was related to her dependence on the employers. Firstly, she was dependent on accommodation, living with the 
employers. Secondly, she needed to earn money, having recently divorced her husband and wanting to support her child, who was left in Ukraine in the care of her parents. Thirdly, at that time she had a limited social network in Poland. She was initially not aware that by accepting the increasing workloads she placed the aim of her migration at risk. Clearly, the weaker the position of the migrant, the higher the dependency on one employer and the higher the risk of labour exploitation.

It was the employer who was the consumer of services, the one who demanded, set the rules and decided when the work of the migrant started and when it ended. The lack of clearly defined tasks in domestic work gave the employer more freedom to judge the migrant's work as not completed or not carried out well enough. During the interview, Irina described the increasing expectations of the employers.

At that time, they paid me one thousand zloty [per month] [approximately $€ 250$ ] and I was available from early morning, I ironed, cleaned, washed the windows, the bathrooms....and cooked for the child on their terms. Also the grandma praised me a lot, saying that I am the only one who can cook for the child, and so ...The child was taken care of with all his medications, and the house and the child were very well taken care of. Everything was always washed and ironed. That's just the way I am, I don't feel well in a house when there is disorder. And it was always like that [...], you see they had catering, then there were sometimes a lot of dirty dishes and a lot of dirty and clean table-cloths to separate, so this was additional work. And sometimes they were angry that I was not following an educational programme with the child, because I could have done it. But when was I supposed to do it? When? I also did their shopping, I had this on my shoulders, so when?

Irina's lack of control over her workload was an example of how living conditions affected working conditions. As a live-in worker, Irina was constantly 'available' to the employer's demands, thus continuously on duty. By living-in, she initially did not feel in a position to oppose the employer's increasing demands. However, Irina made attempts to empower herself: during our interview, she claimed that she did set some of the standards of cleaning and care. With growing experience, the migrant introduced her own work standards, in terms of how she fulfilled the tasks. Having solidified her work position, she was also able to reject some of the additional new chores.

One of the strategies the interviewed women used in order to improve the working conditions was to shift from living-in to living-out. Living-out meant having more control over one's work hours than when one lived with the employer. This is what Marijka said comparing the conditions of 
living with the employer and on her own:

It's better psychologically, much better [...] [to live-out]...that you are not under [someone's] supervision, that you are not... that [when living with the employer] you have no control over yourself, that... $[\ldots]$ there is someone above you, that you do not have the right [to go] anywhere you want to, this and that. And so [when living independently] I went to work when I wanted, went here or to my home, or someplace for shopping or simply to sit in the park or something else, or I met the girls, because my sister and a friend are here, one, two [friends]. So I have someone to meet and to talk with. So, it was nice, we met on Sunday, went to the old town, took photos, we were together. That is great, nice, relaxing.

The cyclical character of migration meant having to return to Ukraine for a particular period and also gave the migrant a chance to reflect upon his or her situation in a safe, familiar setting. While she was in Ukraine, Irina decided to change her working conditions and, after returning to Poland, moved out of her employers' home. The employers were eager to continue employing Irina because she was a good care worker and they were dependent on her services. In this way, Irina gained control over her work and life. Her trustworthiness and quality of work empowered her to improve her working conditions, changing the relationship with the employers. The employers clearly defined her duties, gave her a higher wage and asked her to stay with their son overnight from time to time when they had to work late in the evening. The following quote by Irina illustrated this change.

I knew that it is only today and tomorrow and then I leave. They [the employers] were away. I was alone with K. [child]. But there were no other duties, as in the past, only K. and preparing food for him. Only some ironing... if I had some [extra] time. It was a completely changed relationship. In the end we became friends because they got very used to me and I got used to them.

Another strategy used by migrants was to actively familiarise their employers. This was visible in the story of Marta. At the time of our interview, she was working in a Warsaw suburb as a cleaner and care worker for a person with a mental disability. This person's mother was, according to Marta, 'simply like a mother'. As she recalled:

And even when I leave for some time and I am at a friend's place, I am not there [at the workplace], but if something [happens], I call Mrs. M., right away, immediately, like a mom. She will manage 
everything, she will tell me what is right, and what is not, how to behave, what to say even...I am telling you, I just felt immediately at home, like in a family.

Marta took a proactive role and, instead of being familiarised by the employer, she familiarised her employer. Marta did not live with the caredfor person, which gave her more privacy, freedom and control over her work. Marta's relationship with her employers was based on trust; she cared well for the disabled person and the employers did not have to explicitly instruct her about her work. As she stressed, she did not have a fixed schedule and was not obliged to assist the cared-for person all the time; she simply had to be available when her employers called. Their work relations were flexible.

Still, there was an asymmetry of power visible in how Marta described asking her employer for advice and the employer telling her how to behave and 'what to say' in given situations. The employer was the knowledgeable woman, while the migrant woman was the one in need of assistance. This asymmetry was also partly related to the age difference between the women. Marta used the unequal power relations between the employer and herself to gain information and protection. It can be assumed that by accepting this familiarisation and providing Marta with social capital, the employer had more trust that her disabled son would be well cared for.

In general, the migrant women treated domestic work as the activity of every woman, thus recreating dominant gender relations. When asked about the good and bad sides of domestic work, Marta said:

There are no bad sides [to this work] because what I do...what every woman in the household does. When I am home, there are dishes in the sink, I will normally wash them or clean, but there is no one standing next to me saying: 'You have to do this.' So I say, all this...I cook dinner with pleasure, because I like to cook...

Marta not only familiarised her employers, but also saw herself as a helper and as a friend to everyone: 'I was mostly happy that I can come here and that, in that sense, I can ... to help someone mainly, and because, I feel good here.'

Marta used the so-called 'help' discourse, present also among other interviewed migrant women, empowering herself by claiming to be helping others. The word 'help' hid the work aspect of the migrant's activity, while at the same time allowing her to cement her position vis-à-vis the employers or cared-for persons. The interviewed women spoke of the latter as 'needing' their help. They showed themselves as 'the last hope' for the elderly whom they took care of and whose own children did not give them assistance. They also portrayed themselves as better nurturers 
of children than Polish mothers. For many of the interviewed migrants, this emotional engagement and helping attitude took place in the context of guilt due to their absence from their own care responsibilities in Ukraine. But this was not the case with Marta, who did not have children. Marta's life was now based in Poland. She liked the anonymity of living in a city, as compared to the curiosity of neighbours in her small hometown. She liked the freedom and autonomy that being in Poland gave her. She built up her network by familiarising her employers. Marta described the situation as follows:

...someone calls and says, for example, 'Maybe you could come to my...', for example, 'My friend's mom lives alone, so maybe you can come and help and clean the windows.' And apart from that, some people even want company, for the whole day. When she sits alone in a three-bedroom apartment for a whole day, this grandma, well then...She simply wants someone to visit. So even with those whom I have contact with here, so very close, they know me well and even when we meet once in half a year, we have half a day or a whole day to discuss what is going on at home, how is my mom, what my mom [is doing]. So I am friends with a lot of people.

By referring to employers as 'friends', Marta made the work relation 'invisible'. She saw the relationship with the employers less as a financial investment and more as a social one. The employers responded to her friendliness by showing interest in her personal and family life. Building up relationships with Polish employers - a form of migration social capital - was Marta's strategy not only to respond to the potential risks of migration, but also to gain from those relations. This was visible in how she attended to her health problems by getting help from employers who were doctors and how one of her employers paid for her to finish a beautician course in Poland, so that she would be able to leave the domestic work sector.

\subsubsection{Depersonalised work relations}

In some cases the migrant women were unable to create a personal tie to the employer. Depersonalisation of the work relationship was presented by the migrant women as the creation of distance by the employer: both spatial (in regard to household and personal space) and symbolic (in terms of limiting rights). According to the interviewed women, such depersonalised work relations placed them at risk of being exploited at work and insulted their dignity. Depersonalisation of a work relationship may be an attempt to make it more 'professional'. But it may also result in intensification of work, making it more 'time efficient' and cheaper (Aronson \& 
Neysmith 1996). Often, pressure from the employer to be more efficient was related to the method of payment. When the migrant was paid on an hourly basis, it was in the employer's interest to set a time limit within which the cleaning was to be done.

In cases of depersonalised work relations, the services the domestic worker provided and the work's efficiency and quality were all that mattered to the employers. This was the only justification for his or her presence in the household. However, it meant less predictability and control over the work relationship on the side of the migrant. Depersonalised work relations were visible in the case of care workers who built the emotional tie with the cared-for person and not with the actual employer, even though it was they who nevertheless decided on the workload, the payment or, as in the case below, the continuation of employment. With emotional separation between the migrant and the employer, it seemed easier for the employer to reduce the migrant to a simply replaceable service. Chrystyna shared the story of a friend who wanted to leave earlier for Ukraine during her last stay in Poland because of health problems. She told her employer - the daughter of the elderly couple she had been taking care of - about her plans to leave.

This daughter behaved like that: in the house, instead of saying, 'Thank you very much, that you have helped my parents for so many years, respected them, were good to them, friendly, thank you. Well, too bad, you also have your problems,' she said the following: 'What do you imagine?! Since you came here, I always have had problems with you. I can have several [caregivers] such as you for one zloty!'

According to Chrystyna, in this extreme instance the employer - without warning - ended up firing someone who had worked for her for four years. The employer did not acknowledge the woman's personal qualities, her trustworthiness, emotional involvement and the care she provided her parents. These characteristics are usually the 'gambling card' migrants use to stabilise and/or improve their informal working conditions.

Working for several employers as a cleaner, Larysa, complained about instances when an employer decided to check the quality of her work.

...It was very unpleasant for me...I couldn't...this was a humiliation for me. I always did - that means, when there were four doors - the upper landing, of those four doors and simply I forgot to clean one of them. You know, it is not that I didn't want to [clean it], but you know how it is, I am human, I am not a machine [...]...I thought: 'Well, I will clean it immediately,' and something else happened and I forgot. So the husband of this woman came and checked the whole house. This was very strange for me that it was him and not her who 
went [to check], and later on it was just terribly sad. And she was coming all the time, was checking whether I just sit and do nothing. But I do not have such habits, even when I am alone at home I do not have the habit of sitting. I just simply work at a regular pace. I just got used to it, although it was difficult at the beginning [...].

Her employer's intrusive work checks made Larysa feel that she was mitrusted as a person and suspected of working inadequately and thus dishonestly. The fact that the household's husband, a man (who, in her opinion, did not know much about cleaning), checked on the quality of her work felt humiliating. This meant that Larysa accepted the idea of domestic work as 'women's work'.

Some of the migrant women adopted a 'professional' attitude in response to depersonalised work relations. Larysa, who resented the employer's impersonal treatment, adopted such a strategy of emotional detachment, which reflected what she had experienced.

I am not afraid of this. I am already...[...] you know what I mean, I was in different jobs. I even was in such a job where a woman was standing in the door, leaned against them and I worked, and she was standing and watching. So I said, 'I am sorry, but maybe [...] you will not look at my hands...' Because now I no longer pay attention, I just work and that's it. But then, at the beginning, my hands were trembling when someone was looking at me like that, I could not work. Now I don't pay any attention. One time I said: 'I am sorry, but maybe you will not watch me like that, you will come and check later. I am not afraid, you can come and check.' But she didn't understand this, so let her stand if her feet don't hurt...

During the interview, Larysa is ridiculing the behaviour of the Polish woman. The treatment she received was followed by an act of resistance: although the employer expected her to return, she refused to do so. At the same time, she worked for employers with whom she entered into a 'professional' relationship based on her reputation as a trustworthy worker.

There are many such [people] for whom I have worked, for two, three years, sometimes longer. They are pleased that I work and they all want me [...]: 'You know everything, I don't have to tell you anything, just come.' [...] I have somewhere I have already been five years, five years, in July it will be five years.

The migrant women tried to find a balance between a personalised knowledge of their employers while, at the same time, not becoming too 
familiar with them. Depending on the degree of trust, the migrants modified the strategy, in some instances creating more distance and in others becoming more familiar with the employer. To 'professionalise' their work relationship, the migrant women had to have a longer migration experience together with what it entailed: living independently of the employer and having developed a reputation for reliability and efficiency among employers.

When dissatisfied with the working conditions, some of the migrants decided to leave employers. Leaving work involved changing from live-in to live-out arrangements. Marijka, who worked as a care worker, initially as a live-in, moved out and stressed during the interview how that gave her new options.

When the work is not good and it doesn't suit me, I don't have to be there. Because I can find something else, I can be for some time without work, when there is somewhere to live. This is most important, to have somewhere to live.

The relationship with the employer, as already mentioned, was not solely or primarily built on monetary exchange, but also on the migrant counting on the employer as a source of social capital. The development of a work routine through socially rooted informal strategies is an important response to the risks related to instability of work status during irregular migration. This was possible only in long-lasting relationships. When changing jobs, the migrant had to start the process of building her reputation from the beginning. Leaving the job also meant not getting recommended for further employment and losing access to the employer's social network. Switching employers meant lack or change of a work routine and was regarded as a risk by some migrants. For that reason, those migrant women who had more than one employer could more easily exit unfavourable working conditions.

Selecting jobs, however, is important. This is what Olga said about her employers (she had already worked for seven years as a cleaner in Warsaw): 'I choose the better ones, who really treat me well and help.' Switching jobs allowed migrants to improve their working conditions.

The behaviour of the employers, who felt, as one of the migrant women claimed, 'offended' when left by a domestic worker, showed how they assumed that the person with the higher social position should decide whether the relationship would or would not be created and when it should end. The pattern of power relations was challenged the moment the migrant displayed agency. Face-to-face criticism may have had very negative consequences for the domestic worker. Using alibis and lies, claiming that one has to leave for Ukraine, giving signs of dissatisfaction such as 'getting ill' were ways to avoid leaving work directly. As 
Hondagneu-Sotello (2003a: 65) wrote:

A domestic employee who tells her employer that she is leaving because she has a better job prospect or because she was dissatisfied with her job may be accused of betrayal and disloyalty. She may be accused of theft, justly or unjustly. She may fear that the former employer will call the immigration authorities in retaliation. Or she may fear that by quitting verbally, she will ignite the flame of unpleasant verbal encounter...

\subsubsection{Declining social status}

Domestic work is a job of little social prestige, thus providing the migrant with a low occupational status. The interviewed migrant women, although only temporary migrants, were unable fully to disassociate their social status from their work in Poland. ${ }^{20}$ Through care work and domestic chores provided for their families at home, the women, sustained their status as mothers and wives. Now, through remunerated domestic work, they affirmed someone else's status - that of the employer. At the same time, however, there was financial opportunity, leading to an increased social status in Ukraine. ${ }^{2 \mathrm{I}}$ In addition, some of the migrant women whom I interviewed had a university education and the majority had secondary education. Most had many years of work experience and were skilled employees. With migration, domestic work became their main source of income. The risks related to domestic work at first glance seemed obvious: loss of skills, no possibility of upward mobility in the Polish labour market and an overall decline in social status. Chrystyna had been working as a bookkeeper in Ukraine and now works as a care worker and cleaner in Warsaw. As she describes it: 'A so-called sprzataczka [cleaning lady in Polish] - that's what they call us here - degrading it is, I would say [laughs]'. The higher the educational level and the more years of work experience, the more the women reflected upon their decline in social status.

The fact that domestic work is a job of low social prestige led to the migrant women experiencing something that Goffman referred to as nonperson treatment. This means that the person's presence is not acknowledged as socially significant and therefore requires no effort by the person to impress those in his or her presence. ${ }^{22}$ The non-person treatment signifies 'social invisibility' ascribed to certain people. An example of such treatment was the behaviour towards slaves and servants in the past; today children, very old and ill people experience this sort of treatment (Goffman I967: 208). So, too, do domestic workers, as Chrystyna noted when discussing the way her employer treated her: like 'a machine'.

As was already mentioned, migrant women who came to Poland for 
the first time were in a difficult financial situation and had a limited social network. This increased the probability of their accepting jobs with exploitative conditions. During our interview, Chrystyna returned several times to memories of the Polish woman who was her 'manager' in her first migrant job (a live-in care worker looking after the employer's eight children). ${ }^{23}$

You couldn't just sit down simply and eat. Because if only you sat down, she came straightaway. She didn't ask: 'Why are you sitting here?' She gave you work right away and you had to do this work immediately. That means [...] there was no time to eat.

Chrystyna claimed she had lost fifteen kilograms during her three-monthlong stay there. In her view, she was not treated as a person with particular needs, but as a service, a function. The employer considered the migrant's wants as an excuse for not working. Chrystyna's 'manager' did not allow her to react to the insubordination of the children, who were under Chrystyna's supervision, but she was held responsible for the outcome of their disobedience.

[W] hen I woke up every morning at five, I had to get up at five, go to every child, wake him or her up, and the child didn't wake up because they ignored me [...]. They woke up when it was already daylight and I felt the results: 'Why is the child not awake?' [said in Polish, impersonating the Polish woman]. And what about me.., I guess I am to be blamed, because I woke them up, what do they [the children] care, right?

Chrystyna responded to this depersonalised, functional treatment by criticising her Polish 'manager' for having raised her children badly. Chrystyna reached for the power of the 'powerless' - she claimed moral superiority. During the interview, she acted out her hidden transcript, letting out the emotions she had to control in front of her employer.

For the women, it was difficult to accept the role of a servant who plays no social role in their family, as some other migrants had experienced, apart from providing services. Chrystyna shared a story about a friend who used to work near Warsaw.

[...] Well, this Holy Evening [Christmas] she was in the kitchen alone, no one invited her to sit at the table. Can you imagine?! [...] And this person who works there, who washes their underwear, who washes, gives them food, who serves food, takes care of the dog, cleans every corner, because this Polish woman never lifts a finger around the house - she can't do anything, certainly. Maybe I talk harshly, but 
do I make myself clear? [...] And she called me and she was crying and said: 'Chrystyna, I am lucky that there were doors to the kitchen, that I could close them, because my heart was breaking.' They were eating, feasting all the Holy Evening. I am telling you, [Pope] John Paul hanging on every wall! No one would allow that [not inviting someone to Christmas dinner] to happen [in Ukraine]. Have a piece of bread, come, the poor ones, I would share this piece of bread with you. But this wealthy family, who can afford to employ a care worker but cannot give her food, cannot seat her at the table.

Chrystyna used this story to vent her frustrations. In her interview, she confronted the Polish employers by negatively evaluating their family responsibilities, religiosity and morals, clearly contrasting them with those of Ukrainians. The Polish woman was judged as failing in her role as wife and mother. Ridiculing the employer is a form of resistance to domination (Scott I990). During the interview, Chrystyna acted out the reciprocal aggression denied by the presence of the employer.

The migrant women did not remain passive in the face of risking loss of social status. In the patron-client relationship, the client increased her own status by being close to persons with a higher social standing (Tarkowski I994: 55). Through the familiarisation of the relationship to Poles - be it the cared-for person, the employer or the landlord, who had a relatively higher social status than the migrants - the interviewed women attempted to change the meaning of their own status in Poland. Some of the interviewed migrants stressed this during the interviews, particularly in the way they presented their employers, as well as other Poles. Irina, an engineer working in Warsaw in child-care, commented on the qualities and status of people from whom she managed to rent accommodation.

Mrs. B [the employer and landlady]... her husband was a professor, connoisseur of fine arts, who died..., he is very well known in Poland and [...] she was very religious [...]. And she was also very educated and somehow very eccentric. I remember [...] she would come from church and she would play classical [music], Bach or Vivaldi at full blast and read a book in French, a love story, or in German, because she knew it perfectly $[\ldots]$

Although Irina's husband was doing renovations for this woman, he and the woman were presented by Irina during the interview as sort of equals. Similarly, Irina underlined the qualities of her other landlady: 'this was really interesting, she was wise, very wise, she knew about bookkeeping, mathematics, history...such a down-to-earth woman'.

Zenya, who also came from a background of higher education, underscored the special emotional attachment she had for her care charge. 
A very interesting woman, she will remain in my memories for my whole life. I really loved her, respected her a lot, liked her, this was all very good.

[I asked: And why was she so interesting?]

Because she also raised two sons. She was a nurse [...] And during the war, her husband was killed, he was a doctor and she saved [...] she saved 33 Jews. [...] and I have a photocopy with a short note about her life story, which she described in some journals and in some publications and so on. A very interesting woman. And I was with her almost one and a half years, one year and some three months, yes, something like that. Sadly, she died. Ninety-six years she lived, this grandma, and in her 97th [year], she passed away. I, naturally, went to her funeral. Now I work for someone else.

Zenya could relate to this woman who, like herself, had two sons. Her narrative underscores the woman's braveness and the emotional relationship they cultivated - using such words as 'love' and respect - and saying it was 'natural' that she, like the women's relatives and closest friends, attended her funeral. The migrant women displayed agency by presenting work of little social prestige in a different light, improving its status thanks to their personal ties with those they cared for, who had relatively high social status.

\subsection{Conclusions}

Migrant domestic work in contemporary Poland is a relatively new phenomenon. There are several reasons for the development of this niche in the labour market. Care institutions in Poland are weak, both in terms of facilities available and quality of services provided. There also continues to be little social acceptance for placing one's parents in an elderly care institution (and few elderly are happy to accept such arrangements) or one's child in a nursery. The less developed the institutional solutions and the less social acceptance for such care practices, the higher the employer's dependency on private care solutions and the higher the chances for finding work in this niche for migrant women.

When searching for work for the first time, the migrant women had to rely on their social networks at home. However, with growing experience, they got to know more migrants and had better access to information. One can even claim that the relationship between the migrant domestic worker and the employer was characterised by the presence of certain unwritten rules. The employer 'knew' what to do to find a domestic worker. The migrant domestic worker, in turn, 'knew' how to search for 
work, how much she could earn and how to leave one job for another one. She evaluated her work situation and chose the preferred option. Migrant domestic workers from Ukraine made use of their understanding of the rules of interaction and took advantage of their access to resources within the migrant institutions in order to obtain and keep work in Poland.

The migrant combined ties to other migrants and a patron-client relationship with the employer in order to create a sense of stability in undeclared work. The quality of the migrants' working conditions - payment, in particular - improved when they possessed migration social capital gained through ties to their employers. Recommendations given by employers as well as experience from several jobs allowed the migrant domestic workers to achieve satisfactory working conditions and to create a work routine. The form of payment was a way to balance the risks of not being paid for one's workload. The information gathered from other migrants via weak ties did not require investment on the side of the migrant and was treated instrumentally.

As domestic workers, the Ukrainian women were liminal figures. According to them, they were treated like someone falling between worker and family member. Being treated 'like a family member' was presented by them as an achievement, an indication of having cemented their position in the household. This was especially so in the case of care work, a relationship between at least two parties that requires the exchange of intimate knowledge. The migrant domestic workers found it difficult to accept impersonal treatment from the employers. They were conscious of the locale they were working in - that is, someone's home - and associated it with familiarity. For that reason, they expected the rules of interaction to remain less formal. The women stressed how they felt more 'at ease' being treated with familiarity. The employer was also interested in developing friendly relations with the migrant to guarantee their loyalty and quality service. However, their liminality both increased and decreased the risks of migrant domestic work. On the one hand, the migrant increased his or her chances of receiving not only financial gratification, but also a source of information about jobs and a form of protection from the employer. On the other hand, the employer was interested in a specific service provided by the migrant. However, excessive dependence on the employer, related to social capital during migration, made the migrant vulnerable to exploitation by the employer.

The familiarisation of work relationships ceased to be the migrants' preference at the point where the employer started abusing his or her power to gain unpaid services from the migrants. Familiarisation may lead to exploitation the moment dependency of the migrant vis-à-vis the employer passes the former's threshold of acceptability. It sometimes reached the point where the migrant could no longer be able to negotiate or exit work. In this manner, the employers posed a risk to the migrants: 
the time of work increased, but did not bring them closer to the migration goal - that is, earning money. With their earnings, migrants hoped to be able to sustain or improve their own material situation and that of their families.

The ability to respond to risk was related to the migrant's choices and dependence on the employer. The dependence of the migrant on the employer was highly conditioned by the living arrangements. Live-in migrants were dependent on the employer for accommodation and work. Their access to information about new jobs and other forms of social support was also limited, due to scarce time off from work. The weaker the migrants' position within the household, the less possibility for negotiation and the higher the risks of being forced to accept new workloads without additional payment.

Live-out migrants, while having fewer opportunities to develop a personal relationship with their employer, were not as dependent on him or her for work and accommodation and thus could leave undesirable work. With increasing migration experience, the migrants had more self-confidence and opportunities for negotiating their working conditions. For these migrants, power relations changed, as did possibilities for responding to the risks of demands for unpaid work on the part of the employer.

The migrants developed social capital on the basis of ties to their employer, but simultaneously attempted to keep emotionally distant by living independent of the employer or choosing cleaning instead of care work. These strategies allowed them to gain more control over their work. By negotiating their role and conditions of their work, they made themselves indispensable and drew benefits from the employer. The seemingly contradictory strategies of familiarising and depersonalising the relationship with the employers allowed many of the Ukrainian domestic workers to maintain an optimal proximity-distance balance with the Polish employers. In so doing, they balanced their risks, thus turning migrant domestic work into an opportunity to achieve their migration goal. 


\section{Familiar risk: Ukrainian women in the Polish domestic work sector}

As Short (I984: 712) noted, there had been little research into 'how people in fact live with risks and how living with risks affects their perceptions and behaviour'. Risk is an element of everyday life. We are taught to fear particular things and to cope with the potential negative or positive outcomes of our action and other events. Risk means that we may lose something valuable to win something else. In this research, risk was defined as a potentially undesirable outcome, which is socially interpreted as such.

Why study risk as illustrated among Ukrainian migrant women working in the Polish domestic work sector? A simple answer: no one has carried out such research so far. To put it in more explicit terms: the purpose of taking a risk approach to analyse the experience of Ukrainian migrant women in Poland's domestic work sector was to learn what irregular labour migration outcomes the migrants evaluate as a risk and how they respond to it. Also important is to ask what extent this applies to migrant domestic work - as a specific niche of the informal labour market. This approach allowed me to reach beyond research into migration in terms of its costs and opportunities, pointing to the complexity of decisions made during the actual migration process. What might seem a risky behaviour is not necessarily deemed as such by the migrant. 'I am not a risk taker,' declared one of my interviewees. She had circulated between Ukraine and Poland for several years, frequently having to cross the border and working in an undeclared fashion, with no guarantee of earning a wage, health insurance to protect her in the event of an accident or social security for her future. However, this woman managed to mediate the relationship between migration's possible negative and positive outcomes. In that sense, by migrating she took a risk. Without taking this risk and moving out of the security of their routine, the studied women could hardly have adapted to their changing environment. Migration - understood here as a form of voluntary risk-taking - did give them a sense of personal agency, of being in control of their own life, having successfully tackled potentially dangerous situations. Such behaviour opened new opportunities to the migrants. 


\subsection{Risks of migration to Poland and of migrant domestic work}

Recalling the risk typology I developed in chapter three, the risks from this study can also be divided into three basic types: I) risk in Ukraine (systemic political and economic changes), 2) risk of migration to Poland (irregularity and temporariness) and 3) risk of migrant domestic work in Poland (undeclared work and low social prestige).

Concerning the first point, according to the interviewed migrant women, risk in Ukraine transpired primarily because of political and economic changes. It can be understood as involuntary. The studied women faced a risk to their income. They regarded decreased social status as a risk (following the risk typology), pointing to social exclusion resulting from their long-term unemployment. The women's exposure to risk increased, which was visible when analysing their shrinking opportunities on the local labour market. They began being at risk when their income was no longer sufficient to sustain their households (the money they had was losing its value due to inflation), shifted to hidden unemployment (the situation of a worker without a salary or wage) and then to actual unemployment (no income or social or health insurance). This was accompanied by borrowing money and lasted until they were no longer able to repay the debts and/or had nobody left to turn to. As in the risk typology, some of the interviewed women did mention domestic violence, though it was not a dominant trend. Risk in Ukraine was a relevant factor inasmuch as it provided a background against which the interviewed women assessed their situation in Poland. Yet, it is not the main focus of my study and for that reason only limited conclusions are presented in this respect.

In this study, the second type of risk - connected with migration to Poland - concerned risk images evoked by migration stories, as well as potentially undesirable outcomes related to the migrants' entry and stay in Poland. Overall, when this research was carried out, labour migration from Ukraine (not only to Poland) was already a mass phenomenon. Thus, it was regarded as an accepted strategy to cope with risk at home rather than a risk in itself. However, the migrant women had a conception of risk related to migration before actually engaging in it. During the interviews, the women shared stories of other migrants that provided them with images of risk (as well as opportunity). Their stories contained warnings concerning the trustworthiness of other migrants (who could be deceptive) and of their informal employers (who could be financially, physically, mentally and sexually exploitative). These stories travelled primarily through female-based networks and thus their estimations of risk were influenced by the migration experiences of female friends, acquaintances and relatives. The women then migrated abroad to feminised 
sectors of the labour market and bore the migration costs typically incurred by both male and female migrants, while still being subjected to particular gender-related costs. As such, the migrant women saw labour exploitation and sexual abuse as potential unwanted outcomes of their migration.

The interviewed women carried out a risk assessment process when it came to the choice of their migration destination. They weighed the safety of Poland's spatial and cultural proximity (low risk) against potential higher financial gains as well as higher risks of going farther abroad. Overall, the choice of Poland as the migration destination was the result of the interplay between the migrants' limited financial resources, the available social networks useful for migration and family obligations in Ukraine (which prevented them from going farther abroad). Some of the migrant women clearly saw the absence from their families in Ukraine as a risk.

The migrant workers did not identify risk in the abstract sphere of legality. Rather, they saw it as real 'barriers' that are difficult to overcome: the visa requirement, restrictive border controls and a shrinking margin for informal negotiations with border guards. In the early I990s, the spatial closeness of Poland, combined with the easy quasi-tourist entrance and access to an extensive informal labour market, meant low-cost migration for the interviewed Ukrainian migrants. At that time, officials actually extorted what Stola (1997: 27) refers to as 'tolerance tax' rather than actually deporting migrants. Consequently, migration carried low risk. However, with Poland's changing migration policy, the migrant women experienced a gradual increase of risk: starting in 1998 with a number of entry restrictions and culminating in 2003 with the introduction of a visa regime. The financial cost of migration to Poland increased. Although the Polish visa was officially free of charge for Ukrainians, the women claimed that to receive a visa they had to pay bribes. Since the mid-I990s, they engaged in various strategies to overcome the risk of non-entry, which made their migration irregular and, in turn, placed them at risk of, for example, being deported. The balance between costs and opportunities of migration was at stake when migrants received a visa for less than 90 days (attempting to enter as 'tourists'). Another factor was introduction of the so-called 'time corridor', allowing these migrants to spend only i8o days a year in Poland. The more experienced migrant women tampered with their travel documents to be able to enter Poland. To overcome entrance barriers, some of the women used alternative entry channels, such as volunteering or falsely declared employment. Their irregular status placed them at risk of money extortion (lost migration savings).

The migrant women engaged in temporary and circulatory migration, which may decrease the risks related to migration. While temporary labour migrants use their remittances to diversify risks to household income, that very household plays a role of insuring the migrant (Stark \& Bloom I985: I73; Stark 2003: 9; Katz \& Stark I986: I36). Circulation is motivated 
by the security associated with home through access to resources, social affiliations and the presence of the migrant's family (Chapman \& Prothero I983-1984). However, when resources at home and social ties are scarce (as in the case of the Ukrainian migrant women), circulation and the temporary nature of migration do not necessarily translate into more security. The women experienced so-called lasting temporariness, with their circulation between Ukraine and Poland continuing for several years already. On the one hand, the high frequency of crossing the PolishUkrainian border by the women meant that the risk of migration became 'normalised' and familiar. As Lupton (I999: 153) claimed, a frequently taken risk may turn into a predictable routine with the passing time. On the other hand, a new risk came to the fore: some of the women's ties to Poland increased while lessening those to Ukraine, even though they had no prospects for a stable legal status in Poland. In addition, the women were less inclined to circulate due to more entry restrictions and some decided to overstay. The women did not seem to link overstaying to potential abuse by the employer (as in the risk typology) because the employer simply was unaware that the migrant had overstayed. Finally, the temporary and circulatory character of migration was at first an opportunity (the purchasing power of profits from migration was much higher in Ukraine than in Poland), which with time became a 'trap'. Having sustained or even upgraded their social status in Ukraine thanks to migration, the women were fully depended on the migration income. This source of income was potentially no longer accessible if and when refused entry (which meant a return to an undesirable status quo in Ukraine).

Finally, the studied women considered being without work in Poland a risk. Although it can be seen from their stories that there was a clear demand for labourers in domestic work, access to the niche depended on recommendations. For inexperienced migrants without proper social capital, it was difficult to enter the sector. However, the interviewed women did not perceive undeclared work as a risk, per se. They were well aware that the risk of being apprehended in Poland for working without proper documents is low and that social acceptance for undeclared work, especially in the domestic work sector, tends to be high. In addition, they often did not regard cleaning or care as proper labour themselves and so they did not see the undeclared character of work as a serious breach of law. It should be underscored that working in the informal labour market in Poland was a 'familiar' risk for many of the migrant women: they had experienced undeclared work in Ukraine. All these factors combined to create a particular opportunity structure for the migrant women, in which they could balance the risk of migrant domestic work.

However, this approval of undeclared work changed as they gained more migration experience. This was especially the case for younger women, who never worked in the official labour market and wanted to 
have employment stability in either Poland or Ukraine. Women whose employment status was falsely declared did not reflect on the security of declared work or on the potential risk of losing their residence status (which was tied to the work permit). Rather, they saw it as a strategy enabling them to circulate between Ukraine and Poland legally. For them, the undeclared character of work meant the lack of a binding contract, which involved exposure to the risk of not being paid or being paid below the agreed rate. Still, undeclared work in Poland was seen as more predictable in economic terms (more secure and less risky) than declared work in their place of origin. Not insured (not being able to go to a doctor other than for a private consultation), they regarded their health to be at risk due to tasks that were physically demanding (e.g. having to carry the cared-for person, contact with cleaning detergents) and psychologically taxing (e.g. a sense of isolation).

At first, the women did not associate domestic work, especially cleaning, with risk. They thought of it as a familiar activity. With time, the women became aware that migrant domestic work placed at risk not only their health, but also their social status. Remunerated domestic work, carried out on a daily basis, was highly strenuous, physically, and often emotionally exhausting. Working abroad as a cleaner and/or a care worker (both jobs of little social prestige) became their main occupation, while in the past in Ukraine these roles were an additional chore on top of their proper employment in the labour market. The sense of social degradation intensified with some employers treating them as persons with no social status, a replaceable service. The higher the women's social status and professional was in Ukraine, the stronger they felt their presence in the domestic work sector in Poland posed a risk to their social status.

The migrant women did not compare themselves to Polish women working in the informal sector in Poland, but they were well aware that Polish women used to and continue to migrate to work in the domestic work sector abroad. Still, they did experience ethnic discrimination due to the mostly negative attitude of Poles towards Ukrainians. ${ }^{\mathrm{I}}$

The interviewed migrants were aware that the following factors might lead to labour exploitation in domestic work:

- Having one employer or an ad hoc work schedule and thus not being able to quit jobs with unfavourable conditions (usually linked to lack of migratory experience)

- Dependency on the employer for accommodation (living-in)

- Dependency on the employer for entry and stay (e.g. through notarised invitation letters or falsely declared employment)

- Extensive familiarisation that could conceal the financial premise of their work

- Far-reaching depersonalisation together with exploitative emphasis on 'efficiency'. 
A trading of risks did occur through migration: the migrants exchanged the risk of unemployment in Ukraine (systemic and involuntary) for the risk of undeclared work in Poland (voluntary). Migrants also ended up having to cope with involuntary risk in the country of migration, resulting from the changing legal conditions of migration (the visa requirement) and the unexpected outcomes of their actions (growing dependency on the employer leading to labour exploitation).

\subsection{Responses to risk of migrant domestic work}

Migrants respond to risk in the local context. Responding to risk is a form of agency, which requires access to particular resources. The interviewed women's risk strategies during migration were shaped by experiencing the collapse of a known institutional order and the necessity to respond to risk individually. The degree of a person's social embeddedness will determine if his or her risk strategies are group-based or more individualised.

Analysis of the structural conditions under which action must be taken suggests a gradation of the need to respond to risk. At the one end of this continuum is the migrant who does not have to respond to a risk, but decides to respond to risk so as to reach particular gains (voluntary risk). At the other end is the migrant who must respond to risk placed by an external force (involuntary risk). When attempting to place Ukrainian migrants in Poland on this continuum of agency, one can conclude that little agency was needed from them in the early I990s, with almost no entry barriers allowing an easy entry as quasi-tourists. In that period, the interviewed women migrated primarily on the basis of ties to other migrants already working on Poland's informal labour market. They engaged in petty trade and worked seasonally in agriculture, circulating between Ukraine and Poland on a regular basis.

The second step on the risk agency gradation came with the introduction of entry barriers in the late I990s. Here migrants could be refused entrance to Poland by the border guards when suspected of having declared a false aim of travel or having insufficient financial means to support their stay in Poland. As can be seen from the migrant women's stories, it is in this period that they began to use the services of the vodiy, a driver who not only brought them across the border in his car or bus, but also safely transported them and their belongings from their households in Ukraine directly to their work places. Although migrant institutions, such as the vodiy, minimise some aspects of the risk of non-entry, they simultaneously create new ones.

The third step in the risk agency gradation comes with the introduction of the visa regime in 2003 . The migrant had to apply to receive, at the very 
least, a 9o-day visa to enter Poland for the migration to be worthwhile. In addition, crossing the border required declaring a (false) purpose of travel and proving the possession of financial means for one's stay in the country of destination. With the introduction of the visa regime, the migrant women were obliged to remain at least half a year in Ukraine. As domestic work is a regular job (carried out everyday or once, or possibly twice, a week) and thus necessitates continuation, it involved a significant risk to the security of the migrant's job in Poland. It required developing ties with Polish employers, who could facilitate their entry and stay in Poland and thus decrease risk of migration. At the same time, this meant the migrant's greater dependency on the employer and thus greater vulnerability to abuse of power.

Migrant domestic workers have their own 'risk portfolio'. They must respond to risks specific to their work niche and have to secure access to particular types of resources that are unique to their group. The interviewed migrant women shared many features: they had all experienced unemployment in Ukraine and felt responsible for their families' material well-being. An important factor for the migrant women's risk strategies was access to social capital and thus to information about jobs and working conditions.

According to the interviewed women, the ability to respond to the risk of migration and, in particular, the risk of migrant domestic work is related to access to and quality of social capital. The migrant women's social networks with their co-ethnics were not very well developed and they were difficult to expand, due to limited free time and circulation between Ukraine and Poland. It seems they had a number of weak ties and few strong ties, rather than anything that could be called a network. The quality of social capital received via weak ties depended on the type of information and the degree to which the informer was established in the migrant domestic work niche. On the one hand, migrants (especially those who did not yet have a stable work routine themselves) often shared information about jobs they were no longer interested in (those of poor working conditions or of an ad hoc nature). Such jobs did not allow the women to develop a work routine (necessary for a sense of security in an informal work environment). On the other hand, many weak ties involved a quick exchange of information about work standards, which meant that the women were knowledgeable about informal wage rates. The migrant women were generally highly dependent on ties to Poles, mainly their informal Polish employers, for entrance, stay and finding new work opportunities in Poland. On this basis, the interviewed migrant women entered a patron-client relationship and developed employer-centred networks.

Quality of social capital depended on the work conditions offered by the employer, who set standards of pay, determined workload and might 
offer the worker additional assistance (in terms of entrance and stay). Moreover, the migrant women used different types of social capital at different moments in the migration process; their ability to display agency and respond to risks and opportunities therefore changed with time. The quality of social capital and the complexity of the migrant institution used depended on the migrant's experience. To enter Poland, the more experienced migrants used ties to the Polish employers and migrant services, such as the driver, while the less experienced migrants used mainly their home-based network to borrow money for the trip. In general, those migrant women who worked as care workers and who lived with a cared-for person displayed weak agency and had limited access to social capital. Those who lived independently, combined care work with cleaning or solely did cleaning jobs displayed more agency and had access to different types and quality of social capital.

The studied group was also diverse in their risk responses. The Ukrainian women's response to risks at home (migrating to domestic work as part of a household strategy) conformed to group norms and expectations. When already involved in domestic work migrants followed more individualistic patterns of behaviour, relying on self-regulation of risk. These women already knew a migration reality, which was unknown to their families in Ukraine. While migrating, they learned what standards of work abroad they were prepared to accept and how to balance their irregular status with working conditions, thus making migration worthwhile.

\subsection{Types of risk response}

Among my interviewees I distinguished three types of risk response. The first type can be referred to as the risk bearers. The primary risk that the women responded to by migrating was the risk of their household falling into poverty. They were unemployed in Ukraine. Simultaneously, as divorcees, they were the only potential breadwinners in the household. They had to support their young children who remained in Ukraine (in many cases they also had to support their parents). The women's migration job was their main - and sometimes only - source of income. For that reason, at the beginning of their migration to Poland they were willing to accept poorly paid jobs. However, as they developed their networks, they were able to select job offers and improve their working conditions. Having secured (via remittances) the basic needs of their families (money for food and housing payments), they also invested in the education of their children.

Their choice of Poland as a destination country was mainly due to its low costs of migration, when compared with migrating to Southern or 
Western Europe. Yet, with the introduction of new migration barriers, the cost and risk of entering and staying in Poland became higher. Difficulties entering Poland meant that the women's income was at stake. That is why, considering all three types of risk, they were most willing to take high risks in order to enter Poland. Among them were those who had overstayed their visas or tampered with their travel documents.

The second type of response came from risk sharers. They were strongly family-oriented and, despite the financial opportunity, saw migration as a great risk to their family lives. They were aware of the risk of children of migrant parents becoming 'orphans', as cautioned by the media. Prior to their departure, the migrant women falling into this type discussed their migration decision with their husbands and children and reached a consensus. The group decision on migration resulted in a shared responsibility for the risks taken by family members. In their migration narrative, the women focused on the risk of separation from their families and offered the well-being of the family as a rationalisation for choosing Poland. By rationalising their migration decision this way, they showed that they were competent members of their society and they 'knew' what was expected of them. Migration to Poland, although not as attractive financially as, for example, Italy, allowed them to be present at home, returning to Ukraine at least twice a year. According to the interviewed women, this was not possible when migrating to Italy because of the spatial distance and the high costs of obtaining a Schengen visa. By circulating between Poland and Ukraine, the migrant women created a routine, managing to maintain regular contact with their families and familiarising the risk related to separation. The women planned to use the remittances to pay for their children's higher education. The risk sharers wanted to prevent their children from a decrease in social status, which they themselves had experienced through migration and irregular work, notably in migrant domestic work. In general, these women had not had earlier migration experience and went directly to a pre-appointed job, replacing another migrant within the rotation system. The risk-sharers were more often found in care than in cleaning and lived with the cared-for person. The money earned during migration complemented their own or their husband's income in Ukraine. Relying primarily on people in the country of origin, they maintained only few ties to other migrants in Poland, having limited access to information. They were dependent on the employer both for work and accommodation. When they were dissatisfied with working conditions, they did not quit their job; rather, they attempted to negotiate their workload, working hours or payment, until these changed or a safe alternative for work appeared. This group also included women who had already retired in Ukraine. They claimed migration was supporting their adult children (so that they would not have to migrate themselves), a major rationalisation of their migration decisions. 
A third type of risk response can be classified as the opportunityseekers. The migrant women belonging to this type emphasised financial and personal autonomy as a priority of their migration. Migration was a strategy to escape the shrinking opportunities in Ukraine. They were in their thirties and early forties. Although many of them had children, they did not emphasise 'migrating for the family'. Some admitted it was curiosity that made them migrate to Poland. In the past, these women often had traded or worked seasonally in Poland or migrated to work in the Czech Republic. Compared to Ukraine, Poland offered more opportunities, which were limited at the beginning, but allowed them firstly to imagine and then to actually pursue an independent lifestyle, both in terms of their personal life and work opportunities. They mainly worked in cleaning, sometimes in child-care, and they lived independently from their employer. Their migration network was not aimed solely at increasing their work security, but also at having a social life. The opportunityseekers treated domestic work as a temporary remedy and had plans for different future work in Poland. At the time of the interviews, they all generally were struggling for a stable residence status in Poland and were endeavouring to get out of the domestic work sector, namely by giving Russian language lessons, working in small restaurants or finishing beautician courses. They found Warsaw attractive, coming as they did from small towns or villages. Living in a capital city raised their social status in the eyes of their family and friends in Ukraine. Moreover, they also cherished their freedom and anonymity. The women commented on how full of activities their life in Poland was.

These conclusions provide a basis for further exploration of migration via a risk approach. In the case at hand, further questions. Will the number of domestic workers in Poland decrease? Will remunerated domestic work become primarily a migrant job, as is the case in Western Europe? If so, will Ukrainian women continue to be the dominant group among such migrants? How has the introduction of Schengen visas affected the presence of Ukrainian women in the Polish domestic work sector? Will the future see the development of more complex forms of irregularity that require more agency, or might Poland make an agreement with sending countries to channel migrant domestic workers into legal labour? As I tried to demonstrate in this study, the notion of risk - which is first evaluated, then acknowledged or denied and finally responded to by the migrant through various risk strategies - is essential to answer these questions, as well as many others. 


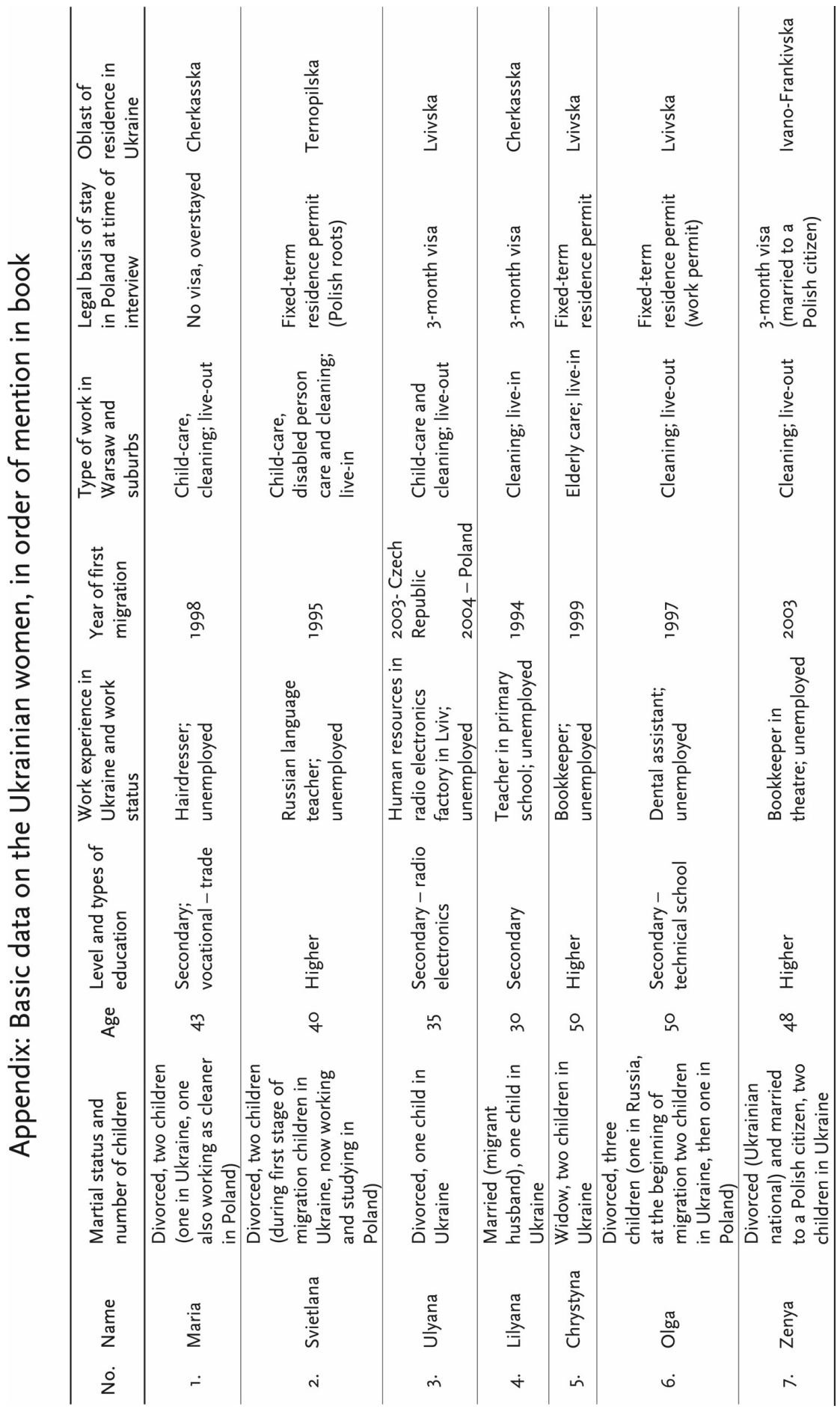




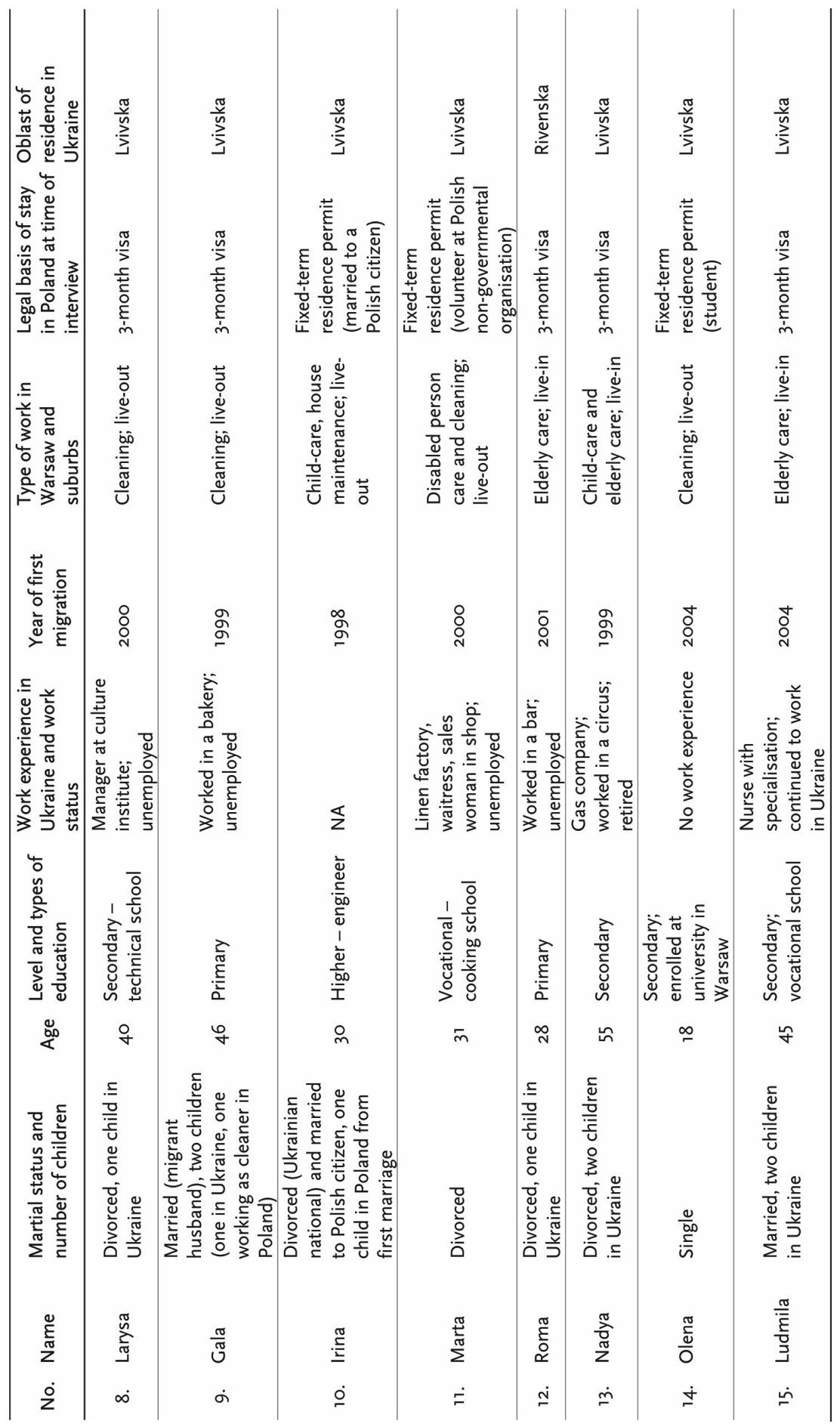




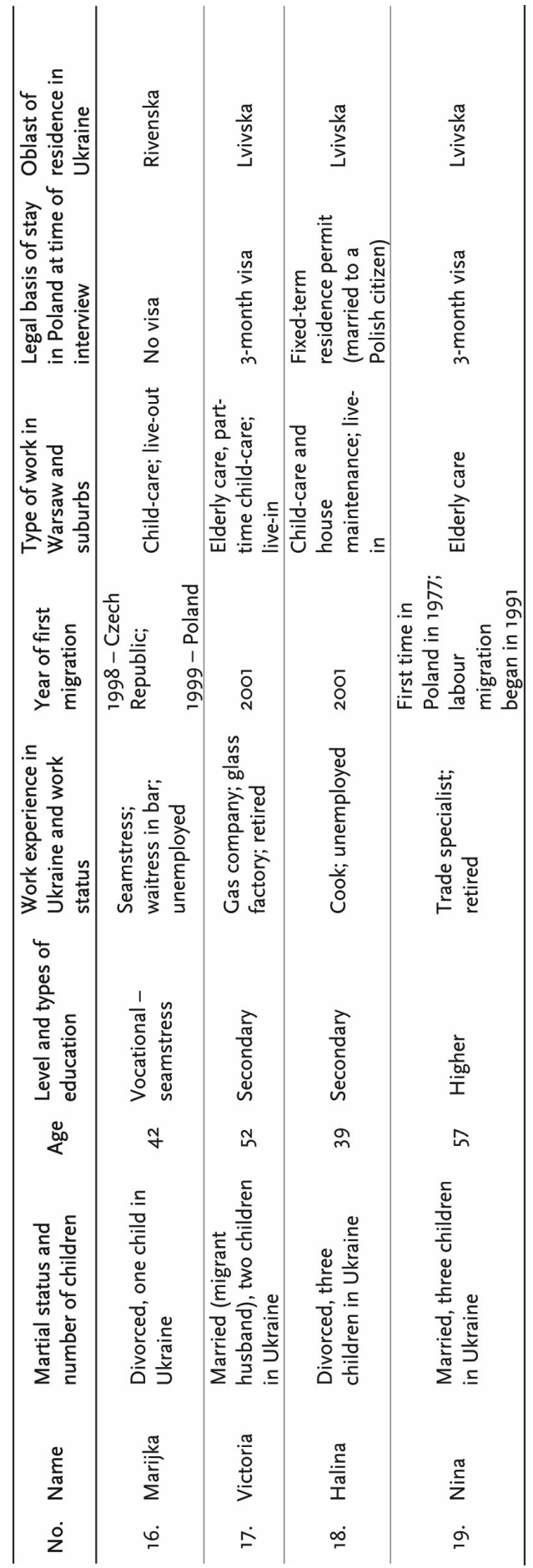




\section{Notes}

\section{Chapter 1}

I In the second half of the I990s, the Centre of Migration Research (CMR) at the University of Warsaw carried out several studies on immigration to Poland analysing Ukrainian petty traders and circular migration (Lukowski I997; Okólski I998, I997; Stola 1997; Iglicka \& Sword I999). Research focusing on migration of Ukrainian nationals to Poland gradually advanced (Antoniewski I997; Iglicka 2003; Bieniecki, Bojar, Frelak, Gąsior-Niemiec, Konieczna \& Kurczewska 2005; Bojar, Gąsior-Niemiec, Bieniecki \& Pawlak 2006; Drbohlav 2003; Górny \& Kępińska 2004; Górny, Grzymała-Kazłowska, Fihel, Kępińska \& Piekut 2007; Kępińska 2002; Kloc-Nowak 2007). Current Ukrainian migration was also addressed in general studies on foreigners on the Polish labour market (Iglicka 2000, 2003; Golinowska 2004; Bednarski, Kryńska, Pater \& Walewski 2008). Most recent publications concern integration issues and their related policies (Grzymała-Kazłowska 2008; Górny, Grabowska-Lusińska, Lesińska \& Okólski 20Iо; Kindler \& Szulecka 20I0).

\section{Chapter 2}

I The authors of the value-expectancy model present seven values and goals influencing the decision to migrate (De Jong \& Fawcett I98I). The most common goal is to improve or maintain one's financial standing in order to gain or keep social position and prestige. The higher the migrant's status, the higher the expectations in regard to the standard of living, quality of work and level of education acquired during migration. A person who has a particular social status and expects to improve or maintain it might actually experience a decrease in status due to migration.

2 For a comparison of the realist and the constructionist approaches, see ShraderFrechette (I99I) and Clarke and Short (I993).

3 Author of the risk-society approach, Beck displays in his writings a realist approach to risk, understanding it as a hazard or danger. However, he is inconsistent in this approach, also highlighting social and cultural processes by which the understanding and perception of risk is filtered (Lupton I999: 60).

4 'Governmentality' is a term Foucault used to refer to the strategy and rationale that developed in Western Europe in the sixteenth century and dominated politics and social regulations in the eighteenth century (Lupton I999: 85).

5 The notion of risk is absent from the neo-classical migration theories in which action results in one outcome, rather than a set of possible outcomes, and is 
considered certain because of assumed perfect information flow. There is little space for doubt, uncertainty or risk. The rational actor calculates expected gains on the basis of his or her skill multiplied by the probability of getting a job and then subtracts the anticipated costs from them. Migration is seen as an investment in human capital (Sijaastad I962). In those theories, the labour market is treated as the migrants' basic environment whereby choice is institutionalised and conditions are restricted, various variables can be 'controlled for' and the outcome of specific actions calculated. This approach has been criticised for failing to take risk into account. It is argued that the market, with high uncertainty and cost of information, is actually responsible for creating a situation where the principle directing the tactics of actors is not maximisation of their income, but rather the prevention of risk (Guilmoto \& Sandron 200I:I37). In addition, the role of actors, such as the state (which can influence both the political and economic situation) or of the household (which can influence who migrates), is not taken into account in this highly individualistic approach. The focus is thus on the economic aspects of migration and a pure cost-benefit calculation, leaving out the social, political and historical factors.

6 In economics, risk is understood as 'the fact that the results of any action are not certain, but may take more than one value' (Black I977).

7 Migration as a risk strategy has been analysed in earlier economic studies (Elkan I959).

8 Although the notion of family and household are not synonymous - with the household encompassing the family, but also consisting of non-family members this paragraph uses them interchangeably, as social and economic units.

9 This contrasts with active recruitment of foreign domestic service by some states, such as the French governesses in Europe in the eighteenth and nineteenth centuries, as well as the 'export' of European domestic servants to colonies in North America and Australia (Sarti 2008).

Io In contrast to domestic work carried out for households, cleaning offices and buildings by cleaning companies is a professionalised domain. Still, the social status and wages for this work remain low (Lutz 2008: 49).

II In the EU, the au pair system has been regulated by the European Agreement on Au Pair Placement since I969.

I2 Until the late I980s, neither national nor international law contained articles on the protection of migrant women. Poor unmarried migrant women of an ethnic background different than that of the receiving society's dominant group were regarded with suspicion, as a potential threat to the society 'morale' (Chapkis 2003: 923). Evidence from research on the exploitation of migrant women led to the I990 adoption of the UN International Convention on the Protection of the Rights of All Migrant Workers and Members of Their Families, where migrant women's status is to some extent recognised. However, the convention does not mention sexual exploitation, victimisation of migrant women workers or the question of legal status of the second generation of migrant women (Hune I99I: 8I3). Some regulations, at first glance seemingly covering all migrants, protect only a very small fraction of them. For example, the US Trafficking Victims Protection Act exempts only a small group of trafficked migrants from punitive immigration and welfare measures (Chapkis 2003: 924).

I3 The demands concerned recognition of domestic work as 'real work', a legally enforceable contract of employment, right to health insurance, family life, leisure and personal time and immigration status independent of any employer (http:// 
assembly.coe.int/Documents/AdoptedText/TAo4/ERECr663.htm; accessed 23 June 2008).

I4 Framework Directive 89/39I, article 3 a): "worker: any person employed by an employer, including trainees and apprentices but excluding domestic servants' (http://eur-lex.europa.eu/LexUriServ/LexUriServ.do?uri=CELEX:31989Lo39I:EN: HTML; accessed 23 June 2008).

I5 http://cms.iuf.org/sites/cms.iuf.org/files/Committee\%2oon\%20Domestic\%2oWorkerse.pdf, http://www.domesticworkerrights.org/sites/default/files/ILO\%2oDomestic\% 20Work\%20Report_o.pdf; accessed 4 July 20 IO.

I6 This research was carried out by the UK domestic workers organisation Kalayaan, recording the experiences of 775 workers.

I7 The survey was carried out in eight countries: Germany, Austria, Finland, France, Italy, the Netherlands, Portugal and the UK.

I8 Communication from the Commission of 7 April I998 on undeclared work (online summary available at http://europa.eu/scadplus/leg/en/cha/cirjio.htm; accessed 23 June 2008).

I9 Council Directive 20I0/I8/EU of 8 March 20I0 implementing the revised Framework Agreement on parental leave concluded by BUSINESSEUROPE, UEAPME, CEEP and ETUC and repealing Directive 96/34/EC (http://eur-lex. europa.eu/LexUriServ/LexUriServ.do?uri=OJ:L:2010:068:0013:0020:EN:PDF; accessed I7 November 20I0).

20 For example, in the domestic sector in the UK, only men work as butlers and chauffeurs (Cox 2006). However, Italy and Spain seem to be experiencing a 'remasculinisation' of domestic staff. In Italy, migrant men constituted 15.5 per cent of all domestic workers in 2003. In Spain, I8.5 per of those who applied for regularisation as domestics were men (Sarti 2008: 9I).

2I In a study carried out in Germany before 2004, migrant domestic workers received, on average, $€ 8$ Io per hour for cleaning and $€ 58$ per hour for child-care. The monthly salary for elderly care ranged between $€ 800$ and $€ \mathrm{I}, 200$ (Lutz 2008: 45-46).

22 An example of how the overall understanding of risk changes can be seen in Britain's Royal Society report from 1992 that states: 'the view that a separation can be maintained between "objective" risk and "subjective" or perceived risk has come under increasing attack, to the extent that it is no longer a mainstream position' (in Adams i995: 9).

23 In the present-day Western cultural realm, risk is associated primarily with danger. Even though in technical analysis there is focus on both positive and negative possible outcomes, positive aspects of risk-taking tend to be downplayed (Short I984). Games of chance and competitions are one of the few areas where the positive aspects of risk are accentuated. Knight, among others, claimed that the economic assumption that men are directed toward the 'satisfaction of wants' is limited in scope because human beings are generally influenced in their decisionmaking by emotions, similar to when playing a game (Knight I973; LeRoy \& Singell I987). 


\section{Chapter 3}

I Giddens has been criticised for presenting the notion of reflexivity as requiring a rational, calculating actor; it has been argued that Giddens' reflexivity is more a response to expert knowledge, whereas risks are dealt with at the everyday, local level (Wynne I996). He has also been criticised for his notion of reflexivity being overly based on the processing of information, not on signs and symbols (Lash I993). However, he understands the intentionality of human action in reflexive monitoring as a routine feature. Intentionality does not mean here that an actor has clear goals that he or she is conscious of throughout acting. According to Giddens (1979: 59) the whole process of reflexive monitoring takes place in unacknowledged conditions of action and the intentional action often has unintended consequences.

2 As Giddens (I993: 39) claims: resources are drawn upon by actors in the production of interaction, but are constituted as structures of domination. Resources are the media whereby power is employed in the routine course of social action, but they are at the same time structural elements of social systems, reconstituted in social interaction. Social systems are space: power in social systems can thus be treated as involving reproduced relations of autonomy and dependence in social interaction. Thus, structures of domination imply 'asymmetries of resources employed in the sustaining of power relations in and between systems of interaction'.

3 In contrast, group social capital involves a particular level of trust, effectiveness of norms and social relations in the group.

4 Although international mobility during Communism was restricted, Poles began engaging in international short-term mobility as early as the I970s. These were migrations of an exploratory nature, where migrants were investigating prospective opportunities, mainly within the Communist bloc. These short and frequent trips (primarily for petty trade) came to a halt with the introduction of martial law in I98I. Between then and I988, the second most popular destination place for the majority of migrants after Germany was the US (Okólski I996: 97). In turn, the I 990 s saw a visible return to international temporary migrations among Poles (Jaźwińska I996: 88). Although Western Europe remained the main destination, migrants chose geographically closer 'employment centres', engaging in shorter (i.e. under three months) yet more frequent periods of mobility and participating in activities not in accordance with their tourist entry status, as given by the receiving country (Okólski I998: I4). For example, in the community of Podlasie, the migration flow went from being bound for the US to Belgium. Trips to the former Soviet Union were no longer dominant; instead, the pull of Germany increased. Since Poland's 2004 entry into the EU, the country's six main migration destinations are the UK, Germany, Ireland, Italy, the US and the Netherlands (Kępińska 2007).

5 The stock of foreigners who had permanent residence at the end of 2006 was equal to 54,800 (0.I4 per cent of the total population of Poland), with three groups dominating: Germans (primarily because of Poles' double citizenship), Ukrainians and Russians. Asylum applicants have mainly been nationals of the Russian Federation (mostly Chechens) (Kępińska 2007).

6 This is partially due to the fact that border guards upon return to Ukraine check registration.

7 A total of 39,673 foreigners was registered for temporary stay. 
8 The total comprised 5,563 persons.

9 The bazaar's location at the sports stadium was closed in September 2007. The traders were moved to new bazaar areas.

Io Each interview lasted between one and two hours. All the interviews, apart from one, were recorded and fully transcribed. Some of the stories of the migrant women interviewed are presented in detail, while others are only briefly mentioned. This is mainly related to the quality of the interviews, some of the women being much more talkative and expressive in relating their stories. I use pseudonyms for all of the migrants.

II The interview script was partly based on an analysis of interviews selected from CMR archives. I attempted to identify key themes in the experience of women migrating to perform undeclared work and the role of risk in this experience. The interview script is semi-structured and semi-standardised. It consists of openended questions, starting with those concerning the women's overall life experiences before migration (education, employment, material situation, internal migration), which allowed me to gather - apart from my demographic questions at the end of the interview - some background data about the respondent. This helped me understand their motivations for migration and the risks they had experienced in their country of origin, such as working in an undeclared fashion. Following up on this were questions about experiences of their first trips to Poland, crossing the Polish-Ukrainian border and at their workplaces. This allowed me to find out about strategies of entrance, stay and finding work in Poland. I continued with questions concerning their current working conditions, everyday strategies and reflections on fears and hopes related to their migration to Poland. After the first two interviews, I rephrased some questions in the interview script that the interviewees did not seem to find comprehensible.

I2 The use of Ukrainian seems to have influenced the quality and type of information provided during the interview. An interview conducted in Ukrainian made me a person that the migrants could trust, and the interviewees were willing to share more of their negative experiences with Polish employers and other Poles.

I3 Obviously, this meant that the presence of the cared-for person could have had an influence on the quality of the interview. However, the cared-for person usually was in a separate room from where I conducted the interview. I am also aware of other factors that influenced the quality of the data gathered: the fact that I am Polish as well as the fact that I come from a milieu from which many of the migrant women's employers originated. However, thanks to the time I spent with them as well as my learning to speak Ukrainian, I was able to build a certain amount of trust in these relationships.

\section{Chapter 4}

I The phenomenon of people being officially employed in a company but not receiving any pay is also referred to as under-employment (Dudwick et al. 2002).

2 Throughout the book, euro equivalents of Polish zloty and Ukrainian hryvnia are generally given. The currency is given in US dollar equivalents if that is how it is specifically relayed in the stories of the migrant women or in the original sources.

3 According to a study monitoring social changes in Ukrainian society, in I995 there was a high level of distrust towards Parliament (6o per cent) and government (49 
per cent) and an even higher lack of trust towards political parties ( 67 per cent) (Panina 2005: tables d6.I3, d6.I4, d6.I8). Between I994 and 2005, the majority of Ukrainians continued to trust their family and relatives. However, in 1994 they tended to distrust (I9 per cent) and were uncertain whether to trust (47 per cent) their compatriots (Panina 2005: 404I, tables d6.I, d6.2).

4 Field-work on I6 December 2004 in Warsaw. Interviewee no. I (see Appendix).

5 Field notes from meeting in Larysa's living space in Warsaw - a garage - on 26 December 2005 .

6 All references to 'dollars' or use of the \$ sign throughout this book refer to US dollars.

$7 \quad$ Field notes from August 2005, town B., Ukraine.

8 Field research 6 August 2005 in village K-B, Ukraine.

9 Fieldnotes from ig December 2004, Warsaw.

Io A similar phenomenon was noted by Ho (2005) in her study on women in Taiwan.

II This follows a pattern visible in a study conducted by the Centre of Migration Research (CMR) at the University of Warsaw in the I990s. According to this research, the majority of migrant workers in Poland experienced a higher sense of physical security than foreign traders. This was due to the fact that they were not exposed to extortion by criminals, encounters with police and direct conflicts with Poles competing for their work (Stola I997).

I2 In the nineteenth century in Galicia (today partly Ukrainian western borderland), the Polish-Ukrainian conflict was based on strong social tensions (Szporluk 2004:2I). The social segmentation to a large extent reflected the two ethnicities. In general, Poles belonged to the landowning strata, while the Ruthenians (western Ukrainians) were peasants. At that time, Poles attempted to become independent (in the eighteenth century, the Polish-Lithuanian Commonwealth was partitioned into Prussia, Russia and Habsburg Austria). But Ukrainians were denied the right to their own state (Konieczna 2003: I; Szporluk 2004: 2I). The ethnic conflicts existing during the Second Polish Republic (I9I8-I939) were aggravated during World War II as a consequence of German and Russian politics (Motyka I997, 2000). After the war, Poland's borders were shifted: its eastern borderland (today Ukrainian western borderland) became part of the Soviet Union. For this reason, some Poles refer to the Ukrainian western borderland as the lost 'outskirts' (kresy in Polish).

I3 Poland has also a large Ukrainian minority (Łodziński 2003; Berdychowska I998). However, at the time of carrying out this research there were almost no ties between Ukrainian labour migrants and the Ukrainian minority (Stefańska 2008). The minority did not identify with the migrants, largely perceiving them through negative stereotypes similar to those present in Polish society (Konieczna 2003: 2I).

I4 Taras Babiy, 'Strashne Kino (Horrific cinema)', Ekspress io5 (2964) 8I0. 09.06; Olecya Pasternak, 'Mama v Italyi (Mother in Italy)', Vysokiy Zamok I72 (3335).

I5 A much broader approach to parenthood and motherhood is present in migrant domestic work literature, acknowledging that it is historically and socially constructed, with contemporary variants distinguished according to ethnicity, class and culture. The term 'transnational motherhood' is used in various studies to explore the changing meaning of motherhood, trying to accommodate spatial and temporal separation (Hondagneu-Sotelo \& Avilla I997: 548; Lutz 2004: 54; Parreñas 2005: 319). Also, transnational care of the elderly is addressed, looking at the way ageing parents and adult children who live at a distance relate to one 
another (Baldassar 2007). Family identities, in the same way as national and ethnic identities, can be maintained across time and negotiate space via particular rituals (Baldassar 2007: 276; Gardner \& Grillo 2002).

I6 By way of comparison, in 2003, there were 25 divorces per 100 marriages in Poland (every fourth marriage fell apart) and 34 divorces per Ioo marriages in the EU-25 (every third marriage fell apart). However, in other former Soviet Republics (such as Estonia, Latvia and Lithuania), the number of divorces almost equalled (and in some cases exceeded) the number of marriages. http://www.eurofound.europa. eu/areas $/$ qualityoflife/eurlife $/$ index.php?template $=3 \&$ radioindic $=54 \&$ idDomain=5; accessed 25 September 2010). In 2005, the ratio of divorce to contracted marriages in Poland was approximately one to three (GUS 20I0: I79: table I (36)); The total divorce rate in Europe ranges from fewer than ten divorces per Ioo initial marriages to more than 50 (Sobotka \& Toulman 2008: IIO).

I7 The study was carried out on the basis of semi-structured interviews with I03 children of labour migrants, between ages twelve and seventeen, experts and members of the children's social environment. Parents of most of the children in this study had been abroad for one to three years at the time of the interview. According to the experts, families ought to be registered for specific surveillance, especially with law enforcement agencies, if both parents are away for I3 months or if one parent is abroad for over one year. This means that the experts do consider the children to be potential criminals in the first place, and only then as victims of violence (Halustyan et al. 2006: I4). In Ukraine, parents can be deprived of parental rights, following article $\mathrm{I}_{4}$ of the Family Code in Ukraine. Experts claimed that this could happen if the parents do not keep in touch with the child, if they do not provide financial support and if they have committed crimes or are using abusive substances (Halustyan et al. 2006: I6).

I8 According to my informers, the Schengen visa combined with the trip to Italy costs $€ \mathrm{I}, 500-2,000$. In comparison, the Polish visa, including a necessary bribe, costs \$IOO and the trip to Poland costs PLN 70-IOO (approximately € 22-25).

\section{Chapter 5}

I Goss and Lindquist (I995) used Giddens' concept of institution to analyse the process of labour migration. According to Giddens, institutions are the most deeply layered social strategies. They are strategies that are very well known to the members of a society; the knowledge of these strategies is involved in the functioning of the society. Individuals and institutions interact in a reflexive relationship in a reorganised time and space context.

2 The Act on Passports of 29 November I990 (Journal of Law I99I, no. 2, item 5).

3 The Aliens Act of I963 (Journal of Law I963, no. I5) was passed under Communism, when immigration to Poland hardly existed and was thus not a subject of public debate. Since the main trend experienced was emigration, the state tended to focus not on entry, but on exit policy.

4 In I99I, Poland became a member of the Council of Europe and began to participate in the creation of a common strategy towards migration. It signed the Geneva Convention and the New York Protocol. In I992, UNHCR opened its office in Poland. In 1993, Poland signed agreements with Schengen countries regarding readmission. Regional cooperation also developed with Poland joining the Berlin 
Group in I991: work began on issues of illegal migration, border control and reentry agreements, later known as the readmission agreements. In I993, an agreement between Poland and Germany was signed on cooperation in combating the consequences of migration flows (in force since June 1993). Poland received I20 million DM from Germany as compensation for the costs of intake of readmitted persons; the money was spent on border infrastructure and asylum infrastructure (Weinar 2006: 4; Kicinger 2005: 5).

5 In December 2007, Poland entered the Schengen zone and changed the visa requirements for Ukrainian citizens, who are currently able to enter Poland either on a Schengen visa or a national visa.

6 According to the interviewees, the fee was in the $€ \mathrm{I}, 500-2,000$ range in 2005 .

7 The JHA chapter began in 2000 and included implementation of the Schengen acquis.

8 Poland received funds from the PHARE programme, which were also spent on training and workshops.

9 Aliens Act of 25 June 1997 (Journal of Law I997, no. II4, item 739). That same year, Polish Parliament adopted a new constitution, stating that foreigners should enjoy equal rights with the country's nationals and any restrictions to this rule must be justified and specified by law.

Io Reasons include the foreigner being a danger to state security or public health and the state having a well-founded suspicion of the foreigner participating in terrorism, smuggling or trafficking. The act also incorporated regulations of entrance to Poland that until then were contained in the Act on Border Guards of I2 October 1990 (Journal of Law no. 78, item 462).

II Regulation of the Ministry of Interior Affairs and Administration of 29 September 2003 (Journal of Law 2003, no. I78, item I748).

I2 Act on Population Registration and Identity Documents (Journal of Law 2006, no. 139, item 993).

I3 Amendment of Aliens Act of II April 200 I (Journal of Law 200I, no. 42, item 475).

I4 The Aliens Act of I3 June 2003 with amendments (Journal of Law 2003, no. I28, item II75). At that time, the Act on Granting Protection to Aliens (Journal of Law 2003, no. I28, item II76) was also implemented.

I5 Council Regulations (EC) No 539/200I of I5 March 200I lists countries whose nationals must be in possession of visas when crossing the external borders and those whose nationals are exempt from the requirement: http://eur-lex.europa. eu/LexUriServ/LexUriServ.do?uri=CONSLEG:200IR0539:20070II9:EN:PDF.

I6 In such cases, a person is obliged to leave Poland within seven days. Other reasons for expulsion are an attempt at crossing the border illegally, failure to leave Poland within the time specified by the authorities and failing to meet fiscal obligations.

I7 A foreigner had the right to appeal this decision. A deported person had his or her photograph and fingerprints taken. Data on deported persons was kept by the border guard in an index on aliens whose stay in Poland is seen as undesirable.

I8 A voivodship refers to an administrative unit or province.

I9 Act on Employment of 29 December I989 (Journal of Law I989, no. 75, item 446).

20 The agreement from I994 set the following conditions of work: I) it gave Ukrainian workers in Poland protection under the Polish Labour Code; 2) it restricted the worker to carrying out only the activity for which the work permit was issued; 3) employment could not exceed twelve months; 4) the Polish employer was responsible for submitting all requisite documents and paying the application fees. 
2I Act on Employment and Counteracting Unemployment of I4 December I994 (Journal of Law I995, no.I, item I).

22 Act on the change of the Act on Employment and Counteracting Unemployment of 26 April 2002 (Journal of Law, 2002 no. 74, item 675).

23 When this research was being carried out, this amount was equal to approximately PLN 900 (approximately € 225).

24 Since 2007 , the cost of applying to employ a foreigner has substantially decreased: it costs PLN ioo for the first application and PLN 50 for subsequent ones.

25 Journal of Law 2003, no. I28, item II75.

26 Entering as tourists to carry out economic activities for profit was also a known strategy of Polish migrants (Jaźwińska \& Okólski 200I).

27 During my study visit to the Polish-Ukrainian border in August 2006, some of the Polish border guards mentioned being aware of the fact that the majority of crossing Ukrainians intended to work in Poland. The guards claimed they had to show a certain degree of 'tolerance' and, for that reason, introduced informal rules - based on how often the person had already crossed the border and for how long he or she had stayed in Poland - to determine whether to let the person pass. In the case of young men, they looked at their hands, trying to check if they were bruised from manual labour. The guards claimed that if they were to follow the regulations strictly, traffic at the Polish-Ukrainian border would come to a halt.

28 Journal of Law I997, no. I25, item I28.

29 The Aliens Act of 13 June 2003 with amendments (Journal of Law 2003, no. I28, item II75).

30 By 2003 , there were Polish consulates in the Ukrainian cities of Kiev, Lviv, Lutsk, Kharkiv and Odessa. Initially, right after the introduction of visas, up to 2,000 persons would queue daily at the consulates in Lviv and Łuck, fewer in Kiev. Between October 2003 and September 2004, more than 600,000 visas were issued to citizens of Ukraine, with a large share of visas issued in the Ukrainian western borderlands, approximately 210,000 in Lviv and 190,000 in Łuck (Boratyński, Burakowskyj \& Dodonow 2004: 44, 63).

3I At the time of this study, the Lviv consulate had introduced a computerised service assigning 'queue numbers'. However, few of the potential migrants, who generally came from rural areas and small towns, had home access to the internet. A new informal service appeared: in exchange for a few dollars, one could obtain a 'queue number' from a van parked in front of the consulate that had a computer with internet access. The computerised queuing was abandoned in 2008 due to hackers cracking the system and selling the queue numbers.

32 'During participant observation in January 2005, going from Ukraine to Poland, I learned about how this service worked and who its users were. My fieldnotes are as follows:

I. [the driver] was supposed to arrive at ten in the morning. Before ten o'clock, a neighbour of Z. [woman who works as a cleaner in Warsa w] tells us that I. called and said that he would be there at 1 p.m. [Z. does not have a phone in her house]. Apparently one of the passengers could not leave in the morning and asked him to postpone the trip until the afternoon. At 1:30 p.m. he arrives and picks me up from the house of $Z$. From there, we go to the nearby town of $M$. to pick up a man who has been migrating to Poland for six years already - at first he worked in construction, then traded homemade vodka at the Stadion, now again he works for a construction company (he got the contact from someone at the Stadion) laying bricks and painting. He told me how he carefully wrote down all his hours of work, because his boss owes him money now. He 
has a new passport now and so he enters Poland once on the old one and once on the new one. [...] He is a retired music teacher. His wife is ill and he claims that the money he earns in Poland allows him to provide medical treatment for her. His son also used to work in Poland. From this town, we drive to Lviv to pick up two more people from the train station. One of them, a woman, is from a village right next to the border. She speaks Polish very well. She is going to Poland to a textile company, where she had already worked once before. She said it is difficult because they get no free days during the week and they are not allowed to leave the premises of the company. Before that, she worked collecting cherries. The third person is an Armenian with a Ukrainian passport, who stays in Poland on the basis of a temporary residence permit. He claims to be married to a Polish woman, wears a long black coat, dark sunglasses and a signet ring on his finger. His clothes and overall appearance contrast with the rather impoverished looks of other passengers.

33 Waiting in the queue concerns only private vehicles, since buses have a separate lane to pass the border-crossing point.

34 Participant observation at one of the Ukrainian-Polish border-crossing points in February 2006.

35 Journal of Law 2006, no. I39, item 993.

36 The fee amount was arbitrarily established by the border guards.

37 Journal of Law 2003 , no. 96, item 873 .

38 In 2005, 2,260 marriages between Polish citizens and foreigners took place in Poland. Of those, I68 involved a Ukrainian citizen (Kępińska 2006: 72, table 26). Since October 2005 , marriage to a Polish citizen has also protected a foreigner from deportation (Kępińska 2005: 20).

39 For more information on bazaars in Poland, see Peterlik (2000).

\section{Chapter 6}

I http://data.un.org/CountryProfile.aspx?crName=Ukraine, http://data.un.org/CountryProfile.aspx?crName=Poland; accessed 2I September 20 Iо.

2 The number of those accepting foreigners at every job in Poland has quadrupled since I992.

3 According to projections, those aged 65 and older will rise to 29.4 per cent in 2050. According to 2002 census data, the total population of Poland comprised 38,230,000 persons (GUS 2007: III, table I (6I)).

4 This is due to the birth ratio being lower in Poland than in old EU member states.

5 Between 1999 and 2002, total health expenses in Poland constituted between 5 and 6 per cent of GDP, which is the second-lowest figure in Europe after Slovakia (Nunckowska \& Perek-Białas 2004: 20). In 2002, investment in health care in Poland was the lowest among selected OECD countries.

6 The Law on Public Benefit Activity and Volunteering of 24 April 242003 states that the public administration is responsible for implementing public tasks in cooperation with civil society associations. Among the objectives of such cooperation is the provision of nursing services as well as development of long-term care facilities and hospice care facilities (Nunckowska \& Perek-Białas 2004: 29). According to the Constitution of I997, the state is obliged to provide special health care to children, the disabled and the elderly (article 68). However, the article remains largely a letter of the law (Journal of Law 2003, no. 96, item 873). 
7 In 200I, a research project involving I,603 non-governmental organisations was carried out in Warsaw. Of them, 280 declared that they provided care services for the elderly (CIS 200I).

8 Labour Code article I86 paragraph I and article I89 (I) paragraph I, the act of I December 1998 on family, child-care and nursing allowances (Journal of Law I998, no. I02, item 65I) and the ordinance of MOLSP of 28 May I996 on leaves and child-care allowances (Journal of Law I996, no. 60, item 277 with subsequent amendments).

9 In 200I, a new law was introduced allowing fathers to take the last ten weeks of their partner's maternity leave, if the mother decides to return to work. This provision was later modified, allowing parents to divide the extended leave into four periods and decide who will stay home during which period (Saxonberg \& Szelewa 2007: 363). However, men are generally not expected to use these benefits in Poland.

Io Those looking for domestic elderly care in Poland usually do so through informal arrangements. According to opinion polls, elderly people receive most help from family and neighbours. The least help is received from institutions that are officially responsible for the care provision (CBOS 2000). Compared to the period before I989, more senior citizens live together with their children and children's families. This also means that grandparents are close by to care for their grandchildren, compensating for the lack of institutional child-care. Interestingly, care services given by the elderly are more substantial than those they receive (Czekanowski 2002). According to research carried out by CBOS, the role of grandparents in raising grandchildren increases from generation to generation, in contrast to trends observed in Western Europe (CBOS 2008). Almost half of all adult Poles (47 per cent) received care from their grandparents when they were children. Taking into account the fact that I4 per cent of the respondents never met their grandparents (the latter had died before their grandchildren were born), this makes grandparents a substantial source of care support and shows how much the family in Poland depends on informal care solutions (CBOS 2008: 3).

II Declared remunerated domestic care and housework in Poland is carried out on the basis of a written contract of paid services, i.e. the 'activating contract', which is regulated by the Polish Civil Code. Polish men and women are officially employed as cleaners and care workers by cleaning and care agencies as well as public institutions, such as schools and hospitals.

I2 According to the 2002 population census, there are $13,337,000$ households in Poland.

I3 In 2006, the Mazowieckie province only issued 4,743 permits, 899 of which went to women.

I4 The following categories of workers were issued permits by the Mazowieckie labour office: care worker (24), child-care worker/housekeeper (4), care worker for a person with Parkinson's disease (2), house care worker (7I), home-based child-care worker (2), child-care worker (4), child-care worker, home (I4), care worker for a disabled person (I), care worker for an elderly person (I), care worker for a person with a disability (I), elderly care worker (6), domestic help (I03) and housekeeper (4) (categories and data derived from the migration department of the Mazowieckie Voivodship labour office).

I5 Furthermore, 7,069 Ukrainian women registered their stay in Poland (Kępińska 2007: table I9).

I6 In neither my interviews nor informal conversations with the migrant women in 
Poland did I come across any information on the phenomenon of migrants charging a fee for job referrals, as is practised in Italy (for the case of Filipino migrant domestic workers in Italy, see Pareñas 200I).

I7 By 20I0, the hourly wage rose to a range of PLN IOI5.

I8 In 2000, the average level of earnings on the Polish labour market was equal to PLN I,894 (approximately € 470); in 2005, it was PLN 2,36I (approximately € 590).

I9 Ukrainian women had a different experience from the Filipina domestic workers in Hong Kong in Constable's (2003: 133) studies, who had separate 'servant areas'. Spatial division in the household changed the dynamics in the power relation, which were clearly outlined by spatial segregation.

20 Piore (I979) claimed that accepting work in the secondary labour market is possible for the temporary labour migrant because he or she separates social status from work status. The social status is related to the position in the country of origin, but not in the receiving society.

2I Referring to it as 'contradictory class mobility', this phenomenon was observed by Parreñas (2000: 150, 244) in her study on migrant Filipina domestic workers in Rome and Los Angeles. This contradiction occurs due to a decline in the migrants' occupational status and an increase in their earnings. The Filipina women in Parreñas' study experienced underemployment as an 'excruciatingly painful experience'.

22 A similar finding was noted in research carried out by Rosińska-Kordasiewicz (2010) on Polish women in the Italian domestic sector.

23 Female domination of the household in Poland compelled researchers to coin the term 'matriarchal manager' (Titkow, Duch-Krzystoszek \& Budrowska 2004), describing women who build their social status around their role as mother and wife. The concept serves as a possible explanation for the treatment some of the interviewees experienced.

\section{Chapter 7}

I According to the opinion polls carried out in the late I990s, over half of Poles declared a dislike of Ukrainians (CBOS I998, I999a). This negative attitude towards Ukrainians changed to some extent in 2004: Poles not only sympathised with, but often actively supported, the Orange Revolution in Ukraine (CBOS 2004). However, in the following years the same level of negative attitudes was visible, showing the strength of historically rooted ethnic stereotypes (CBOS 2005 , 2006). 


\section{References}

Adam, B. \& J. van Loon (2000), 'Introduction: Repositioning risk: The challenge of social theory', in B. Adam, U. Beck \& J. van Loon (eds.), The Risk Society and Beyond. Critical Issues for Social Theory, I-3I. London: Sage Publications.

Adams, J. (1995), Risk. London/New York: Routledge.

Akalin, A. (2007), 'Hired as a caregiver, demanded as a housewife: Becoming a migrant domestic worker in Turkey', European Journal of Women's Studies I4 (3): 209-225.

Aldrich, H. E. \& R. Waldinger (I990), 'Ethnicity and entrepreneurship', Annual Review of Sociology I6: III-I35.

Andall, J. (2000), Gender, Migration and Domestic Service: The Politics of Black Women in Italy. Aldershot: Ashgate.

Anderson, Benedict (1983) Imagined Communities: Reflections on the Origin and Spread of Nationalism. London/New York: Verso.

Anderson, Bridget (2006), 'A very private business: Migration and domestic work', Working Paper no. 28. Centre on Migration, Policy and Society. http://www.compas. ox.ac.uk/fileadmin/files/pdfs/Bridget\%20Anderson\%20WPo628.pdf. Accessed 29 July 2009.

Anderson, Bridget (200I), 'Reproductive labour and migration', paper presented at the Sixth Metropolis Conference, Rotterdam, 26-30 November $200 \mathrm{I}$.

Anderson, Bridget (2000), Doing the Dirty Work? The Global Politics of Domestic Labour. London/New York: Zed Books.

Anderson, Bridget (I999), 'Overseas domestic workers in the European Union: Europe's invisible women', in J. Momsen (ed.), Gender, Migration and Domestic Service, II3-I3I. London: Routledge.

Anderson, B. \& J. O'Connel Davidson (2004), Demand and trafficked labour. Geneva: International Organisation for Migration.

Anthias, F. (200I), 'The material and the symbolic in theorising social stratification: Issues of gender, ethnicity and class', British Journal of Sociology 52 (3): 367-39o.

Anthias, F. (2000), 'Metaphors of home: Gendering new migrations to Southern Europe', in Anthias, F. \& G. Lazaridis (eds.), Gender and Migration in Southern Europe: Women on the Move, I5-49. Oxford: Berg.

Antoniewski, R. (I997), 'Przyczynek do badań nad nieformalnym rynkiem pracy cudzoziemców: Funkcjonowanie "giełdy pracy" w jednej z podwarszawskich miejscowości (Pilot study for researching the informal labour market for foreigners. The functioning of the "job market" in one of Warsaw's suburbs)', Warsaw CMR Working Papers. http://www.migracje.uw.edu.pl/publ/549. Accessed 30 July 2009.

Arendt, H. (2000), Kondycja ludzka (The Human Condition), Warsaw: Aletheia Grupa Wydawnicza.

Aronson, J. \& Sh. M. Neysmith (I996), “You're not just in there to do the work": Depersonalising policies and the exploitation of home care workers' labor', Gender and Society io (I): 59-77. 
Ashwin, S. (2000), 'Gender, state and society in Soviet and post-Soviet Russia', in S. Ashwin (ed.), Gender, State and Society in Soviet and Post-Soviet Russia, I-29. London: Routledge.

Ayres, R. \& T. Barber (2006), 'Statistical analysis of female migration and labour market integration in the EU', Working Paper 3, Projekt FemiPol: Frankfurt/Main. http://www.femipol.uni-frankfurt.de/docs/working_papers/wp3/Statistical_analysis.pdf. Accessed 29 October 2008.

Baldassar, L. (2007), 'Transnational families and aged care: The mobility of care and the migrancy of ageing', Journal of Ethnic and Migration Studies 33 (2): 275-297.

Barburska, O. (2006), 'Polska wobec europejskich aspiracji Ukrainy (Poland in relation to the European aspirations of Ukraine)', in J. Borkowski (ed.), Rola Polski w ksztaltowaniu polityki wschodniej Unii Europejskiej na przykladzie Ukrainy (The Role of Poland in shaping the Eastern politics of the European Union on the example of Ukraine), 5I-64. Warsaw: Centrum Europejskie Uniwersytetu Warszawskiego.

Beck, U. (2000), 'Risk society revisited: Theory politics and research programmes', in B. Adam, U. Beck \& J. van Loon (eds.), The Risk Society and Beyond: Critical Issues for Social Theory, 2II-229. London: Sage Publications.

Beck, U. (I992), Risk Society: Toward a New Modernity. New Delhi: Sage Publications.

Bednarski, M., E. Kryńska, K. Pater \& M. Walewski (2008), 'Przyczyny pracy nierejestrowanej w Polsce (The reasons for undeclared work in Poland)'. Warsaw: Ministerstwo Pracy i Polityki Społecznej (Ministry of Work and Social Policy).

Berdychowska, B. (I998) (ed.), Mniejszości narodowe w Polsce: Praktyka po I989 roku. (National Minorities in Poland: Practice after 1989). Warsaw: Wydawnictwo Sejmowe.

Bieniecki, M., H. Bojar, J. Frelak, A. Gąsior-Niemiec, J. Konieczna \& J. Kurczewska (2005), Regulacja migracji zarobkowej: Wyzwania dla Ukrainy w kontekście polskich doświadczeń (Regulation of Labour Migration: Challenges for Ukraine in the Context of Polish Experiences). Warsaw: CPCFPU, PAUCI, Instytut Spraw Publicznych.http:// www.isp.org.pl/?v=page\&c=2\&id=I43\&ln=pl\&a=I. Accessed 2 June 2006.

Bilsborrow, R. \& H. Zlotnik (I995), 'The systems approach and the measurement of the determinants of international migration', in R. van der Erf \& L. Heering (eds.), Causes of International Migration, 6I-77. Brussels: ESCE-EC-AEAC.

Black, J. (I997), Oxford Dictionary of Economics. Oxford/New York: Oxford University Press.

Bojar, H., A. Gąsior-Niemiec, M. Bieniecki \& M. Pawlak (2006), Migranci na rynku pracy w Polsce: Wyniki badań przeprowadzonych wśród migrantów ekonomicznych i pracowników polskich (Migrants on the Polish Labour Market: The Results of Research Carried out among Labour Migrants and Polish Workers). Warsaw: Institute of Public Affairs. http://www.isp.org.pl/files/6832569250505I77001119877937. pdf. Accessed 30 June 2007.

Boratynski, J., I. Burakowskyj \& B. Dodonow (2004), Więcej niż sąsiedztwo: Rozszerzona Unia Europejska i Ukraina - nowe relacje (More than Neighbours: The Enlarged European Union and Ukraine - New Relations). Stefan Batory Foundation, Warsaw. International Renaissance Foundation, Kiev. http://www.batory.org.pl/ mnarod/pub.htm\#granica. Accessed ro August 2006.

Bourdieu, P. (I986), 'The forms of capital', in J. G. Richardson (ed.), Handbook of Theory and Research for Sociology for Education, 24I-258, New York/London: Greenwood Press. 
Bourdieu, P. (I983), 'Ökonomisches Kapital, kulturelles Kapital, soziales Kapital', in R. Kreckel (ed.), Soziale Ungleichheiten (Social Disparity) (Soziale Welt, Sonderheft 2) (Social World, Special edition 2), I83-I98. Goettingen: Otto Schartz \& Co.

Boyd, M. (2004), 'International labour migration of women: Past, present and future challenges in North America and Europe', paper prepared for the Consultative Meeting on Migration and Mobility and How this Movement Affects Women, organised by the United Nations Division for the Advancement of Women Malmö, Sweden, 2-4 December 2003.

Boyd, M. (1989), 'Family and personal networks in international migration: Recent developments and new agendas', International Migration Review 23 (3): 638-670.

Bradley Dunbar Associates Consortium (2002), 'Effects on Western Ukraine of Poland's accession to the EU'. DFID Project. Polish-Ukrainian Cross Border Regional Development Agency. http://www.upcbcagency.org.ua. Accessed I5 October 2008.

Burant, S. R. (I993), 'International relations in a regional context: Poland and its Eastern Neighbours', Europe-Asia Studies 45 (3): 395-4I8.

Caceres, M. J. (200I), Concealed Unemployment in Ukrainian Industry: A Statistical Analysis. Geneva: International Labour Office.

Castles, S. \& M. J. Miller (I999), The Age of Migration. Hampshire/London: Macmillan Press Ltd.

CBOS (Public Opinion Research Centre) (2008), Co im zawdzięczamy? Opinie w przeddzień święta babć $i$ dziadków (What are We Grateful for? Attitudes before the Grandmother and Grandfather Holiday), January. BS/3/2008. Joanna Szczepańska. http://www.cbos.pl/SPISKOM.POL/2008/K_003_08.PDF. Accessed 2 October 2008.

CBOS (Public Opinion Research Centre) (2006), Stosunek Polaków do innych narodów. (Attitude of Poles towards Other Nations) Komunikat z Badań. BS I48/2006. http:// www.cbos.pl/SPISKOM.POL/2006/K_I48_06.PDF. Accessed I7 November 2010.

CBOS (Public Opinion Research Centre) (2005), Sympatie i niechęć do innych narodów (Sympathy and Dislike of Other Nations). Komunikat z Badań BS I96/2005. http:// www.cbos.pl/SPISKOM.POL/2005/K_I96_05.PDF. Accessed I7 November 2010.

CBOS (Public Opinion Research Centre) (2004), Wpływ ostatnich wydarzeń na Ukrainie na stosunek Polaków do Ukraińców (Influence of Recent Events in Ukraine on Attitudes of Poles towards Ukrainians). Komunikat z Badań BS I90/2004. http:// www.cbos.pl/SPISKOM.POL/2004/K_I90_04.PDF. Accessed I7 November 2010.

CBOS (Public Opinion Research Centre) (2000), Polacy wobec ludzi starych $i$ wtasnej starości (Poles' Attitudes towards Elderly People and towards their Own Ageing), December BS/I72/2000. Bogna Wciórka. http://www.cbos.pl/SPISKOM.POL/2000/ K_I72_oo.PDF. Accessed 2 October 2008.

CBOS (Public Opinion Research Centre) (I999a), Sympatia i niechęć do innych narodów (Sympathy and Dislike of Other Nations). Komunikat z Badań. BS I73/99. http:// www.cbos.pl/SPISKOM.POL/I999/K_I73-99.PDF. Accessed I7 November 2010.

CBOS (Public Opinion Research Centre) (I999b), Stosunek do obcokrajowców przebywajacych $w$ Polsce (Attitude towards Foreigners in Poland). Komunikat z Badań BS I6I/99. http://www.cbos.pl/SPISKOM.POL/I999/K_I6I_99.PDF. Accessed I7 November 2010.

CBOS (Public Opinion Research Centre) (1998), Stosunek Polaków do innych narodowości (Attitudes of Poles towards Other Nations). Komunikat z Badań BS 158/158/98. http://www.cbos.pl/SPISKOM.POL/I998/K_I58_98.PDF. Accessed I7 November 2010. 
CIS (200I), Informator o organizacjach i instytucjach działających na polu pomocy społecznej w powiecie warszawskim: 200I (Guidebook on Organisations and Institutions Active in Social Help in the Warsaw Poviat: 200I). Warsaw: Stowarzyszenie Klon/Jawor.

Chapkis, W. (2003), 'Trafficking, migration and the law: Protecting innocents, punishing immigrants', Gender and Society I7 (6): 923-937.

Chapman, M. (I978), 'On the cross-cultural study of circulation', International Migration Review I2 (4): 559-569.

Chapman, M. \& M. R. Prothero (I983-I984) 'Themes on circulation in the Third World', International Migration Review I7 (4): 597-632.

Chin, C. B. N. (1997), 'Walls of silence and late twentieth century representations of the foreign female domestic workers: The case of Filipina and Indonesian female servants in Malaysia', International Migration Review 3I (2): 353-385.

Compact Oxford English Dictionary of Current English (2008), 3rd edition revised. Oxford: Oxford University Press.

Clarke, L. \& J. F. Short, Jr. (I993), 'Social organization and risk: Some current controversies', Annual Review of Sociology I9: 375-399.

Coleman, J. S. (I990), Foundations of Social Theory. Cambridge: Harvard University Press.

Constable, N. (2003), 'Filipina workers in Hong Kong homes: Household rules and relations', in B. Ehrenreich \& A. R. Hochschild (eds.), Global Woman: Nannies, Maids and Sex Workers in the New Economy. New York: Metropolitan Books.

Cox, R. (2006), The Servant Problem: The Home Life of a Global Economy. London: I. B. Tauris \& Company Limited.

Cyrus, N. (2008), 'Being illegal in Europe: Strategies and policies for fairer treatment of migrant domestic workers', in H. Lutz (ed.), Migration and Domestic Work: A European Perspective on a Global Theme, I77-I95. Aldershot: Ashgate.

Czekanowski, P. (2002), 'Rodzina w życiu osób starszych i osoby starsze w rodzinie (Family in the life of elderly people and elderly people in the family)', in B. Synak (ed.), Polska starość (Polish Seniority). Gdańsk: Wydawnictwo Uniwersytetu Gdańskiego.

De Jong, G. F. \& J. Fawcett (I98I), 'Motivations for migration: An assessment and a value: Expectancy research model', in G. F. De Jong \& R. Gardner (eds.), Migration Decision Making: Multidisciplinary Approaches to Microlevel Studies in Developed and Developing Countries, 15-58. New York: Pergamon Press.

Degiuli, F. (2007), 'Work with no boundaries', European Journal of Women's Studies I4 (3): $193-207$.

Derzhkomstat (State Statistical Committee of Ukraine) (2003), 2003. http://www.ukrstat.gov.ua. Accessed I7 November 2010.

Domaradzka, E. (2004), 'Popyt na pracę cudzoziemców w gospodarstwach domowych (Demand for the work of foreigners in private households)', in S. Golinowska (ed.), Popyt na pracę cudzoziemców (Demand for the Work of Foreigners), I82-I86. Warsaw: IPiSS.

Donato, K. M., D. Gabaccia, J. Holdaway, M. Manalansan IV \& P. R. Pessar (2006), 'A glass half full? Gender in migration studies', International Migration Review 40 (I): 3-26.

Drbohlav, D. \& E. Janska (2004), 'Current Ukrainian and Russian migration to the Czech Republic: Mutual similarities and differences', in A. Górny \& P. Ruspini (eds.), Migration in the New Europe: East-West Revisited. Basingstoke/Hampshire: Palgrave Macmillan. 
Drbohlav, D. (2003), 'Immigration and the Czech Republic (with a special focus on the foreign labor force)', International Migration Review 37 (I): I94-224.

Doeringer, P. B. \& M. Piore (I97I), International Labour Markets and Manpower Analysis. Lexington: Heath.

Douglas, M. (I992), Risk and Blame: Essays in Cultural Theory. London/New York: Routledge.

Douglas, M. (1985), Risk Acceptability According to the Social Sciences. Social Research Perspectives II. New York: Russell Sage Foundation.

Douglas, M. \& A. Wildavsky (1982), Risk and Culture: An Essay on the Selection of Technical and Environmental Dangers. Berkeley: Los Angeles University of California Press.

Dudwick, N., R. Srinivasan \& J. Braithwaite (2002), Ukraine: Gender Review. Washington, D.C.: World Bank.

Ehrenreich, B. \& A. R. Hochschild (eds.), (2003), Global Woman: Nannies, Maids and Sex Workers in the New Economy. New York: A Metropolitan/Owl Book, Henry Holt and Company.

Elkan, W. (1959), 'Migrant labor in Africa: An economist's approach', American Economic Review 49 (2): I88-I97.

England, P. (2005), 'Emerging theories of care work', Annual Review of Sociology 31: 38I-99.

Escrivá, A. \& E. Skinner (2008), 'Domestic work and transnational care chains in Spain', in H. Lutz (ed.), Migration and Domestic Work: A European Perspective on a Global Theme, II3-I26. Aldershot: Ashgate.

ETUC (European Trade Union Confederation) (2005), 'Out of the shadows conference. Organising and protecting domestic workers in Europe: The role of trade unions', report. European Trade Union Confederation. Primavera Quint: Amsterdam. http://www.etuc.org/IMG/pdf/Raort_dosmestic_workers.pdf. Accessed 3 October 2008.

European Foundation for the Improvement of Living and Working Conditions (2007), Gender and Career Development Report. http://www.eurofound.europa.eu/pubdocs/2007/23/en/I/efo723en.pdf. Accessed io April 2007.

Eurostat (2005), Health in Europe, Data 1998-2003. Luxemburg for Official Publications of the European Communities. http://epp.eurostat.ec.europa.eu/cache/ITY_OFFPUB/KS-7I-05-I82/EN/KS-7I-05-I82-EN.PDF. Accessed 8 August 20II.

Faist, T. (I997), 'The crucial meso-level in migration', in T. Hammar, G. Brochmann, K. Tamas \& T. Faist (eds.), International Migration, Immobility and Development. Multidisciplinary Perspectives, I87-219. Oxford/New York: Berg.

Fasano, L. \& F. Zucchini (2002), 'Local implementation of the consolidated law on immigration', The Seventh Italian Report on Migrations 2001. Milan: Fondazione per le Iniziative e lo Studio sulla Multietnicita.

Fawcett, J. T. \& F. Arnold (I987), 'Explaining diversity: Asian and Pacific immigration systems', in J. T. Fawcett \& B. V. Carino (eds.), Pacific Bridges: The New Immigration from Asia and the Pacific Islands, 453-474. Staten Island: Center for Migration Studies.

Fihel, A. (2007), 'Cechy społeczno-demograficzne i rozmieszczenie przestrzenne cudzoziemców w Polsce (The socio-demograhpic characteristics and the spatial distribution of foreigners in Poland)', in A. Górny, A. Grzymała-Kazłowska, E. Kępińska, A. Fihel \& A. Piekut (eds.), 'Od zbiorowości do społeczności: rola migrantów osiedleńczych w tworzeniu się społeczności migranckich w Polsce (From a group to community: The role of settled migrants in the development of migrant 
communities in Poland)', CMR Working Papers 27/85. http://www.migracje.uw. edu.pl/publ/556. Accessed 29 July 2009.

Fidelis, M. (2004), 'Equality through protection: The politics of women's employment in postwar Poland, I945-I956', Slavic Review 63 (2): 30I-324.

Foucault, M. (I99I), 'Governmentality', in G. Burchell, C. Gordon \& P. Miller (eds), The Foucault Effect: Studies in Governmentality, II9-I50. Hemel Heampstead: Harvester Wheatsheaf.

Frąckiewicz, L. (2002), 'Społeczne i ekonomiczne konsekwencje procesu starzenia się ludności (Social and economic consequences of the ageing process of the population)', in L. Frąckiewicz (ed.), Polska a Europa: Procesy demograficzne u progu XXI wieku: Proces starzenia się ludności Polski i jego społeczne konsekwencje (Poland and Europe: Demographic Processes at the Dawn of the 21st century: Process of Ageing of Poland's Population and its Social Consequences), II (27). Katowice: Polskie Towarzystwo Polityki Społecznej.

Frątczak, E. (2002), 'Proces starzenia się ludności Polski (The process of ageing of Polish population)', Studia Demograficzne 2 (I42).

Freedom House Country Report: Ukraine (2004). http://www.freedomhouse.org/ template.cfm?page $=47 \&$ nit $=347 \&$ year=2004. Accessed I5 November 2010.

Gamburd, M. R. (2000), The Kitchen Spoon's Handle: Transnationalism and Sri Lanka's Migrant Housemaids. Ithaca: Cornell University Press.

Gardner, K. \& R. Grillo (2002), 'Transnational households and ritual: An overview', Global Networks 2 (3): I79-I90.

Giddens, A. (1999), Risk: The Runaway World Debate. http://www.bbc.co.uk/radio4/ reithi999/lecture2.shtml. Accessed 2 July 2007.

Giddens, A. (1994), 'Living in a post-traditional society', in U. Beck, A. Giddens \& S. Lash (eds.), Reflexive Modernisation: Politics, Tradition and Aesthetics in the Modern Social Order, 56-io9. Cambridge: Polity Press.

Giddens, A. (1990), The Consequences of Modernity. Cambridge: Polity Press.

Giddens, A. (I979), Central Problems in Social Theory: Action, Structure and Contradiction in Social Analysis. Houndmills: MacMillian.

Glass, C. \& E. Fodor (2007), 'From public to private maternalism? Gender and welfare in Poland and Hungary after I989', Social Politics: International Studies in Gender, State \& Society I4 (4): 323-350.

Goffman, E. (1967), Interaction Ritual: Essays on Face-to-Face Behaviour. New York: Pantheon Books.

Goss, J. \& B. Lindquist (I995), 'Conceptualising international labour migration: A structuration perspective', International Migration Review 29 (2): 3I7-35I.

Golinowska, S. (2004) (ed.), 'W trosce o prace: Raport o rozwoju społecznym Polska 2004 (Concern for Work: Report on Social Development Poland 2004)', Warsaw: UNDP. http://www.undp.org.pl/nhdr/nhdr2004.php. Accessed 30 May 2006.

Górny A., I. Grabowska-Lusińska, M. Lesińska \& M. Okólski (eds.) 2oIo, Immigration to Poland: Policy, Dmployment, Integration. Warsaw: Wydawnictwo Naukowe Scholar.

Górny, A., A. Grzymała-Kazłowska, E. Kępińska, A. Fihel \& A. Piekut (2007), 'Od zbiorowości do społeczności: rola migrantów osiedleńczych w tworzeniu się społeczności immigranckich w Polsce (From settlement towards community: The role of settlement migrants in the formation of immigrant communities and a multicultural society)', Working Papers Series 27/85. http://www.migracje.uw.edu. $\mathrm{pl} / \mathrm{publ} / 556$. Accessed 29 July 2009 . 
Górny, A. \& E. Kępińska (2004), 'Mixed marriages in migration from the Ukraine to Poland', Journal of Ethnic and Migration Studies 30 (2): 353-372.

Górny, A. \& D. Stola (200I), 'Akumulacja i wykorzystanie migracyjnego kapitału społecznego (Accumulation and use of migrant social capital)', in E. Jaźwinska \& M. Okólski (eds.), Ludzie na Huśtawce. Migracje między Peryferiami Polski a Zachodem (People on a swing: Migration between peripheries of Poland and the West). Warsaw: Wydawnictwo Naukowe Scholar.

Grabowska-Lusińska, I. \& A. Żylicz (2008), Czy polska gospodarka potrzebuje cudzoziemców? (Does the Polish economy need foreigners?). Warsaw: Centre for Migration Research, University of Warsaw.

Granovetter, M. (I973), 'The strength of weak ties', American Journal of Sociology 78 (6): I360-1380.

Grzymała-Kazłowska, A. (ed.) (2008), Między wielością a jednością. Integracja odmiennych grup i kategorii migrantów w Polsce (Between Diversity and Unity: Integration of Different Migrant Groups and Categories in Poland). Warsaw: OBM WNE UW.

Guilmoto, Z. Ch. \& F. Sandron (200I), 'The internal dynamics of migration networks in developing countries', Population: An English Selection I3 (2): I35-I64.

Gurak, D. T. \& F. Caces (I992), 'Migration networks and the shaping of migration systems', in M. M. Kirtz, L. L. Lim \& H. Zlotnik (eds.), International Migration Systems: A Global Approach, I50-I76. Oxford: Warendon Press.

GUS (Central Statistical Office) (2010), Concise Statistical Yearbook of Poland 2010. Warsaw: Central Statistical Office.

GUS (Central Statistical Office) (2007), Concise Statistical Yearbook of Poland 2007. Warsaw: Central Statistical Office.

GUS (Central Statistical Office) (2005), Praca nierejestrowana w Polsce w 2004 roku (Unregistered Work in Poland in 2004). Informacje i Opracowania Statystyczne. Warsaw: Central Statistical Office.

GUS (Central Statistical Office) (2003), Podstawowe informacje o rozwoju demograficznym Polski do 2003 roku (Basic Information about the Demographic Developments in Poland until 2003). Warsaw: Central Statistical Office.

GUS (Central Statistical Office) (2002), Migracje wewnętrzneludności (Internal Migration of Population). Warsaw, December 2002. http://www.stat.gov.pl/cps/rde/xbcr/gus/ PUBL_migracje_wewnetrzne_ludnosci.pdf. Accessed 2 October 2008.

Haidinger, B. (2008), 'Contingencies among households: Gendered division of labour and transnational household organization - The case of Ukrainians in Austria', in H. Lutz (ed.), Migration and Domestic Work: A European Perspective on a Global Theme. Aldershot: Ashgate.

Halik, J. (ed.) (2002), Starzy ludzie w Polsce: Społeczne i zdrowotne skutki starzenia sie spoteczeństwa (Old People in Poland: Social and Health Consequences of Population Ageing). Warsaw: Institute of Public Affairs.

Halustyan, Y., T. Doroshok, L. Kovalchuk, K. Levchenko, I. Trubavina \& I. Shvab (2006), Problems of Children of Labour Migrants: An Analysis of the Situation. Kiev: The International Women Rights Centre La Strada - Ukraine/Ukrainian Institute for Social Research after Olexander Yaremenko.

Hałagida, I. (2002), Ukraińcy na Zachodnich i Pótnocnych Ziemiach Polski 1947-1957 (Ukrainians on Western and Northern Polish Territories 1947-1957). Warsaw: Instytut Pamieci Narodowej (Institute of National Remembrance).

Hammersley, M. \& P. Atkinson (1983), Ethnography Principles in Practice. London/New York: Tavistock Publications. 
Heinen, J. \& M. Wator (2007), 'Childcare in Poland before, during, and after the transition: Still a women's business', Social Politics: International Studies in Gender, State \& Society I4 (4): I89-2I6.

Hess, S. (2002), 'Au Pairs als informelle Haushaltsarbeiterinnen: Flexibilisierung und Ethnisierung der Versorgungsarbeit (Au pairs as informal domestic workers: flexibilisation and ethnization of care work)', in C. Gather, B. Geissler \& M. Rerrich (eds.), Weltmarkt Privathaushalt. Bezahlte Hausarbeit im globalen Wandel (The World Market Private Household: Remunarated Domestic Work in Global Change), I03-II9. Münster: Westfälisches Dampfboot.

Hochschild, A. (2003), 'Love and gold', in B. Ehrenreich \& A. R. Hochschild (eds.), Global Woman: Nannies, Maids and Sex Workers in the New Economy, 15-30. New York: Henry Holt and Co.

Hoffman-Novotny, H. J. (I98I), 'A sociological approach toward a general theory of migration, in M. M. Kritz, C. B. Keely, S. M. Tomasi (eds.), Global Trends in Migration: Theory and Research on International Population Movements. New York: Center of Migration Studies.

Hondagneu-Sotelo, P. (2003), 'Gender and immigration: A retrospective and introduction', in P. Hondagneu-Sotelo (ed.), Gender and U.S. Immigration: Contemporary Trends. Berkeley/Los Angeles: University of California Press.

Hondagneu-Sotelo, P. (200I), Doméstica: Immigrant Workers Cleaning and Caring in the Shadows of Affluence. Berkeley: University of California Press.

Hondagneu-Sotelo, P. (I994), Gendered Transitions: Mexican Experiences of Immigration. Berkeley/Los Angeles/London: University of California Press.

Hondagneu-Sotelo, P. \& E. Avila (I997), 'I'm here but I'm there: The meanings of Latina transnational motherhood', Gender and Society II (5): 548-57I.

Hugo, G. J. (I998), 'Migration as survival strategy: The family dimension of migration', in Proceedings of the United Nations Expert Group Meeting on Population Distribution and Migration, Santa Cruz, Bolivia, I8-22 January I993, I39-I49. New York: United Nations.

Human Rights Watch Report (2003), Women's Work: Discrimination Against Women in the Ukrainian Labour Force. http://www.hrw.org/reports/2003/ukraineo803. Accessed 30 May 2006.

Humm, M. (I995), The Dictionary of Feminist Theory. New York; London: Prentice Hall/Harvester Wheatsheaf/Ohio State University Press.

Hune, S. (I99I), 'Migrant women in the context of the International Convention on the Protection of the Rights of All Migrant Workers and Members of Their Families', International Migration Review 25 (4): 800-8I7.

Iglicka, K. (2000), 'Ethnic division on emerging foreign markets in Poland during the transition period', Europe-Asia Studies 52 (7): I237-I255.

Iglicka, K. (ed.) (2003), Migration and Labour Markets in Poland and Ukraine. Warsaw: Institute of Public Affairs.

Iglicka, K. \& K. Sword (eds.) (I999), The Challenge of East-West Migration for Poland: Studies in Russia and East Europe. Great Britain: MacMillan Press Ltd.

IOM (2008), Ukrainian Migrants on the Polish Labour Market. Kiev: International Organization for Migration (unpublished manuscript).

Ismail, M. (I999), 'Maids in space: Gendered domestic labour from Sri Lanka to the Middle East', in J. H. Momsen, (ed.), Gender, Migration and Domestic Service, 223-237. London: Routledge.

Jakubiak, M. (2002), 'Macroeconomic situation of Ukraine', paper presented at conference of the Stefan Batory Foundation in 2002. CASE. 
Jaeger C. C., O. Renn, E. A. Rosa \& T. Webler (200I), Risk, Uncertainty and Rational Action. London/Sterling: Earthscan Publications Ltd.

Jølstad, F. O. (2005), 'Transforming undeclared work into regular employment', presentation at ETUC seminar, Brussels.

Kacharaba, S. (2003), Emihracja z Zahidnoj Ukrainy (1991-1939) (Emigration from Western Ukraine (1991-1939)) Lviv: Lvivski Nacjonalnij Universitet im. Ivana Franka.

Katz, E. \& O. Stark (I986), 'Labour migration and risk aversion in less developed countries', Journal of Labour Economics 4 (I): I34-I49.

Keough, L. J. (2006), 'Globalising "post-socialism”: Mobile mothers and neoliberalism at the margins of Europe', Anthropological Quarterly 79 (3): 43I- 46I.

Kempadoo, K. (2005), 'From moral panic to global justice: Changing perspectives on trafficking' in K. Kempadoo, J. Sanghera \& B. Pattanaik (eds.), Trafficking and Prostitution Reconsidered: New Perspectives on Migration, Sex Work, and Human Rights. London: Paradigm Publishers.

Kersten, K. (I993), Miedzy Wyzwoleniem a Zniewoleniem. Polska 1944-1956 (Between liberation and constraint: Poland 1944-1956). London: Aneks Publisher.

Kępińska, E. (2007), 'Recent trends in international migration: The 2007 SOPEMI report for Poland', CMR Working Papers 29/87. http://www.migracje.uw.edu.pl/ publ/558. Accessed 29 July 2009.

Kępińska, E. (2006), 'Recent trends in international migration: The 2006 SOPEMI report for Poland', CMR Working Papers I5/73. http://www.migracje.uw.edu.pl/ publ/394. Accessed 29 July 2009.

Kępińska, E. (2005), 'Recent trends in international migration: The 2005 SOPEMI report for Poland', CMR Working Papers 2/6o. http://www.migracje.uw.edu.pl/ publ/396. Accessed 29 July 2009.

Kępińska, E. (2004), 'Recent trends in international migration: The 2004 SOPEMI report for Poland', CMR Working Papers 56. http://www.migracje.uw.edu.pl/ publ/398. Accessed 29 July 2009.

Kępińska, E. (2003), 'Recent trends in international migration: The 2003 SOPEMI report for Poland', CMR Working Papers 52. http://www.migracje.uw.edu.pl/ publ/583. Accessed 29 July 2009.

Kępińska, E. \& M. Okólski (2002), 'Recent trends in international migration: The 2002 SOPEMI report for Poland', CMR Working Papers 48. http://www.migracje.uw. edu.pl/publ/284. Accessed 29 July 2009 .

Kępińska, E. \& D. Stola (2004), 'Migration policy and politics in Poland', in A. Górny \& P. Ruspini (eds.), Migration in the New Europe: East-West Revisited, 159-176. Basingstoke/Hampshire: Palgrave Macmillan.

Kicinger, A. (2005), 'Between Polish interests and the EU influence: Polish migration policy development I989-2004', Central European Forum for Migration Research Working Paper 9/2005. http://www.cefmr.pan.pl/docs/cefmr_wp_2005-09.pdf. Accessed 29 July 2009.

Kindler, M. (2008a), 'Risk and risk strategies in migration: Ukrainian domestic workers in Poland', in H. Lutz (ed.), Migration and Domestic Work, I45-I6O. Aldershot: Ashgate.

Kindler, M. (2008b), 'Niewidoczne pracownice: Ukraińskie kobiety pracujące w charakterze pomocy domowych w Polsce (Invisible workers: Ukrainian women as domestic workers in Poland)', in K. Slany (ed.), Migracje kobiet (Migration of Women), 209-220. Cracow: Wydawnictwo Uniwersytetu Jagiellońskiego.

Kindler, M. (2009a), 'The relationship to the employer in migrant's eyes: The domestic work Ukrainian migrant women in Warsaw', Les cahiers de l'URMIS I2. 
http://urmis.revues.org/index853.html.

Kindler, M. (2009b), 'Wyobrażenia migracji: Między możliwościami a ryzykiem (Images of migration: Between opportunities and risk)', Studia Migracyjne-Przeglad Polonijny XXXV: I. Warsaw: WDN PAN.

Kindler, M. \& M. Szulecka (20I0), 'Integracja ekonomiczna migrantek na polskim rynku pracy: Przyczynek do badań (Economic integration of migrant women in the Polish labour market: Contribution to the research)', in M. Kindler \& J. Napierała (ed.), Migracje kobiet przypadek Polski. (Migration of Women: The Case of Poland), I38-I6o. Warsaw: WN Scholar.

King, R. \& E. Zontini (2000), 'The role of gender in the South European immigration model', Papers: Revista de sociologia 60: 35-52.

Kloc-Nowak, W. (2007), 'Functioning of female imigrants from Ukraine on the Polish labour market: Present situation and recommendations for the receiving society'. Analizy, Reporty, Ekspertyzy 9/07. Warsaw: Association for Legal Intervention. http://www.interwencjaprawna.pl/docs/ARE-907-Ukrainki-na-polskim-rynkupracy.pdf. Accessed 3 October 2008.

Knight, F. (I97I), Risk, Uncertainty and Profit. Chicago: University of Chicago Press.

Kofman, E. (I999), 'Female "birds of passage" a decade later: Gender and immigration in the European Union', International Migration Review 33 (2): $269-299$.

Kofman, E., A. Phizacklea, P. Raghuram \& R. Sales (2000), Gender and International Migration in Europe: Employment, Welfare and Politics. London: Routledge.

Konieczna, J. (2003), Polacy-Ukraińcy, Polska-Ukraina. Paradoksy Stosunków Sąsiedzkich (Poles-Ukrainians, Poland-Ukraine: The Paradoxes of Neighbourly Relations). Instytut Socjologii (Institute of Sociology), University of Warsaw. http://www.batory.org.pl/ $\mathrm{ftp} /$ program/forum/ukraina_ue/pOlacy_ukraincy_paradoksy_stosunkow.pdf. Accessed 2 October 2008.

Koryś, P. \& A. Weinar (2005), 'Poland', in J. Niessen \& Y. Schibel (eds.), Immigration as a Labour Market Strategy: European and North American Perspectives, I29-I58. Brussels: Migration Policy Group.

Kritz, M., L.L. Lim \& H. Zlotnik (eds.) (I992), International Migration Systems: A Global Approach. Oxford: Clarendon Press.

Krzyszkowski, J. (2002), 'Social care and social work in Poland since I989: Evidence from recent research', Social Work in Europe 10 (3): 7I-76.

Kuper, A. \& J. Kuper (eds.), (1996), The Social Sciences Encyclopaedia, 2nd edition. London/New York: Routledge.

Lash, S. (I993), 'Reflexive modernization: The aesthethic dimension.' Theory, Culture and Society Io: I-23.

LeRoy, F. S. \& L. D. Singell, Jr. (I987), 'Knight on risk and uncertainty', The Journal of Political Economy 95 (2): 394-406.

Lupton, D. (I999), Risk. London/New York: Routledge.

Lutz, H. (2008), 'When homes become a workplace: Domestic work as an ordinary job?', in Lutz, H. (ed.), Migration and Domestic Work: A European Perspective on a Global Theme, 43-60. Aldershot: Ashgate.

Lutz, H. (2004), 'Life in the twilight zone: Migration, transnationality and gender in the private household', Journal of Contemporary European Studies I2 (I) 47-55.

Łodziński, S. (2003), 'Dyskryminacja czy nierówność. Problemy dyskryminacji osób należących do mniejszości narodowych i etnicznych w Polsce po I989 roku (Discrimination or inequality: Discrimination problems of persons belonging to national and ethnic minorities in Poland after I989)', in K. Iglicka (ed.), Integracja czy dyskryminacja: polskie wyzwania i dylematy u progu wielokulturowości (Integration or 
discrimination: Poland's Challenges and Dilemas at the Dawn of Multiculturalism). Warsaw: Institute of Public Affairs.

Łukowski, W. (I997), 'Czy Polska staje się krajem imigracyjnym? (Is Poland becoming an immigration country?)', CMR Working Papers I2. http://www.migracje.uw.edu. $\mathrm{pl} / \mathrm{publ} / 43$. Accessed 29 July 2009 .

Mahler, J. S. (2003), 'Engendering transnational migration: A case study of Salvadorans. Introduction' in P. Hondagneu-Sotelo (ed.), Gender and U.S. Immigration: Contemporary Trends, 287-316. Berkeley/Los Angeles: University of California Press.

Malynovska, O. (2004), 'International migration in contemporary Ukraine: Trends and policy', Global Migration Perspectives I4. http://www.gcim.org/attachements/ GMP\%20No\%20I4.pdf. Accessed 30 May 2006.

Massey, D. S., J. Arango, G. Hugo, A. Kouaoci, D. Pellgrino \& J. E. Taylor (I993), 'Theories of international migration: A review and appraisal', Population and Development I9 (3): 43I-466.

Misra, J., S. Merz \& J. Woodring (2004), 'The globalization of carework: Immigration, economic restructuring and the world-system', paper presented at the annual meeting of the American Sociological Association, San Francisco.

Momsen, J. H. (ed.), (I999), Gender, Migration and Domestic Service. London: Routledge.

Morokvasic, M. (I984), 'Birds of passage are also women...', International Migration Review special issue 'Women in migration' I8 (4): 886-907.

Motyka, G. (2000), 'Problematyka stosunków polsko-ukraińskich w latach I939-I948 w polskiej historiografii po roku I989 (The theme of Polish-Ukrainian relations in the years I939-I948 in Polish historiography after I989)', in P. Kosiewski \& G. Motyka (eds), Historycy Polscy i Ukraińscy wobec Problemów XX wieku (Polish and Ukrainian Historians on Problems of the 2oth Century), I66-I78. Forum Europy Środkowo-Wschodniej, Fundacja im. Stefana Batorego. Cracow: Universitas.

Motyka, G. \& M. Wierzbicki (1997), Ocalone Archiwum Polski Podziemnej. Ziemie Wschodnie II RP w dokumentach ze zbioru Wojciecha Bukata (Saved Archives of Underground Poland: Eastern Land of the Second Republic of Poland in the Documents from the Collection of Wojciech Bukat). Warsaw: Instytut Studiów Politycznych Polskiej Akademii Nauk.

Moukarbel, N. (2009), Sri Lankan Housemaids in Lebanon: A Case of 'Symbolic Violence' and 'Everyday Forms of Resistance'. IMISCOE Dissertations Series. Amsterdam: Amsterdam University Press.

Murray, S. B. (I996), “We all love Charles": Men in childcare and the social construction of gender', Gender and Society 10 (4): $368-385$.

Näre, L. (2003), Ukrainian and Polish Domestic Workers in Naples: A Case of East-South Migration. http://www.migrationonline.cz. Accessed 27 October 2008.

Nunckowska, M. \& J. Perek-Białas (2004), 'Active ageing and European health care sector', National Report Poland. ICCR. http://www.iccr-international.org/activage/ docs/ActivAge-WP4-Poland.pdf. Accessed I5 October 2008.

Okólski, M. (2004), 'Migration trends in Central and Eastern Europe on the eve of the European Union enlargement: An overview', in A. Górny \& P. Ruspini (eds.), Migration in the New Europe: East-West Revisited, 23-48. Basingstoke/Hampshire: Palgrave Macmillan.

Okólski, M. (200I), 'Incomplete migration: A new form of mobility in Central and Eastern Europe: The case of Polish and Ukrainian Migrants', in C. Wallace \& D. Stola, (eds.), Patterns of Migration in Central Europe. New York: Palgrave.

Okólski, M. (I998), 'Transformacja mobilności przestrzennej a nowe formy migracji 
międzynarodowych', paper presented at VII Conference of Faculty of Sciences University of Warsaw, Kazimierz Dolny.

Okólski, M. (I997), 'Najnowszy ruch wedr wkowy z Ukrainy do Polski. Charakterystyka Strumieni, cech migrantów i okoliczności pobytu w Polsce ('Recent migration from Ukraine to Poland)', ISS UW Working Papers, Migration Series I4. Warsaw. http:// www.migracje.uw.edu.pl/obm/pix/or4.pdf. Accessed on 4 July 2007.

Oksamytna, S. \& V. Khmelko (2004), 'The dynamics of household income stratification and change in some social exclusion indicators during post-Soviet transformation of Ukraine', University of Kiev-Mohyla Academy. Kiev International Institute of Sociology. Online: http://www.kiis.com.ua/txt/doc/ı90I2006/KhmelkoOksamytna.doc. Accessed I5 October 2008.

Panina, N. (2005), Ukrainian Society 1994-2005: Sociological Monitoring. Institute of Sociology, National Academy of Sciences of Ukraine. Kiev: Democratic Initiatives Foundation.

Parreñas, R. (2005), 'Long distance intimacy: Class, gender and intergenerational relations between mothers and children in Filipino transnational families', Global Networks 5 (4): 3I7-336.

Parreñas, R. (2004), 'The care crisis in the Philippines', in B. Ehrenreich \& A. R. Hochschild (eds.), (2004), Global Woman: Nannies, Maids and Sex Workers in the New Economy. New York: Henry Holt and Co.

Parreñas, R. S. (200I), Servants of Globalization: Women, Migration, and Domestic Work. Stanford: Stanford University Press.

Pavlychko, S. (1997), 'Progress on hold: Conservative faces of women in Ukraine', in M. Buckley (ed.), Post-Soviet Women: From the Baltic to Central Asia, 219-235. Cambridge: Cambridge Press.

Pei-Chia, L. (2003), 'Maid or Madam? Filipina migrant workers and the continuity of domestic labor', Gender and Society I7 (2): I87-208.

Perek-Białas, J., A. Ruzik (2004), 'Aktywizacja starszych ludzi na rynku pracy: bariery i możliwości (Activation of elderly people in the labour market: Barriers and opportunities)', in J. T. Kowaleski, P. Szukalski (eds.), Nasze starzejace sie spoleczenstwo. Nadzieje i zagrozenia (Our Ageing Society: Hopes and Dangers), 43I-439. Lódz: Lódz University Press.

Perek-Białas, J., A. Ruzik \& L. Vidovicova (2006), 'Active ageing policies in the Czech Republic and in Poland', International Social Science Journal 58 (I90): 559-570.

Pessar, P. R. (2003), 'Engendering migration studies: The case of new immigrants in the United States', in P. Hondagneu-Sotelo (ed.), Gender and U.S. Immigration: Contemporary Trends. Berkeley/Los Angeles: University of California Press.

Pessar, P. R. (I984), 'The linkage between the household and the workplace of Dominican women in the U.S.', International Migration Review special issue 'Women in migration' I8 (4): II88-I2II.

Peterlik, M. (2000), Handel Targowiskowy w Polsce (Bazaar trade in Poland). Warsaw: Instytut Badan nad Gospodarka Rynkowa.

Piore, M. J. (I979), Birds of Passage: Migrant Labour and Industrial Societies. Cambridge: Cambridge University Press.

Portes, A. (I998), 'Social capital: Its origins and applications in modern sociology', Annual Review of Sociology 24: I-24.

Pribilsky, J., (2004), “'Aprendemos a convivir”: Conjugal relations, co-parenting, and family life among Ecuadorian transnational migrants in New York City and the Ecuadorian Andes', Global Networks 4 (3): 313-334.

Prybytkowa, I. (2004), 'Migranci zarobkowi w hierarchii społecznej społeczeństwa 
ukraińskiego: status, wartości, strategie życiowe, styl i sposób życia (Labour migrants in the social hierarchy of Ukrainian society: status, values, life strategies, lifestyle)', Studia Socjologiczne 4 (I75): 6I-89.

Raiser, M. (I997), 'Informal institutions, social capital and economic transition: Reflections on a neglected dimension', Working Paper no. 25. http://www.ebrd.com/pubs/index.htm. Accessed 3 May 2006.

Rajiman, R., S. Schammah-Gesser \& A. Kemp (2003), 'International migration, domestic work, and care work: Undocumented Latina migrants in Israel', Gender Society I7: 727-749.

Ravenstein, E. G. (I885), 'The laws of migration', Journal of the Statistical Society of London 48 (2): I67-235.

Renn, O. (I992), 'Concepts of risk', in S. Krimsky \& D. Golding (eds.), Social Theories of Risk, 53-79. Westport/London: Praeger.

Revenko, A. (I997), 'Poverty in Ukraine', a report based on the Household Budget Survey of Goskomstat, Ukraine, prepared for the Department for International Development to contribute to the policy review of the Know How Fund. http://www. warwick.ac.uk/fac/soc/complabstuds/russia/Poverty.htm. Accessed 25 September 2010.

Rivas, L. M. (2003), 'Invisible labours: Caring for the independent person', in B. Ehrenreich, \& A. R. Hochschild (eds.), Global Woman: Nannies, Maids and Sex Workers in the New Economy. New York: Henry Holt and Co.

Romero, M. (I992), Maid in the USA. New York: Routledge.

Rosińska-Kordasiewicz, A. (20I0), 'Profesjonalizacja i personalizacja - strategie Polek pracujących w sektorze usług domowych w Neapolu (Profesionalisation and personalisation: Strategies of Polish women working in the domestic sector in Naples)', in J. Napierała \& M. Kindler (eds.), Migracje kobiet: przypadek Polski. (Migration of Women: The Case of Poland), 37-68. Warsaw: WN Scholar.

Rosińska-Kordasiewicz, A. (2008), 'Służąca, pracownik, domownik. Polki jako pomoce domowe w Neapolu w kontekście retradycjonalizacji instytucji (The servant, the worker, the home-person: Polish women as domestic workers in Neapol in the context of retraditionalisation of institituion)', Kultura i Spoleczenstwo 2 (52): 80-Io9.

Rutkowski, J. J. (1999), Welfare and the Labour Market in Poland: Social Policy during Economic Transition. World Bank Technical Paper no. 4I7.

Sarti, R. (2008), 'The globalisation of domestic service: An historical perspective', in H. Lutz, (ed.), Migration and Domestic Work: A European Perspective on a Global Theme, 77-98. Aldershot: Ashgate.

Sarti, R. (2006), 'Domestic service: Past and present in Southern and Northern Europe', Gender Q History I8 (2): 222-245.

Saxonberg, S. \& D. Szelewa (2007), 'The continuing legacy of the Communist legacy? The development of family policies in Poland and the Czech Republic', Social Politics: International Studies in Gender, State Q Society I4 (4): 35I-379. http://sp.oxfordjournals.org/cgi/content/full/jxmoI7vi. Accessed 3 December 2007.

Schiffauer, W. (2006), 'Transnationale Solidaritätsgruppen, Imaginäre Räume, Irreale Konditionalsätze (The Structure of Imaginary Space and the Problem of Unreal Conditional Sentences)', in H. Berking (ed.), Die Macht des Lokalen in einer Welt ohne Grenzen, I65-I80. Frankfurt/New York: Campus Verlag.

Schwenken, H. (2005), “'Domestic slavery” versus "workers rights”: Political mobilization of migrant domestic workers in the European Union”, CCIS Working Paper no. I6, January.

Scott, A. (I992), 'Risk society or angst society? Two views of risk, consciousness and 
community', in B. Adam, U. Beck \& J. van Loon (eds.), The Risk Society and Beyond: Critical Issues for Social Theory, 33-46. London: Sage Publications.

Scott, J. C. (I990), Dominance and the Arts of Resistance: Hidden Transcripts. New Haven/ London: Yale University Press.

Scott, J. C. (1985), Weapons of the Weak: Everyday Forms of Peasant Resistance. New Haven/London: Yale University Press.

Scrinzi, F. (2008), 'Migrations and the restructuring of the welfare state in Italy: Change and continuity in the domestic work sector', in H. Lutz (ed.), Migration and Domestic Work: A European Perspective on a Global Theme, 29-42. Aldershot: Ashgate.

Shrader-Frechette, K. (I99I) 'Risk assessment and uncertainty', PSA: Proceedings of the Biennial Meeting of the Philosophy of Science Association I988, volume 2: Symposia and invited papers, 504-517.

Short, J. F. (1984), 'The social fabric at risk: Toward the social transformation of risk analysis', American Sociological Review 49: 7II-725.

Siemieńska, R. (2002), 'Economic restructuring, social policies, and women's work in Poland', in R. Becker-Schmidt (ed.), Gender and Work in Transition: Globalization in Western, Middle and Eastern Europe, I75-216. Opladen: Leske Budrich.

Sik, E. (I993), 'From the second economy to the informal economy', Journal of Public Policy I2 (2): I53-I75.

Sijaastad, L. A. (I962), 'The costs and returns of human migration', Journal of Political Economy 70: 80-93.

Simon, H. (1957), A Behavioral Model of Rational Choice in Models of Man, Social and Rational: Mathematical Essays on Rational Human Behavior in a Social Setting. New York: Wiley.

Snyder, T. (2003), The Reconstruction of Nations: Poland, Ukraine, Lithuania, Belarus, 1569-1999. New Haven/London: Yale University Press.

Sobotka, T. \& L. Toulemon (2008), 'Overview chapter 4: Changing family and partnership behaviour: Common trends and persistent diversity in Europe', Demographic Research I9, article 6: 85-I38. http://www.demographic-research.org/Volumes/Vo1ig/6/19-6.pdf. Accessed i7 November 2010.

Solari, C. (2006), 'Professionals and saints: How immigrant careworkers negotiate gender identities at work', Gender and Society 20 (3): 30I-33I.

Sørensen, N. (2005), 'Transnational family life across the Atlantic: The experience of Colombian and Dominican migrants in Europe', paper presented at the International Conference on Migration and Domestic Work in a Global Perspective, Wassenaar, The Netherlands.

Stark, O. (2003), 'Tales of migration without wage differentials: Individual, family and community context', paper presented for conference on African Migration in Comparative Perspective, Johannesburg, South Africa.

Stark, O. (I99I), The Migration of Labour. Cambridge: Blackwell.

Stark, O. \& D. E. Bloom (I985), 'The new economics of labour migration', American Economic Review 75 (2): I73-I78.

Stefańska, R. (2008), 'Instytucje etniczne a proces integracji różnych kategorii migrantów (Ethnic institution and the integration proces sof different categories of migrants), in A. Grzymała-Kazłowska (ed.), Między jednością a wielością. Integracja odmiennych grup i kategorii imigrantów w Polsce. (Between Unity and Multiplicity: Integration of Diverse Groups and Categories of Immigrants in Poland), 197-216. Warsaw: Ośrodek Badań nad Migracjami WNE UW.

Stępień, Cz. (2006), 'Przemiany umieralności i przeciętnego trwania życia osób w starszym wieku w Polsce (Changes in mortality and average life span of people of 
old age in Poland)', in J. T. Kowalewski (ed.), Ludzie starzy w polskim społeczeństwie w pierwszych dekadach XXI wieku (Old people in Polish society in the first decades of the twenty-first century), 203-228. Łódź: Wydawnictwo Uniwersytetu Łódzkiego.

Stola, D. (200I), 'Introduction: Patterns of migration in Central Europe', in C. Wallace \& D. Stola (eds.), Patterns of Migration in Central Europe, 3-44. Houndmills/Basingstoke/Hampshire: Palgrave Macmillan.

Stola, D. (I997), 'Mechanizmy i uwarunkowania migracji zarobkowych do Polski (Mechanisms and conditions of labour migration to Poland)', CMR Working Papers II, http://www.migracje.uw.edu.pl/publ/469. Accessed 29 July 2009.

Szatur-Jaworska, B. (2000), Ludzie starzy i starość w polityce społecznej (Old people and old-age in social policy). Warsaw: Aspra-JR.

Szporluk, R. (2004), Zachodni Wymiar Ksztattowania się Wspótczesnej Ukrainy (The Western Dimension of the Development of Contemporary Ukraine), Ośrodek Badań nad Tradycją Antyczną w Polsce i w Europie Środkowowschodniej (Research Centre on the Antic Tradition in Poland and in Central- Eastern Europe). Warsaw: Wydawnictwo DiG.

Szczepańska, J. (2007), 'Opinia Społeczna o Sytuacji Kobiet w Polsce (Public opinion on the situation of women in Poland)', Opinie i Diagnozy 6. Warsaw: CBOS.

Tarkowski, J. (I994), 'Patroni i Klienci (Patrons and clients)', Socjologia Świata Polityki, vol. 2, Instytut Studiów Politycznych Polskiej Akademii Nauk.

Taylor, B. J. \& M. Donnelly (2006), 'Risk to home care workers: Professional perspectives', Health, Risk \& Society 8 (3): 239-256.

Titkow, A., D. Duch-Krzystoszek \& B. Budrowska (2004), Nieodptatna praca kobiet: mity, realia, perspektywy (Unpaid Womens' Work: Myths, Realities, Perspectives). Warsaw: IFIS PAN.

Tolstokorova, A. (2007), 'Effect of external labour migration on Ukrainian family: "Poisoned gift" or "dream realised"?', paper presented at International Conference Sophia Antipolis, France, 6-8 December.

UNDP (2003), Gender Issues in Ukraine: Challenges and Opportunities. Kiev.

UNICEF (I997), 'Children at risk in Central and Eastern Europe: Perils and promises: Economies in transition studies', Regional Monitoring Report no. 4. Florence: United Nation's Children Fund.

United Nations (I998), Recommendations on Statistics of International Migration, revision I.

UNFPA (2006), 'Selling hope and stealing dreams: Trafficking in women and the exploitation of domestic workers', in United Nations Population Fund (ed.), State of World Population. New York: United Nations. Accessed 30 October 2008. http:// www.unfpa.org/swp/2006/english/chapter_3/print/chapter_3.html.

Vianello, F. (2009), 'Suspended migrants: Return migration to the Ukraine', paper presented at Social Inequalities and Migration in Post-Communist Societies conference, Poznań. Poland 2I-22 September 2009.

Vianello, F. (2008), 'The Italian side of Ukrainian migration: The social networks role', in Metodologja, Teorija ta Praktika sociologičnogo analizu sučasnogo suspil'stva: Zbirnik Naukovich Praz, vol. 2, Charkivskii Nazionalnii Universitet Imeni B.N. Karazina, Charkiv.

Wallace, C. (2002), 'Household strategies: Their conceptual relevance and analytical scope in social research', Sociology 35 (2): 275-292.

Wallace, C. (1999), Migration and Survival Strategies in East-Central Europe. Vienna: Insitut fur Hoechere Studien (Institute for Advanced Studies).

Wallace, C., V. Bedezir, O. Chmouliar \& E. Sidorenko (I998), 'Some Characteristics 
of Labour Migration and the Central European Buffer Zone', Sociological Series 25. Vienna: Institute for Advanced Studies.

Wallace, C., V. Bedezir \& O. Chmouliar (I997), 'Spending, saving or investing social capital: The case of shuttle traders in post-Communist Central Europe', East European Series No. 43, http://ideas.repec.org/p/ihs/ihsrop/43.html.

Wallace, C. \& D. Stola (200I), Patterns of Migration in Central Europe. New York: Palgrave.

Wallerstein, I. (2000), The Essential Wallerstein. New York: The New Press.

Waldinger, R. (I994), 'The making of an immigrant niche', International Migration Review 28 (I): 3-30.

Wallman, S. (200I), 'Global threats, local options, personal risks: Dimensions of migrant sex work in Europe' in Health, Risk \& Society 3 (I): 75-87.

Weinar, A. (2006), 'Europeizacja polskiej polityki wobec cudzoziemców i990-2003 (Europeanization of Polish policy towards foreigners, I990-2003)'. Warsaw: Scholar.

Weinar, A. (2005), 'Polityka Migracyjna Polski w latach I990-2003: Próba podsumowania' (Poland's Migration Policy in the Years 1990-2003: A Summary), Raporty $i$ Analizy I0/5. Warsaw: Centre for International Relations.

Williams, C. P. (2005), “'Knowing one's place”: Gender, mobility and shifting subjectivity in Eastern Indonesia', Global Networks 5 (4): 40I-4I7.

Williams, F. \& A. Gavanas (2008), 'The intersection of childcare regimes and migration regimes: A 3-country study', in Lutz, H. (ed.), Migration and Domestic Work: A European Perspective on a Global Theme. Aldershot: Ashgate.

Wolpert, J. (I966), 'A regional simulation model of information diffusion', Public Opinion Quarterly 30 (4): 597-608.

Wolpert, J. (I964), 'The decision process in spatial context', Annals of the Association of American Geographers 54 (4): 537-558.

World Bank (I996), 'Poverty in Ukraine'. http://www-wds.worldbank.org/servlet/ WDSContentServer/WDSP/IB/I996/06/27/000009265-396I2I4I34500/Rendered/PDF/multi_page.pdf. Accessed 30 October 2008.

Wynne, B. (1996), 'May the sheep safely graze? A reflexive view of the expert-lay knowledge divide', in S. Lash, B. Szerszinski \& B. Wynne (eds.), Risk, Environment and Modernity: Towards a New Ecology, 44-83. London: Sage.

Young, K. (2004), 'Globalisation and the changing management of migrating service workers in the Asia Pacific', Journal for Contemporary Asia 34 (3): 287-303.

Zhurzhenko, T. (200I), 'Free market ideology and new women's identities in postsocialist Ukraine', European Journal of Women's Studies 8 (I): 29-49.

Zolberg, A. (I98I), 'International migration in political perspective', in M. M. Kritz, C. B. Keely \& S. Tomasi (eds), Global Trends in Migration: Theory and Research on International Population Movements, I5-51. Staten Island: Center for Migration Studies. 


\section{Other IMISCOE titles}

\section{IMISCOE Research}

Rinus Penninx, Maria Berger, Karen Kraal, Eds.

The Dynamics of International Migration and Settlement in Europe: A State of the Art 2006 (ISBN 9789053568668 )

(originally appearing in IMISCOE Joint Studies)

Leo Lucassen, David Feldman, Jochen Oltmer, Eds.

Paths of Integration: Migrants in Western Europe (1880-2004)

2006 (ISBN 9789053568835 )

Rainer Bauböck, Eva Ersbøll, Kees Groenendijk, Harald Waldrauch, Eds. Acquisition and Loss of Nationality: Policies and Trends in 15 European Countries, Volume 1: Comparative Analyses 2006 (ISBN 9789053569207 )

Rainer Bauböck, Eva Ersbøll, Kees Groenendijk, Harald Waldrauch, Eds. Acquisition and Loss of Nationality: Policies and Trends in 15 European Countries, Volume 2: Country Analyses 2006 (ISBN 978905356 921 4)

Rainer Bauböck, Bernhard Perchinig, Wiebke Sievers, Eds.

Citizenship Policies in the New Europe 2007 (ISBN 978905356922 I)

Veit Bader

Secularism or Democracy? Associational Governance of Religious Diversity 2007 (ISBN 9789053569993 )

Holger Kolb, Henrik Egbert, Eds.

Migrants and Markets: Perspectives from Economics and the Other Social Sciences 2008 (ISNB 9789053566848 )

Ralph Grillo, Ed.

The Family in Question: Immigrant and Ethnic Minorities in Multicultural Europe 2008 (ISBN 978905356869 9) 
Corrado Bonifazi, Marek Okólski, Jeannette Schoorl, Patrick Simon, Eds. International Migration in Europe: New Trends and New Methods of Analysis 2008 (ISBN 978905356894 I)

Maurice Crul, Liesbeth Heering, Eds.

The Position of the Turkish and Moroccan Second Generation in Amsterdam and Rotterdam: The TIES Study in the Netherlands 2008 (ISBN 978908964 o6I I)

Marlou Schrover, Joanne van der Leun, Leo Lucassen, Chris Quispel, Eds. Illegal Migration and Gender in a Global and Historical Perspective 2008 (ISBN 9789089640475 )

Gianluca P. Parolin

Citizenship in the Arab World: Kin, Religion and Nation-State 2009 (ISBN 978908964045 I)

Rainer Bauböck, Bernhard Perchinig, Wiebke Sievers, Eds. Citizenship Policies in the New Europe: Expanded and Updated Edition 2009 (ISBN 978908964 I08 3)

Cédric Audebert, Mohamed Kamel Dorai, Eds.

Migration in a Globalised World: New Research Issues and Prospects 2010 (ISBN 978908964 I57I)

Richard Black, Godfried Engbersen, Marek Okólski, Cristina Pantîru, Eds. A Continent Moving West? EU Enlargement and Labour Migration from Central and Eastern Europe 2010 (ISBN 978908964 I56 4)

Charles Westin, José Bastos, Janine Dahinden, Pedro Góis, Eds.

Identity Processes and Dynamics in Multi-Ethnic Europe

2010 (ISBN 9789089640468 )

Rainer Bauböck, Thomas Faist, Eds.

Diaspora and Transnationalism: Concepts, Theories and Methods 2010 (ISBN 9789089642387 )

Liza Mügge

Beyond Dutch Borders: Transnational Politics among Colonial Migrants, Guest Workers and the Second Generation 20Iо (ISBN 9789089642448 ) 
Peter Scholten

Framing Immigrant Integration: Dutch Research-Policy Dialogues in Comparative Perspective

2OII (ISBN 978908964284 4)

Blanca Garcés-Mascareñas

State Regulation of Labour Migration in Malaysia and Spain: Markets, Citizenship and Rights

2OII (ISBN 978908964286 8)

Albert Kraler, Eleonore Kofman, Martin Kohli, Camille Schmoll, Eds.

Gender, Generations and the Family in International Migration

2OII (ISBN 978908964285 I)

Michael Bommes, Giuseppe Sciortino, Eds.

Foggy Social Structures: Irregular Migration, European Labour Markets and the Welfare State

2OII (ISBN 978908964 34I 4)

Giovanna Zincone, Rinus Penninx, Maren Borkert, Eds.

Migration Policymaking in Europe: The Dynamics of Actors and Contexts in Past

and Present

2OII (ISBN 9789089643704 )

Marcel Maussen, Veit Bader, Annelies Moors, Eds.

Colonial and Post-colonial Governance of Islam: Continuities and Ruptures

2OII (ISBN 9789089643568 )

Bram Lancee

Immigrant Performance in the Labour Market: Bonding and Bridging Social Capital 2OII (ISBN 978908964357 5)

Julie Vullnetari

Albania on the Move: Links between Internal and International Migration

2OII (978 90 8964 355 I)

\section{IMISCOE Reports}

Rainer Bauböck, Ed.

Migration and Citizenship: Legal Status, Rights and Political Participation 2006 (ISBN 978905356888 o) 
Michael Jandl, Ed.

Innovative Concepts for Alternative Migration Policies:

Ten Innovative Approaches to the Challenges of Migration in the 21st Century 2007 (ISBN 978905356990 o)

Jeroen Doomernik, Michael Jandl, Eds.

Modes of Migration Regulation and Control in Europe

2008 (ISBN 9789053566893 )

Michael Jandl, Christina Hollomey, Sandra Gendera, Anna Stepien,

Veronika Bilger

Migration and Irregular Work In Austria: A Case Study of the Structure and Dynamics of Irregular Foreign Employment in Europe at the Beginning of the 21st Century

2008 (ISBN 9789089640536 )

Heinz Fassmann, Ursula Reeger, Wiebke Sievers, Eds.

Statistics and Reality: Concepts and Measurements of Migration in Europe 2009 (ISBN 9789089640529 )

Karen Kraal, Judith Roosblad, John Wrench, Eds.

Equal Opportunities and Ethnic Inequality in European Labour Markets

Discrimination, Gender and Policies of Diversity

2009 (ISBN 978908964 I26 7)

Tiziana Caponio, Maren Borkert, Eds.

The Local Dimension of Migration Policymaking

2010 (ISBN 9789089642325 )

Raivo Vetik, Jelena Helemäe, Eds.

The Russian Second Generation in Tallinn and Kohtla-Järve: The TIES Study in Estonia

2010 (ISBN 9789089642509 )

\section{IMISCOE Dissertations}

Panos Arion Hatziprokopiou

Globalisation, Migration and Socio-Economic Change in Contemporary

Greece: Processes of Social Incorporation of Balkan Immigrants in

Thessaloniki

2006 (ISBN 9789053568736 ) 
Floris Vermeulen

The Immigrant Organising Process: Turkish Organisations in Amsterdam and Berlin and Surinamese Organisations in Amsterdam, 1960-2000 2006 (ISBN 978905356875 ㅇ)

Anastasia Christou

Narratives of Place, Culture and Identity: Second-Generation

Greek-Americans Return 'Home'

2006 (ISBN 978905356878 I)

Katja Rušinovic

Dynamic Entrepreneurship: First and Second-Generation Immigrant Entrepreneurs in Dutch Cities

2006 (ISBN 9789053569726 )

Ilse van Liempt

Navigating Borders: Inside Perspectives on the Process of Human Smuggling into the Netherlands

2007 (ISBN 9789053569306 )

Myriam Cherti

Paradoxes of Social Capital: A Multi-Generational Study of Moroccans

in London

2008 (ISBN 978905356032 7)

Marc Helbling

Practising Citizenship and Heterogeneous Nationhood: Naturalisations in Swiss Municipalities

2008 (ISBN 978908964034 5)

Jérôme Jamin

L'imaginaire du complot: Discours d'extrême droite en France et aux Etats-Unis 2009 (ISBN 978908964048 2)

Inge Van Nieuwenhuyze

Getting by in Europe's Urban Labour Markets: Senegambian Migrants'

Strategies for Survival, Documentation and Mobility

2009 (ISBN 9789089640505 )

Nayla Moukarbel

Sri Lankan Housemaids in Lebanon: A Case of 'Symbolic Violence' and 'Every Day Forms of Resistance'

2009 (ISBN 978908964 05I 2) 
John Davies

'My Name Is Not Natasha': How Albanian Women in France Use

Trafficking to Overcome Social Exclusion (1998-2001)

2009 (ISBN 9789053567074 )

Dennis Broeders

Breaking Down Anonymity: Digital Surveillance of Irregular Migrants

in Germany and the Netherlands

2009 (ISBN 978908964 I59 5)

Arjen Leerkes

Illegal Residence and Public Safety in the Netherlands

2009 (ISBN 978908964049 9)

Jennifer Leigh McGarrigle

Understanding Processes of Ethnic Concentration and Dispersal:

South Asian Residential Preferences in Glasgow

2009 (ISBN 978905356 67I 8)

João Sardinha

Immigrant Associations, Integration and Identity: Angolan, Brazilian

and Eastern European Communities in Portugal

2009 (ISBN 9789089640369 )

Elaine Bauer

The Creolisation of London Kinship: Mixed African-Caribbean and White British

Extended Families, 1950-2003

2010 (ISBN 978908964235 6)

Nahikari Irastorza

Born Entrepreneurs? Immigrant Self-Employment in Spain

20I0 (ISBN 978908964243 I)

\section{IMISCOE Textbooks}

Marco Martiniello, Jan Rath, Eds.

Selected Studies in International Migration and Immigrant Incorporation 2010 (ISBN 978908964 I60I) 